\title{
EVALUATION OF SOLID SORBENTS AS A RETROFIT TECHNOLOGY FOR $\mathrm{CO}_{2}$ CAPTURE FROM COAL-FIRED POWER PLANTS FINAL TECHNICAL REPORT
}

Reporting Period: September 30, 2008-July 31, 2011 Issued: October 2011

DOE Award Number DE-NT0005649 Report Number 05649FR01

Project Director: Sharon Sjostrom, P.E.

Principle Authors: Holly Krutka, Sharon Sjostrom 


\section{ACKNOWLEDGMENT}

This material is based upon work supported by the Department of Energy under Award Number DE-NT0005649.

\section{DISCLAIMER}

This report was prepared as an account of work sponsored by an agency of the United States Government. Neither the United States Government nor any agency thereof, nor any of their employees, makes any warranty, express or implied, or assumes any legal liability or responsibility for the accuracy, completeness, or usefulness of any information, apparatus, product, or process disclosed, or represents that its use would not infringe privately owned rights. Reference herein to any specific commercial product, process, or service by trade name, trademark, manufacturer, or otherwise does not necessarily constitute or imply its endorsement, recommendation, or favoring by the United States Government or any agency thereof. The views and opinions of authors expressed herein do not necessarily state or reflect those of the United States Government or any agency thereof. 


\begin{abstract}
Through a U.S. Department of Energy (DOE) National Energy Technology Laboratory (NETL) funded cooperative agreement DE-NT0005649, ADA Environmental Solutions (ADA) has begun evaluating the use of solid sorbents for $\mathrm{CO}_{2}$ capture. The project objective was to address the viability and accelerate development of a solid-based $\mathrm{CO}_{2}$ capture technology. To meet this objective, initial evaluations of sorbents and the process / equipment were completed. First the sorbents were evaluated using a temperature swing adsorption process at the laboratory scale in a fixed-bed apparatus. A slipstream reactor designed to treat flue gas produced by coal-fired generation of nominally $1 \mathrm{kWe}$ was designed and constructed, which was used to evaluate the most promising materials on a more meaningful scale using actual flue gas. In a concurrent effort, commercial-scale processes and equipment options were also evaluated for their applicability to sorbent-based $\mathrm{CO}_{2}$ capture. A cost analysis was completed that can be used to direct future technology development efforts.
\end{abstract}

ADA completed an extensive sorbent screening program funded primarily through this project, DOE NETL cooperative agreement DE-NT0005649, with support from the Electric Power Research Institute (EPRI) and other industry participants. Laboratory screening tests were completed on simulated and actual flue gas using simulated flue gas and an automated fixed bed system. The following types and quantities of sorbents were evaluated:

- 87 supported amines

- 31 carbon based materials

- 6 zeolites

- 7 supported carbonates (evaluated under separate funding)

- 10 hydrotalcites

Sorbent evaluations were conducted to characterize materials and down-select promising candidates for further testing at the slipstream scale. More than half of the materials evaluated during this program were supported amines. Based on the laboratory screening four supported amine sorbents were selected for evaluation at the $1 \mathrm{~kW}$ scale at two different field sites.

ADA designed and fabricated a slipstream pilot to allow an evaluation of the kinetic behavior of sorbents and provide some flexibility for the physical characteristics of the materials. The design incorporated a transport reactor for the adsorber (co-current reactor) and a fluidizedbed in the regenerator. This combination achieved the sorbent characterization goals and provided an opportunity to evaluate whether the potential cost savings associated with a relatively simple process design could overcome the sacrifices inherent in a co-current separation process. The system was installed at two field sites during the project, Luminant's Martin Lake Steam Electric Station and Xcel Energy's Sherburne County Generating Station (Sherco). Although the system could not maintain continuous $90 \% \mathrm{CO}_{2}$ removal with the sorbents evaluated under this program, it was useful to compare the $\mathrm{CO}_{2}$ removal properties of several different sorbents on actual flue gas. 
One of the supported amine materials, sorbent R, was evaluated at both Martin Lake and Sherco. The $1 \mathrm{kWe}$ pilot was operated in continuous mode as well as batch mode. In continuous mode, the sorbent performance could not overcome the limitations of the cocurrent adsorbent design. In batch mode, sorbent $\mathrm{R}$ was able to remove up to $90 \% \mathrm{CO}_{2}$ for several cycles. Approximately 50\% of the total removal occurred in the first three feet of the adsorption reactor, which was a transport reactor. During continuous testing at Sherco, $\mathrm{CO}_{2}$ removal decreased to approximately $20 \%$ at steady state. The lack of continuous removal was due primarily to the combination of a co-current adsorption system with a fluidized bed for regeneration, a combination which did not provide an adequate driving force to maintain an acceptable working $\mathrm{CO}_{2}$ capacity. In addition, because sorbent $\mathrm{R}$ consisted of a polymeric amine coated on a silica substrate, it was believed that the $50 \%$ amine loaded resulted in mass diffusion limitations related to the $\mathrm{CO}_{2}$ uptake rate.

Three additional supported amine materials, sorbents AX, F, and BN, were selected for evaluation using the $1 \mathrm{~kW}$ pilot at Sherco. Sorbent AX was operated in batch mode and performed similarly to sorbent R (i.e. could achieve up to $90 \%$ removal when given adequate regeneration time). Sorbent $\mathrm{BN}$ was not expected to be subject to the same mass diffusion limitations as experienced with sorbent $\mathrm{R}$. When sorbent $\mathrm{BN}$ was used in continuous mode the steady state $\mathrm{CO}_{2}$ removal was approximately double that of sorbent $\mathrm{R}$, which highlighted the importance of sorbents without kinetic limitations.

Many different processes and equipment designs exist that may be applicable for postcombustion $\mathrm{CO}_{2}$ capture using solids in a temperature-swing system. A thorough technology survey was completed to identify the most promising options, which were grouped and evaluated based on the four main unit operations involved with sorbent based capture:

- Adsorption

- Heating and cooling, or heat transfer

- Conveying

- Desorption

The review included collecting information from a wide variety of sources, including technology databases, published papers, advertisements, web searches, and vendor interviews. Working with power producers, scoring sheets were prepared and used to compare the different technology options. Although several technologies were interesting and promising, those that were selected for the final conceptual design were commercially available and performed multiple steps simultaneously. For the adsorption step, adsorption and conveying were both accomplished in a circulating fluidized bed. A rotary kiln was selected for desorption and cooling because it can simultaneously accomplish conveying and effective heat transfer. The final technology selection was used to complete preliminary costs assessments for a conceptual $500 \mathrm{MW} \mathrm{CO}_{2}$ capture process.

The high level cost analysis was completed to determine the key cost drivers. The conceptual sorbent-based capture options yielded significant energy penalty and cost savings versus an aqueous amine system. Specifically, the estimated levelized cost of electricity (LCOE) for final concept design without a $\mathrm{CO}_{2}$ laden/lean sorbent heat exchanger or any other integration, was over $30 \%$ lower than that of the MEA capture process. However, this cost savings was not enough to meet the DOE's target of $\leq 35 \%$ increase in LCOE. In order 
to reach this target, the incremental $\mathrm{LCOE}$ due to the $\mathrm{CO}_{2}$ capture can be no higher than 2.10 $\phi / \mathrm{kWh}$ above the LCOE of the non-capture equivalent power plant (6.0 $\phi / \mathrm{kWh})$. Although results of the $1 \mathrm{kWe}$ pilot evaluations suggest that the initial full-scale concept design must be revisited to address the technical targets, the cost assessment still provides a valuable high-level estimate of the potential costs of a solids-based system. A sensitivity analysis was conducted to determine the cost drivers and the results of the sensitivity analysis will be used to direct future technology development efforts.

The overall project objective was to assess the viability and accelerate development of a solid-based post-combustion $\mathrm{CO}_{2}$ capture technology that can be retrofit to the existing fleet of coal-fired power plants. This objective was successfully completed during the project along with several specific budget period goals. Based on sorbent screening and a full-scale equipment evaluation, it was determined that solid sorbents for post-combustion capture is promising and warrants continued development efforts. Specifically, the lower sensible heat could result in a significant reduction in the energy penalty versus solvent based capture systems, if the sorbents can be paired with a process and equipment that takes advantage of the beneficial sorbent properties. It was also determined that a design using a circulating fluidized bed adsorber with rotary kilns for heating during regeneration, cooling, and conveying highlighted the advantage of sorbents versus solvents. However, additional technology development and cost reductions will be required to meet the DOE's final technology goal of $90 \% \mathrm{CO}_{2}$ capture with $\leq 35 \%$ increase in the cost of electricity. The cost analysis identified specific targets for the capital and operating costs, which will be used as the targets for future technology development efforts. 


\section{Table of Contents}

ABSTRACT ...................................................................................................... ii

EXECUTIVE SUMMARY ...............................................................................12

INTRODUCTION ………………………...............................................................16

APPROACH........................................................................................................19

Task 1. Team Coordination and Planning................................................................ 19

Task 2. Sorbent Selection and Viability Assessment ............................................... 19

Task 2.1. Sorbent Selection, Characterization, and Lab-Screening ................... 19

Task 2.2. $1 \mathrm{~kW}$ pilot-Scale Equipment Design and Construction ........................ 28

Task 2.3. Parametric Field Tests ............................................................................... 29

Task 2.4. Sorbent Performance Report ................................................................. 29

Task 3. Full-Scale Equipment Assessment and Design ............................................. 29

Task 3.1. Technology Survey to Identify Equipment Options............................ 29

Task 3.2. Technology Assessment........................................................................................ 30

Task 3.3. Develop Capital and Operating Costs ................................................... 30

Task 3.4. Identify and Assess Impacts .................................................................. 31

Task 3.5. Conduct Cursory Life-Cycle $\mathrm{CO}_{2}$ Emissions Estimate ......................... 31

Task 3.6. Final Technology Selection ...................................................................... 31

Task 3.7. Development of 500-MW Conceptual Design and Cost Estimate....... 31

Task 4. Management and Reporting ............................................................................. 32

RESULTS AND DISCUSSION $\ldots . \ldots \ldots \ldots \ldots \ldots \ldots \ldots \ldots \ldots \ldots \ldots \ldots \ldots \ldots \ldots \ldots \ldots \ldots \ldots \ldots \ldots \ldots \ldots . \ldots . \ldots \ldots 3$

Task 2. Sorbent Selection and Viability Assessment ................................................ 33

Task 2.1. Sorbent Selection, Characterization, and Lab-Screening .................... 33

Task 2.2. $1 \mathrm{~kW}$ Pilot-Scale Equipment Design and Construction ....................... 62

Task 2.3. Parametric Field Tests ............................................................................... 69

Task 2.4. Sorbent Performance Report .................................................................. 80

Task 3. Full-Scale Equipment Assessment and Design ............................................... 80

Task 3.1. Technology Survey to Identify Equipment Options............................. 81

Task 3.2. Technology Assessment.......................................................................... 85

Task 3.3. Develop Capital and Operating Costs ..................................................... 88

Task 3.4. Identify and Assess Impacts ....................................................................... 89

Task 3.5. Conduct Cursory Life-Cycle $\mathrm{CO}_{2}$ Emissions Estimate.......................... 89

Task 3.6. Final Technology Selection ............................................................................... 90

Task 3.7. Develop Commercial-Scale Initial Concept Design \& Cost Estimate. 92

Task 4. Project Management and Reporting ........................................................... 100

SUMMARY AND CONCLUSIONS ......................................................102

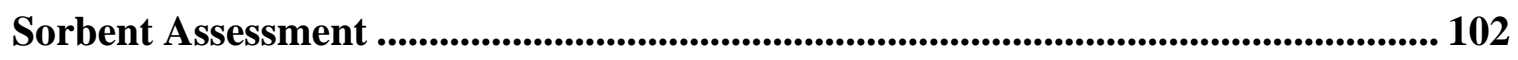

DOE Report No. 05649FR01 vi 
Full Scale Equipment Assessment and Design ................................................................. 104

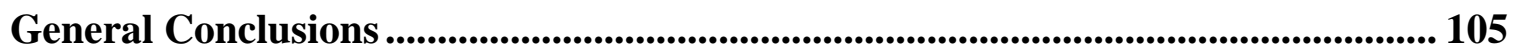

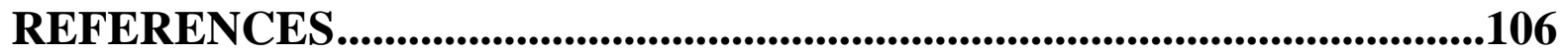

LIST OF ACRONYMS AND ABBREVIATIONS....................................108

APPENDIX A: Stantec Report: Solid Sorbent Cost of Electricity ..............111 


\section{List of Figures}

Figure 1: Generic Post-Combustion Temperature Swing Process................................ 16

Figure 2: Schematic of the Sorbent Screening Test Unit .................................................. 22

Figure 3: Example of an Adsorption Breakthrough Profile ............................................... 23

Figure 4: Example of a Regeneration Breakthrough Profiles ........................................ 24

Figure 5: Schematic of Sorbent Screening Test Unit Configured for Field Testing....... 26

Figure 6: Attrition Testing Equipment Operated by Jenike \& Johanson ....................... 28

Figure 7: Select Supported Amine Adsorption Profiles ............................................... 36

Figure 8a: Theoretical Regeneration Energy of Supported Amine Sorbents .................. 36

Figure 8b: Theoretical Regeneration Energy of Supported Amine Sorbents.................. 37

Figure 9: Sorbent CU Laboratory Adsorption Profiles ................................................. 37

Figure 10: First and Second Generation Supported Amine Clay-Based Sorbent .......... 38

Figure 11: Sorbent CQ Laboratory Adsorption Profiles ........................................................ 39

Figure 12: Sorbent CE Laboratory Total $\mathrm{CO}_{2}$ Capacities................................................ 39

Figure 13: $\mathrm{CO}_{2}$ Capacity versus Cycle Number for 100 ppm $\mathrm{SO}_{2}, 100$ ppm $\mathrm{NO}_{2}$, and 100

ppm NO............................................................................................................................................... 40

Figure 14: Theoretical Regeneration Energies for Carbon-Based Sorbents.................... 41

Figure 15: Sorbent AM Laboratory Adsorption Profiles ............................................ 42

Figure 16: Theoretical Regeneration Energies for Several Zeolites ............................... 43

Figure 17: Sorbent J Laboratory Adsorption Profiles ........................................................ 44

Figure 18: Theoretical Regeneration Energies for Several Hydrotalcites....................... 45

Figure 19: Sorbent DM Laboratory Total $\mathrm{CO}_{2}$ Capacities............................................. 46

Figure 20: Sorbent BR Field $\mathrm{CO}_{2}$ Capacity ............................................................ 48

Figure 21: Sorbent BR Field Adsorption Profiles......................................................... 49

Figure 22: Sorbent AY Field $\mathrm{CO}_{2}$ Capacity ..........................................................5 50

Figure 23: Sherco Sorbent R Breakthrough Adsorption Profiles ...................................... 51

Figure 24: Sherco Sorbent AX Adsorption Breakthrough Profiles .................................. 52

Figure 25: Sherco Sorbent F Adsorption Breakthrough Profiles ................................... 53

Figure 26: Sherco Sorbent BN Adsorption Breakthrough Profiles ..................................... 53

Figure 27: Crushed and Beaded Sorbent BN Breakthrough Profiles............................... 54

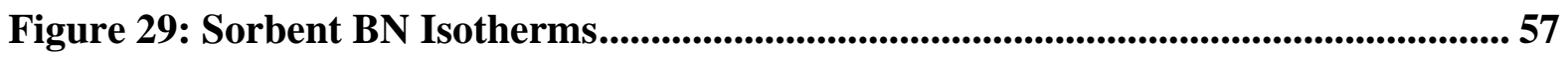

Figure 30: Sorbent R Substrate ...................................................................................... 58

DOE Report No. 05649FR01 viii 
Figure 31: Sorbent X Substrate .......................................................................................................... 59

Figure 33: Sorbent X Particle Size Distribution ...................................................................6 60

Figure 34: Sorbent BN Crush Strength Analysis........................................................................ 62

Figure 35: Picture of Tower for the $1 \mathrm{~kW}$ Pilot Equipment .................................................. 63

Figure 36: 3D Model Sketch and Photo of $1 \mathrm{~kW}$ System ...................................................... 64

Figure 37: Diagram of $1 \mathrm{~kW}$ Pilot $\mathrm{CO}_{2}$ System...................................................................... 65

Figure 38: Sketch of Gas Sampling Locations ............................................................................ 66

Figure 39: Sketch of Temperature Measurement Locations ................................................. 67

Figure 40: Sketch of Pressure Measurement Locations........................................................... 67

Figure 41: 1 kW Pilot with Theoretical Isotherms .................................................................... 68

Figure 42: Picture of the $1 \mathrm{~kW}$ Pilot Installed at Martin Lake .......................................... 69

Figure 43: Picture of $1 \mathrm{~kW}$ Pilot Installed at Sherco............................................................. 70

Figure 44: $\mathrm{CO}_{2}$ Concentration, $\mathrm{CO}_{2}$ Removal, and Temperature Information Collected

During Parametric Testing of Sorbent R..................................................................................... 71

Figure 45: Outlet $\mathrm{CO}_{2}$ and $\mathrm{CO}_{2}$ Removal after Batch Regeneration................................. 72

Figure 46: $\mathrm{CO}_{2}$ Concentrations and Removal during Continuous $1 \mathrm{~kW}$ Testing of

Sorbent R ................................................................................................................................... 73

Figure 47: $\mathrm{CO}_{2}$ Concentrations at Different Locations in the Riser .................................. 74

Figure 48: $\mathrm{CO}_{2}$ Concentrations and Removal during Batch $1 \mathrm{~kW}$ Testing of Sorbent $\mathrm{R}$ 75

Figure 49: $\mathrm{CO}_{2}$ Removal Levels during Batch Operation of Sorbent R............................ 75

Figure 50: Summary of Sorbent Screening Results................................................................. 76

Figure 51: Maximum $\mathrm{CO}_{2}$ Removal for Sorbent $\mathrm{R}$ at Martin Lake and Sorbent $\mathrm{AX}$ at

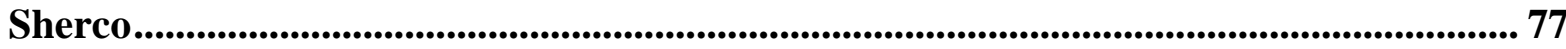

Figure 52: 1 kW Pilot Evaluation of Sorbent $R$ at Sherco ...................................................... 78

Figure 53: 1 kW Pilot Evaluation of Sorbent BN at Sherco .................................................. 80

Figure 54: Solid-Based $\mathrm{CO}_{2}$ Capture Process Flow Diagram................................................ 82

Figure 55: Conceptual Flow Sheet............................................................................................... 91

Figure 56: Carbon Capture Estimated Footprint...................................................................... 92

Figure 57: Comparison of Energy Penalty for MEA and Solid Sorbent-Based $\mathrm{CO}_{2}$ Capture at AEP's Conesville Power Plant.

Figure 58: Contribution of LCOE Increases for $\mathrm{CO}_{2}$ Capture Options at AEP's Conesville Power Plant ("MEA Costs from NETL, 2007 with costs scaled to 2010

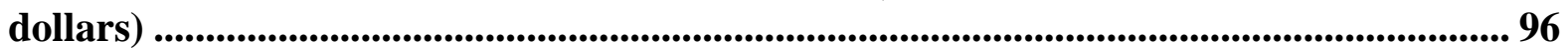

Figure 59: Incremental LCOE Contributions................................................................................ 98

DOE Report No. 05649FR01 ix 
Figure 60: Sensitivity Analysis of Capital Cost and Variable O\&M Cost of Base Case 100 


\section{List of Tables}

Table 1: Key flue gas characteristics for field tests .................................................26

Table 2: TGA Operating Conditions.....................................................................................27

Table 3: Key Sorbent Physical Properties ..........................................................................34

Table 4. Key Sorbent $\mathrm{CO}_{2}$ Capture Effectiveness Properties and Tasks of

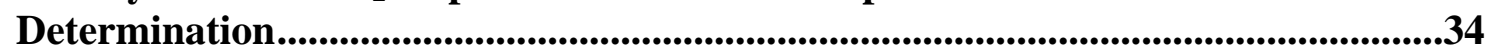

Table 5: $\mathrm{CO}_{2}$ Capacity Measured During Field Tests ..............................................................47

Table 6: Key Solid Sorbent Energy Requirements..............................................................54

Table 7: Key Solid-Sorbent Related Costs..................................................................81

Table 8: Adsorption Screening Criteria ..........................................................................86

Table 9: Technology Screening Results ..............................................................................887

Table 10: Emissions and Cost Comparison ..................................................................97

Table 11: Comparable Incremental LCOE Between Base Case and Base Case with $35 \%$ Increase in LCOE - Reduction in Costs ........................................................99

DOE Report No. 05649FR01 - xi 


\section{EXECUTIVE SUMMARY}

Through a U.S. Department of Energy (DOE) National Energy Technology Laboratory (NETL) funded cooperative agreement DE-NT0005649, ADA Environmental Solutions (ADA) has begun evaluating the use of solid sorbents for $\mathrm{CO}_{2}$ capture. The project objective was to address the viability and accelerate development of a solid-based $\mathrm{CO}_{2}$ capture technology. To meet this objective, initial evaluations of sorbents and the process / equipment were completed. First the sorbents were evaluated using a temperature swing adsorption process at the laboratory scale in a fixed-bed apparatus. A slipstream reactor designed to treat flue gas produced by coal-fired generation of nominally $1 \mathrm{kWe}$ was designed and constructed, which was used to evaluate the most promising materials on a more meaningful scale using actual flue gas. In a concurrent effort, commercial-scale processes and equipment options were also evaluated for their applicability to sorbent-based $\mathrm{CO}_{2}$ capture. A cost analysis was completed that can be used to direct future technology development efforts.

\section{Sorbent Assessment}

The sorbent assessment program conducted by ADA under the current and other related projects included both laboratory and small-scale slipstream tests. Based on the program results, supported amine sorbents offer the potential to significantly reduce the energy penalty associated with post-combustion $\mathrm{CO}_{2}$ capture if they can be used in a system/process that can take advantage of their beneficial properties. With further development it is possible that carbonbased sorbents may also be useful for this application.

\section{Laboratory-Scale Screening}

ADA completed an extensive sorbent screening program funded primarily through this project, DOE NETL cooperative agreement DE-NT0005649, with support from the Electric Power Research Institute (EPRI) and other industry participants. Laboratory screening tests were completed on simulated and actual flue gas using simulated flue gas and an automated fixed bed system. The following types and quantities of sorbents were evaluated:

- 87 supported amines

- 31 carbon based materials

- 6 zeolites

- 7 supported carbonates (evaluated under separate funding)

- 10 hydrotalcites

Sorbent evaluations were conducted to characterize materials and down-select promising candidates for further testing at the slipstream scale. Criteria established for evaluation included the $\mathrm{CO}_{2}$ working capacity, the cyclic stability, the tendency of the sorbents to be affected by typical flue gas constituents, range of adsorption and regeneration temperatures, theoretical regeneration temperature, and the cost and projected availability of the materials. The benchmark theoretical regeneration energy used for comparison was $3600 \mathrm{~kJ} / \mathrm{kg} \mathrm{CO}_{2}(1550$ BTU/lb $\mathrm{CO}_{2}$ ) for a liquid MEA $\mathrm{CO}_{2}$ capture system, as reported by DOE in 2007. ${ }^{3}$ This is not a un-integrated theoretical regeneration energy, but is an actual regeneration energy based on achievable working capacities and heat integration. It is important to note that a comparison of theoretical to actual regeneration energies is valuable only for a high level assessment. 
More than half of the materials evaluated during this program were supported amines. This promising family of sorbents consists of various types of amines supported on inert substrates. In general, supported amines exhibited high $\mathrm{CO}_{2}$ capacities under simulated flue gas conditions (up to $14 \mathrm{wt} \%$ total capacity by weight), with several demonstrating cyclic stability over many adsorption/regeneration cycles. Theoretical regeneration energies as low as $1240 \mathrm{~kJ} / \mathrm{kg} \mathrm{CO} 2$ (530 BTU/lb CO 2 ) were calculated based on laboratory results. Nine supported amine sorbents were selected and tested in the laboratory-scale fixed bed system on actual flue gas. The laboratory-scale fixed bed field tests in conjunction with specialized laboratory testing confirmed that $\mathrm{SO}_{2}$ can permanently degrade the supported amine sorbents. In addition, $\mathrm{NO}_{2}$ can also partially degrade the sorbents. NO did not result in any noticeable degradation in performance. $\mathrm{CO}_{2}$ capacities, qualitative attrition characteristics for two substrates, and crush strength for a beaded sorbent were also measured.

Thirty-one different carbon-based $\mathrm{CO}_{2}$ sorbents were also evaluated under this program. The $\mathrm{CO}_{2}$ capacities of these materials were much lower than that of supported amine sorbents, usually $<1.2 \mathrm{wt} \%$. However, an advantage of carbon-based sorbents is that many of these sorbents demonstrated cyclic stability on simulated and actual flue gas. They were much more resistant to poisoning and degradation from flue gas constituents compared to supported amines. If the $\mathrm{CO}_{2}$ capacity for carbon-based sorbents is improved and selectivity is quantified, it is possible that a process can be developed using carbon-based sorbents that will decrease the regeneration energy penalty versus aqueous monoethanolamine (MEA).

Several zeolites were also evaluated on simulated flue gas using the fixed bed apparatus and a single zeolite was evaluated on actual flue gas using the same test equipment. On dry flue gas zeolites were able to separate $\mathrm{CO}_{2}$ effectively. However, in the presence of moisture these materials preferentially adsorb $\mathrm{H}_{2} \mathrm{O}$ over $\mathrm{CO}_{2}$, making them ineffective for the purpose of postcombustion $\mathrm{CO}_{2}$ capture.

Prior to the initiation of DE-NT0005649 several supported carbonates were produced by ADA and their breakthrough curves were measured. The materials produced and evaluated by ADA were not optimized, but allowed for some screening and evaluation to be completed in the laboratory (no field testing of these materials). The heat of reaction for carbonates was significantly higher than that of other materials (i.e. approximately $-130 \mathrm{~kJ} / \mathrm{mol}$ for regeneration of sodium carbonate versus $-60 \mathrm{~kJ} / \mathrm{mol}$ for supported amines). The resulting theoretical regeneration energy for the materials evaluated by ADA was significantly greater than the benchmark MEA system and no additional materials were contributed to the project, supported carbonates were not pursued further.

Several hydrotalcites were included in the sorbent screening program. These materials were only evaluated on simulated flue gas in the laboratory. The fixed bed tests were conducted without any study of the optimal adsorption and regeneration temperatures. Based on the hydrotalcites evaluated, there may be some applicability for post-combustion $\mathrm{CO}_{2}$ capture, although these materials may be useful at temperatures greater than what was used for the simulated flue gas in this project.

Based on the laboratory screening four supported amine sorbents were selected for evaluation at the $1 \mathrm{~kW}$ scale at two different field sites. 


\section{1 kW Pilot Evaluations}

ADA designed and fabricated a slipstream pilot to allow an evaluation of the kinetic behavior of sorbents and provide some flexibility for the physical characteristics of the materials. The design incorporated a transport reactor for the adsorber (co-current reactor) and a fluidized-bed in the regenerator. This combination achieved the sorbent characterization goals and provided an opportunity to evaluate whether the potential cost savings associated with a relatively simple process design could overcome the sacrifices inherent in a co-current separation process. The 1 kWe slipstream system was designed with support from engineers at Southern Company, who provided the design concept and expertise in transport reactor design and operation.

The system was installed at two field sites during the project, Luminant's Martin Lake Steam Electric Station and Xcel Energy's Sherburne County Generating Station (Sherco). Although the system could not maintain continuous $90 \% \mathrm{CO}_{2}$ removal with the sorbents evaluated under this program, it was useful to compare the $\mathrm{CO}_{2}$ removal properties of several different sorbents on actual flue gas.

One of the supported amine materials, sorbent R, was evaluated at both Martin Lake and Sherco. The $1 \mathrm{kWe}$ pilot was operated in continuous mode as well as batch mode. In continuous mode, the sorbent performance could not overcome the limitations of the co-current adsorbent design. In batch mode, sorbent $\mathrm{R}$ was able to remove up to $90 \% \mathrm{CO}_{2}$ for several cycles. Approximately $50 \%$ of the total removal occurred in the first three feet of the adsorption reactor, which was a transport reactor. During continuous testing at Sherco, $\mathrm{CO}_{2}$ removal decreased to approximately $20 \%$ at steady state. The lack of continuous removal was due primarily to the combination of a co-current adsorption system with a fluidized bed for regeneration, a combination which did not provide an adequate driving force to maintain an acceptable working $\mathrm{CO}_{2}$ capacity. In addition, because sorbent $\mathrm{R}$ consisted of a polymeric amine coated on a silica substrate, it was believed that the 50\% amine loaded resulted in mass diffusion limitations related to the $\mathrm{CO}_{2}$ uptake rate.

Three additional supported amine materials, sorbents AX, F, and BN, were selected for evaluation using the $1 \mathrm{~kW}$ pilot at Sherco. Sorbent AX was operated in batch mode and performed similarly to sorbent R (i.e. could achieve up to $90 \%$ removal when given adequate regeneration time). Sorbent $\mathrm{BN}$ was not expected to be subject to the same mass diffusion limitations as experienced with sorbent $\mathrm{R}$. When sorbent $\mathrm{BN}$ was used in continuous mode the steady state $\mathrm{CO}_{2}$ removal was approximately double that of sorbent $\mathrm{R}$, which highlighted the importance of sorbents without kinetic limitations.

\section{Equipment Evaluation}

Many different processes and equipment designs exist that may be applicable for postcombustion $\mathrm{CO}_{2}$ capture using solids in a temperature-swing system. A thorough technology survey was completed to identify the most promising options, which were grouped and evaluated based on the four main unit operations involved with sorbent based capture:

- Adsorption

- Heating and cooling, or heat transfer

- Conveying

- Desorption 
The review included collecting information from a wide variety of sources, including technology databases, published papers, advertisements, web searches, and vendor interviews. Working with power producers, scoring sheets were prepared and used to compare the different technology options. Although several technologies were interesting and promising, those that were selected for the final conceptual design were commercially available and performed multiple steps simultaneously. For the adsorption step, adsorption and conveying were both accomplished in a circulating fluidized bed. A rotary kiln was selected for desorption and cooling because it can simultaneously accomplish conveying and effective heat transfer. The final technology selection was used to complete preliminary costs assessments for a conceptual $500 \mathrm{MW} \mathrm{CO}_{2}$ capture process.

The high level cost analysis was completed to determine the key cost drivers. The conceptual sorbent-based capture options yielded significant energy penalty and cost savings versus an aqueous amine system. Specifically, the estimated levelized cost of electricity (LCOE) for final concept design without a $\mathrm{CO}_{2}$ laden/lean sorbent heat exchanger or any other integration, was over 30\% lower than that of the MEA capture process. However, this cost savings was not enough to meet the DOE's target of $\leq 35 \%$ increase in LCOE. In order to reach this target, the incremental $\mathrm{LCOE}$ due to the $\mathrm{CO}_{2}$ capture can be no higher than $2.10 \phi / \mathrm{kWh}$ above the LCOE of the non-capture equivalent power plant $(6.0 \mathrm{c} / \mathrm{kWh})$. Although results of the $1 \mathrm{kWe}$ pilot evaluations suggest that the initial full-scale concept design must be revisited to address the technical targets, the cost assessment still provides a valuable high-level estimate of the potential costs of a solids-based system. A sensitivity analysis was conducted to determine the cost drivers and the results of the sensitivity analysis will be used to direct future technology development efforts.

\section{General Conclusions}

The overall project objective was to assess the viability and accelerate development of a solidbased post-combustion $\mathrm{CO}_{2}$ capture technology that can be retrofit to the existing fleet of coalfired power plants. This objective was successfully completed during the project along with several specific budget period goals. Based on sorbent screening and a full-scale equipment evaluation, it was determined that solid sorbents for post-combustion capture is promising and warrants continued development efforts. Specifically, the lower sensible heat could result in a significant reduction in the energy penalty versus solvent based capture systems, if the sorbents can be paired with a process and equipment that takes advantage of the beneficial sorbent properties. It was also determined that a design using a circulating fluidized bed adsorber with rotary kilns for heating during regeneration, cooling, and conveying highlighted the advantage of sorbents versus solvents. However, additional technology development and cost reductions will be required to meet the DOE's final technology goal of $90 \% \mathrm{CO}_{2}$ capture with $\leq 35 \%$ increase in the cost of electricity. The cost analysis identified specific targets for the capital and operating costs, which will be used as the targets for future technology development efforts. 


\section{INTRODUCTION}

Before the industrial revolution, anthropogenic greenhouse gas emissions were negligible. However, it was projected that over 30 billion tons of carbon dioxide were released in $2007 .{ }^{1}$ In addition, emissions are expected to grow with increased power consumption of highly populated developing countries. Stationary point sources, such as coal-fired power plants, offer the most promising option for a reduction in carbon dioxide emissions in the near future.

The most important difference between $\mathrm{CO}_{2}$ and other emissions is the volume at which they are produced. Sulfur oxides $\left(\mathrm{SO}_{\mathrm{x}}\right)$, nitrogen oxides $\left(\mathrm{NO}_{\mathrm{x}}\right)$, and mercury concentrations are measured in parts per million (ppm) or parts per billion ( $\mathrm{ppb}$ ) while $\mathrm{CO}_{2}$ is measured as a percentage of the flue gas. Without any modifications, 10 to $15 \%$ of the gas released by coal-fired power plants is $\mathrm{CO}_{2}$. Each ton of carbon in the coal produces nearly 4 tons of gaseous $\mathrm{CO}_{2}$. Carbon capture and sequestration (CCS) is the most promising option for reducing $\mathrm{CO}_{2}$ emissions from coal-fired power plants. Obtaining a pure $\mathrm{CO}_{2}$ stream is the first step of CCS. After the separation, CCS includes compression of the pure $\mathrm{CO}_{2}$ and sequestration so that it does not enter the atmosphere.

The vast majority of coal-fired power plants burn pulverized coal in a boiler and are thus referred to as PC plants. Post-combustion capture is one of the few viable options to retrofit such plants. Currently, the most advanced post-combustion capture options are based upon contacting $\mathrm{CO}_{2^{-}}$ laden flue gas with a solvent containing amines or ammonia and regenerating the solvent via a temperature-swing absorption process. A generic sketch of a post-combustion temperature swing system is shown in Figure 1.

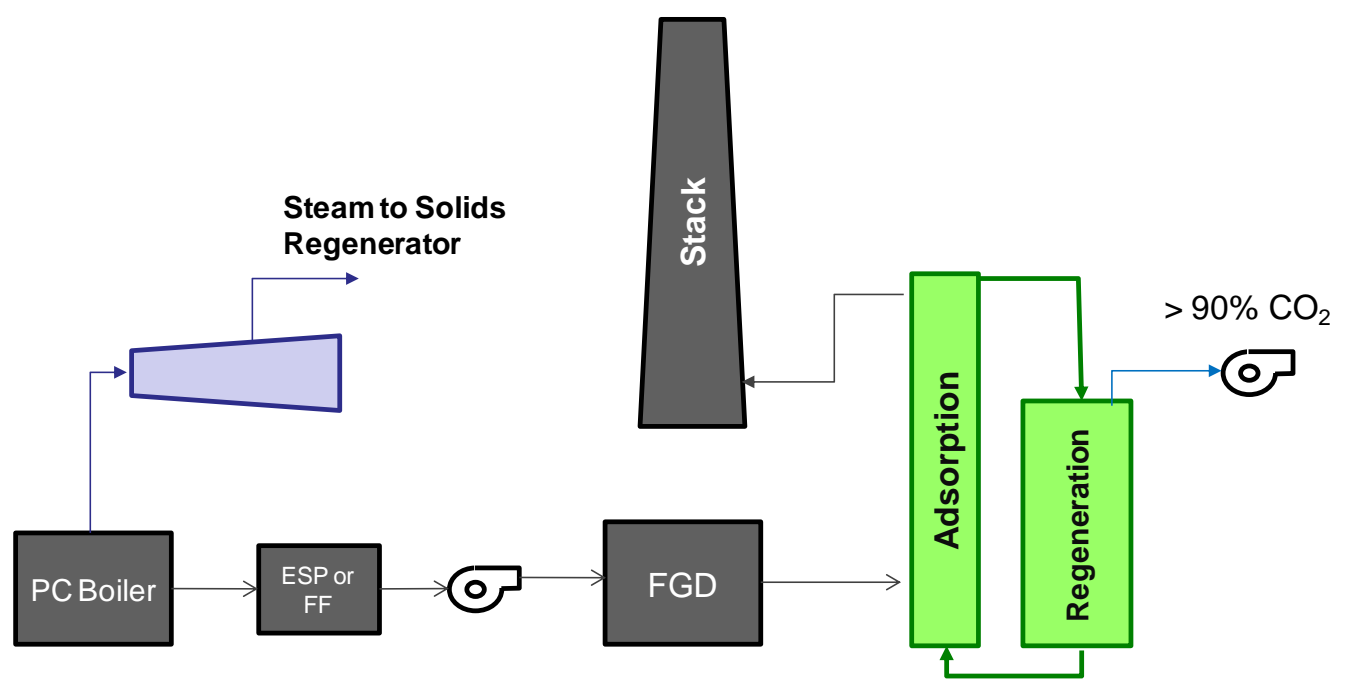

Figure 1: Generic Post-Combustion Temperature Swing Process

The energy penalty associated with solvent-based temperature swing processes is relatively high. For example, recent studies have shown that aqueous monoethanolamine (MEA) for $90 \% \mathrm{CO}_{2}$ capture from a retrofit coal-fired power plant can reduce the thermal efficiency from approximately $35 \%$ (HHV basis) to $24.4 \%$ and cost $\$ 80$ per ton $\mathrm{CO}_{2}$ removed. ${ }^{2,3}$ Most of this cost is associated with the energy penalty incurred when releasing the purified $\mathrm{CO}_{2}$ in the 
regeneration step shown in Figure 1. To reduce the costs associated with commercial-scale CCS, emissions control options must continue to be evaluated and improved. One promising option to reduce the energy penalty and cost associated with the material regeneration is to use solid sorbents since these materials require less energy to heat due to a lower specific heat.

Sorbents can be classified into two general families: those that chemically react with the $\mathrm{CO}_{2}$, called supported reactants, and those that adsorb or use their molecular structure or Van der Waals forces to screen $\mathrm{CO}_{2}$ from other gases, called non-reacting adsorbents. Chemically reacting sorbents usually include an inert, high surface area support, with an immobilized amine or other reactant on the surface. The surface area allows for numerous sites for the desired reaction to occur. Many different types of solid materials for $\mathrm{CO}_{2}$ capture have been or are currently being investigated including: supported amines ${ }^{4-10}$, carbon-based sorbents ${ }^{11-14}$, supported carbonates $^{15,16}$, zeolites ${ }^{17}$, metal organic frameworks (MOFs) ${ }^{18-21}$, etc. These materials are being developed and tested at universities, government laboratories, and by private institutions worldwide.

Although research institutions throughout the world have spearheaded many solid-sorbent development projects geared towards $\mathrm{CO}_{2}$ capture, the majority of these projects are currently being conducted on either lab- or bench-scale and will require further support and development before the materials are commercially viable. ${ }^{2}$ In addition, the testing conditions often utilized in such development research are often highly varied, leading to difficulty in comparing material performance. Due to the urgency of addressing $\mathrm{CO}_{2}$ emissions, it is important that the development of these technologies is accelerated.

Through a U.S. Department of Energy (DOE) National Energy Technology Laboratory (NETL) funded cooperative agreement DE-NT0005649, ADA Environmental Solutions (ADA) addressed the most critical challenges of this new application using an efficient, proven approach in the hopes of minimizing the technology development time cycle. The overall objective of the project was to assess the viability and accelerate development of solid sorbent-based $\mathrm{CO}_{2}$ capture technologies that can be retrofitted to conventional coal-fired power plants. This document is a comprehensive report discussing the key observations, findings, and conclusions based on the work performed.

For Budget Period 1 (October 2008 through January 2010), the specific objectives were as follows:

- Identify the most promising sorbents from multiple developers

- Narrow the field of sorbents with lab-scale screening on simulated and actual flue gas

- Design and fabricate a slipstream contactor/regenerator

- Demonstrate successful operation of the slipstream contactor/regenerator

- Complete a technology survey to identify process equipment that is applicable to $\mathrm{CO}_{2}$ capture with solid sorbents 
For Budget Period 2 (February 2010 through July 2011), the specific objectives were as follows:

- Determine whether $90 \% \mathrm{CO}_{2}$ capture is achievable in a slipstream, small-scale ( $\left.5 \mathrm{acfm}\right)$ pilot using actual flue gas

- Determine whether $\mathrm{CO}_{2}$ capture and compression can be implemented with $<35 \%$ increase in $\mathrm{COE}$

- Complete a conceptual design for integration of $\mathrm{CO}_{2}$ capture process into a $500 \mathrm{MW}$ power plant 


\section{APPROACH}

The overall approach to develop a solid-based $\mathrm{CO}_{2}$ capture process is based on the same approached used to develop other emissions control technologies for coal-fired power plants. Specifically, this program was divided into the following a series of tasks:

Task 1. Team Coordination and Project Planning

Task 2. Sorbent Selection and Viability Assessment

Task 3. Full-Scale Equipment Assessment and Design

Task 4. Management and Reporting

The approaches for the tasks are described in the following sections.

\section{Task 1. Team Coordination and Planning}

Efforts within this task included planning the tests with the host sites, DOE NETL, and contributing team members. The planning process included meeting with plant personnel at sites hosting the field testing, corporate and environmental personnel from participating utilities and other industry participants to discuss and agree upon the overall scope of the program, and to gather preliminary information necessary to develop a detailed draft test plan, scope of work, and quality assurance criteria.

\section{Task 2. Sorbent Selection and Viability Assessment}

The purpose of this task was to determine which sorbents are optimal for use in a temperature swing adsorption (TSA) $\mathrm{CO}_{2}$ capture process. Work began with identification of many promising sorbents; as the scale and cost of testing increased, the field was systematically narrowed. Task 2 is divided into four subtasks, and the approach for each subtask is discussed below.

\section{Task 2.1. Sorbent Selection, Characterization, and Lab-Screening}

\subsubsection{Sorbent Selection and Acquisition}

With advice from the project team, a previously performed literature search, and some initial testing conducted by ADA, a wide variety of potential $\mathrm{CO}_{2}$ sorbents were identified. Sorbent developers were invited to submit materials to the program. Using funding from several different sources, over 140 different sorbents from 23 different sorbent developers were evaluated. The goal of testing a wide array of materials was to provide industry with an increased number of options.

\subsubsection{Lab-Scale Screening}

ADA built and operated a lab-scale fixed bed sorbent screening device to quickly evaluate potential $\mathrm{CO}_{2}$ sorbents on simulated and actual flue gas. Initially the screening device was operated by manually turning valves to change the gas flow. However, it quickly became apparent that to run an adequate number of adsorption/regeneration cycles the system should be automated. The description below was based on the final configuration of the fixed bed system. 
Four sorbent developer reports that include detailed description of the fixed bed screening device at different stages of the project were published and are attached to Topical Report $5 .^{22}$

The specialized fixed bed reactor was designed to be used in the laboratory on simulated flue gas as well as in the field on actual flue gas with minimal modifications. A Programmable Logic Controller (PLC) was employed to completely automate the testing process. With an automated system, a series of adsorption/regeneration cycles were completed with little to no supervision. The flow rate of either simulated or actual flue gas was approximately $400 \mathrm{~mL} / \mathrm{min}$, and the amount of sorbent in the reactor was usually in the range of 0.4 to $2.5 \mathrm{~g}$, depending on the material particle size and how much sorbent was provided for testing. The sorbent and flue gas were contacted in a fixed bed through a sequence of temperature controlled tubes and electrically controlled valves.

The fixed bed was used to measure the adsorption and regeneration breakthrough curves. The adsorption breakthrough curve was measured using simulated or actual flue gas (field testing with actual flue gas is described in section 3.1.1.2). The regeneration profile was measured while the sorbent was being heated under a nitrogen $\left(\mathrm{N}_{2}\right)$ purge. The sorbent key characteristics evaluated using the fixed bed included:

1. $\mathrm{CO}_{2}$ capacity (when reported as a weight percentage): $\frac{100 * \text { mass } \mathrm{CO}_{2} \text {-removedfromgas }}{\text { mass }_{\text {sorbent }}}$

2. Cyclic stability (i.e. regeneration potential): ability of a sorbent to be used repeatedly without any reduction in capacity

3. Poisoning from other flue gas constituents: Decrease in capacity due to $\mathrm{SO}_{2}, \mathrm{NO}_{\mathrm{x}}$, etc.

4. $\Delta \mathrm{T}_{\text {capture-regen: }}$ The difference between capture and regeneration temperatures

5. Theoretical energy required for regeneration (calculated)

Equation 1 shows a simplified energy balance that can be used to calculate the heat duty during regeneration (i.e. theoretical regeneration energy).

$$
\frac{Q}{m_{c}}=\frac{m_{e}}{m_{c}} C_{e} \Delta T+\frac{B}{L} C_{s} \Delta T+\frac{Q_{r}}{m_{c}}
$$

Where $Q$ is the regeneration heat input, $\mathrm{kJ}$

$m_{c}$ is the mass of adsorbed $\mathrm{CO}_{2}, \mathrm{~kg}$

$m_{e}$ is the equipment mass, $\mathrm{kg}$

$\Delta T$ is the temperature difference between adsorption and regeneration, ${ }^{\circ} \mathrm{C}$ or $\mathrm{K}$

$L$ is the $\mathrm{CO}_{2}$ loading, $\mathrm{g} \mathrm{CO}_{2} / \mathrm{g}$ sorbent

$C_{e}$ is the equipment specific heat, $\mathrm{kJ} / \mathrm{kg} \cdot \mathrm{K}$

$B$ is a dimensional conversion term

$Q_{r}$ is the heat of reaction (positive for endothermic regeneration), $\mathrm{kJ} / \mathrm{mol} \mathrm{CO}_{2}$ 
Due to pressure drop, heat transfer, and mixing concerns, ADA does not believe that a fixed bed reactor will be a viable option beyond the laboratory scale. Therefore, the first term on the right hand side of Equation 1 can be neglected because no equipment heating will be required during regeneration (i.e. the regeneration system will be kept at the regeneration temperature and the sorbent will be moved). The second term on the right hand side of Equation 1 is the energy required to heat the sorbent from the adsorption temperature to the regeneration temperature (i.e. sensible heat). To reduce the energy related to this term, sorbent loading can be increased or the difference between the adsorption and regeneration temperature can be decreased. The second term on the right hand side of Equation 1 is the energy required to overcome the endothermic reaction associated with desorbing the $\mathrm{CO}_{2}$ from the sorbent (i.e. latent heat of reaction). For physical adsorbents, this term can be an order of magnitude lower than sorbents that chemically react with the $\mathrm{CO}_{2}$. However, the $\mathrm{CO}_{2}$ working capacity is also usually significantly lower.

For all the sorbents tested in this program, the theoretical energy required for regeneration was calculated using Equation 1. The purpose of this calculation was to compare different materials and assess their respective viability for use in a commercial-scale $\mathrm{CO}_{2}$ capture system. The calculation of the theoretical regeneration energy involved the average $\mathrm{CO}_{2}$ capacity and the median regeneration temperature from the adsorption/regeneration cycles completed with moisture in the flue gas. Note that from previous reports a liquid $\mathrm{MEA} \mathrm{CO}_{2}$ capture system requires approximately $3600 \mathrm{~kJ} / \mathrm{kg} \mathrm{CO}_{2}\left(1550 \mathrm{BTU} / \mathrm{lb} \mathrm{CO}_{2}\right) .^{3}$ This is not a theoretical regeneration energy, but is an actual regeneration energy based on achievable working capacities and heat integration. Although the sorbents' theoretical regeneration energies are often compared with the actual regeneration energy for MEA, it is important to realize that this is only a high level assessment. If the theoretical regeneration energy for a sorbent is greater than the actual regeneration energy for MEA, it is unlikely that the sorbent can be utilized in a costsaving process versus the benchmark technology.

The theoretical regeneration energy does not include important contributions to the overall process cost such as pressure drop, $\mathrm{CO}_{2}$ compression costs, water usage, environmental concerns, etc. In addition, the total $\mathrm{CO}_{2}$ capacity was used to determine the loading term, $L$. In reality, the loading should be based on the delta loading term (i.e. working capacity), which was not measured during the fixed bed tests. The calculation of the theoretical regeneration energy was used only to compare different sorbents and down select the most promising materials. Far more intensive studies are required to determine realistic values for the energy penalty of a sorbent used in a commercial-scale TSA $\mathrm{CO}_{2}$ capture process.

Figure 2 is a schematic of the sorbent screening testing unit when configured for laboratory testing. The $\mathrm{CO}_{2}$ analyzer was a continuous NDIR sensor with a $90 \%$ response time of 10 seconds. This response time should be taken into consideration when examining results. It was probable that the response time of the instrument affected results for materials tested in $0.4 \mathrm{~g}$ quantities more extensively than those tested in $2.5 \mathrm{~g}$ quantities. 


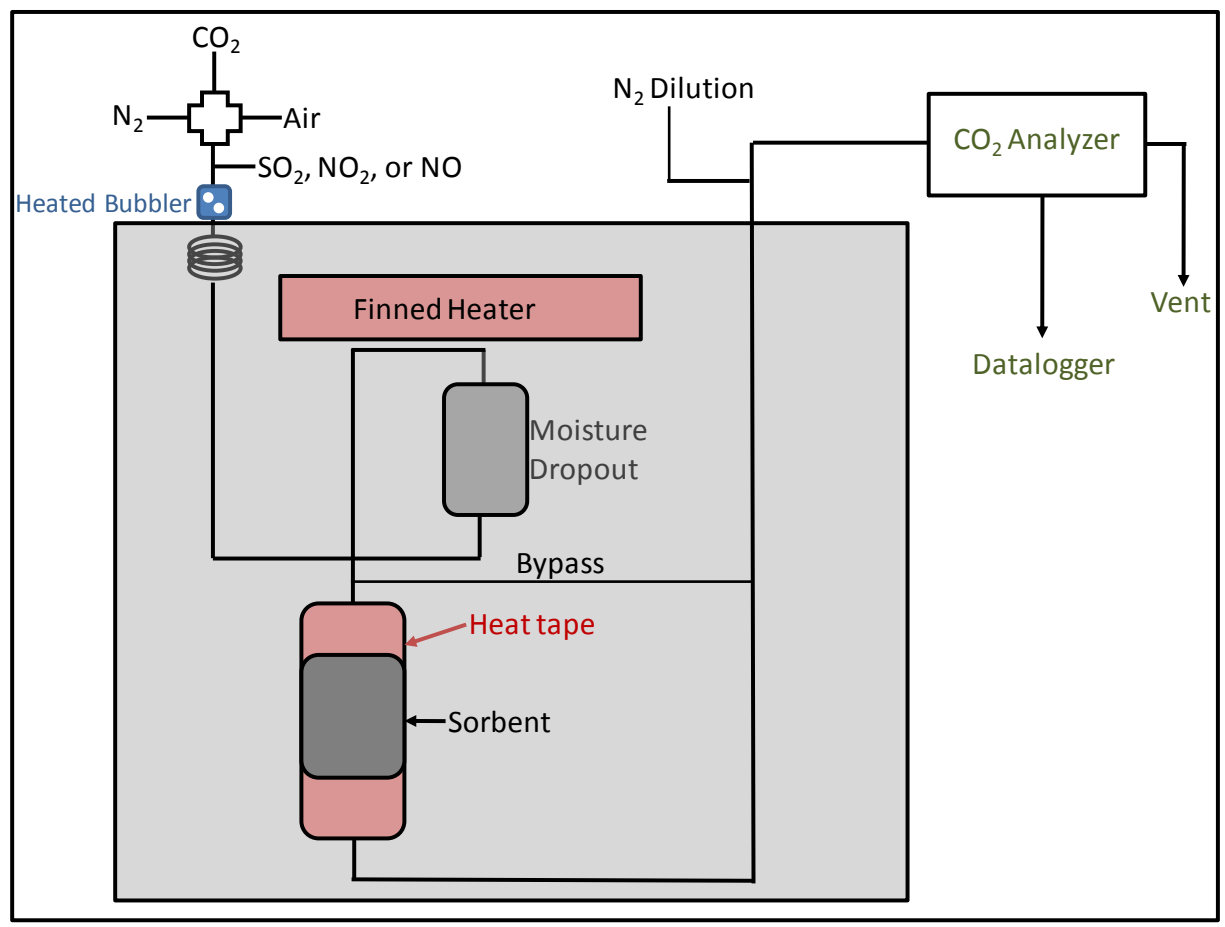

Figure 2: Schematic of the Sorbent Screening Test Unit

After the sorbent was placed into the fixed bed it was heated to an initial flushing temperature. The initial flushing temperature was based on the lowest regeneration temperature. A thermocouple on the outside of the glass fixed bed was used to determine when the bed had reached the desired temperature. When the bed temperature matched the desired adsorption temperature, the sorbent was flushed with dry $\mathrm{N}_{2}$ for 10 minutes or until no $\mathrm{CO}_{2}$ was measured in the purge gas stream, whichever was longer. Then the simulated flue gas, an admixture of compressed gases, was sent through the bypass line circumventing the sorbent. The composition of the laboratory sample gas, by volume, was approximately $12 \% \mathrm{CO}_{2}, 4 \% \mathrm{O}_{2}$, with a balance of $\mathrm{N}_{2}$. Approximately $9 \%$ moisture by volume was added directing the simulated flue gas through a bubbler at a temperature of $40^{\circ} \mathrm{C}$. When the $\mathrm{CO}_{2}$ reading was stabilized at the known $\mathrm{CO}_{2}$ concentration (i.e. baseline reading), the gas flow was directed through the sorbent. The $\mathrm{CO}_{2}$ concentration dropped as the sorbent removed the $\mathrm{CO}_{2}$ and then as this removal decreased the $\mathrm{CO}_{2}$ concentration would, thus, increase. After the $\mathrm{CO}_{2}$ levels returned to their original levels (i.e., the sorbent was saturated with $\mathrm{CO}_{2}$ ) it marked the end of the adsorption step. Figure 3 is an example of a breakthrough curve for sorbent $\mathrm{R}$ (a supported amine sorbent). 


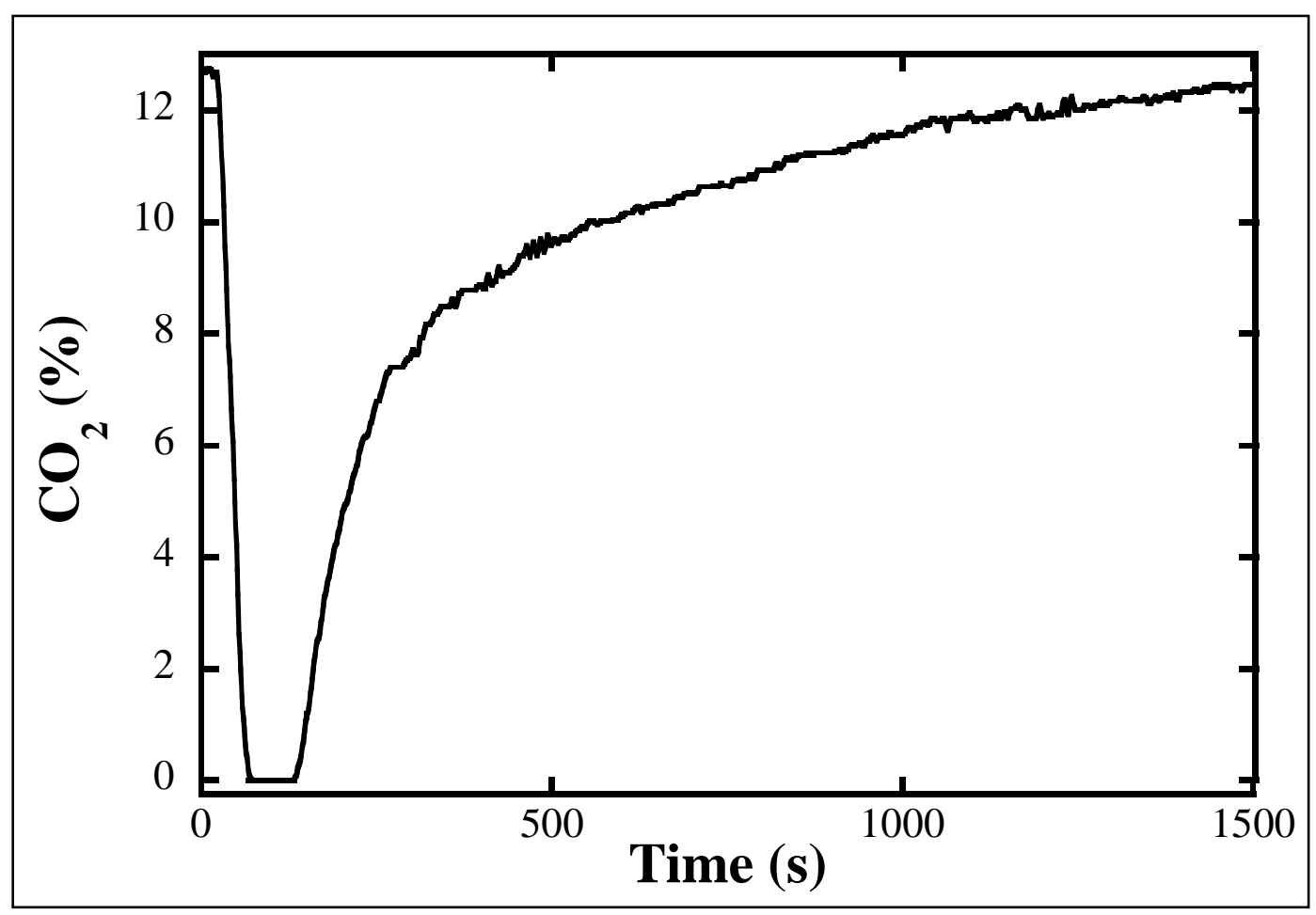

Figure 3: Example of an Adsorption Breakthrough Profile 
A temperature swing with a $\mathrm{N}_{2}$ purge gas was used to regenerate the sorbents and desorb the $\mathrm{CO}_{2}$. The regeneration purge gas flow rate was the same as that of the flue gas, approximately $300 \mathrm{~mL} / \mathrm{min}$. The regeneration step began with the system stopping flue gas flow in order to switch to heated $\mathrm{N}_{2}$ gas only. While the heated purge gas was flowing through the sorbent, heat tape on the outside of the fixed bed was used to ensure that the sorbent was fully heated to the selected regeneration temperature. Upstream of the reactor the $\mathrm{N}_{2}$ purge gas was directed through a bubbler separate from the one used for adsorption. This bubbler was primarily used at room temperature to add less than $2 \%$ by volume moisture to the regeneration gas. Figure 4 is an example of a regeneration breakthrough curve measured for sorbent $\mathrm{R}$.

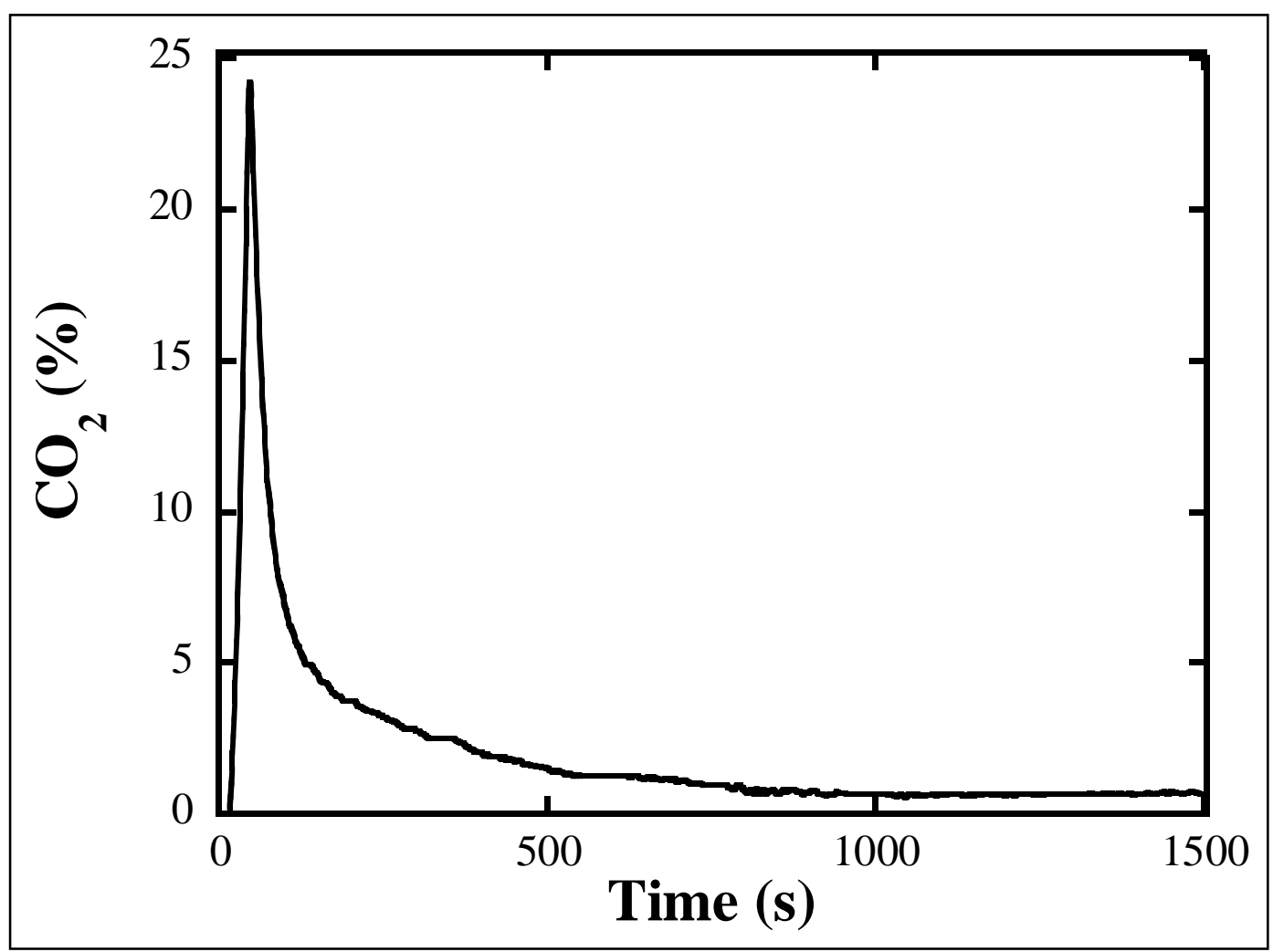

Figure 4: Example of a Regeneration Breakthrough Profiles

One key issue that will limit the use of commercial-scale fixed beds for this application is the heat management. Since all the reactions between the sorbents and $\mathrm{CO}_{2}$ are exothermic, whether physical or chemical, the sorbent temperature increases as it reacts with the $\mathrm{CO}_{2}$. Because the sorbent $\mathrm{CO}_{2}$ capacity decreases with increasing temperature, the test results will show a reduced amount of $\mathrm{CO}_{2}$ capture if the sorbent temperature is allowed to increase. Similarly, if the sorbent is allowed to cool due to the endothermic desorption, all the $\mathrm{CO}_{2}$ may not be released. To control the temperature of the sorbent during these lab-scale tests, the flow rate of the gas through the fixed bed was kept high compared to the amount of sorbent in the bed. Therefore, the sorbent and sample gas during adsorption were maintained at a lower temperature, while the sorbent and hot purge gas was maintained at a higher temperature during regeneration. Although this technique was useful to manage the temperature of the sorbent, the high ratio of gas to sorbent affected the breakthrough.. Since the gas flow rate was high, the residence time was low $(\sim 1 \mathrm{~s})$, and in some tests $\mathrm{CO}_{2}$ passed through the fixed bed un-reacted, even when adsorption 
sites were available (i.e. the $\mathrm{CO}_{2}$ concentration never reached zero). Therefore, the percent removal obtained during laboratory tests does not necessarily represent the total removal that could be realized by the sorbents. In fact, it should be considered a minimum of achievable removal. Even with a high volumetric flow rate of gas through the system, the temperature of the fixed bed would still elevate up to $10^{\circ} \mathrm{C}$ above the temperature set point due to the exothermic reaction. In these cases the adsorption step was not considered complete until the bed temperature had returned to the set point temperature (usually $55^{\circ} \mathrm{C}$ ).

During laboratory testing, $\mathrm{N}_{2}, \mathrm{O}_{2}, \mathrm{CO}_{2}$, trace materials in air, and moisture were included in the simulated flue gas. Other compounds, such as $\mathrm{SO}_{2}, \mathrm{NO}_{\mathrm{x}}$, and $\mathrm{Hg}$ that are present in actual flue gas were not included for this portion of the testing with the exception of a few specific tests.

There were two types of tests completed during laboratory testing: 1) parametric and 2) constant conditions or extended testing. Many materials were evaluated parametrically during which the regeneration temperature was adjusted after a specified number of adsorption/regeneration cycles. In many cases ten adsorption/regeneration cycles were completed at each regeneration temperature and the step change in the regeneration temperature was $10^{\circ} \mathrm{C}$. For example, cycles 1-10 for a particular sorbent were completed using a regeneration temperature of $90^{\circ} \mathrm{C}$, cycles 11-20 were completed using a regeneration temperature of $100^{\circ} \mathrm{C}$, cycles $21-30$ were completed using a regeneration temperature of $110^{\circ} \mathrm{C}$, etc., until the maximum temperature set by $\mathrm{ADA}$ and the sorbent developer was achieved. When the maximum temperature was achieved the tests could continue, but the regeneration temperature would remain constant.

The other type of laboratory test completed was extended cycle. These types of tests were focused on measuring the $\mathrm{CO}_{2}$ capacity and cyclic stability of the materials when the same adsorption and regeneration conditions were used repeatedly. Constant conditions or extended tests were often conducted when the sorbent developer had already completed extensive parametric testing and could provide the optimal operating conditions. In practice, very few sorbent developers have evaluated cyclic stability for more than 10 or 20 adsorption/regeneration cycles, so the results of this type of test provided valuable feedback to the developers.

The same laboratory-scale fixed bed apparatus that was used to initially evaluate over 140 sorbents in the laboratory was also used to collect data related to cyclic testing using a small slipstream of actual flue gas at the two host sites: Luminant's Martin Lake Steam Electric Station (Martin Lake) and at Xcel Energy's Sherburne County Generating Station (Sherco). This labscale equipment was specifically designed to be used in the laboratory on simulated flue gas as well as in the field on actual flue gas with minimal modifications. Similar to the laboratory tests, the flow rate of the actual flue gas was approximately $400 \mathrm{~mL} / \mathrm{min}$, and the amount of sorbent in the reactor was usually in the range of 0.7 to $2.5 \mathrm{~g}$, depending on the material particle size. Figure 5 is a schematic of the sorbent screening testing unit when setup for field testing. 


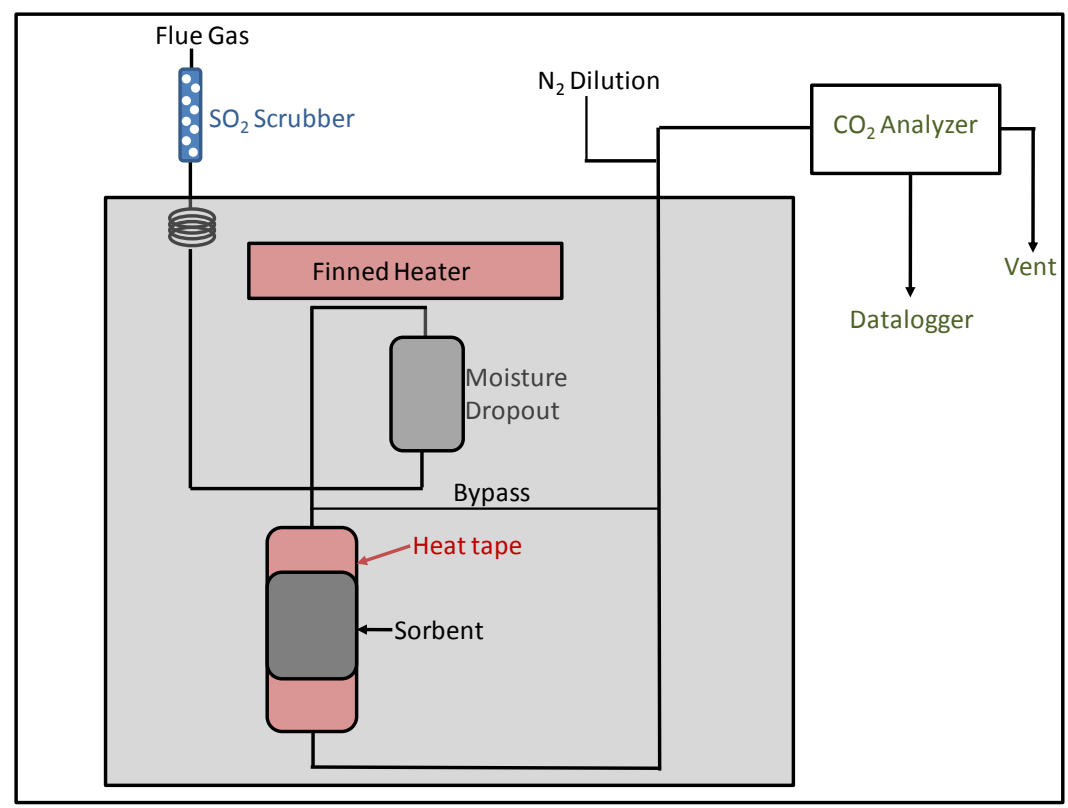

Figure 5: Schematic of Sorbent Screening Test Unit Configured for Field Testing

Note that in several cases the flue gas was treated in a laboratory-scale $\mathrm{SO}_{2}$ scrubber (consisting of sodium bicarbonate and water) before entering the system. This laboratory-scale $\mathrm{SO}_{2}$ scrubber reduced the flue gas $\mathrm{SO}_{2}$ concentration to less than $10 \mathrm{ppm}$. Table 1 lists the key characteristics of the flue gas used for sorbent screening.

Table 1: Key flue gas characteristics for field tests

\begin{tabular}{|l|c|}
\hline Temperature ${ }^{\mathbf{0}} \mathbf{C}\left({ }^{\mathbf{9}} \mathbf{F}\right)$ & $\mathbf{5 5}(\mathbf{1 4 0})$ \\
\hline $\mathrm{CO}_{2}$ Concentration $(\%)$ & 10 to 14 \\
\hline Moisture & Saturated \\
\hline $\mathrm{O}_{2}(\%)$ & 4 to 8 \\
\hline $\mathrm{NO}_{\mathrm{x}}(\mathrm{ppm})$ & 100 to 120 \\
\hline $\mathrm{SO}_{2}(\mathrm{ppm})$ & $\begin{array}{l}\text { 0 to } 250(<10 \mathrm{ppm} \\
\text { when a } \mathrm{SO}_{2} \\
\text { scrubber was used })\end{array}$ \\
\hline
\end{tabular}

\subsubsection{Lab-Scale Characterization of Sorbents}

Samples of the most promising sorbents identified as candidate sorbents during subtask 2.1.2 were evaluated at ADA (isotherms), ARI (particle density and crush strength), and Jenike \& Johanson (qualitative attrition testing) to determine additional fundamental sorbent properties.

\section{Thermogravimetric Analysis}

A thermogravimetric analyzer (TGA) was used by ADA to measure the $\mathrm{CO}_{2}$ loading for select sorbents under different temperatures and $\mathrm{CO}_{2}$ partial pressures. The purpose of this testing was 
to develop isotherms and determine the working capacity for the sorbents. The TGA was a Perkin Elmer Pyris 1. The TGA was operated at less than standard atmospheric pressure, because the tests were located at the company headquarters in Littleton, CO (elevation $1643 \mathrm{~m}$ ); therefore, even when $100 \% \mathrm{CO}_{2}$ gas was used, the $\mathrm{CO}_{2}$ partial pressure was only 0.81 bar. Note that a small amount of moisture was added to the gas during ADA's TGA tests because others have shown that completely dry conditions lead to loss of amine reactivity. ${ }^{24,25}$ The moisture levels were approximately less than $1 \%$ by volume, so the effect on the weight change of the sorbent would be minimal. The test details are provided in Table 2.

Table 2: TGA Operating Conditions

\begin{tabular}{|c|c|c|c|c|c|}
\hline TGA & $\begin{array}{c}\text { Sample } \\
\text { Size } \\
(\mathbf{m g})\end{array}$ & $\begin{array}{c}\text { Gas Flow } \\
\text { Rate } \\
(\mathbf{m L} / \mathbf{m i n})\end{array}$ & $\begin{array}{c}\text { Temperatures } \\
\text { Evaluated } \\
\left({ }^{\circ} \mathbf{C}\right)\end{array}$ & $\begin{array}{c}\mathbf{C O}_{2} \\
\text { Partial } \\
\text { Pressure } \\
(\text { bar })\end{array}$ & $\begin{array}{c}\text { Dew } \\
\text { Point } \\
\left({ }^{\circ} \mathbf{C}\right)\end{array}$ \\
\hline $\begin{array}{c}\text { Perkin Elmer } \\
\text { Pyris 1 }\end{array}$ & $1-5$ & 100 & $\begin{array}{c}40-120 \\
(\text { increments of } \\
\left.10^{\circ} \mathrm{C}\right)\end{array}$ & $\begin{array}{c}0.04, \\
0.081,\end{array}$ & $<22$ \\
\hline
\end{tabular}

\section{$\underline{\text { Attrition Testing }}$}

Depending on the contactor configuration and sorbent properties, sorbent losses due to attrition could be a more costly operating expense than the energy penalty associated with sorbent regeneration. For this reason, the sorbent $\mathrm{R}$ substrate and sorbent $\mathrm{X}$ substrate, two promising supported amine sorbents, were evaluated by attrition experts at Jenike \& Johanson. The substrate particle size distribution was measured prior to any testing. Then, the material was added to a bench-scale circulating fluidized bed, heated to approximately $55^{\circ} \mathrm{C}$. A vacuum system was used to induce an air velocity of $4.6 \mathrm{~m} / \mathrm{s}$. The solids were entrained by the gas with an average air-to-solids ratio of 4.41. A picture of the test setup is provided in Figure 6. A particle distribution size was recorded before and after 6 hours, of testing in the circulating fluidized bed, approximately 3600 cycles. 


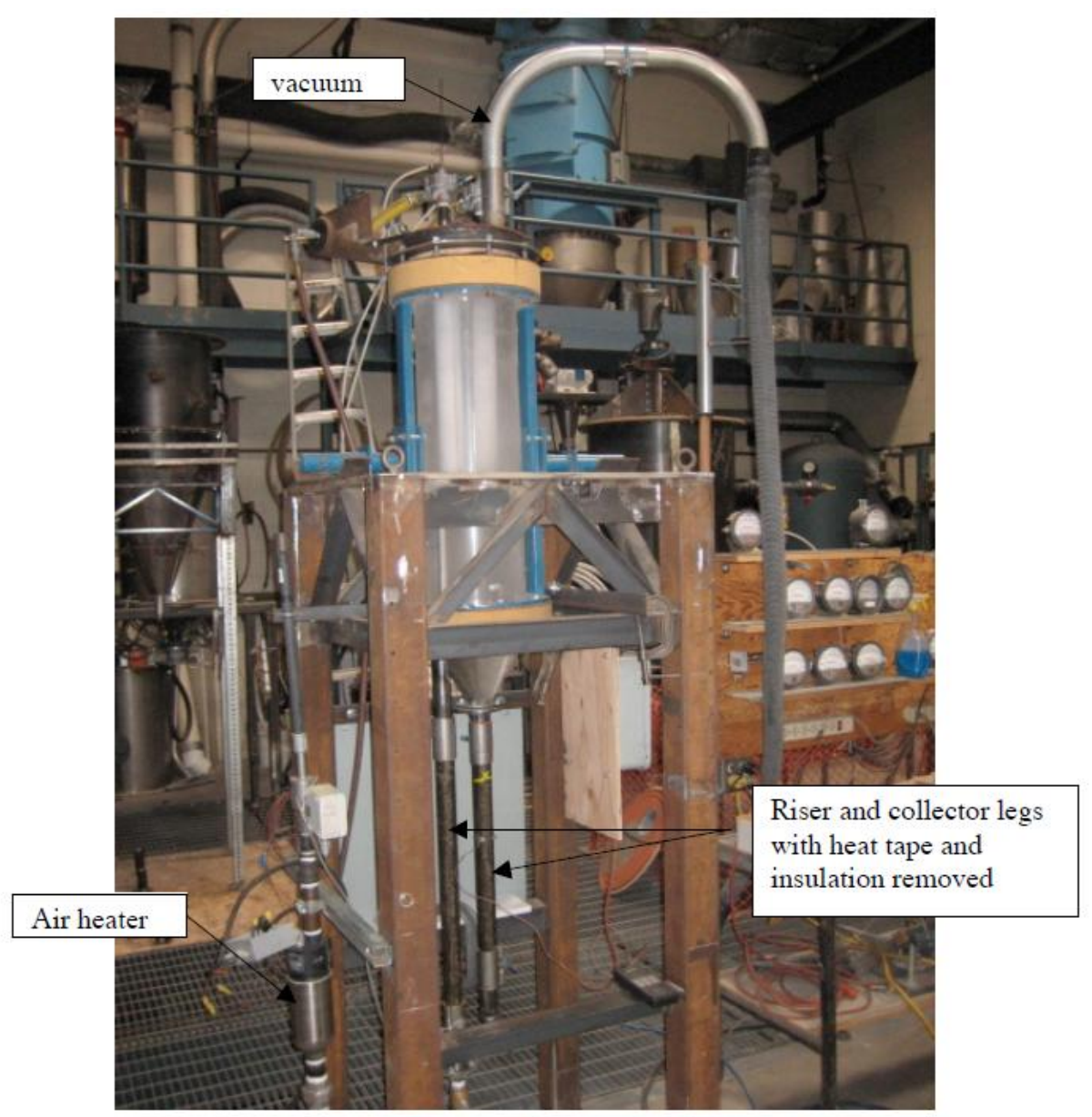

Figure 6: Attrition Testing Equipment Operated by Jenike \& Johanson Particle Density

Under a separate project (DE-FE0004343) particle densities were measured for two promising sorbents. The testing was conducted by Adsorption Research, Inc. using a proprietary experimental method. The particle density is defined as the mass per unit particle. This quantity is useful for determining fluidization and entrainment related properties.

\section{Crush Strength}

Crush strength provides a quantitative measurement of particle hardness. However, it does not provide a means to directly predict attrition because this is a highly process dependent quantity. For the most promising beaded material provided to the sorbent screening program the crush strength was measured, note that the crush strength measurement was conducted by Adsorption Research, Inc. and was funded through a different project (DE-FE0004343).

\section{Task 2.2. 1 kW pilot-Scale Equipment Design and Construction}

During the first budget period, pilot-scale equipment was designed and fabricated to treat the equivalent of approximately 1 to $2 \mathrm{~kW}$ of actual flue gas. Several different contactor designs were considered in depth. 


\subsubsection{System Design}

ADA and solid-gas contactor experts at Southern Company worked together to design the $1 \mathrm{~kW}$ pilot system. The primary function of the pilot-scale apparatus was to evaluate sorbent performance, not to fabricate a miniature version of a full-scale control technology concept.

\subsubsection{Fabrication and Checkout}

ADA supervised fabrication of the $1 \mathrm{~kW}$ pilot reactor and checked out all system components in the shop prior to shipment to the first field site. The system was then checked out again after it was delivered and setup at the first field site.

\section{Task 2.3. Parametric Field Tests}

The $1 \mathrm{~kW}$ pilot was operated on actual flue gas at the two host sites: Luminant's Martin Lake Steam Electric Station (Martin Lake) and Xcel Energy's Sherburne County Generating Station (Sherco). Four supported amine sorbents were evaluated at these sites. The $1 \mathrm{~kW}$ pilot was operated in both batch and continuous mode. A minimum of 10 adsorption/regeneration cycles were completed for all sorbents at both field sites, although at Sherco the laboratory-scale fixed bed system was used to complete several of these cycles.

\section{Task 2.4. Sorbent Performance Report}

A stand-alone document providing a comprehensive review of the testing and a summary of sorbent characteristics was prepared and submitted to the DOE and the project team on May 31, 2011.

\section{Task 3. Full-Scale Equipment Assessment and Design}

A high level full-scale concept was developed to determine whether projected economics were within the range that can be considered viable for this retrofit $\mathrm{CO}_{2}$ capture application. More detailed design efforts were reserved for later stages in the overall development effort. Full-scale equipment was evaluated and selected in Task 3 based on the lab-scale results, $1 \mathrm{~kW}$ pilot-scale results, the technical and cost goals for the project, and feedback from the plant owners and operators that are participated in the project. During this task, ADA worked with engineers at Stantec Consulting to select appropriate equipment to determine the viability of solid sorbents for the application of $\mathrm{CO}_{2}$ capture. Task 3 was divided into several subtasks, which are discussed in detail in the following sections.

\section{Task 3.1. Technology Survey to Identify Equipment Options}

A technology and literature survey of a broad range of gas-solid contactor and thermal regeneration technologies (including fluid bed, entrained flow, gravitational cross flow, moving bed, radial flow fixed bed, and others) was performed. This survey included commercial equipment options from the air pollution control industry, the chemical process industry, and mineral processing industry for technologies that had properties that the team identified as necessary for solid sorbent $\mathrm{CO}_{2}$ capture. This involved making inquiries to vendors and compiling technical and cost information. 


\section{Task 3.2. Technology Assessment}

This task involved developing a list of Mandatory (Must) and Desirable (Want) screening criteria (including technical, economic, commercial, and risk) to be applied in a modified KepnerTregoe ${ }^{27}$ decision analysis to reduce the list developed in Task 3.1 to two or three "preferred" candidates for more detailed analyses. In order to develop a full-scale concept and to estimate the capital and operating costs, it was necessary to select a reference basis for comparison. The hypothetical reference plant was based on the coal-fired power plant selected by the DOE NETL for a similar evaluation for $\mathrm{MEA}^{3}$, AEP's Conesville Unit 5 was used for the analysis.

\section{Task 3.3. Develop Capital and Operating Costs}

Material and energy balances were conducted, and then order-of-magnitude capital and operating cost estimates were developed for the one selected technology based on the approximately 500MW reference plant. The cost estimates were developed from in-house data, published from suppliers and end-users, and consisted of fixed O\&M costs, variable O\&M costs, and incremental O\&M costs. The sorbent costs, when produced in large quantities, were included in the cost considerations. The end product was an estimated cost of capturing $\mathrm{CO}_{2}$ in $\$$ ton $\mathrm{CO}_{2}$ removed.

\subsubsection{Capital Cost Estimate (BP1)}

This estimate was developed from in-house data, published data for current or recent projects, and from equipment suppliers. The estimate is considered $+50 /-30 \%$.

\subsubsection{Operation and Maintenance Cost Estimates (BP1)}

This cost estimate was developed from in-house data, published data and information from suppliers and end users, and consisted of

- Fixed O\&M Costs

- Operating and Maintenance Staff

- Variable O\&M Costs

○ Power

- Steam

○ Water

- Sorbent (see 3.3.3)

○ Waste disposal

○ By-product revenues

- Incremental O\&M Costs

The rationale for the estimates is provided, along with backup information.

\subsubsection{Sorbent Costs (BP1)}

Determining whether solid sorbents, the best of which were tested, can be used economically in a TSA process designed for $\mathrm{CO}_{2}$ capture was the ultimate goal of the proposed project. Detailed cost estimates for full-scale use of the top two or three sorbents were completed and integrated into the operating cost estimates described in 3.3.2. 


\subsubsection{Levelized Costs $(\mathrm{BP1})$}

The end product of the Task 3.3 calculations was an estimated cost of removing $\mathrm{CO}_{2}$, in $\$ /$ ton $\mathrm{CO}_{2}$ removed. These calculations were carried out using industry accepted practices and provided a benchmark for comparison among the preferred solid-sorbent $\mathrm{CO}_{2}$ capture technologies.

\section{Task 3.4. Identify and Assess Impacts}

This subtask included identification and assessment of any synergistic benefits or adverse impacts on the control of other pollutants by the preferred $\mathrm{CO}_{2}$ control technologies. The impacts of $\mathrm{CO}_{2}$ capture were assessed both upstream and downstream of the process.

\subsubsection{Identify Synergistic Effects on Other Emissions}

This subtask included identification and assessment any synergistic benefits or adverse impacts on the control of other pollutants by the preferred $\mathrm{CO}_{2}$ control technologies.

\subsubsection{Identify Upstream and Downstream Balance of Plant Impacts}

The "upstream" and "downstream" impacts of the preferred $\mathrm{CO}_{2}$ control technologies were identified, including but not limited to considerations such as: impact on boilers or other equipment (stack draft, pressure balance points and ID/FD fans), release of other emissions of concern, hazardous materials handling/disposal issues (degraded sorbent), etc. For instance, in the case of an amine enhanced solid sorbent, identify means to correct degradation associated with heat stable salts, due to upstream FGD operating conditions.

\section{Task 3.5. Conduct Cursory Life-Cycle $\mathrm{CO}_{2}$ Emissions Estimate}

During the project, a cursory life-cycle $\mathrm{CO}_{2}$ emissions estimate was conducted for the preferred sorbent. The $\mathrm{CO}_{2}$ generated from the capture/regeneration parasitic power as well as the $\mathrm{CO}_{2}$ emissions associated with the extraction, processing, and transportation of the $\mathrm{CO}_{2}$ sorbent and any waste streams was specifically addressed. The one-time $\mathrm{CO}_{2}$ produced in the manufacturing, fabrication, transportation, and installation of the capital equipment was not included in this evaluation.

\section{Task 3.6. Final Technology Selection}

Based on the results from tasks 3.3 through 3.5, one equipment design and one sorbent was selected for conceptual design and costs. The sorbent selected was a supported amine sorbent. Because sorbent testing was underway concurrently to the Task 3.6. Final Technology Selection and Task 3.7. Development of the 500-MW Conceptual Design and Cost Estimate, several sorbent performance properties from public literature were utilized.

\section{Task 3.7. Development of 500-MW Conceptual Design and Cost Estimate}

A preliminary full-scale concept and cost estimate (+/- 30\%) for retrofitting the selected technology into the 430-MW Conesville reference plant was performed. Accepted power industry cost estimating methodology was used. 


\section{Task 4. Management and Reporting}

This task provided time for overall program management, technology transfer, and preparation of financial and administrative reports. 


\section{RESULTS AND DISCUSSION}

The major technical activities, results, and key findings are provided in the following sections. The technical work can be divided into two main components:

1. Sorbent Selection and Viability Assessment (Task 2)

2. Full Scale Equipment Assessment and Design (Task 3)

These two main components of the program were completed concurrently. Note that the sorbent assessment included extensive laboratory screening, field testing at the laboratory scale, and field testing at the $1 \mathrm{~kW}$ pilot scale using select materials. The efforts related to technology transfer are also highlighted (Task 4).

\section{Task 2. Sorbent Selection and Viability Assessment}

\section{Task 2.1. Sorbent Selection, Characterization, and Lab-Screening}

\subsubsection{Sorbent Selection and Acquisition}

Sorbent developers throughout the world were invited to submit materials to be evaluated. Under funding from DE-NT0005649 and other funding, over 140 different materials were tested. Using simulated flue gas in the ADA laboratory, the following types and quantities of sorbents were evaluated:

- 87 supported amines

- 31 carbon based materials

- 6 zeolites

- 7 supported carbonates (evaluated under separate funding)

- 10 hydrotalcites

All sorbents included in this program were uniquely coded and access to the identity of the provider was limited during testing to minimize potential biases, especially during qualitative assessments.

Although the sorbent screening program was extensive, the results cannot and should not be extrapolated to materials that were not included in the program. There is still a great deal of ongoing sorbent development, with the potential to lead to continued improvement. The discussion for different sorbents is divided by the sorbent families in the following subtasks. In the original proposal, there were several key sorbent physical properties that were identified. The estimates for these properties given in the proposal, the goal provided in the proposal, and the actual calculated or measured values are provided in Table 3. 
Table 3: Key Sorbent Physical Properties

\begin{tabular}{|l|l|l|l|}
\hline Physical Property & $\begin{array}{l}\text { Range Provided } \\
\text { in Proposal }\end{array}$ & $\begin{array}{l}\text { Project Goal Provided } \\
\text { in Proposal }\end{array}$ & $\begin{array}{l}\text { Calculated or } \\
\text { Measured Values }\end{array}$ \\
\hline Sorbent Particle Size $(\mathrm{mm})$ & $\begin{array}{l}\text { Highly varied } \\
\text { and controllable }\end{array}$ & $\sim 1-10$ & $1 \mathrm{e}-5$ to 1.0 \\
\hline $\begin{array}{l}\text { Sorbent Surface Area } \\
\left(\mathrm{m}^{2} / \mathrm{g}\right)\end{array}$ & $0.5-3000$ & $0.5-1500$ & Not measured \\
\hline $\begin{array}{l}\text { Sorbent Active Component } \\
\text { Concentration }(\mathrm{wt} \%)\end{array}$ & $5-100$ & $10-100$ & $\begin{array}{l}\text { For supported } \\
\text { amines or } \\
\text { carbonates: } 20-50\end{array}$ \\
\hline Shape of Sorbent & Varied & Spherical & $\begin{array}{l}\text { Random to } \\
\text { spherical }\end{array}$ \\
\hline $\begin{array}{l}\text { Density of Sorbent }\left(\mathrm{g} / \mathrm{cm}^{3}\right. \\
\left.\left(\mathrm{lb} / \mathrm{ft}^{3}\right)\right)\end{array}$ & $0.6-2.6$ & $\begin{array}{l}\text { Dependant on contactor } \\
\text { design }\end{array}$ & $0.24-0.64^{*}\left(15-40^{*}\right)$ \\
\hline Mechanical Strength & Not reported & $\begin{array}{l}\text { Dependant on contactor } \\
\text { design }\end{array}$ & $\begin{array}{l}\sim 60 \mathrm{~g}-\text { based on } \\
\text { crush strength }\end{array}$ \\
\hline $\begin{array}{l}\text { Attrition fines: form, } \\
\text { processing, and fate }\end{array}$ & Not reported & To be determined & $\begin{array}{l}\text { Form: Smaller } \\
\text { particles, Fate: } \\
\text { Sorbent dependent }\end{array}$ \\
\hline
\end{tabular}

"Only measured for those sorbents evaluated at the $1 \mathrm{~kW}$ pilot scale

\subsubsection{Lab-Scale Screening}

Lab-scale screening using the fixed bed system was completed using both simulated flue gas in the ADA laboratory as well as actual flue gas at the two host site power plants. Important sorbent properties that were evaluated in subtask 2.1.2.

\section{Laboratory Fixed Bed Screening - Supported Amines}

Supported amine sorbents consist of some type of amine supported on an inert substrate. There is a great deal of ongoing research to invent and improve these materials. The adsorption and regeneration breakthrough profiles were measured for approximately 87 supported amine sorbents under several funding mechanisms.

An adsorption profile for sorbents R, EM, and EN are provided in Figure 7 to serve as examples of the shape of the breakthrough curve characteristic for supported amines. These materials were similar and consisted of an amine on a silica substrate. Sorbent R contained 50\% amine loading, while sorbent EM contained $40 \%$ amine loading and sorbent EN contained 30\% amine loading. The amine was similar for all three materials, but EN and EM contained an additive not included for sorbent R. All three of these sorbents were able to remove over $90 \%$ of the $\mathrm{CO}_{2}$ from the simulated flue gas stream used for fixed bed testing. Sorbent $\mathrm{R}$ exhibited first an initial breakthrough that resulted in a fast increase in $\mathrm{CO}_{2}$ concentration, followed by a much slower increase in the $\mathrm{CO}_{2}$ concentration to achieve complete saturation. The second generation sorbents EM and EN, which were submitted to the program from the same sorbent developer, exhibited initial breakthrough and then a fast increase in the $\mathrm{CO}_{2}$ concentration to achieve complete saturation. Although the total $\mathrm{CO}_{2}$ capacity of sorbent $\mathrm{R}$ was greater than that of sorbents EM and EN, the slow tail in the adsorption profile revealed a reaction with $\mathrm{CO}_{2}$ that is 
limited by mass diffusion. In an actual $\mathrm{CO}_{2}$ capture process, it is likely that the working capacity of sorbents EM and EN would be greater than that of R because they do not exhibit the same mass diffusion limitations. These materials are just one of many examples of supported amine sorbents that have been improved throughout the duration of the sorbent screening phase of this project.

Table 4. Key Sorbent $\mathrm{CO}_{2}$ Capture Effectiveness Properties and Tasks of Determination

\begin{tabular}{|l|l|l|l|}
\hline $\mathbf{C O}_{2}$ Capture Effectiveness & $\begin{array}{l}\text { Proposal } \\
\text { Estimates }\end{array}$ & Goal & $\begin{array}{l}\text { Calculated or } \\
\text { Measured During } \\
\text { Project }\end{array}$ \\
\hline $\begin{array}{l}\text { Theoretical Maximum Capacity } \\
\text { (wt } \%)\end{array}$ & $2-35^{*}$ & N/A & 35 \\
\hline $\begin{array}{l}\text { Breakthrough Curves at Different } \\
\text { Conditions }\end{array}$ & N/A & N/A & $\begin{array}{l}\text { Measured - see text in } \\
\text { Subtask 2.1.2 in } \\
\text { Results \& Discussion }\end{array}$ \\
\hline $\begin{array}{l}\text { Actual Working Capacity \& } \\
\text { Adsorption Capacity after Multiple } \\
\text { Cycles (wt\%) }\end{array}$ & $0-28^{*}$ & $>5$ & $\begin{array}{l}5-10 \text { (depending on } \\
\text { operating conditions) }\end{array}$ \\
\hline $\begin{array}{l}\text { CO } 2 \text { Isotherms } \\
\text { (wt\%) vs. T and P }\end{array}$ & N/A & N/A & $\begin{array}{l}\text { Measured - see text in } \\
\text { Subtask 2.1.3 in } \\
\text { Results \& Discussion }\end{array}$ \\
\hline $\begin{array}{l}\text { Targeted Capacity and Approaches } \\
\text { to Reach Target (wt\%) }\end{array}$ & $>12$ & $\begin{array}{l}14 \% \text { total CO } 2 \\
\text { capacity measured }\end{array}$ \\
\hline & $\begin{array}{l}\text { Negligible- } \\
\text { Highly } \\
\text { Susceptible }\end{array}$ & Negligible & $\begin{array}{l}\text { Measured }- \text { highlight } \\
\text { dependent on sorbent } \\
\text { - see text in Subtask } \\
\text { 2.1.3 in Results \& } \\
\text { Discussion }\end{array}$ \\
\hline
\end{tabular}




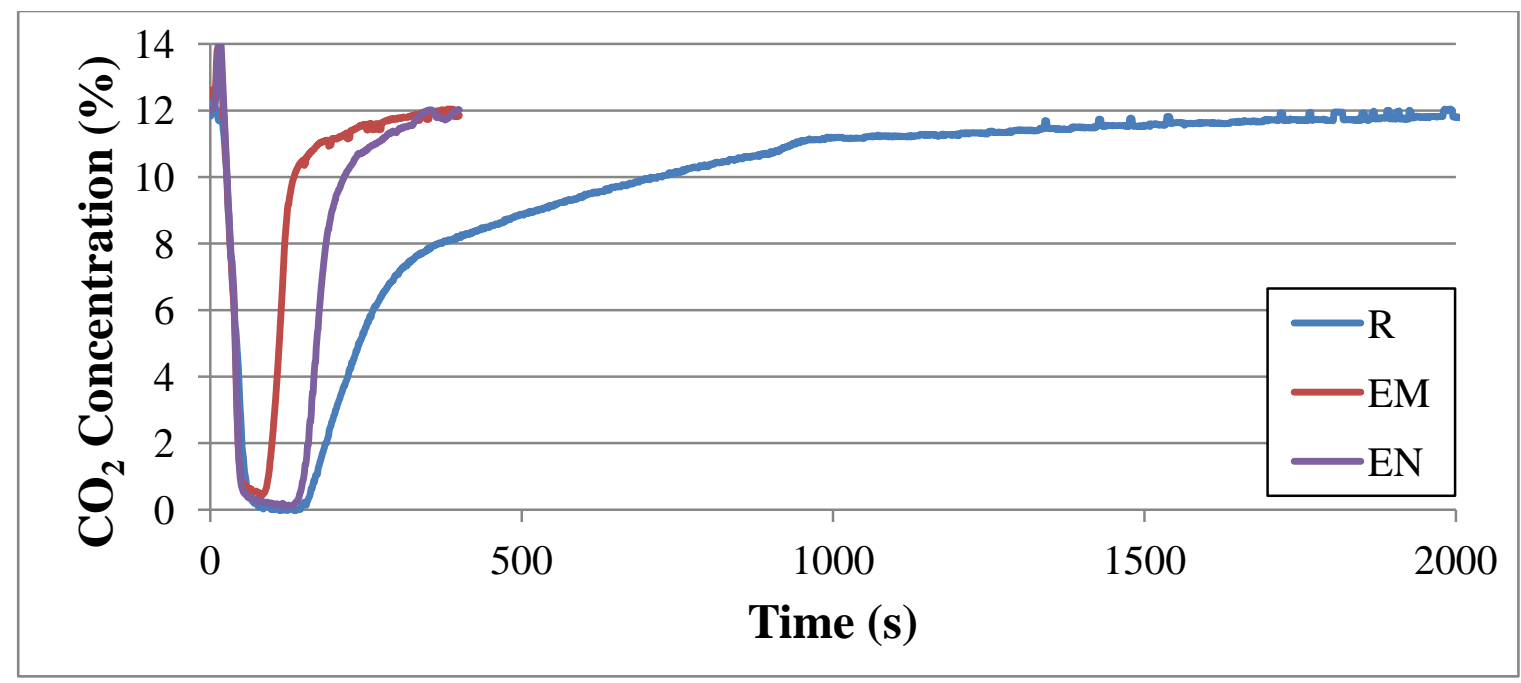

Figure 7: Select Supported Amine Adsorption Profiles

Based on the extensive laboratory results collected, supported amines exhibit the greatest $\mathrm{CO}_{2}$ capacities under simulated flue gas conditions. The theoretical regeneration energies, calculated using the method described in section 2.1.1, are provided in Figure 8a and Figure 8b. The red dashed line represents the regeneration energy for the benchmark aqueous MEA ${ }^{3}$. Due to their high $\mathrm{CO}_{2}$ capacities and low specific heat, many supported amines have the potential to significantly reduce the energy penalty associated with $\mathrm{CO}_{2}$ capture.

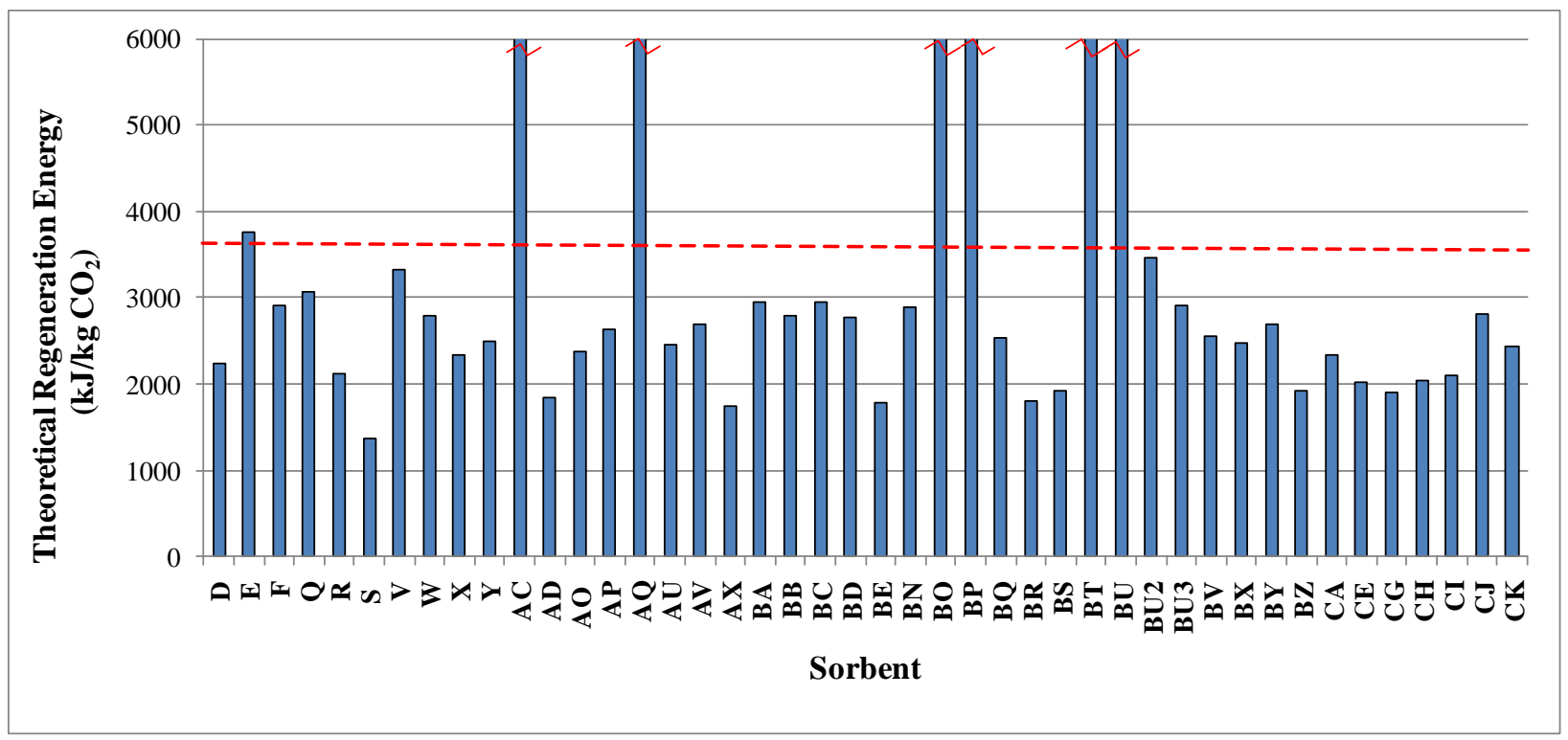

Figure 8a: Theoretical Regeneration Energy of Supported Amine Sorbents 


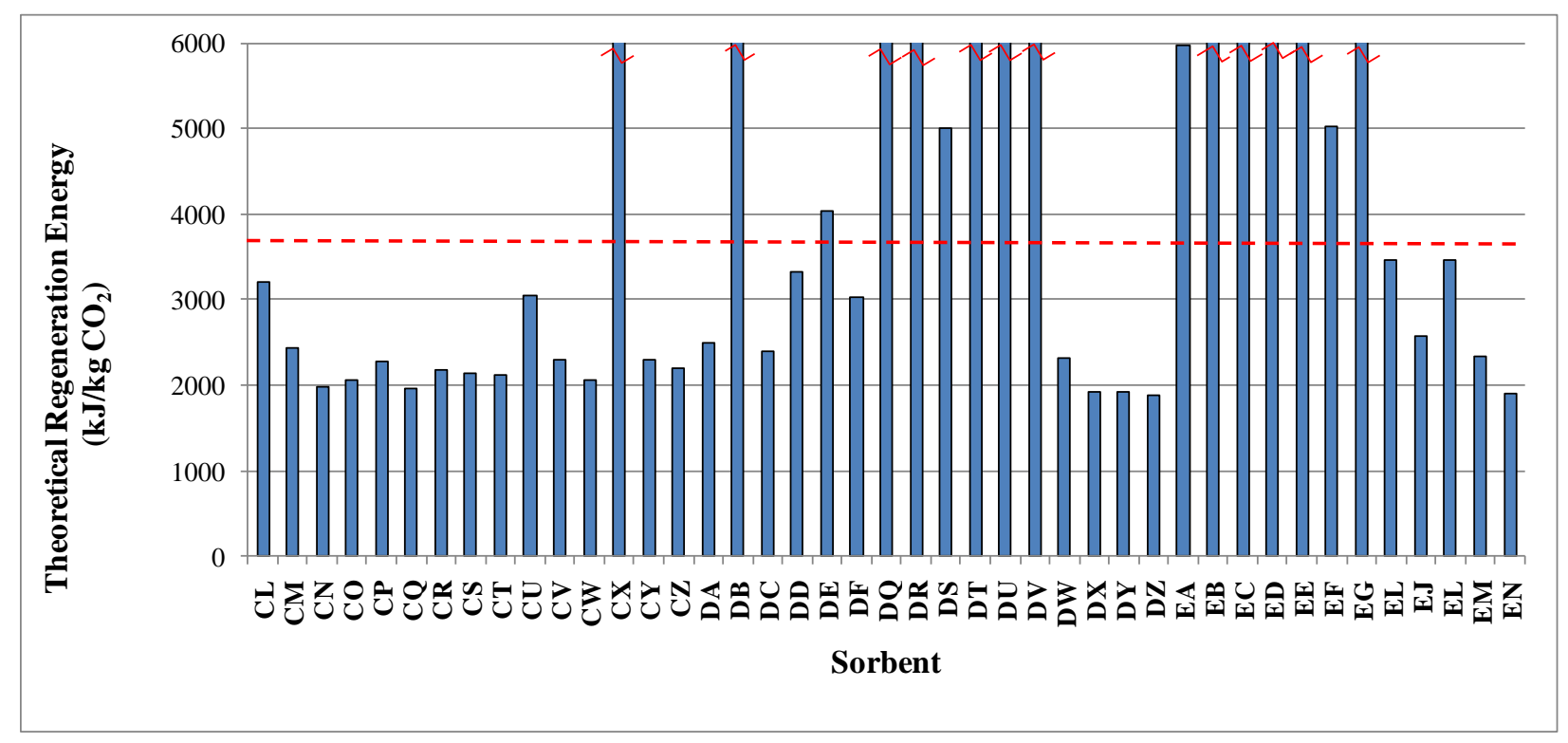

Figure 8b: Theoretical Regeneration Energy of Supported Amine Sorbents

The most important challenges for supported amine sorbents are related to long-term cyclic stability, poisoning by flue gas constituents, cost, and finding a process that can take advantage of their high $\mathrm{CO}_{2}$ capacities. Several, but not all, of the supported amine sorbents demonstrated a loss in $\mathrm{CO}_{2}$ capacity when using simulated flue gas in the laboratory. As an example, select adsorption profiles from laboratory tests for sorbent $\mathrm{CU}$ are provided in Figure 9. Although the testing conditions were the same for all cycles, the adsorption profiles revealed a slow, progressive decrease in the $\mathrm{CO}_{2}$ capacity of the material.

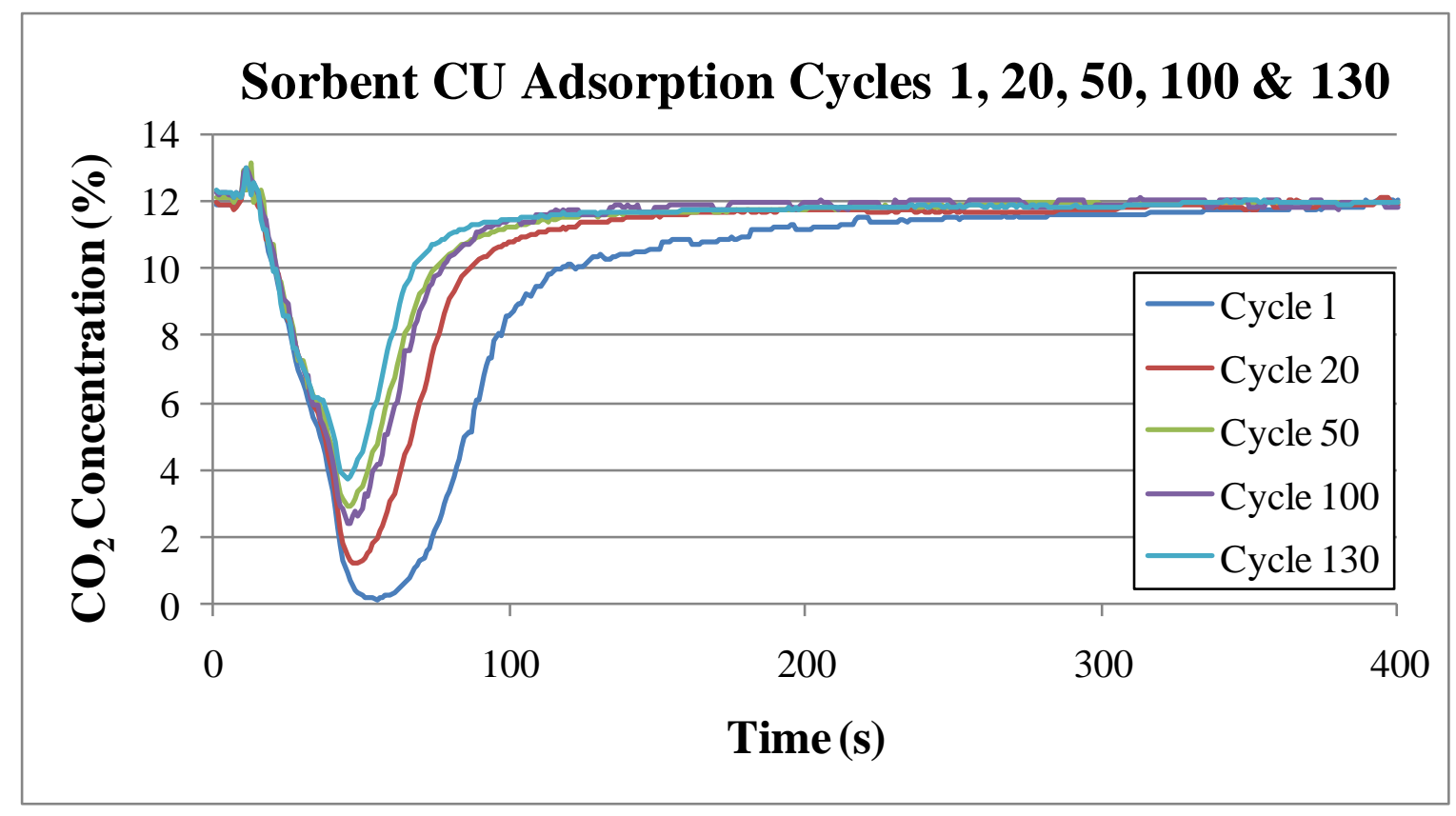

Figure 9: Sorbent CU Laboratory Adsorption Profiles 
One important goal of this program was to work closely with sorbent developers; ADA's testing results were provided to the developers in the hopes of leading to improvements in sorbent performance. In several cases, collaboration between ADA and sorbent developers has led to second or third generation sorbents exhibiting significantly improved performance properties compared to their first generation counterparts. The $\mathrm{CO}_{2}$ capacity versus cycle number for two sorbents is shown in Figure 10. Both sorbents are variations of an amine supported by a clay substrate. The generation 1 sorbent was tested by ADA and was found to degrade with cycle number, even when using simulated flue gas in the laboratory. Several months later the developer provided a similar sorbent that was also tested for multiple cycles. During the 56 cycle test, there was no sign of a decrease in capacity. The improvement of this material is an example of how collaboration can lead to better sorbent options and thus an increase in the chance of success.

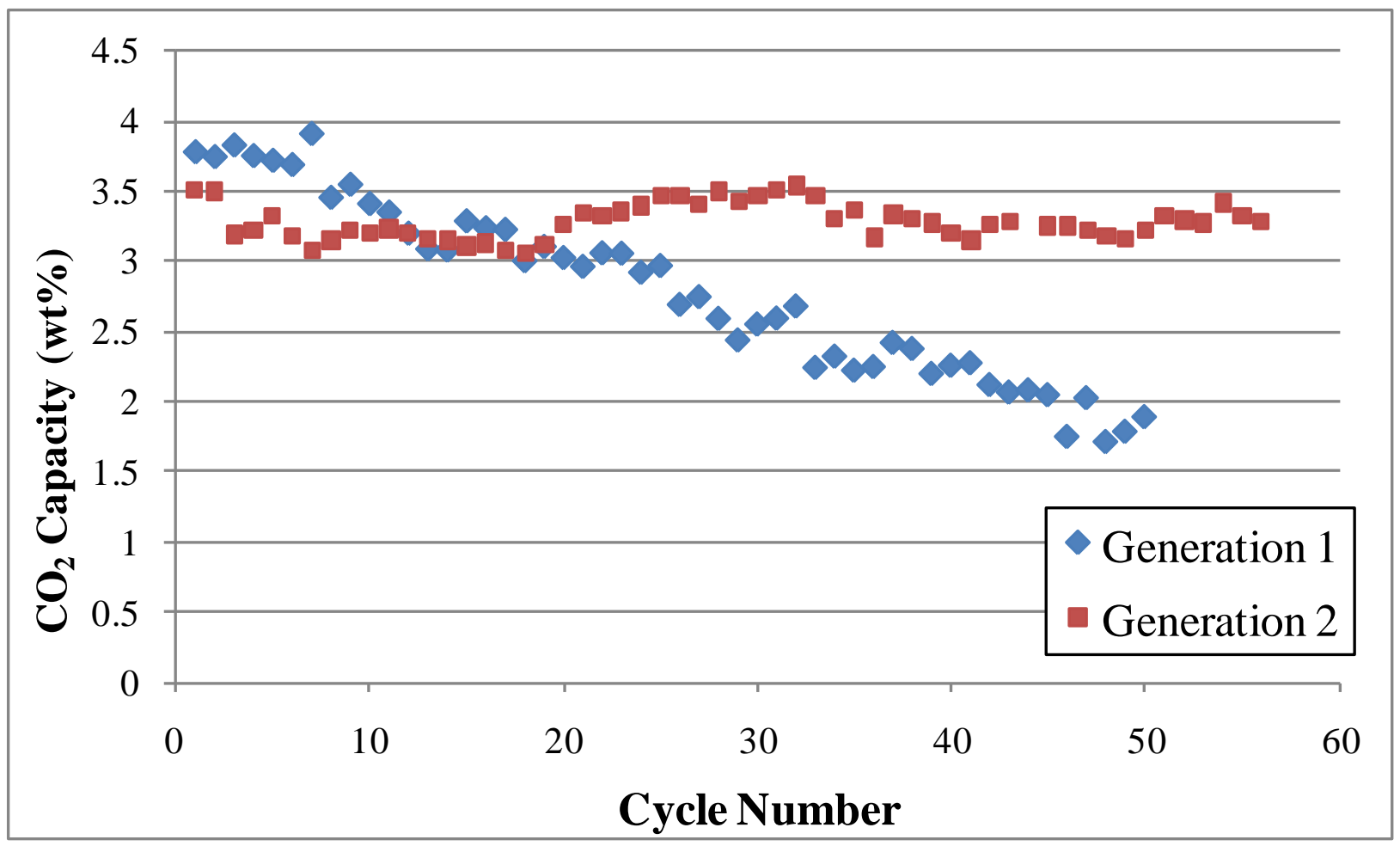

Figure 10: First and Second Generation Supported Amine Clay-Based Sorbent

Cyclic stability is a key parameter when comparing potential sorbents. In general there were many supported amines that demonstrated cyclic stability. As an example, select adsorption profiles for sorbent $\mathrm{CQ}$, an amine grafted to an aerogel substrate, are provided in Figure 11. The repeatability in the adsorption profiles for this material was exceptional. 


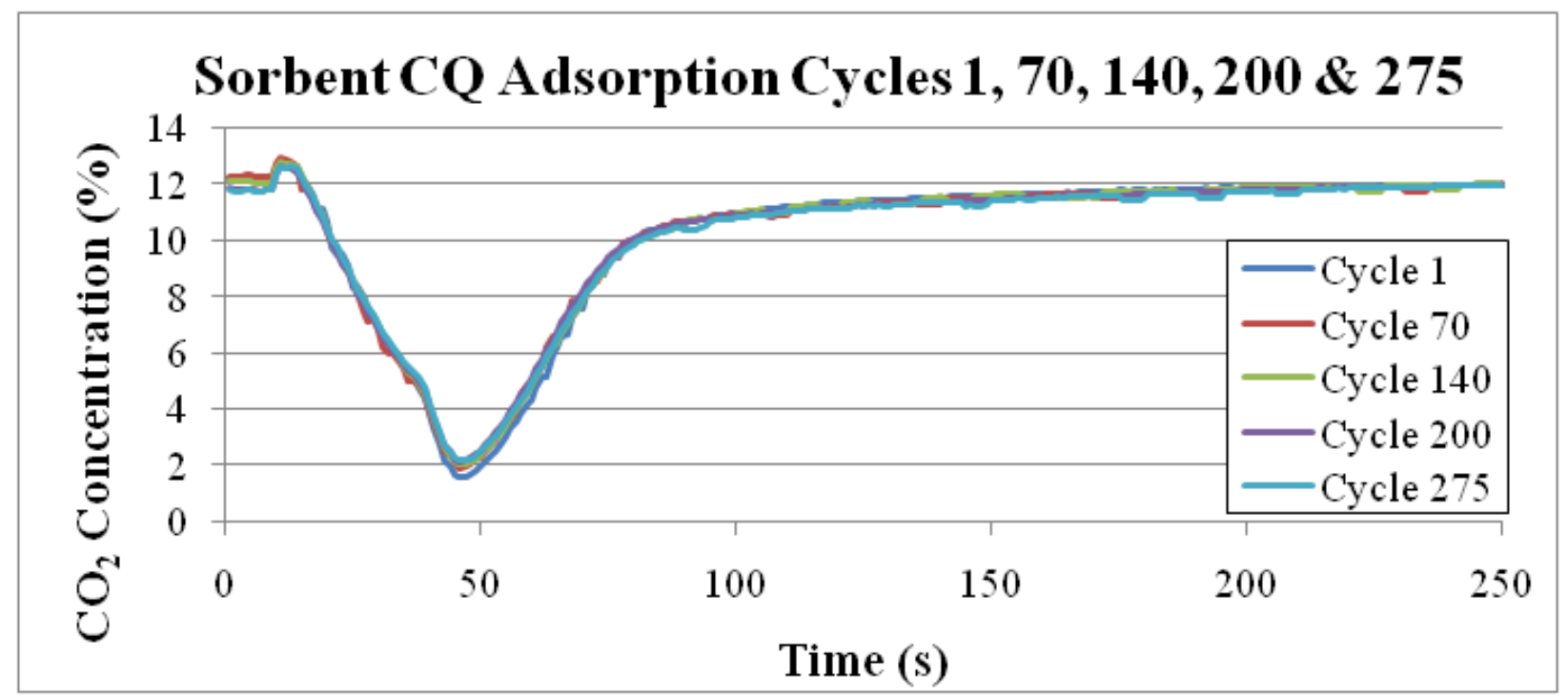

Figure 11: Sorbent CQ Laboratory Adsorption Profiles

To provide another example of a supported amine sorbent that demonstrated cyclic stability, the $\mathrm{CO}_{2}$ capacity for sorbent $\mathrm{CE}$ is provided in Figure 12. This sorbent exhibited a large $\mathrm{CO}_{2}$ capacity $(>8 \mathrm{wt} \%)$. Sorbent $\mathrm{CE}$ was stable using a regeneration temperature of $100^{\circ} \mathrm{C}$ for the 261 cycles. Note that there was an initial decrease in the $\mathrm{CO}_{2}$ capacity, but that the overall stability of the material was superior.

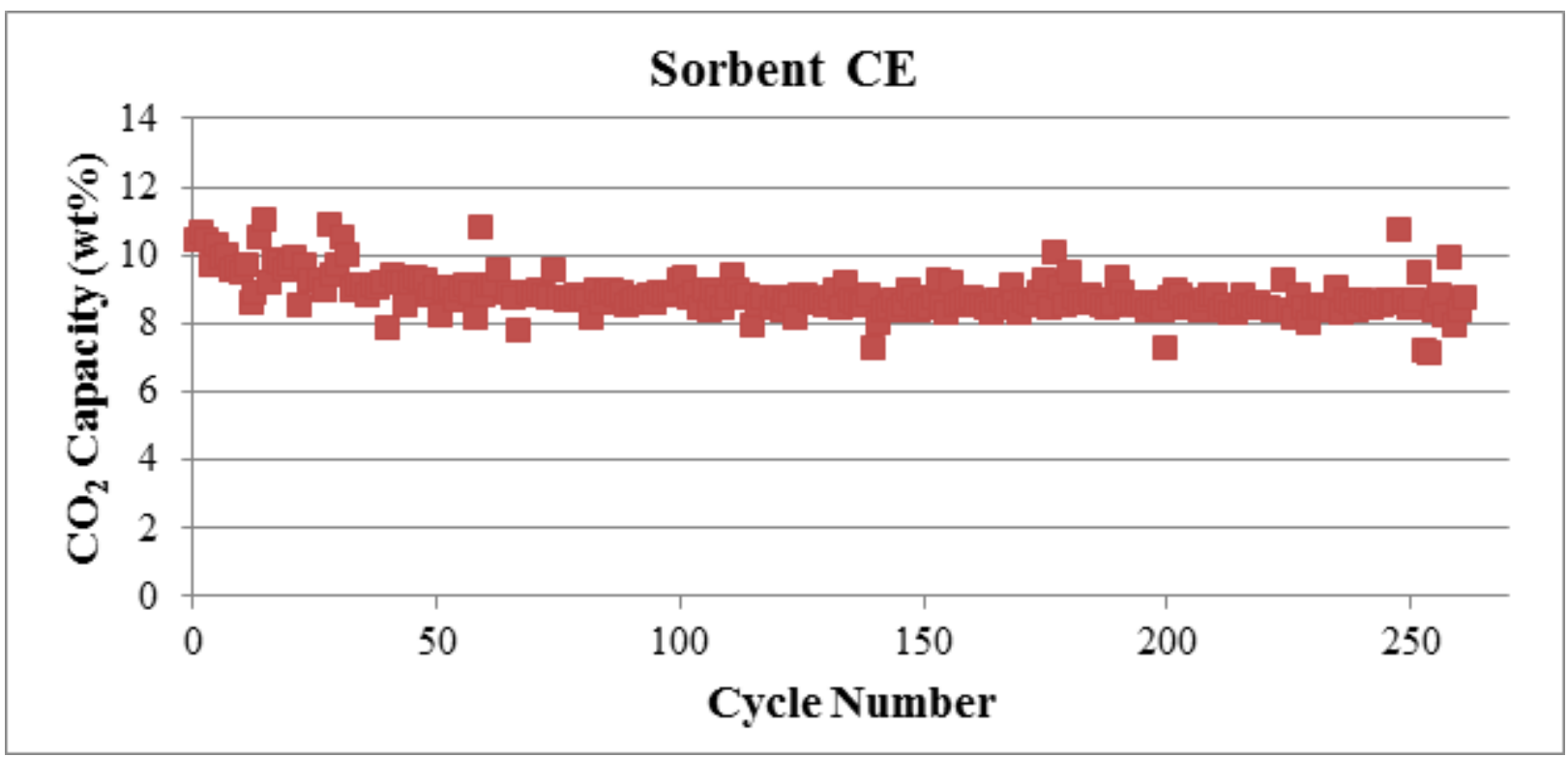

Figure 12: Sorbent CE Laboratory Total $\mathrm{CO}_{2}$ Capacities

While the breakthrough curves measured on simulated flue gas demonstrated that supported amine sorbents could be a promising option for post-combustion $\mathrm{CO}_{2}$ capture, a major concern was the effect of flue gas constituents. Although the field tests revealed that flue gas caused degradation for supported amine sorbents (see section 3.1.1.2.1), such tests cannot be used to determine which flue gas constituents are of concern. Therefore, several laboratory tests were 
conducted to measure the effect of specific gases of concern $\left(\mathrm{SO}_{2}, \mathrm{NO}_{2}\right.$, and $\left.\mathrm{NO}\right)$. Sorbent $\mathrm{R}$ was exposed to either $100 \mathrm{ppm} \mathrm{SO}, 100 \mathrm{ppm} \mathrm{NO}$, or $100 \mathrm{ppm} \mathrm{NO}$ during the $\mathrm{CO}_{2}$ adsorption step. To single out the effect of each gas, three separate tests were run and only one of these flue gas constituents was included at a time. The $\mathrm{CO}_{2}$ capacity versus cycle number for these tests is provided in Figure 13. The loss in active $\mathrm{CO}_{2}$ adsorption sites due to irreversible reaction was most important for $\mathrm{SO}_{2}>\mathrm{NO}_{2}>>\mathrm{NO}$. In fact, $\mathrm{NO}$ does not appear to have a permanently degenerative affect on the sorbent. For this reason, it is most important that $\mathrm{SO}_{2}$ concentrations upstream are reduced of any amine-based $\mathrm{CO}_{2}$ capture system.

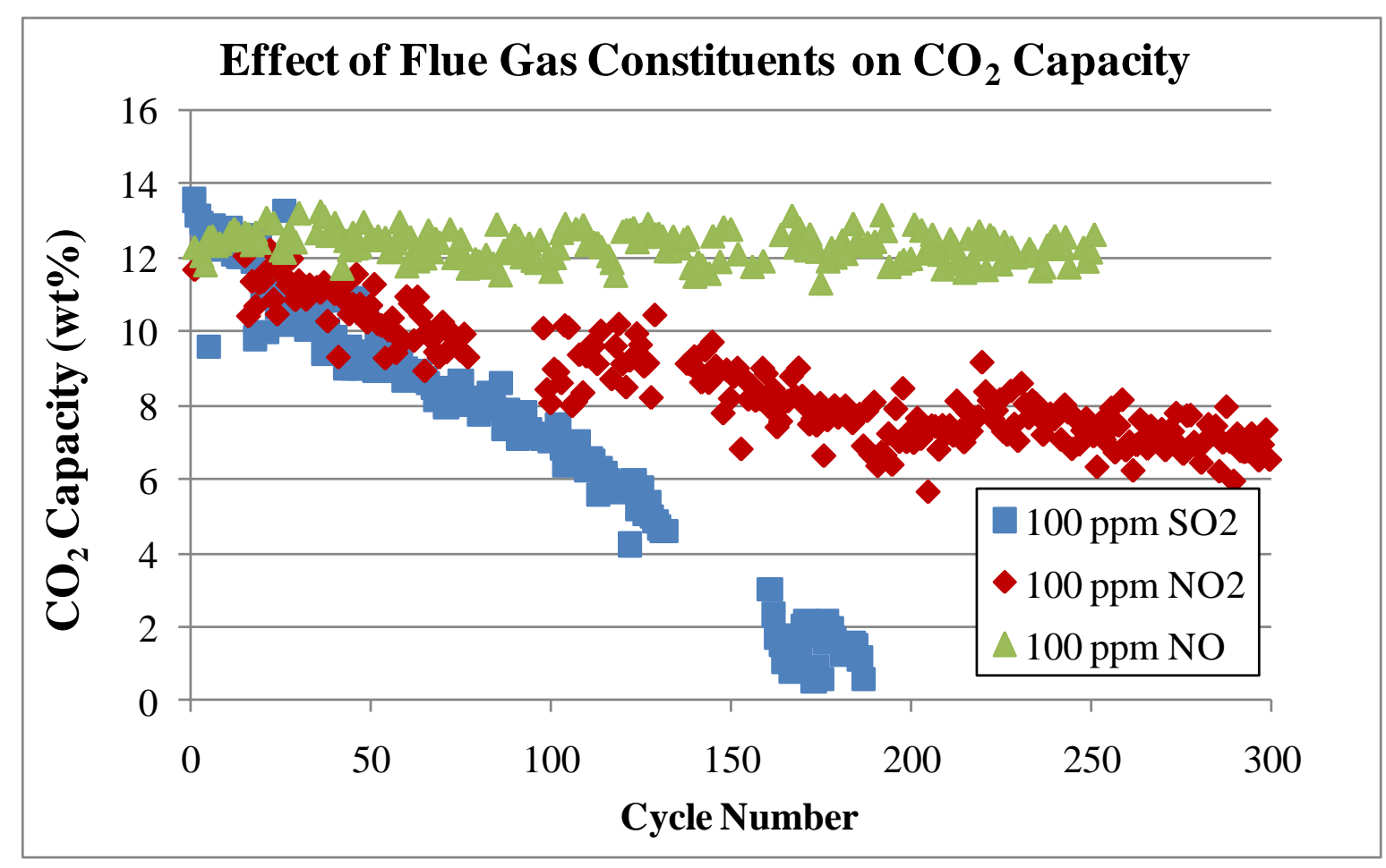

\section{Figure 13: $\mathrm{CO}_{2}$ Capacity versus Cycle Number for $100 \mathrm{ppm} \mathrm{SO}_{2}, 100 \mathrm{ppm} \mathrm{NO}$, and 100 ppm NO}

Many different supported amine sorbents were evaluated using the fixed bed contactor. These materials generally exhibited high $\mathrm{CO}_{2}$ capacities. In the absence of $\mathrm{CO}_{2}$, several of these materials were cyclically stable within the number of cycles completed. Flue gas constituents, especially $\mathrm{SO}_{2}$, are of concern for supported amine sorbents similar to aqueous amine systems. Based on the results collected, supported amine sorbents were the most promising sorbent types for post-combustion $\mathrm{CO}_{2}$ capture.

\section{$\underline{\text { Laboratory Fixed Bed Screening - Carbon Based Sorbents }}$}

The carbon-based sorbents evaluated by ADA on simulated flue gas in the fixed bed screening device consisted of carbon nanotubes, carbon fibers, monoliths, and many different activated carbons. The breakthrough profiles for 31 different carbon-based sorbents were measured in the laboratory-scale fixed bed system using simulated flue gas. The theoretical regeneration energies for most of these materials are provided in Figure 14. The red dashed line represents the regeneration energy for the benchmark MEA process. ${ }^{3}$ 


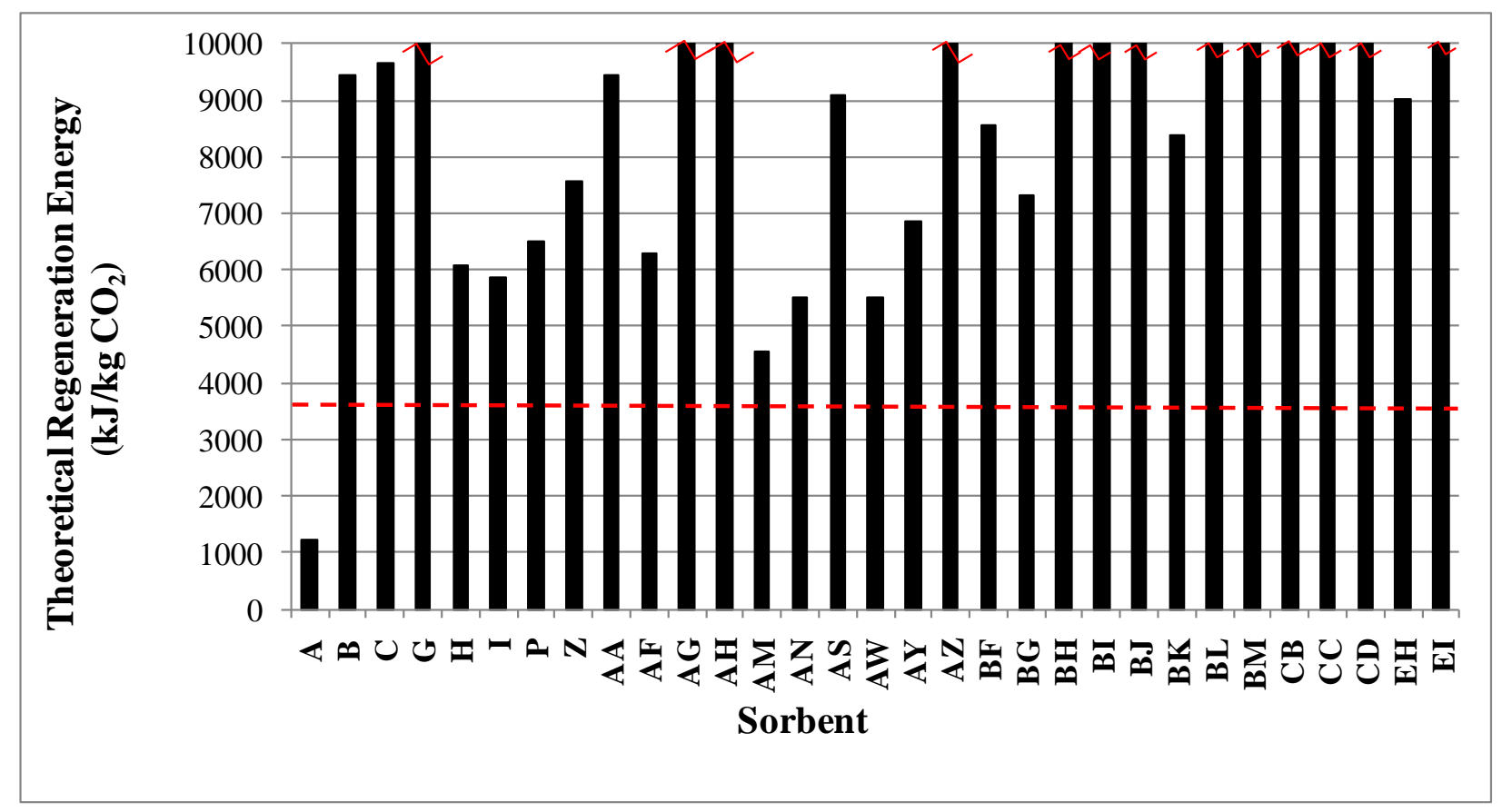

Figure 14: Theoretical Regeneration Energies for Carbon-Based Sorbents

With the exception of sorbent $\mathrm{A}$ (produced using carbon nanotubes) all the $\mathrm{CO}_{2}$ capacities at simulated flue gas conditions were significantly lower than those of the supported amines. In general the $\mathrm{CO}_{2}$ capacities were lower than $1.1 \mathrm{wt} \%$. This presents a materials handling issue due to the larger quantities of material that would be required to achieve $90 \% \mathrm{CO}_{2}$ capture using the low-capacity carbons. However, there are also advantages to using carbon-based materials. Specifically, they are commercially produced today, they can be burned after they are spent (i.e. less waste generated by the $\mathrm{CO}_{2}$ capture process), and they are less easily poisoned by flue gas constituents compared to both amines (negatively affected by $\mathrm{SO}_{2}$ ) and zeolites (prohibitively affected by moisture). Some carbons have exhibited a decrease in $\mathrm{CO}_{2}$ performance in moist versus dry flue gas, but this only decreases the capacity to some equilibrium value, it does not remove all the $\mathrm{CO}_{2}$ capacity.

To serve as an example select adsorption profiles for sorbent AM, one of the better activated carbons evaluated during sorbent screening, are provided in Figure 15. Cycles 1-5 were run using dry simulated flue gas, while cycles 31 to 35 were run using simulated flue gas with $90 \%$ relative humidity. Although there was a noticeable difference in the profiles, the majority of the adsorption capacity is maintained regardless of moisture levels. 


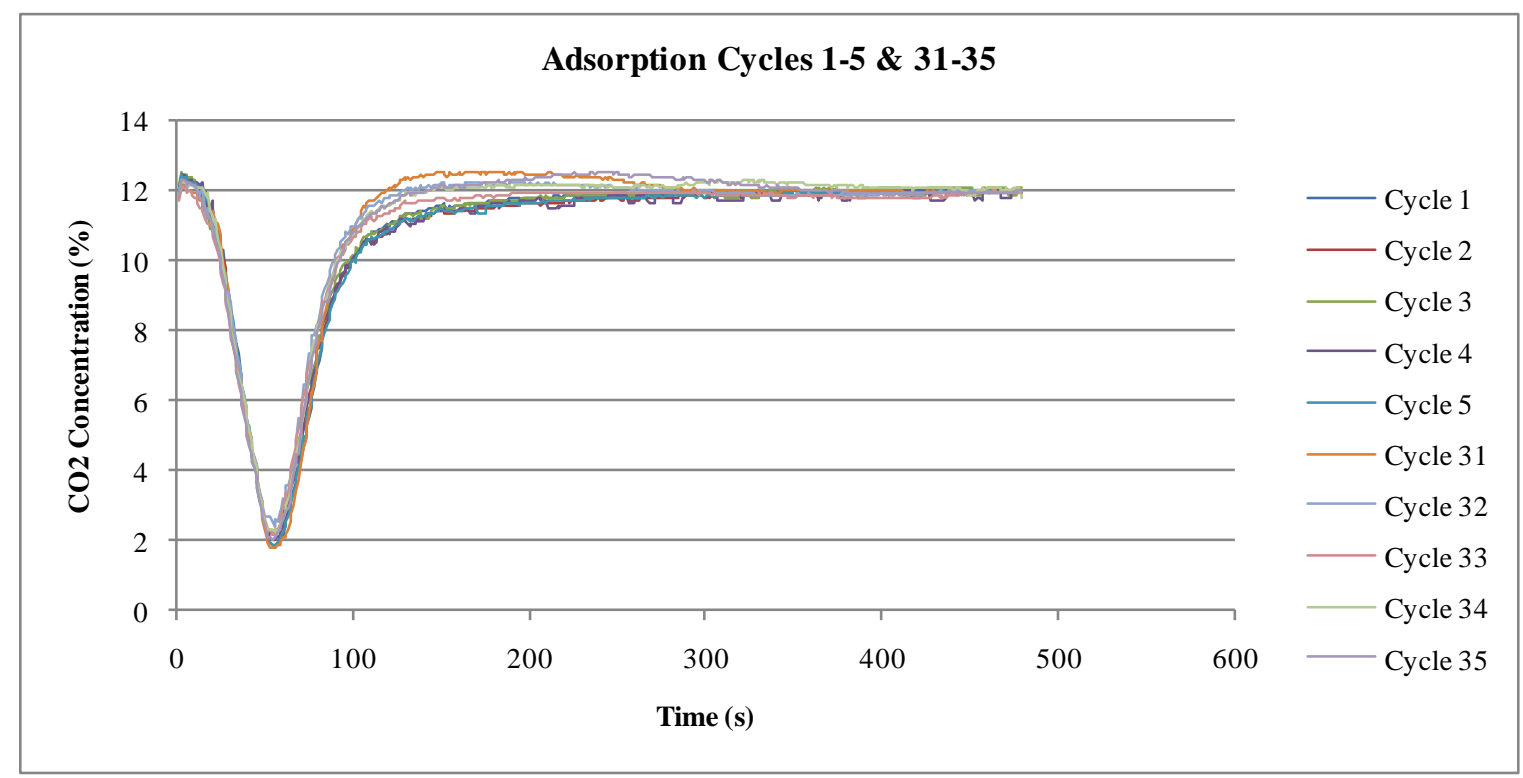

Figure 15: Sorbent AM Laboratory Adsorption Profiles

In general, the simulated flue gas screening of different carbon-based sorbents revealed that they are able to remove $\mathrm{CO}_{2}$ from simulated flue gas. However, the $\mathrm{CO}_{2}$ capacities are currently prohibitively low and carbons do not selectively remove $\mathrm{CO}_{2}$, which is also a concern. If these materials are to be considered a viable option for post-combustion $\mathrm{CO}_{2}$ capture, further advances are required to increase the $\mathrm{CO}_{2}$ capacity (under flue gas conditions) and selectivity towards $\mathrm{CO}_{2}$.

\section{$\underline{\text { Laboratory Fixed Bed Screening - Zeolites }}$}

At first glance zeolites are an attractive option for $\mathrm{CO}_{2}$ capture because several of these materials are commercially available, and may be durable for many adsorption / regeneration cycles even in the presence of other flue gas constituents. During initial fixed bed testing a few zeolites exhibited the ability to remove $\mathrm{CO}_{2}$ from dry simulated flue gas. However, as moisture was added to the simulated flue gas the capacity of the materials dropped dramatically. Even at high regeneration temperatures (up to $200^{\circ} \mathrm{C}$ ), they performed poorly in the presence of moisture. The theoretical regeneration energies for several different zeolite sorbents when evaluated using humid simulated flue gas are provided in Figure 16. 


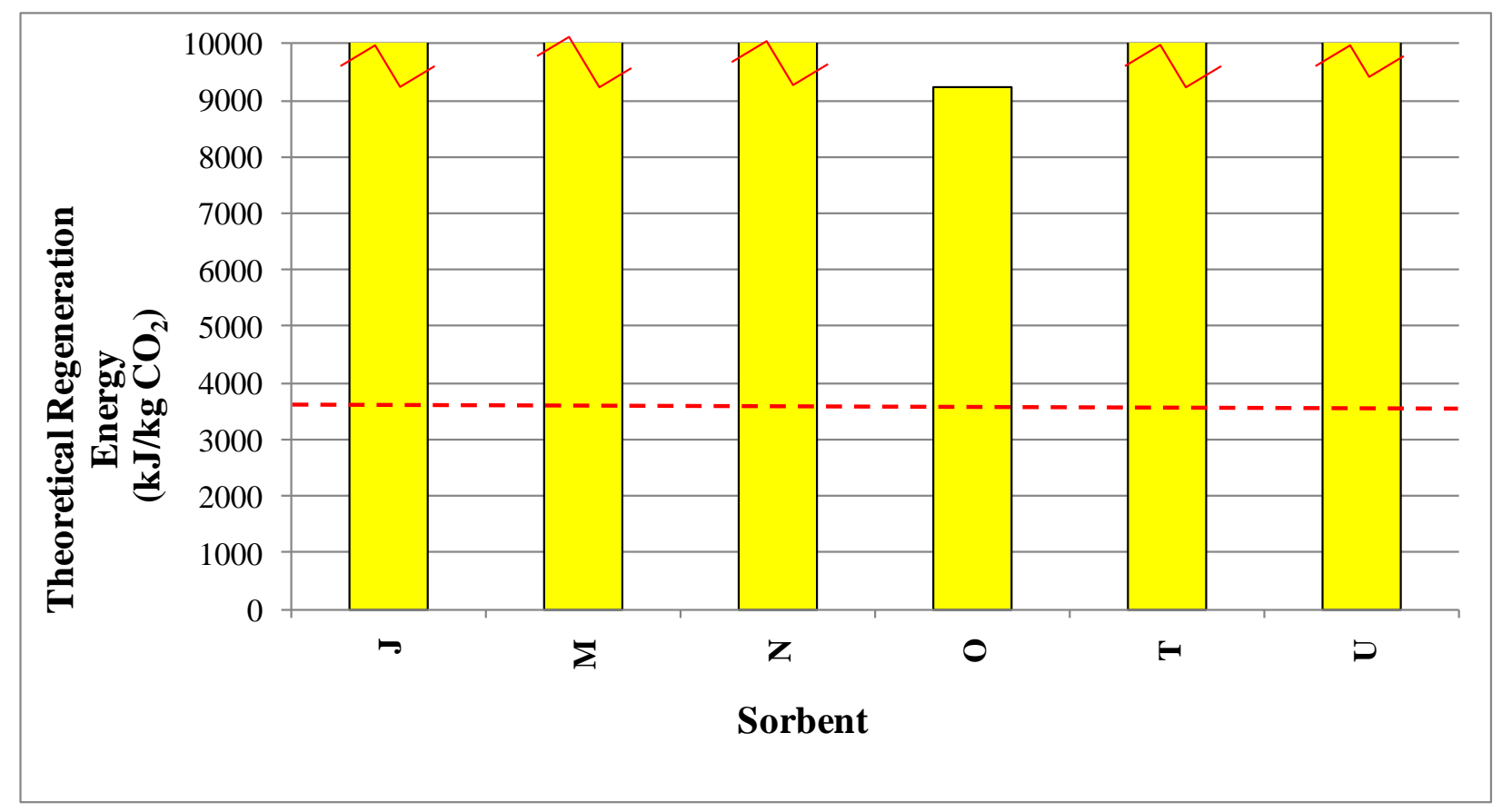

\section{Figure 16: Theoretical Regeneration Energies for Several Zeolites}

Select adsorption profiles from laboratory screening of sorbent $J$ are provided in Figure 17. The first four adsorption/regeneration cycles were conducted using dry simulated flue gas while cycles 5-8 were conducted using humid flue gas. The decrease in $\mathrm{CO}_{2}$ capture performance is clear. When humid simulated flue gas was used, the final $\mathrm{CO}_{2}$ concentration was actually greater than the starting $\mathrm{CO}_{2}$ concentration. Initially, this was a source of confusion; however, additional testing with longer adsorption times revealed that the $\mathrm{CO}_{2}$ concentration eventually returned to the baseline gas $\mathrm{CO}_{2}$ concentration. This can be attributed to the displacement of adsorbed $\mathrm{CO}_{2}$ by $\mathrm{H}_{2} \mathrm{O}$; the adsorption of $\mathrm{CO}_{2}$ is more rapid initially, but given enough time exposure to moist simulated flue gas the $\mathrm{H}_{2} \mathrm{O}$ molecules actually displaced the adsorbed $\mathrm{CO}_{2}$ due to the hydrophilic nature of the zeolites. 


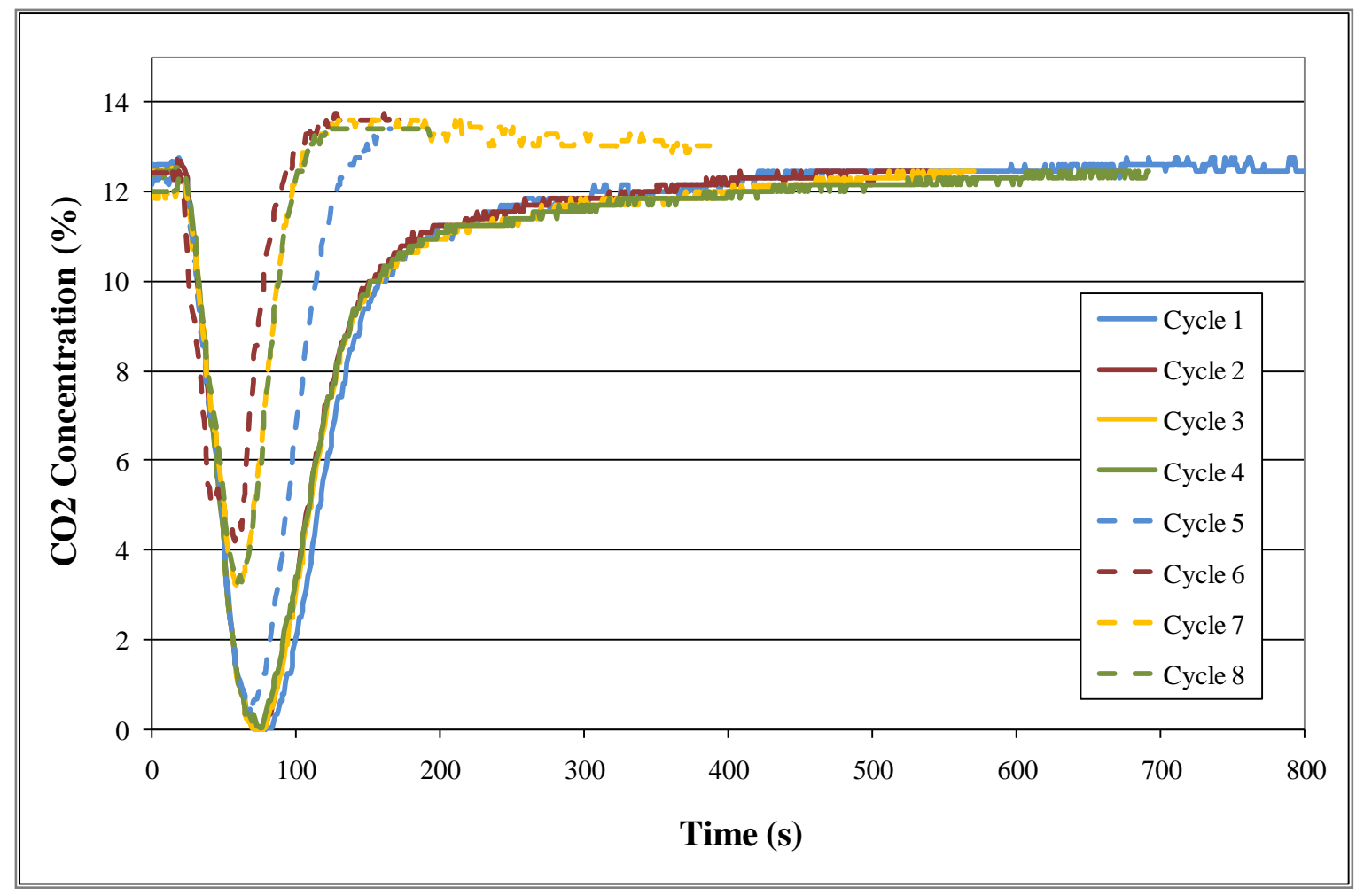

Figure 17: Sorbent J Laboratory Adsorption Profiles

When a low $\mathrm{CO}_{2}$ capacity and a high regeneration temperature are exhibited, the theoretical regeneration energy was exceedingly high, as is shown in Figure 16. Unless flue gas dehumidification is considered a viable pretreatment option (this was not considered the case under this project) zeolites cannot be utilized for effective post-combustion $\mathrm{CO}_{2}$ capture.

\section{Laboratory Fixed Bed Screening - Supported Carbonates}

No supported carbonates were submitted during DE-NT0005649 for inclusion in the sorbent screening program, although sorbent developers working on such materials were contacted repeatedly. Prior to initiation of DE-NT0005649, ADA produced several supported carbonate sorbents that consisted of either sodium carbonate or potassium carbonate distributed on an inert support. The heat of reaction between such carbonates and $\mathrm{CO}_{2}$ is significantly larger than that of other materials (i.e. approximately $-130 \mathrm{~kJ} / \mathrm{mol}$ for regeneration of sodium carbonate versus $60 \mathrm{~kJ} / \mathrm{mol}$ for supported amines). The materials produced and evaluated by ADA were not optimized, but allowed for some screening and evaluation to be completed. The best $\mathrm{CO}_{2}$ capacity measured for one of the ADA supported carbonates was approximately $3.2 \mathrm{wt} \%$. Using this $\mathrm{CO}_{2}$ capacity to calculate the theoretical regeneration energy, and assuming a sorbent specific heat of $1.0 \mathrm{~kJ} / \mathrm{kg} \cdot \mathrm{K}$, the theoretical regeneration energy was approximately $5000 \mathrm{~kJ} / \mathrm{kg}$ $\mathrm{CO}_{2}$. Since this was significantly greater than the benchmark MEA system, supported carbonates were not pursued further. 


\section{Laboratory Fixed Bed Screening - Hydrotalcites}

Hydrotalcites are anionic clays that can occur naturally or can be produced synthetically. For the application of $\mathrm{CO}_{2}$ capture all the hydrotalcites evaluated were produced synthetically by a single sorbent developer. This family of sorbents exhibited stability at greater temperatures than most other sorbents evaluated by ADA. Often these materials are referenced in the public literature when discussing pre-combustion $\mathrm{CO}_{2}$ capture. However, one sorbent developer believed that the materials could be effectively utilized at post-combustion conditions and provided several materials to ADA for evaluation. The fixed bed tests were conducted without any study of the optimal adsorption and regeneration temperatures. Therefore, the theoretical regeneration energies provided in Figure 18 can only be considered order of magnitude estimates with the possibility for significant improvement.

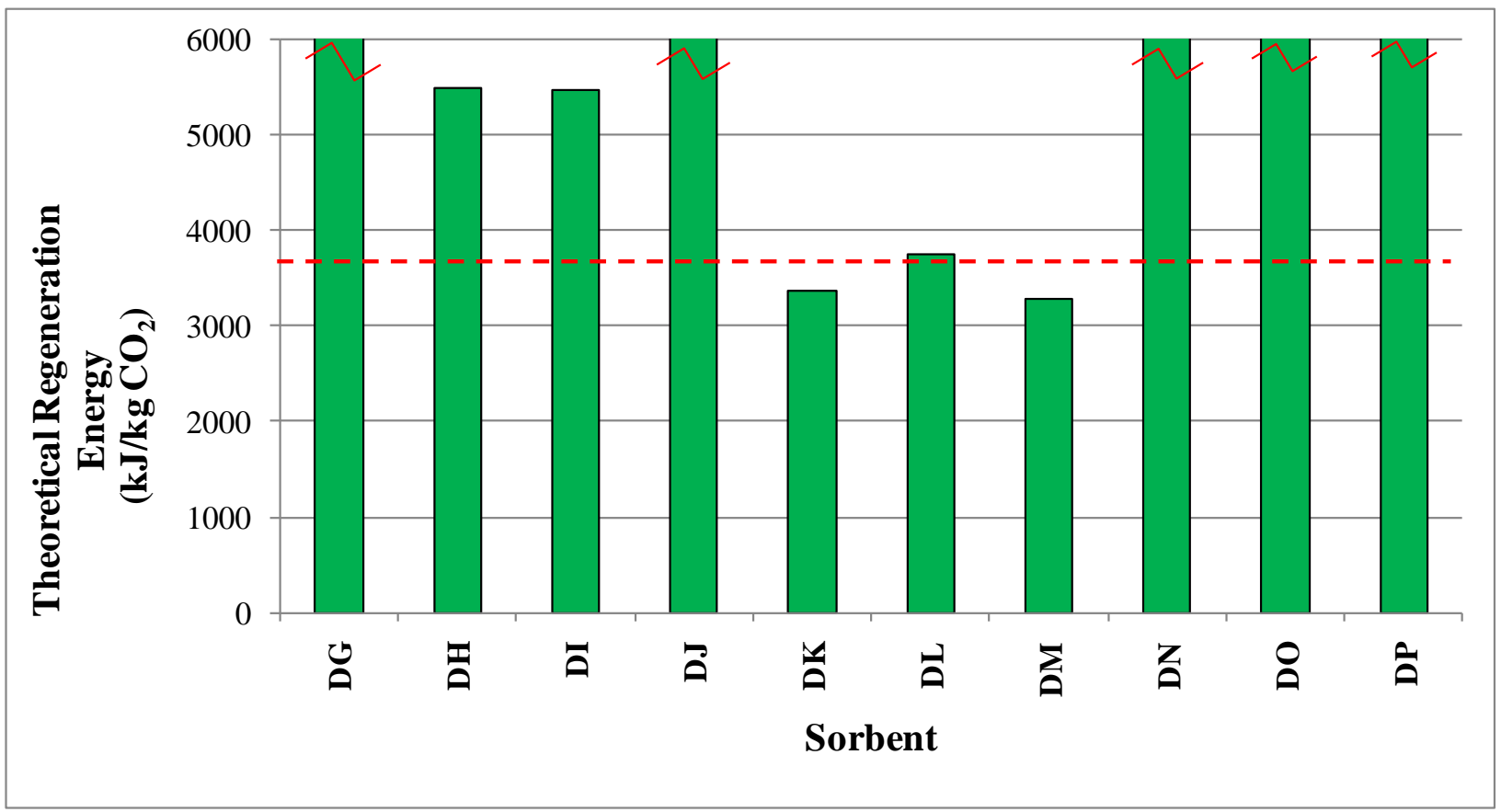

Figure 18: Theoretical Regeneration Energies for Several Hydrotalcites

As an example, Sorbent DM exhibited cyclic stability at all regeneration temperatures tested below $190^{\circ} \mathrm{C}$, as is shown in Figure 19. This sorbent didn't show any signs of degradation until the regeneration temperature was increased to $190^{\circ} \mathrm{C}$. This temperature stability could be useful for creating high driving forces for heat transfer or a reduced concern of damaging sorbent if it was unexpectedly exposed to elevated temperatures. 


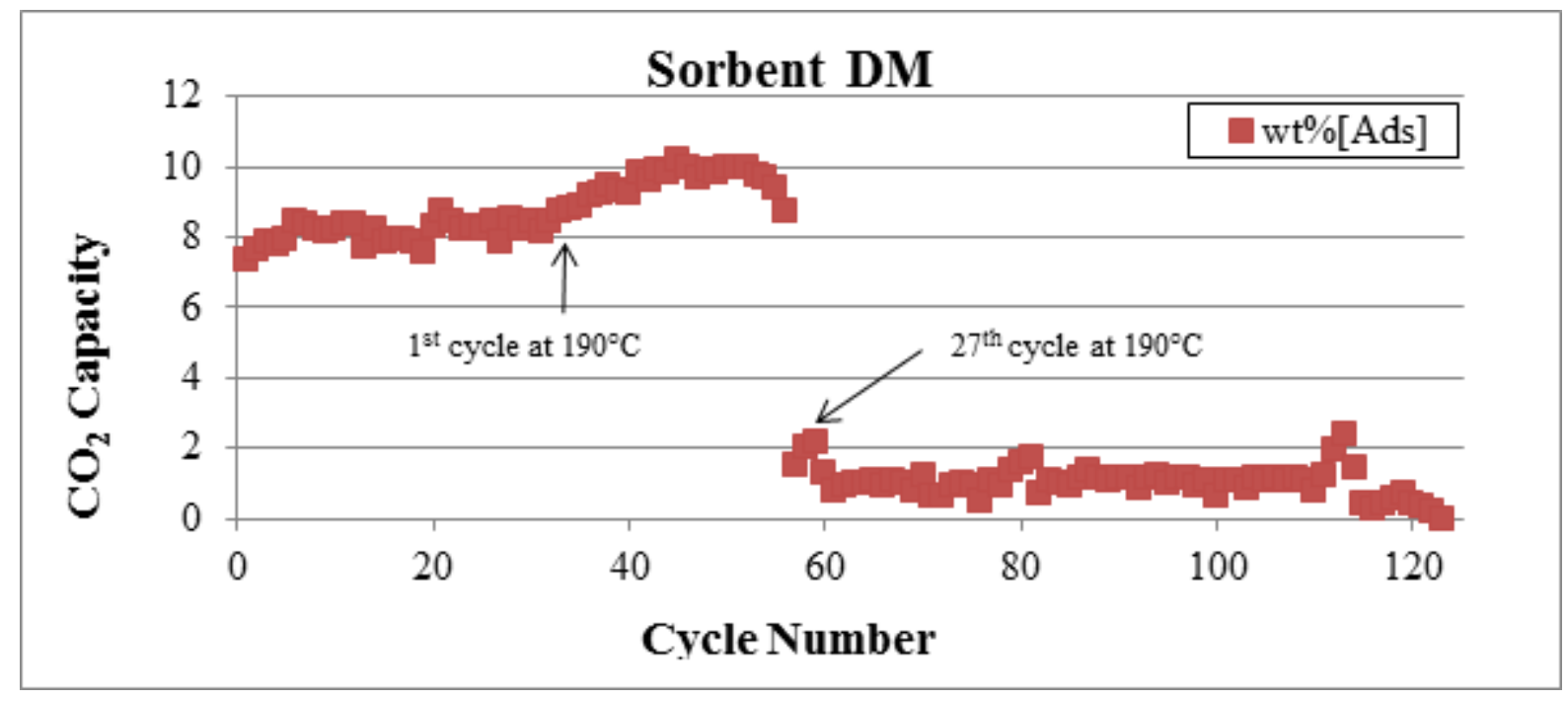

Figure 19: Sorbent DM Laboratory Total $\mathrm{CO}_{2}$ Capacities

Based on the hydrotalcites evaluated, there may be some applicability for post-combustion $\mathrm{CO}_{2}$ capture. Although it will not be completed under this project, ADA may complete more testing to evaluate the optimal operating conditions (i.e. adsorption and regeneration temperature) for these materials.

\section{Field Fixed Bed Screening - Background}

Several field tests were completed using the laboratory-scale fixed bed sorbent screening device. The first field test site was Martin Lake and the second field test site was Sherco (similar to the $1 \mathrm{~kW}$ pilot testing). The first set of field tests were completed before the unit was fully automated and the sorbents were tested for thirty five or less adsorption/regeneration cycles. However, later after the system was automated up to 250 adsorption/regeneration cycles were completed on actual flue gas. The summary of all the laboratory-scale field tests is provided in Table 5. 
Table 5: $\mathrm{CO}_{2}$ Capacity Measured During Field Tests

\begin{tabular}{|c|c|c|c|c|c|c|c|}
\hline \multirow{2}{*}{ Sorbent } & \multirow{2}{*}{ Type } & \multirow{2}{*}{ Site Tested } & \multirow{2}{*}{$\begin{array}{c}\text { Number of } \\
\text { Cycles }\end{array}$} & \multicolumn{3}{|c|}{$\mathrm{CO}_{2}$ Capacity (wt \%) } & \multirow{2}{*}{$\begin{array}{c}\mathrm{SO}_{2} \\
\text { Scrubbing }\end{array}$} \\
\hline & & & & Max & Min & Average & \\
\hline$D^{*}$ & Supported Amine & Martin Lake & 11 & 8.2 & 4.8 & 6.2 & No \\
\hline $\mathrm{F}^{*}$ & Supported Amine & Martin Lake & 35 & 7.2 & 0.9 & 3.9 & No \\
\hline $\mathrm{H}^{*}$ & Carbon & Martin Lake & 18 & 1.1 & 0.7 & 0.9 & No \\
\hline $\mathrm{O}^{*}$ & Zeolite & Martin Lake & 18 & 0.8 & 0.3 & 0.5 & No \\
\hline $\mathrm{Q}^{*}$ & Supported Amine & Martin Lake & 17 & 3.5 & 1.2 & 2.4 & No \\
\hline $\mathrm{R}$ & Supported Amine & Martin Lake & 43 & 16.9 & 4.8 & 9.7 & No \\
\hline $\mathrm{V}$ & Supported Amine & Martin Lake & 11 & 6.1 & 3 & 4.1 & No \\
\hline $\mathrm{BR}^{* *}$ & Supported Amine & Martin Lake & 250 & 14.1 & 6.1 & 8.2 & Yes \\
\hline $\mathrm{AY}^{* *}$ & Carbon & Martin Lake & 250 & 1.3 & 0.1 & 0.5 & Yes \\
\hline $\mathrm{F}$ & Supported Amine & Sherco & 79 & 9.5 & 1 & 5.8 & Yes \\
\hline $\mathrm{R}$ & Supported Amine & Sherco & 51 & 8.8 & 5.6 & 6.5 & Yes \\
\hline $\mathrm{AX}$ & Supported Amine & Sherco & 82 & 7.1 & 2.8 & 5.5 & Yes \\
\hline $\mathrm{BN}$ & Supported Amine & Sherco & 53 & 9.2 & 4.8 & 6.5 & Yes \\
\hline \multicolumn{8}{|c|}{ Funding provided by Luminant } \\
\hline${ }^{* *}$ Funding & provided by TVA & nd EPRI & & & & & \\
\hline
\end{tabular}

Field Fixed Bed Screening - Martin Lake

Five sorbents were evaluated during the first laboratory-scale field test. During the first field test sorbents D, F, H, O, and Q were evaluated. In the second field test sorbents R and V were evaluated. During these first two tests it was determined that flue gas constituents that were not typically included in the simulated flue gas (likely $\mathrm{SO}_{2}$ or $\mathrm{NO}_{2}$ ) were degrading the supported amine sorbents. As was described previously, laboratory tests were used to determine the main flue gas constituent that was causing a problem for the supported amine sorbents was $\mathrm{SO}_{2}$. Therefore, a sodium bicarbonate scrubber was added to the fixed bed system for subsequent field tests to allow a comparison of sorbent performance while minimizing the contribution of variable $\mathrm{SO}_{2}$ and $\mathrm{NO}_{2}$ concentrations. The sorbent $\mathrm{H}$ breakthrough curves measured on actual flue gas were very similar to those measured in the laboratory on simulated flue gas. This indicated that the carbon-based sorbent was affected to a much lesser degree (if at all) by $\mathrm{SO}_{2}$ and other trace flue gas constituents. The zeolite sorbent performed similarly in the field as in the laboratory; it exhibited an extremely low $\mathrm{CO}_{2}$ capacity due to preferential adsorption of moisture. After the first two field tests the test equipment was automated, which allowed for a greater number of adsorption/regeneration cycles to be completed.

Additional funds from TVA and EPRI were secured to complete extended lab-scale field testing (up to 250 adsorption/regeneration cycles for sorbents BR and AY). The results from the extended testing of sorbent BR (supported amine sorbent) and sorbent AY (carbon-based sorbent) helped to provide enough information to draw general conclusions about the state of development for these two types of materials. 
Sorbent BR was selected for extended field tests because of its superior theoretical regeneration energy and because it was produced from commercially available materials. The flue gas was pre-treated with a laboratory-scale $\mathrm{SO}_{2}$ scrubber (discussed in the experimental apparatus and procedure section). The $\mathrm{CO}_{2}$ capacities as a function of the cycle number are shown in Figure 20. Although there was an overall decrease in the $\mathrm{CO}_{2}$ capacity with cycle number, the $\mathrm{CO}_{2}$ capacity was still approximately $8 \mathrm{wt} \%$ after the 250 cycles. In addition, the capacity appeared to be relatively stable between cycles 150 to 250 . However, the only means of ensuring stability is to complete a greater number of cyclic tests.

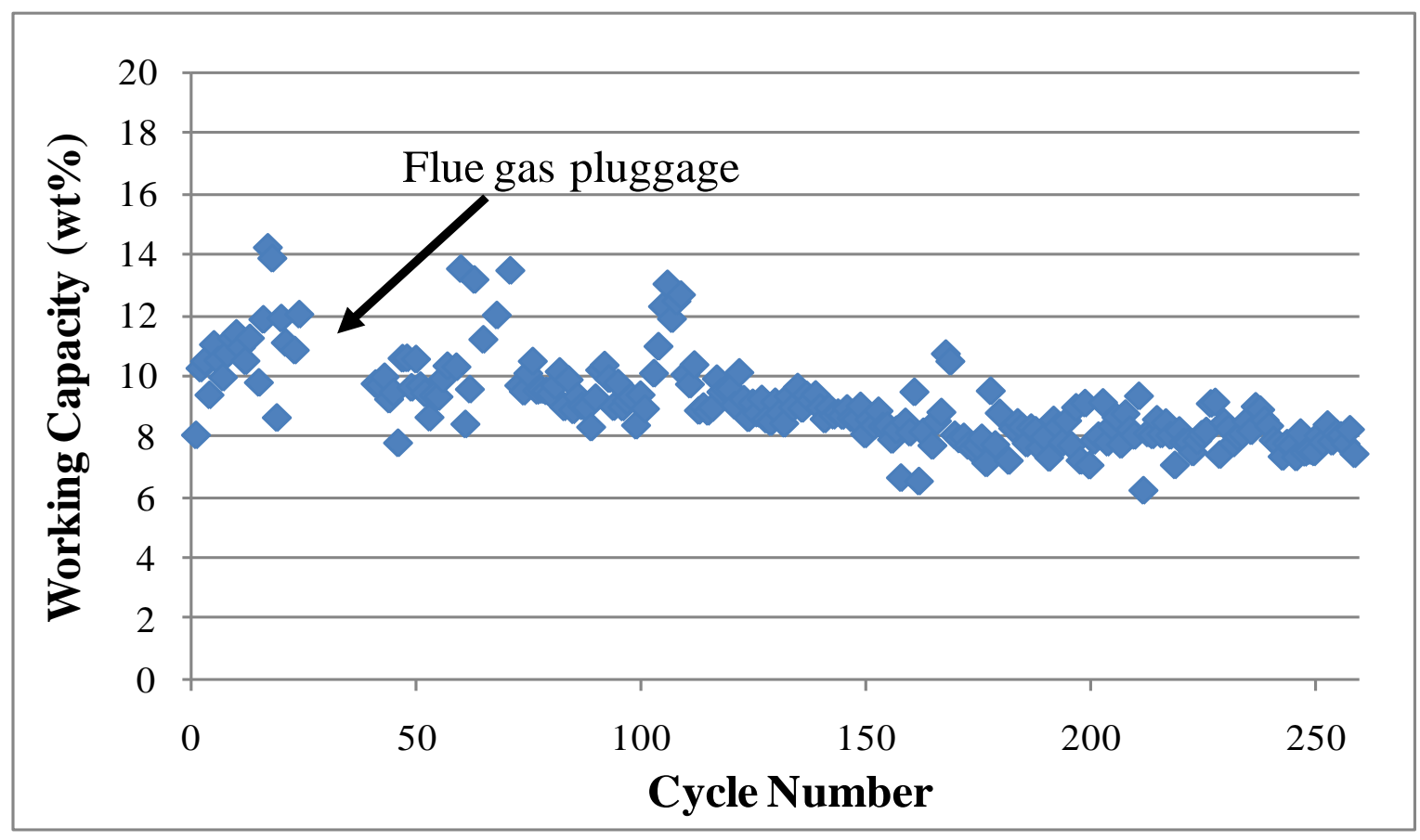

Figure 20: Sorbent BR Field $\mathrm{CO}_{2}$ Capacity

Note that early in the testing, a sample gas line became plugged and flue gas could not flow into the testing system. Also, for the initial series of adsorption/regeneration cycles (up to approximately cycle 100) the sample line that was being used by ADA was shared by another system. If too little flue gas was provided to the sorbent screening unit, then integration of the adsorption profile would result in the calculation of an inaccurately high $\mathrm{CO}_{2}$ capacity, which explains the outliers during the earlier cycles Figure 20. Based on the data provided in Figure 20 , the equilibrium $\mathrm{CO}_{2}$ capacity of sorbent BR decreased notably. However, the breakthrough profiles generated by fixed bed tests are not representative of what will be observed during more realistic evaluations in a larger-scale moving bed or fluidized bed. In such systems the sorbent/flue gas contact time may not be adequate to achieve complete $\mathrm{CO}_{2}$ saturation. However, the better mixing and the ability to remove the heat due to the reaction may have a positive effect on the $\mathrm{CO}_{2}$ capacity.

A breakthrough curve from early in the extended tests (cycle 10) as well as one from late in the extended tests (cycle 240) are provided together in Figure 21. When comparing these two curves, the loss in $\mathrm{CO}_{2}$ capacity is noticeable only after longer time periods (i.e. late in the breakthrough curve); this change may not be observable in more realistic systems. Therefore, after over 250 cycles, if the only $\mathrm{CO}_{2}$ capacity that has been lost is the slower reaction leading up 
to saturation, this loss may not be important or noticeable in larger systems, depending on the result of using a different type of system.

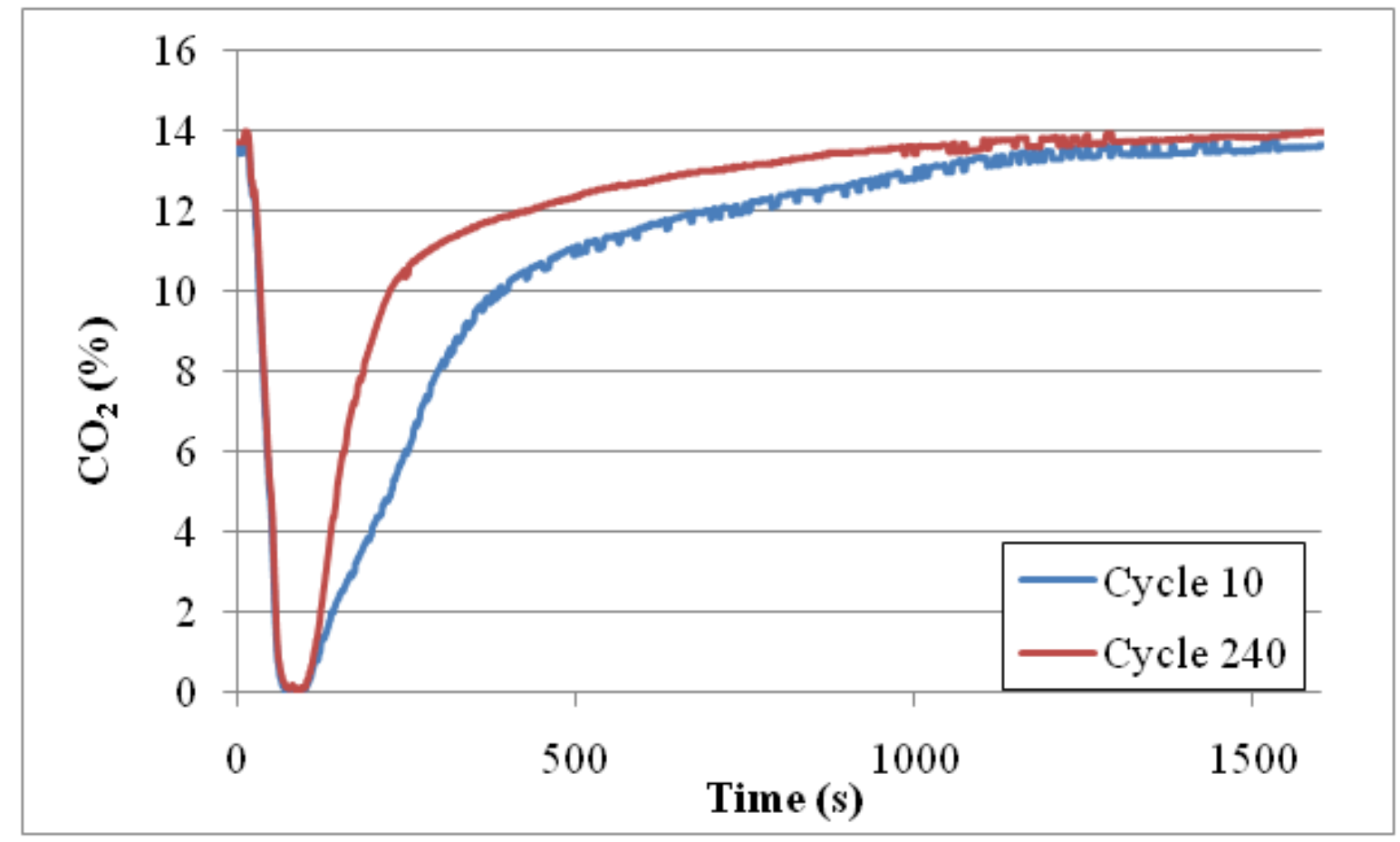

Figure 21: Sorbent BR Field Adsorption Profiles

Sorbent AY was selected for extended cyclic field testing as a representative for activated carbons. Since flue gas constituents quickly degraded the performance of other types of $\mathrm{CO}_{2}$ sorbents, it was important to determine the effect of these constituents on activated carbons as well. For the field tests of sorbent AY, ADA's laboratory-scale $\mathrm{SO}_{2}$ scrubber was not employed. Raw flue gas was utilized for this field test with the exception of a moisture dropout chamber designed to keep droplets from causing operation issues.

It should be noted that only $0.7 \mathrm{~g}$ of sorbent was used for the field testing. Originally the same sample size that was used in the laboratory tests was to be used in the field test. However, once onsite this sample size resulted in an unacceptably high pressure drop across the fixed bed. Therefore a smaller sample size of $0.7 \mathrm{~g}$ was used. As discussed in the experimental and apparatus section, a smaller sample size can lead to greater error due, in part, to the analyzer response time. However, the central purpose of this test was to evaluate the cyclic stability and general trends can still be identified.

The $\mathrm{CO}_{2}$ capacities versus cycle number for the field test of sorbent AY are provided in Figure 22. Over 250 adsorption/regeneration cycles were completed using actual flue gas without any sign of a decrease in $\mathrm{CO}_{2}$ capacity. The activated carbon is clearly more stable than the supported amine sorbent. This can be attributed to 1) the activated carbon is not susceptible to reaction with flue gas constituents (physical adsorption) and 2) there is no loss of active material (in some cases the amine evaporated from the substrate). Therefore, the main goal of researchers developing and demonstrating activated carbon $\mathrm{CO}_{2}$ sorbents should be to increase the capacity and $\mathrm{CO}_{2}$ selectivity; the cyclic stability is superior to other types of $\mathrm{CO}_{2}$ sorbents. 


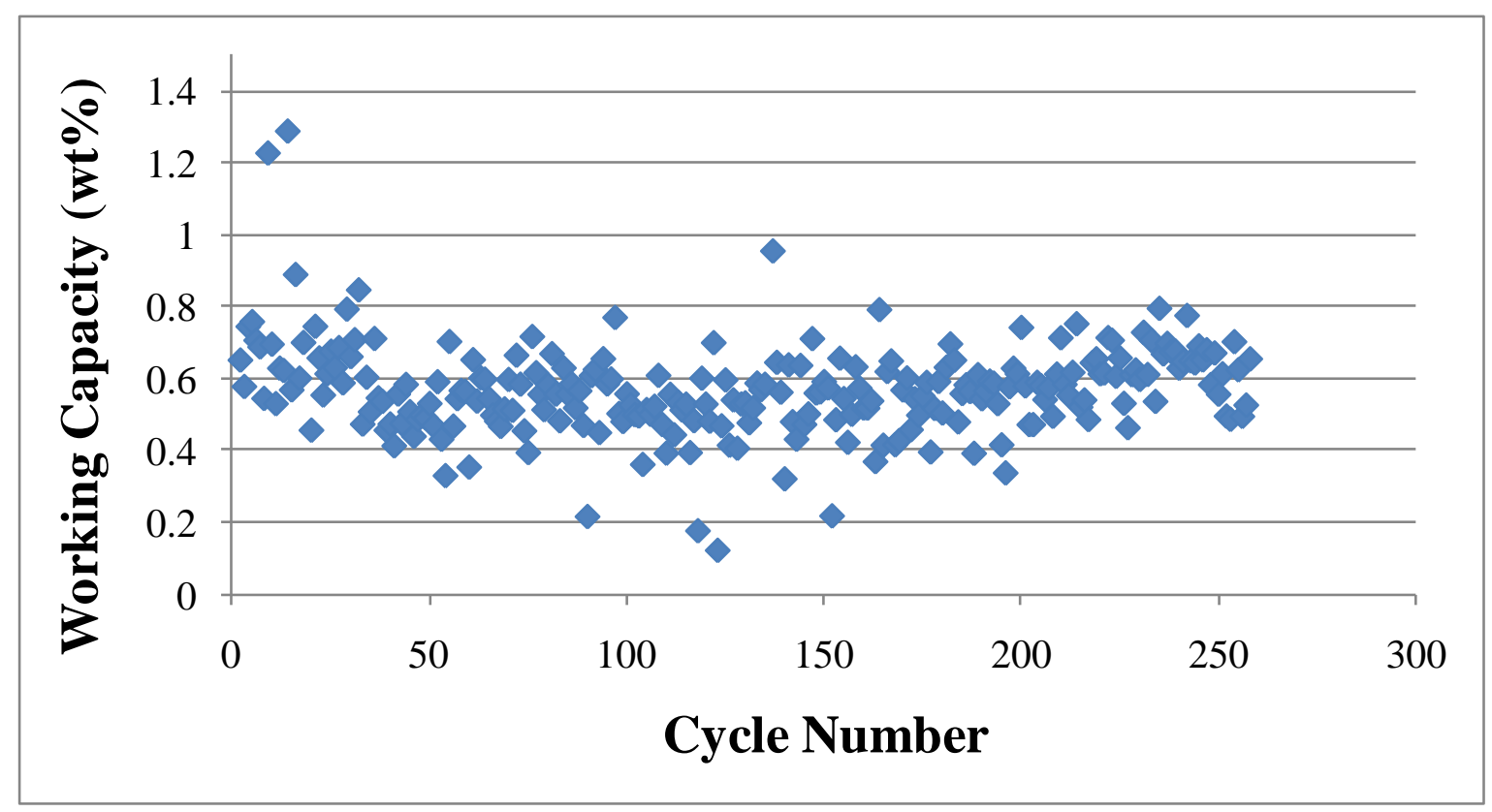

Figure 22: Sorbent AY Field $\mathrm{CO}_{2}$ Capacity

\section{Field Fixed Bed Screening - Sherco}

Extended thermal cycling tests were conducted at Sherco in the fixed-bed system following initial characterization in the $1 \mathrm{kWe}$ pilot.

Sorbent $\mathrm{R}$ was a supported amine sorbent that was evaluated in the laboratory-scale fixed bed system at both Martin Lake and Sherco. The regeneration temperature was $100^{\circ} \mathrm{C}$. At Sherco, the sorbent that was used for the laboratory-scale tests was collected from the $1 \mathrm{~kW}$ pilot after that testing was completed. Select adsorption breakthrough curves are provided in Figure 23. 


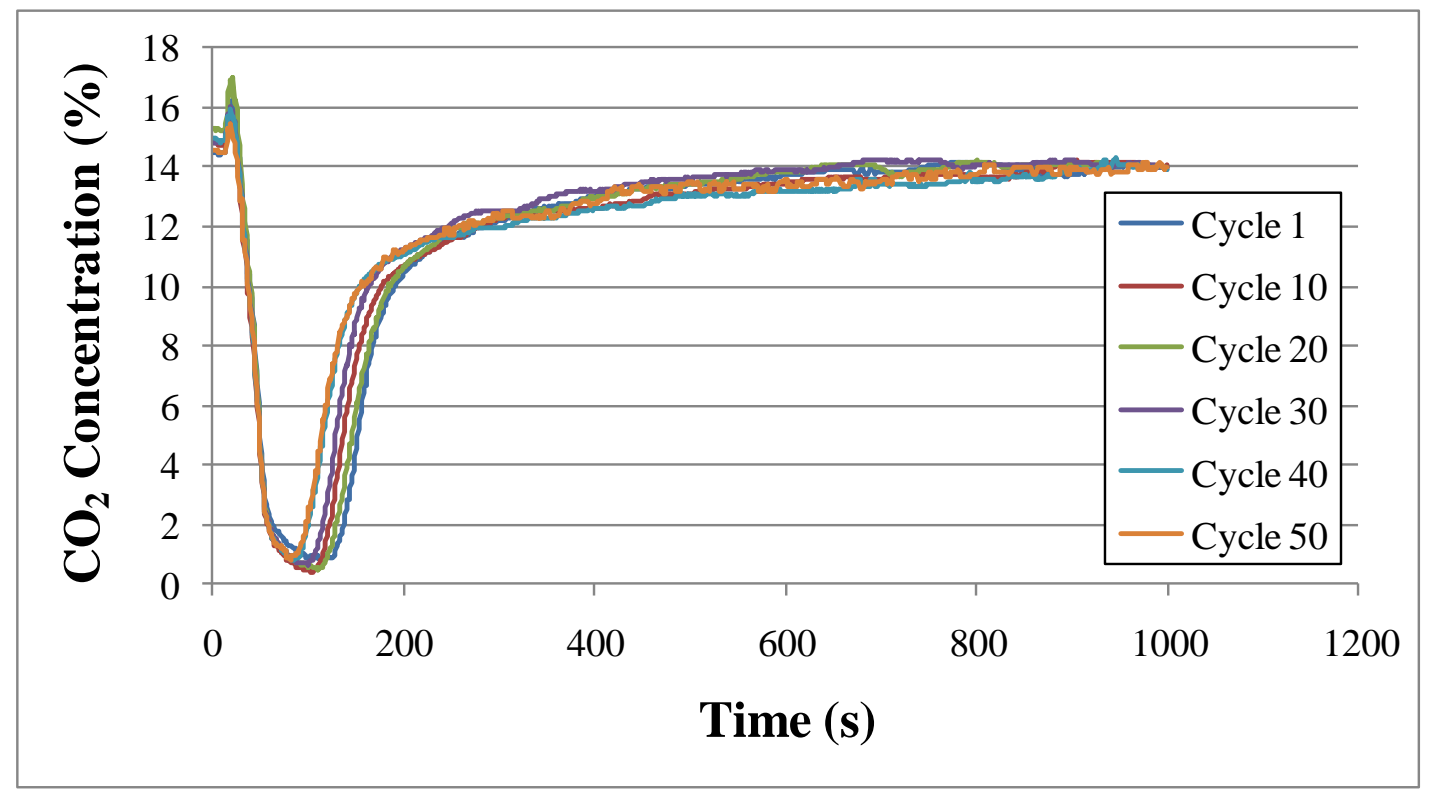

Figure 23: Sherco Sorbent R Breakthrough Adsorption Profiles

The changing shape of the breakthrough curves indicates that the performance of sorbent $\mathrm{R}$ was not completely stable during the 50+ adsorption/regeneration cycles. In addition, the average $\mathrm{CO}_{2}$ capacity for sorbent $\mathrm{R}$ was approximately $6.5 \mathrm{wt} \%$, which is nearly $50 \%$ lower than what was measured in the laboratory using simulated flue gas. It is believed that this degradation in $\mathrm{CO}_{2}$ capture performance was actually caused by $\mathrm{SO}_{2}$ in the flue gas because the scrubber solution had not been changed adequately. This is supported by the fact that sorbent AX, which consisted of the same amine and a similar support, was completely stable during cyclic evaluations (see discussion in subsequent sections).

Sorbent AX was evaluated for over eighty adsorption/regeneration cycles in the laboratory-scale fixed bed system at Sherco following initial testing in the $1 \mathrm{kWe}$ pilot. The regeneration temperature was $100^{\circ} \mathrm{C}$. However, during cycles eight through twenty eight the flue gas sample line became completely plugged. During the cycles where flue gas was not available the sorbent was still exposed to the temperature swing, but not the flue gas. Several adsorption profiles for sorbent AX are provided in Figure 24. 


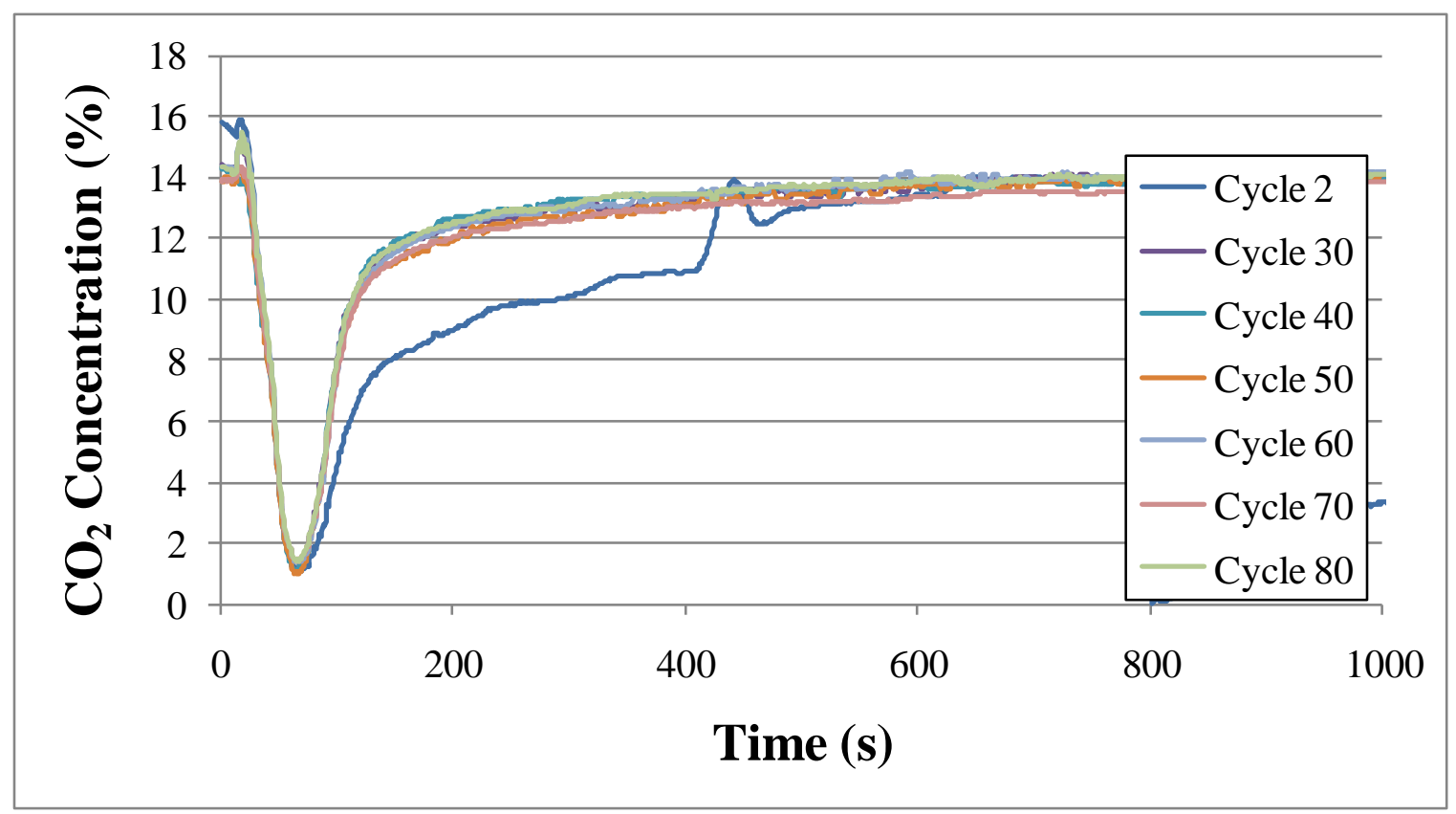

Figure 24: Sherco Sorbent AX Adsorption Breakthrough Profiles

With the exception of cycle 2 , where the flue gas line was already partially plugged, the breakthrough curves for sorbent $\mathrm{AX}$ are consistent. This material did not exhibit any loss in $\mathrm{CO}_{2}$ capacity due to the exposure to the scrubbed Sherco flue gas or the repeated temperature swing. Because the same amine was used to produce sorbents R and AX, this further supports the conclusion that the $\mathrm{SO}_{2}$ levels were elevated during the fixed bed evaluation of sorbent $\mathrm{R}$. The average $\mathrm{CO}_{2}$ capacity of sorbent $\mathrm{AX}$ was $5.5 \mathrm{wt} \%$, which was significantly lower than measured previously in the laboratory. It is possible that some damage occurred to the sorbent in the $1 \mathrm{~kW}$ pilot before it was transferred to the fixed bed system.

Sorbent $\mathrm{F}$ was evaluated in the laboratory-scale fixed bed system for 79 adsorption/regeneration cycles using a slipstream of Sherco flue gas. The regeneration temperature was $120^{\circ} \mathrm{C}$. Because the fine particles resulted in a greater pressure drop across the fixed bed compared to the other sorbents, only 0.7 grams of sorbent $\mathrm{F}$ was used during the laboratory-scale tests. Select adsorption profiles for sorbent $\mathrm{F}$ are provided in Figure 25. 


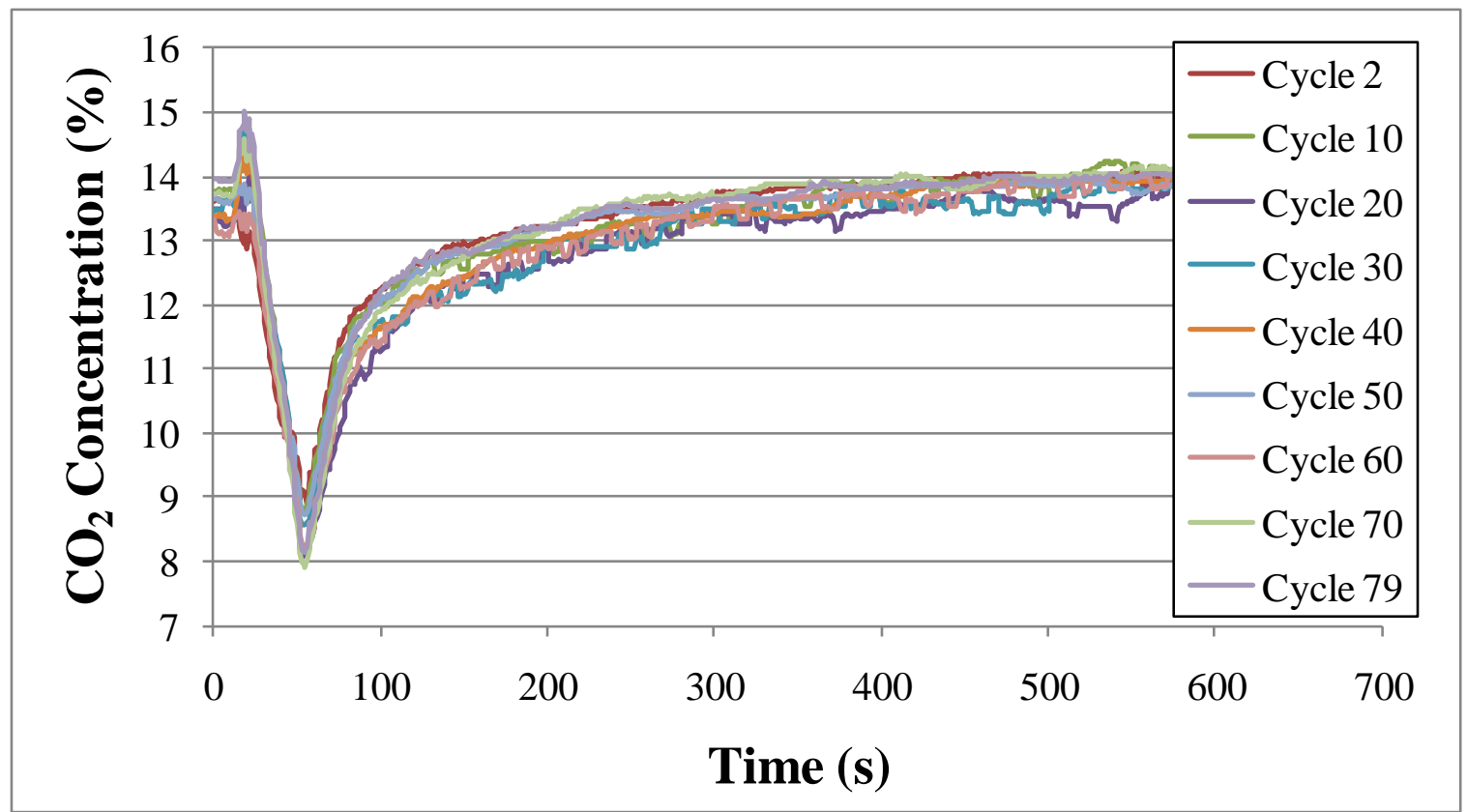

Figure 25: Sherco Sorbent F Adsorption Breakthrough Profiles

The shape of the adsorption profiles for sorbent $\mathrm{F}$ is different from the other sorbents, in part, because the sample size was smaller. The average $\mathrm{CO}_{2}$ capacity measured during the fixed bed tests was $5.8 \mathrm{wt} \%$, which was similar to what was measured during previous laboratory tests using simulated flue gas. Over the $80+$ adsorption/regeneration cycles completed in the fixed bed the $\mathrm{CO}_{2}$ capacity of sorbent $\mathrm{F}$ was constant.

Using crushed $\mathrm{BN}$, over 50 adsorption/regeneration cycles were completed. The regeneration temperature was $120^{\circ} \mathrm{C}$. Select adsorption profiles are provided in Figure 26. During the extent of cyclic testing completed at Sherco, no change in the $\mathrm{CO}_{2}$ capacity was observed.

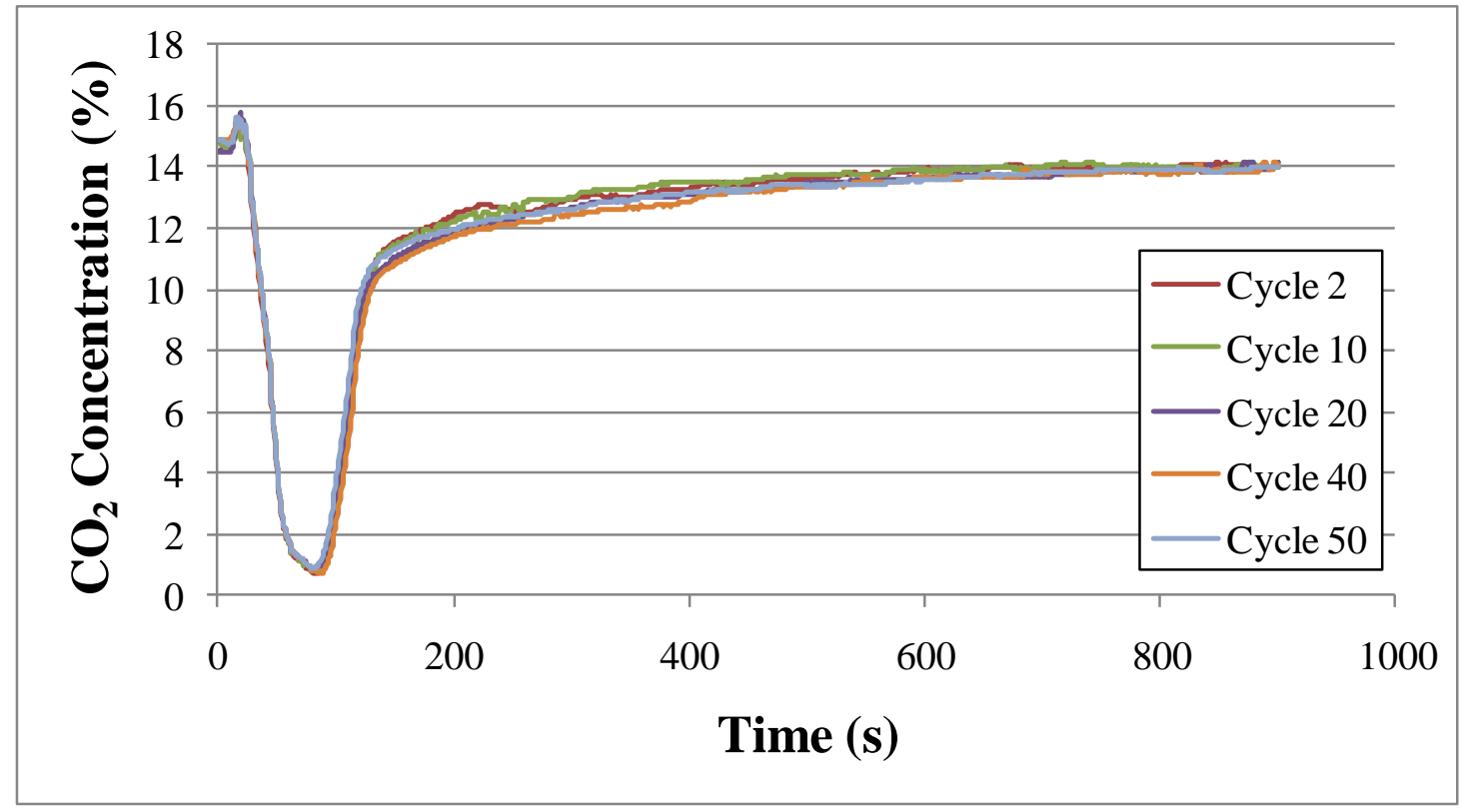

Figure 26: Sherco Sorbent BN Adsorption Breakthrough Profiles 
The average $\mathrm{CO}_{2}$ capacity of the crushed sorbent $\mathrm{BN}$ was $6.5 \mathrm{wt} \%$, which was similar to what was measured using simulated flue gas in the laboratory. When the beaded form of sorbent BN was used to generate breakthrough curves, the $\mathrm{CO}_{2}$ capacity dropped from $6.5 \mathrm{wt} \%$ to approximately $3.1 \mathrm{wt} \%$. A comparison of a breakthrough curve for both forms of sorbent is provided in Figure 27. Per unit mass, both types of sorbent include the same amount of amine content. Therefore, the difference in the breakthrough profiles can be attributed to the diffusion limitations caused by the larger particles. When considering how different reaction times will affect the larger $\mathrm{CO}_{2}$ capture process the reactor type must be taken into consideration. If the gas/solids contact time is short, such as is the case in a fixed bed, faster reactions will be required to achieve the desired $\mathrm{CO}_{2}$ loading levels.

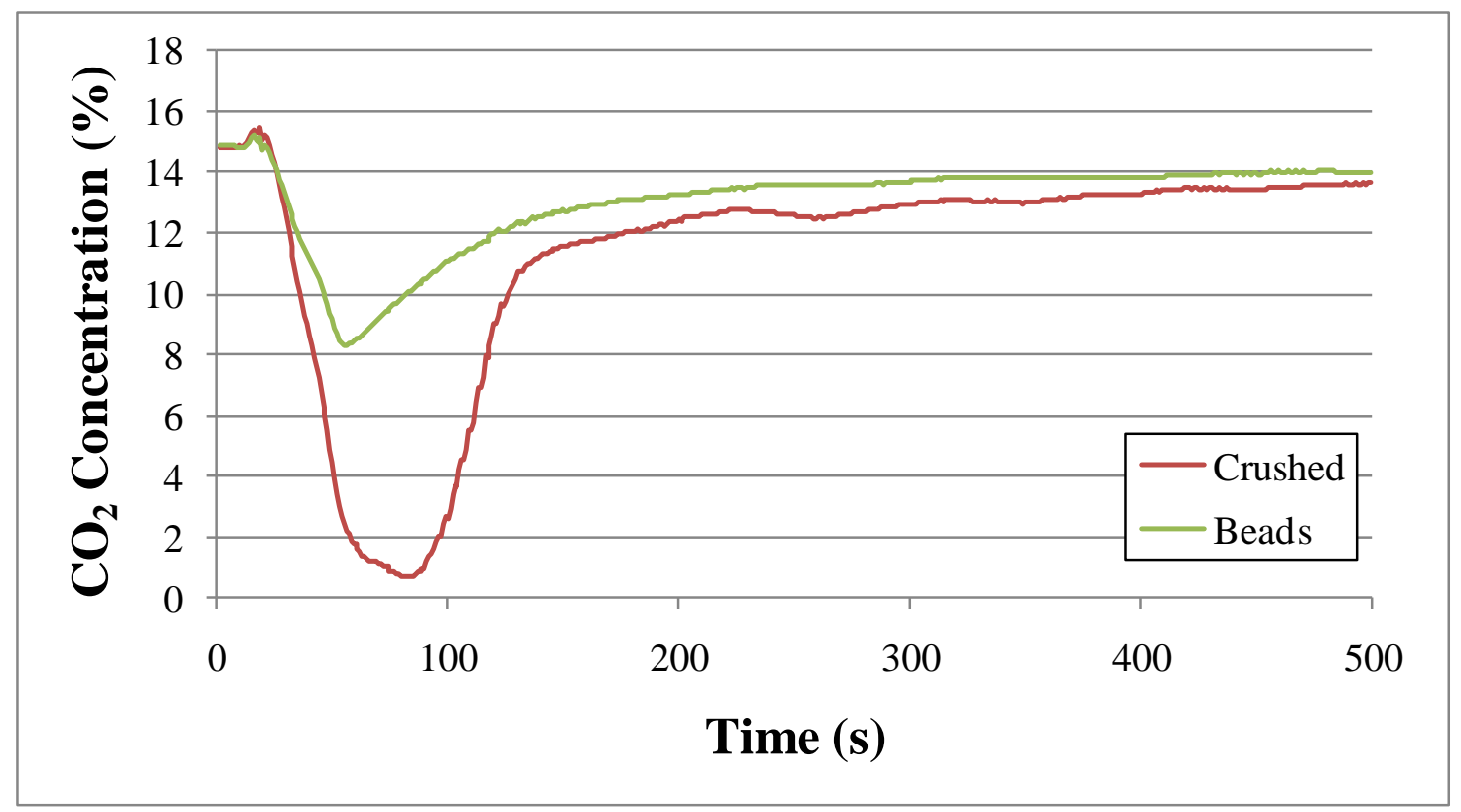

Figure 27: Crushed and Beaded Sorbent BN Breakthrough Profiles

\subsubsection{Lab-Scale Characterization of Sorbents}

In addition to the extensive fixed bed testing that was completed under Subtask 2.1.2, additional laboratory-scale testing was necessary to fully assess the most promising sorbents. The key sorbent properties related to energy requirements, including the estimates and goals provided in the proposal are listed in Table 6 .

Table 6: Key Solid Sorbent Energy Requirements

\begin{tabular}{|l|c|c|c|}
\hline Energy Requirements & $\begin{array}{c}\text { Proposal } \\
\text { Estimates }\end{array}$ & Goal & $\begin{array}{c}\text { Calculated or } \\
\text { Measured During } \\
\text { Project }\end{array}$ \\
\hline $\begin{array}{l}\text { Heat of Adsorption/Reaction } \\
\text { kJ/mol }\end{array}$ & $\begin{array}{c}-30^{*} \text { to - } \\
60^{* *}\end{array}$ & $>-50$ & -30 to -130 \\
\hline $\begin{array}{l}\text { Theoretical Regeneration Energy } \\
\mathrm{kJ} / \mathrm{kg} \mathrm{CO} \text { (BTU/lb)) }\end{array}$ & $\mathrm{N} / \mathrm{A}$ & $\mathrm{N} / \mathrm{A}$ & $\begin{array}{c}1240 \text { to } 74,500 \\
\text { (530 to 32,100) }\end{array}$ \\
\hline $\begin{array}{l}\text { Actual Regeneration Energy } \\
\mathrm{kJ} / \mathrm{kg} \mathrm{CO}\left(\mathrm{BTU} / \mathrm{b} \mathrm{CO} \mathrm{CO}_{2}\right)\end{array}$ & $\begin{array}{c}239-960^{*} \\
(500-\end{array}$ & $<250$ & $\begin{array}{c}1760 \\
(760)\end{array}$ \\
\hline
\end{tabular}




\begin{tabular}{|c|c|c|c|}
\hline & $2000)^{* * *}$ & & \\
\hline $\begin{array}{l}\text { Target Regeneration Energy } \\
\mathrm{kJ} / \mathrm{kg} \mathrm{CO} \mathrm{CO}_{2}\left(\mathrm{BTU} / \mathrm{lb} \mathrm{CO}_{2}\right)\end{array}$ & N/A & $<250$ & $\begin{array}{l}1760 \\
(760)\end{array}$ \\
\hline $\begin{array}{l}\text { Heat Management During } \\
\text { Adsorption and Regeneration }\end{array}$ & N/A & N/A & N/A \\
\hline $\begin{array}{l}\text { Power for Sorbent Cooling } \\
\mathrm{kJ} / \mathrm{kg} \mathrm{CO} \mathrm{CO}_{2} \text { (BTU/ton } \mathrm{CO}_{2} \text { removed) }\end{array}$ & $\begin{array}{l}\text { Not } \\
\text { reported }\end{array}$ & $<1$ & $\begin{array}{l}17^{* * * *} \\
(8)^{* * * *}\end{array}$ \\
\hline $\begin{array}{l}\text { Power for Blowers to Overcome } \\
\text { Pressure Drop } \\
\mathrm{kJ} / \mathrm{kg} \mathrm{CO}_{2} \text { (BTU/ton } \mathrm{CO}_{2} \text { removed) }\end{array}$ & $16-63^{*}$ & $<15$ & $\begin{array}{l}45^{\text {**** }} \\
(20)^{* * *}\end{array}$ \\
\hline $\begin{array}{l}\text { Power Needed for Sorbent } \\
\text { Circulation } \\
\mathrm{kJ} / \mathrm{kg} \mathrm{CO} 2\left(\mathrm{BTU} / \text { ton } \mathrm{CO}_{2} \text { removed }\right)\end{array}$ & $\begin{array}{l}\text { Not } \\
\text { reported }\end{array}$ & $\begin{array}{c}\text { To be } \\
\text { determined }\end{array}$ & $0^{* * * *}$ \\
\hline $\begin{array}{l}\text { Vacuum Pump for Purified } \mathrm{CO}_{2} \\
\mathrm{~kJ} / \mathrm{kg} \mathrm{CO} \mathrm{CO}_{2} \text { (BTU/ton } \mathrm{CO}_{2} \text { removed) }\end{array}$ & $\begin{array}{c}\text { Not } \\
\text { reported }\end{array}$ & $<1$ & $0^{* * * *}$ \\
\hline
\end{tabular}

"Tarka, T.J.; Ciferno, J.P.; Gray, M.L.; Fauth, D. $\mathrm{CO}_{2}$ Capture Systems Using Amine Enhanced Solid Sorbents, $5^{\text {th }}$ Annual Conference on Carbon Capture \& Sequestration, Alexandria, VA, 2006.

** Shigemoto N., Yanagihara T., Sugiyama S., Hayashi H., Material and Energy Consumption for $\mathrm{CO}_{2}$ Recovery from Moist Flue Gas Employing $\mathrm{K}_{2} \mathrm{CO}_{3}$-on-Activated Carbon and Its Evaluation for Practical Adaptation, Energy \& Fuels, 2006, 20, 721-726.

*** Based on Final Technology Selection

\section{Thermogravimetric Analysis}

In addition to the long-term tests, $\mathrm{ADA}$ also completed TGA evaluations to determine the $\mathrm{CO}_{2}$ capacity at multiple $\mathrm{CO}_{2}$ partial pressures and temperatures. In the public literature discussing potential $\mathrm{CO}_{2}$ sorbents, there has been a great deal of focus on the total $\mathrm{CO}_{2}$ capacity, which is measured when regenerating the sorbent under a purge gas with minimal $\mathrm{CO}_{2}$ partial pressure, similar to the fixed-bed tests discussed in this work. However, to minimize compression costs in an actual $\mathrm{CO}_{2}$ capture and compression system, the $\mathrm{CO}_{2}$ partial pressure during regeneration must be as high as possible. The data collected by ADA is important because it can be used to calculate working capacity under different adsorption and regeneration conditions.

Ideally, $\mathrm{CO}_{2}$ capture will occur rapidly and effectively at lower temperature $\left(40-60^{\circ} \mathrm{C}\right)$ shown with unfilled symbols in Figure 28 and lower $\mathrm{CO}_{2}$ partial pressure (0.08-0.15 bar). Regeneration will then occur at increased temperature $\left(90-120^{\circ} \mathrm{C}\right)$ shown with filled symbols in Figure 28 as well as increased partial pressure ( $>0.15$ bar). ADA measured the $\mathrm{CO}_{2}$ capacity at temperatures between $40^{\circ} \mathrm{C}$ and $120^{\circ} \mathrm{C}$ in $10^{\circ} \mathrm{C}$ increments at four different partial pressures, $0.04,0.081,0.5$, and 0.81 bar. The results for sorbent $\mathrm{CE}$ are provided in Figure 28 . 


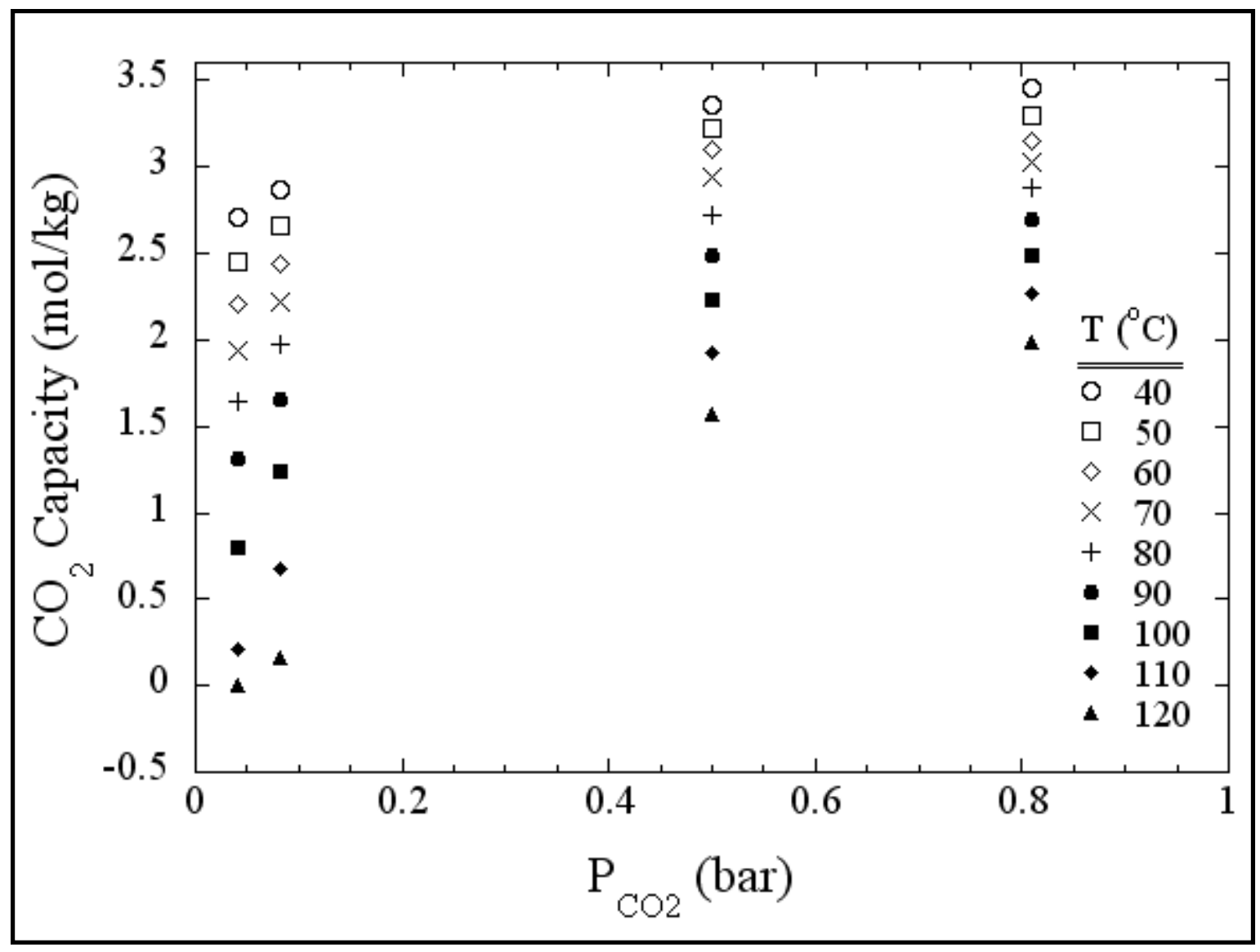

Figure 28: Sorbent CE Isotherms

Recall that the "working capacity" is the difference between the capacity of the sorbent for $\mathrm{CO}_{2}$ under adsorption conditions compared to the capacity of the sorbent for $\mathrm{CO}_{2}$ under regeneration conditions. For a commercial system, the optimal working capacity must be balanced by other considerations such as compression costs. To keep compression costs as low as possible in a commercial $\mathrm{CO}_{2}$ capture system, it is desired to regenerate the sorbent under the highest possible $\mathrm{CO}_{2}$ partial pressure. However, the data provided in Figure 28 clearly illustrate how regeneration at higher $\mathrm{CO}_{2}$ partial pressure will lead to an increase in the capacity under regeneration conditions and a resulting decrease in the overall $\mathrm{CO}_{2}$ working capacity. For example, if $\mathrm{CO}_{2}$ capture occurred at $50^{\circ} \mathrm{C}$ and 0.081 bar partial pressure and regeneration occurred at $120^{\circ} \mathrm{C}$ and 0.81 bar partial pressure (Denver, $\mathrm{CO}$ ), the working capacity would be the difference between the total $\mathrm{CO}_{2}$ capacities at the respective adsorption and regeneration conditions (i.e. $2.7 \mathrm{~mol} / \mathrm{kg}-2.0 \mathrm{~mol} / \mathrm{kg}=0.7 \mathrm{~mol} / \mathrm{kg}=3.1 \mathrm{wt} \%$ ). This calculation is provided only as an illustration. At many coal-fired power plants the partial pressure will be greater than 0.81 bar, which would lead to an increase in the working $\mathrm{CO}_{2}$ capacity.

The isotherms were also measured for a different supported amine sorbent, sorbent BN, which are provided in Figure 29. This material exhibited lower total $\mathrm{CO}_{2}$ capacities during fixed bed tests, but can be produced relatively inexpensively. Using the same procedure described above to determine the working capacity for sorbent $\mathrm{CE}$, the working capacity for sorbent $\mathrm{BN}$ is in the 
range of $1.3 \mathrm{~mol} / \mathrm{kg}(5.7 \mathrm{wt} \%)$. Different supported amine sorbents clearly react differently depending on the temperature and $\mathrm{CO}_{2}$ partial pressure.

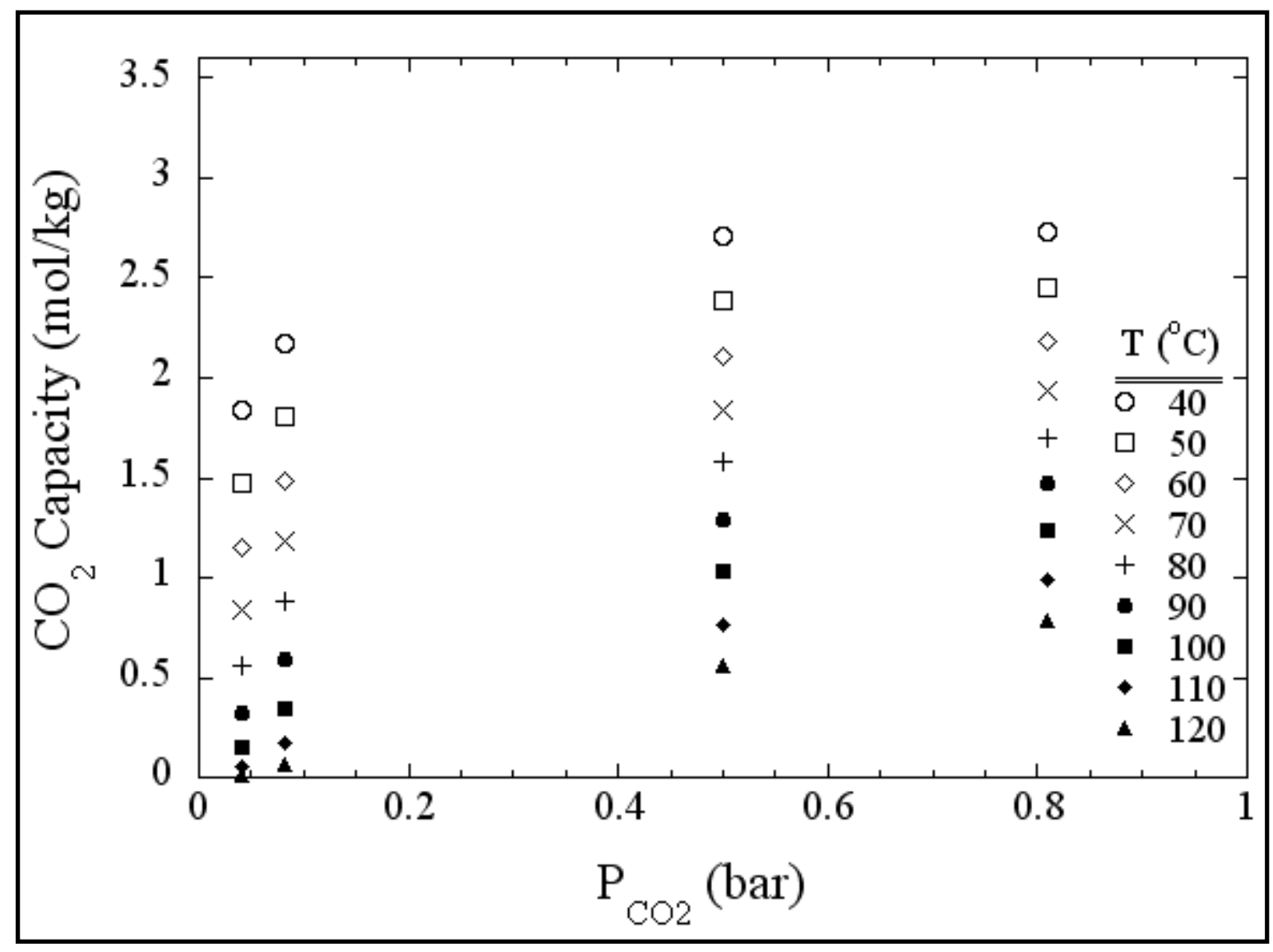

Figure 29: Sorbent BN Isotherms

Although the working capacity for sorbent $\mathrm{BN}$ is greater than that of $\mathrm{CE}$, it is still desirable to increase this working $\mathrm{CO}_{2}$ capacity as much as possible, which will reduce the process energy penalty and potentially will also decrease the equipment size. There are several different means to increase working capacity:

- Decrease the capture temperature

- Increase the regeneration temperature (within the limits of the amine stability)

- Decrease the partial pressure of the $\mathrm{CO}_{2}$ during regeneration by using a vacuum or diluting with steam

Each option for increasing the working capacity will have associated costs. It is outside the scope of this work to determine optimal $\mathrm{CO}_{2}$ capture/regeneration options. However, as sorbents are evaluated at increasing scales and complexity and the equipment/process options are taken into greater consideration, such evaluations will become imperative. Process optimization will be considered in depth in future projects. 
The results shown in Figure 28 and Figure 29 were collected during TGA tests with minimal $(\sim 1.1$ vol\%) moisture. It is not only possible, but expected, that an increase in moisture content during the adsorption step will increase $\mathrm{CO}_{2}$ capacities. If less moisture is present in the regenerator, the overall $\mathrm{CO}_{2}$ working capacity could be greater than what was measured in previous tests. Although this type of detailed analysis is outside the scope of this project, future projects where one or two sorbents are studied in depth, in contrast to the broad screening program completed during this project, the effect of moisture must be quantified.

\section{$\underline{\text { Attrition Testing }}$}

In a commercial sorbent-based $\mathrm{CO}_{2}$ capture system, costs will dictate that sorbents must be used for thousands of cycles. Therefore, if the process involves equipment that can lead to significant levels of attrition, such as has been observed during operation of a circulating fluidized bed, it is important to understand the strength properties of the sorbent. The substrates for sorbent $\mathrm{R}$ (shown in Figure 30) and X (shown in Figure 31) were circulated in a fluidized bed for 6 hours and the particle size distribution before and after were measured. The full report provided by Jenike \& Johanson is included in the appendix of Topical Report 5. ${ }^{22}$ Due to the short duration and the equipment used, the results from the attrition tests carried out during this study can only be discussed qualitatively for comparing two different shapes of similar substrates.

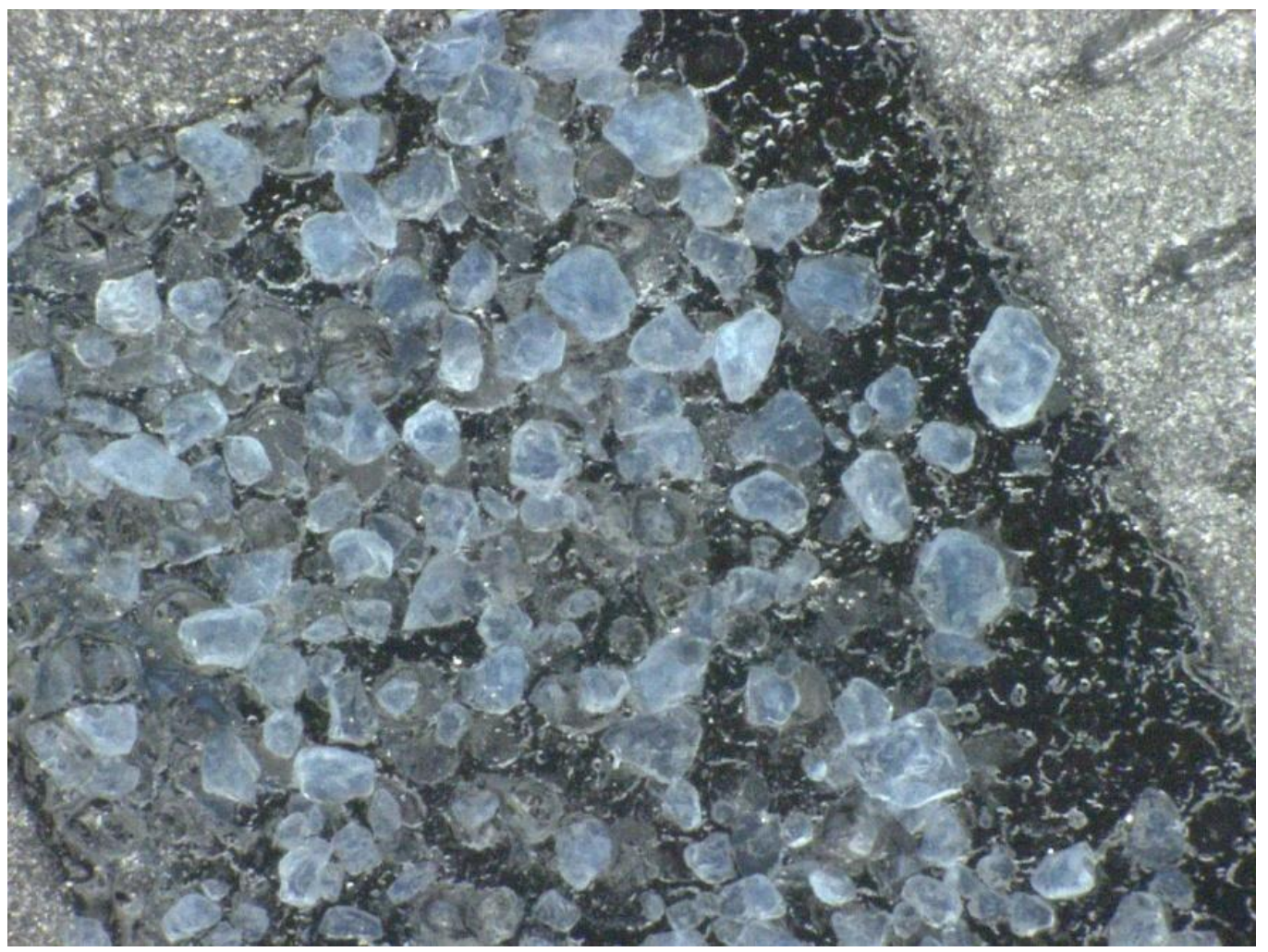

Figure 30: Sorbent R Substrate 


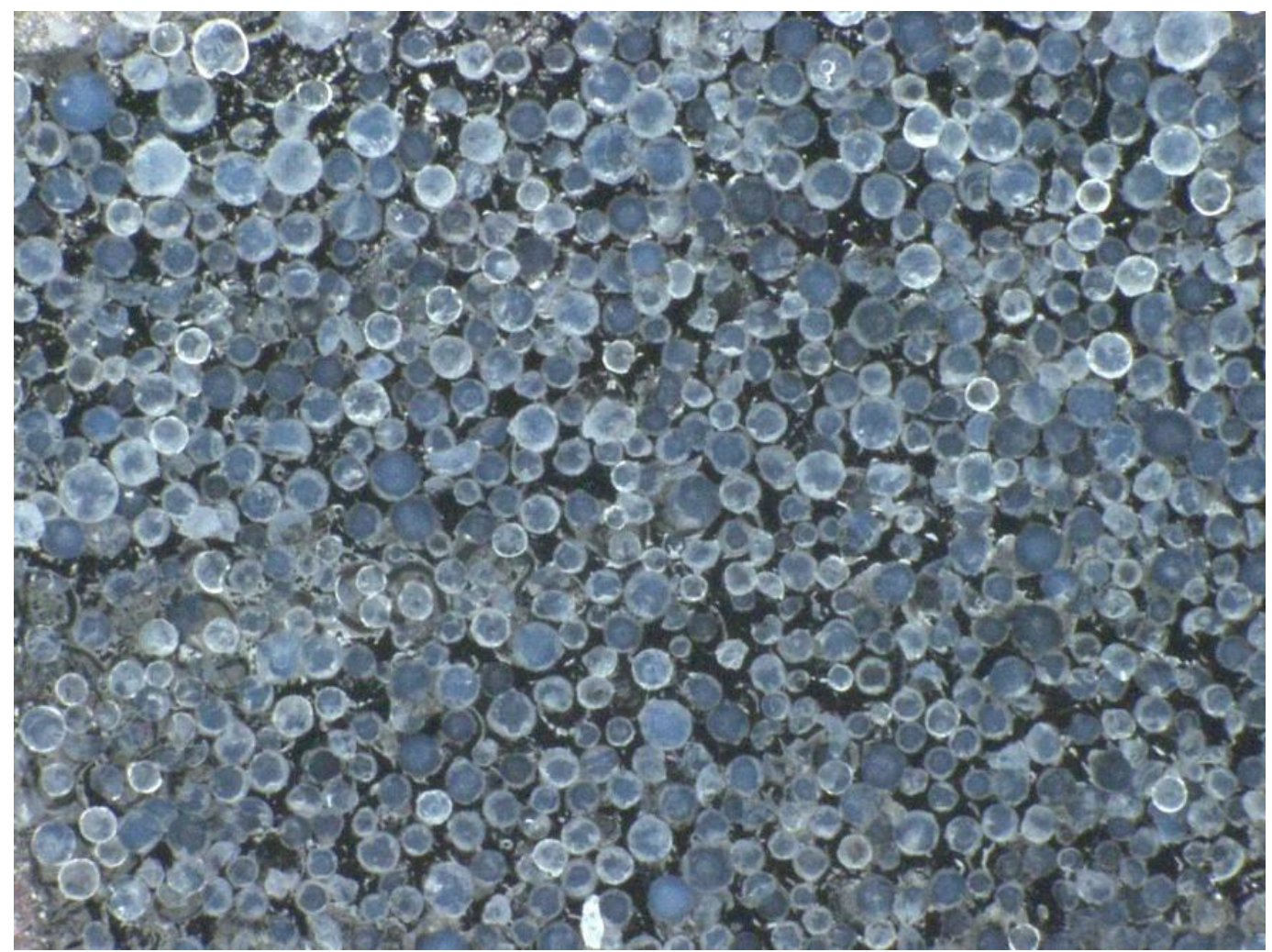

Figure 31: Sorbent X Substrate

The particle distribution for the substrate sorbent $\mathrm{R}$ substrate before and after it was circulated in a fluidized bed system is provided in Figure 32. The median particle size before circulation was approximately $185 \mu \mathrm{m}$; after circulation the median particle size was approximately $155 \mu \mathrm{m}$. This represents a decrease of approximately $16 \%$ in the median. However, when the two curves in Figure 32 are compared, the distribution curves are relatively similar with a small shift to the left (i.e. smaller particles) after circulation. 


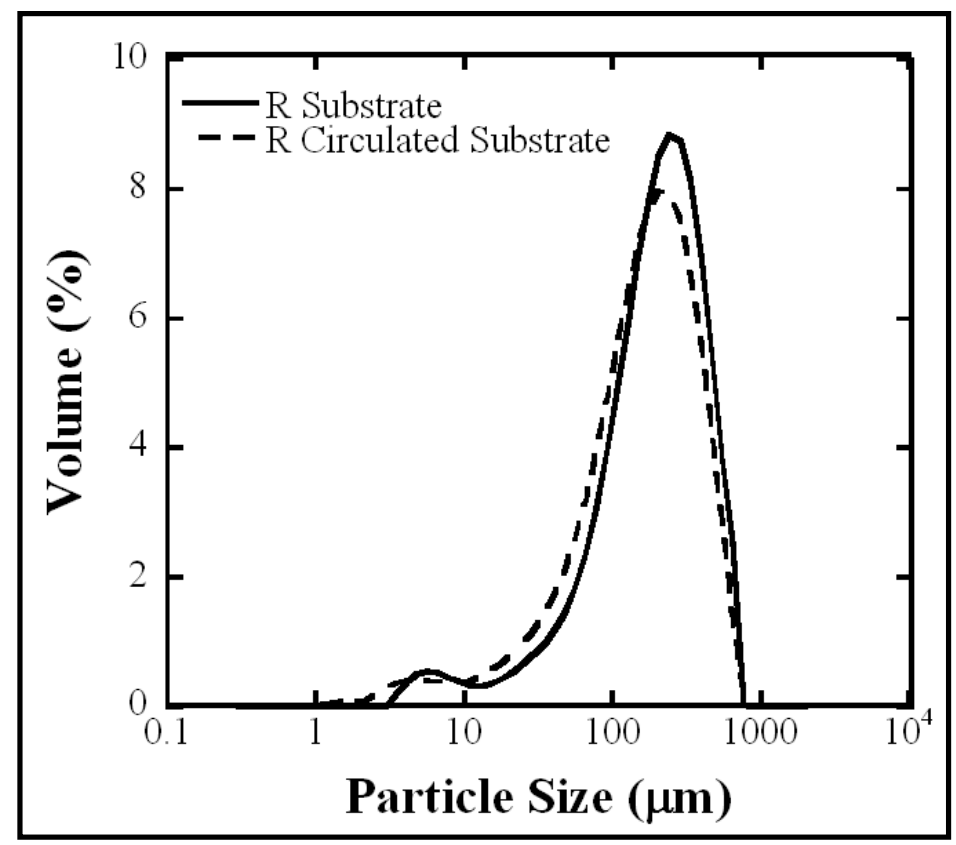

Figure 32: Sorbent R Substrate Particle Size Distribution

The particle size distribution of the sorbent $\mathrm{X}$ substrate before and after circulation is shown in Figure 33. In this case, the median particle size decreased from approximately $212 \mu \mathrm{m}$ to 191 $\mu \mathrm{m}$, representing a decrease of $10 \%$. This decrease is less than that observed for the sorbent $\mathrm{R}$ substrate, but the particle distribution curve between the before and after samples are clearly distinguishable.

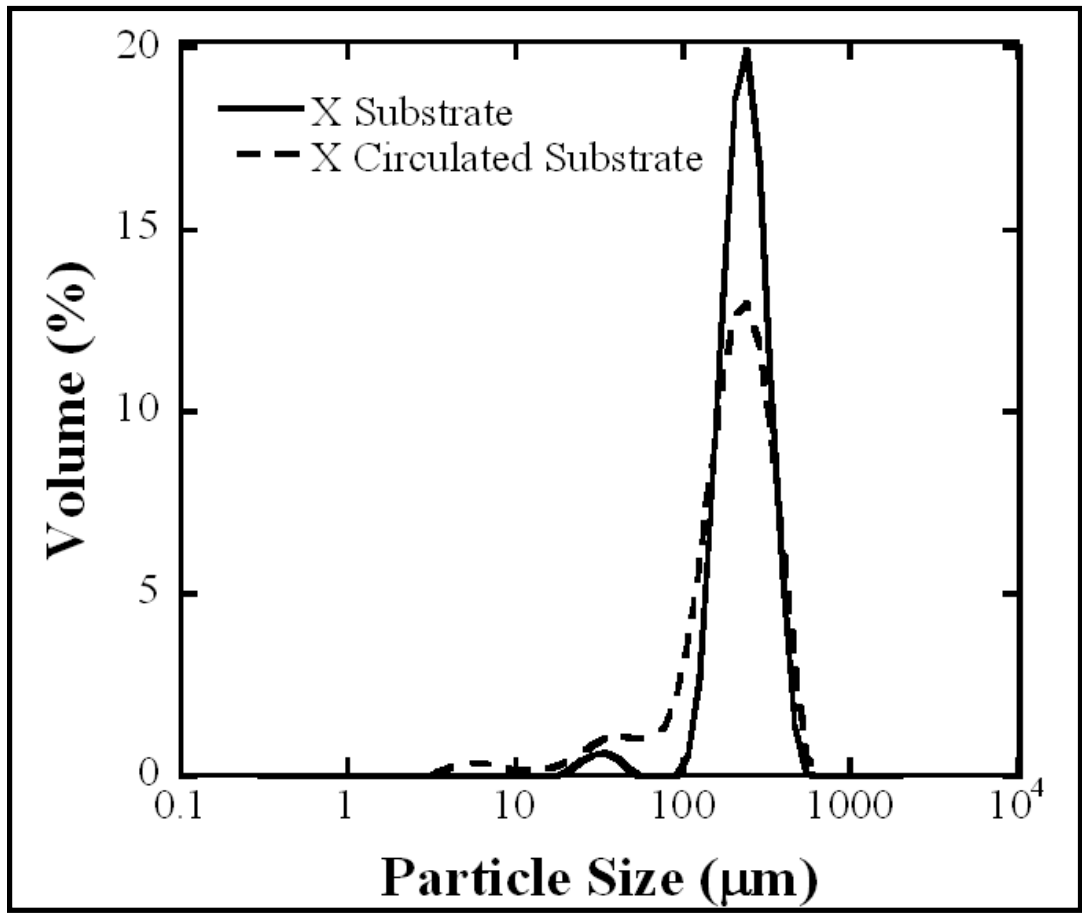

Figure 33: Sorbent X Particle Size Distribution 
The sorbent R substrate is non-uniform and non-spherical as is shown in Figure 30. The sorbent $\mathrm{X}$ substrate is spherical and more uniform as is shown in Figure 31. The uniformity of the materials is confirmed by the particle size distribution curves. It was expected that the nonspherical material would exhibit higher initial attrition levels as the edges of the particles wore down and the particles became more rounded. However, it was somewhat unexpected that the change in median particle size would be similar for the two materials. Longer tests could be conducted in the future to obtain more quantitative results. However, to get a truly quantitative measurement, attrition analysis must be completed after extended circulation of the sorbent in the type of system that will be used for $\mathrm{CO}_{2}$ capture; although outside the scope of this work this will be the focus of future projects.

\section{$\underline{\text { Particle Density }}$}

The particle density is an important property that must be known to design different reactors. Although it was prohibitively expensive to test the particle density for all the sorbents screened under DE-NT0005649, the particle density was measured by Adsorption Research, Inc. for two promising supported amine sorbents under DE-FE0004343. The sorbents evaluated were sorbent $\mathrm{AX}$, which was produced using the same porous silica substrate as sorbent $\mathrm{CE}$ and sorbent $\mathrm{X}$, as well the beaded sorbent $\mathrm{BN}$, which was manufactured using a polystyrene resin substrate.

The particle density for $\mathrm{AX}$, as delivered, was found to be $0.821 \pm 0.016 \mathrm{~g} / \mathrm{cm}^{3}$. The particle density for BN was $0.646 \pm 0.012 \mathrm{~g} / \mathrm{cm}^{3}$. Because the moisture in the sorbent was more of a concern for sorbent $\mathrm{BN}$, the particle density for this material was measured after the sorbent was treated with $\mathrm{H}_{2} \mathrm{O}$ saturated $\mathrm{N}_{2}$ at $55^{\circ} \mathrm{C}$. The particle density for sorbent $\mathrm{BN}$ after pre-treating at $55^{\circ} \mathrm{C}$ was $0.586 \pm 0.009 \mathrm{~g} / \mathrm{cm}^{3}$. There was a $38.9 \%$ mass loss during pretreatment. The change in particle density, however, was only $9.3 \%$, indicating that the particle size also changed somewhat with the moisture pre-treatment. The difference in the particle density for the silica substrate supported amine and the polystyrene supported amine was approximately $29 \%$. These two sorbents would behave very differently regarding fluidization and entrainment. Therefore, it would be difficult, if not impossible, to design a single reactor where such different materials could simply be interchanged.

\section{Crush Strength}

For beaded or granular materials crush strength can provide a quantitative measurement for comparison. Although the crush strength alone will not provide exact attrition rates for different types of reactors, it can be valuable for designing systems/processes. For example, silo specifications or sorbent distribution devices could require stacking or piling of sorbent. The height of the sorbent could be limited by the crush strength. The only promising beaded material that was evaluated under the program was sorbent BN. Crush strength values were measured by Adsorption Research, Inc. under DE-FE0004343. The full report is included in the appendix of Topical Report $5 .^{22}$

Crush strength values were measured for BN. They ranged from 232 to $1019 \mathrm{~g}$. The average mass required was $412.5 \pm 175.8 \mathrm{~g}$. The median of the masses was $363.3 \mathrm{~g}$. The distribution of measured values is shown in Figure 34. The lowest masses required were for the smallest particles and the particle was determined to be "crushed" when the particle audibly cracked. 


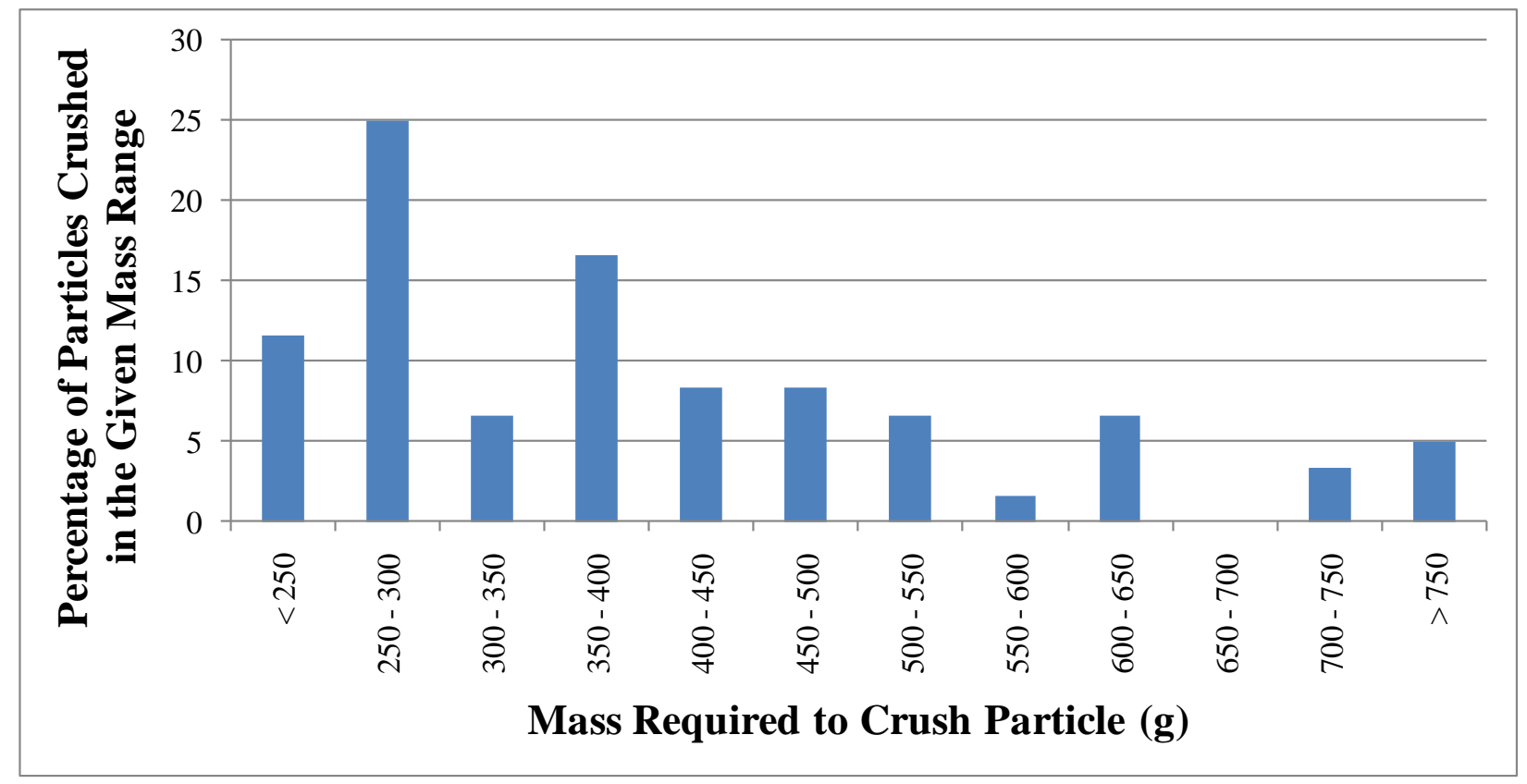

Figure 34: Sorbent BN Crush Strength Analysis

\section{Task 2.2. 1 kW Pilot-Scale Equipment Design and Construction}

One important requirement for the final selection of the slipstream equipment was that it could provide sufficient information on sorbent performance to support viability assessment and scaleup engineering. Selection criteria were developed in collaboration with ADA's process design team, engineers from Southern Company, and NETL personnel. Three primary design concepts were considered for the slipstream unit: fixed-bed, moving bed, and circulating fluidized bed. Experts in each process provided additional details to the ADA design team. Experts included Kent Knaebel, who visited ADA and explained his patented moving bed gas/solid contactor design, Southern Company engineers from the National Carbon Capture Center (NCCC) to discuss the applicability of fluidized beds for $\mathrm{CO}_{2}$ capture and fixed beds for smaller-scale evaluations, and NETL personnel who discussed the pilot-scale fluidized bed and modeling capabilities during ADA's visit to the Morgantown NETL facility. NETL personnel at the Pittsburgh facility also discussed capabilities of a hybrid fixed/moving-bed adsorber.

After discussing the options with the project team a circulating fluidized bed-type of entrained flow contactor was selected for the slipstream apparatus. It was determined that this type of equipment would be the best option to test materials that had highly varied physical properties, which was an important concern because laboratory-scale sorbent screening was conducted concurrently with the $1 \mathrm{~kW}$ equipment design and construction. ADA worked closely with Southern Company to finalize the contactor details.

The size of the pilot-scale test equipment was originally conceived for $100 \mathrm{acfm}$. The equipment design team of ADA and Southern Company engineers determined that the technical information that could be obtained from 100 acfm was not significantly more than what could be obtained from a $5 \mathrm{acfm}$ fluidized bed test. There would also be significantly higher costs associated with the larger equipment and amount of sorbent to run the $100 \mathrm{acfm}$ system. Therefore, a recommendation was made and approved by the DOE to reduce the size of the slipstream reactor 
to $5 \mathrm{acfm}$ (i.e. $\sim 1-2 \mathrm{kWe}$ equivalent of gas - this unit is referred to as the $1 \mathrm{kWe}$ pilot in subsequent discussion) to reduce the quantity of sorbent required for initial scale-up testing.

During 3Q09, the following activities were undertaken to make progress towards completion of the design and construction of the $1 \mathrm{kWe}$ pilot:

- Completion of the design packages

- General arrangement drawings

- $3 \mathrm{D}$ model of the $5 \mathrm{acfm}$ system

- P\&ID

- Process flow diagram

- Fabrication

- Two primary subcontractors were selected

- Construction was completed in November 2009

- Logic control scheme finalized

- Pre-pilot operating manual begun

While the individual equipment components and parts were being procured, the structural tower that intended to house the equipment was fabricated. Figure 35 is a picture of the tower as it was being constructed.

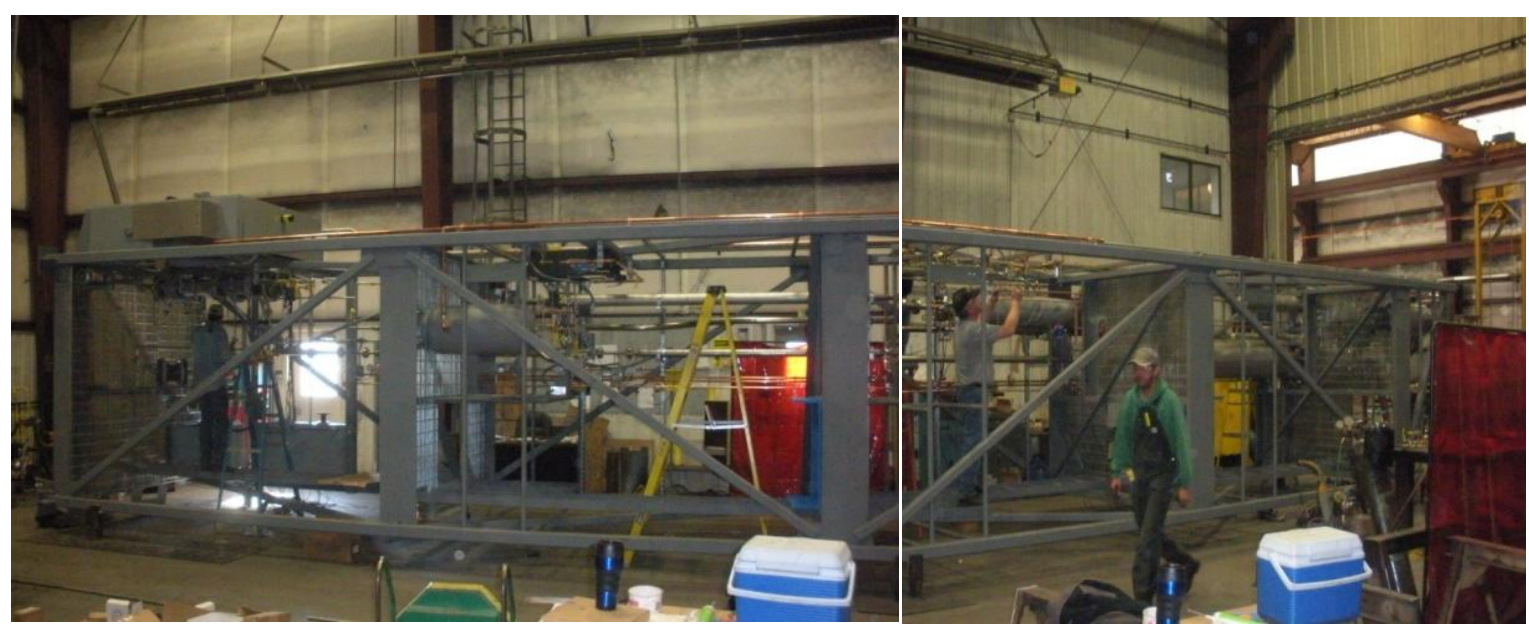

Figure 35: Picture of Tower for the $1 \mathrm{~kW}$ Pilot Equipment

After the tower was fabricated, all equipment components that were not built into the tower were integrated to complete fabrication of the $1 \mathrm{~kW}$ equipment. The equipment was raised and initial shake-down activities were conducted at the fabrication location. The system was tested using sand as a surrogate for sorbent and compressed air as a surrogate for flue gas. A 3D model sketch and photo of the $1 \mathrm{~kW} \mathrm{CO} 2$ capture system at the fabrication shop are shown in Figure 36. 


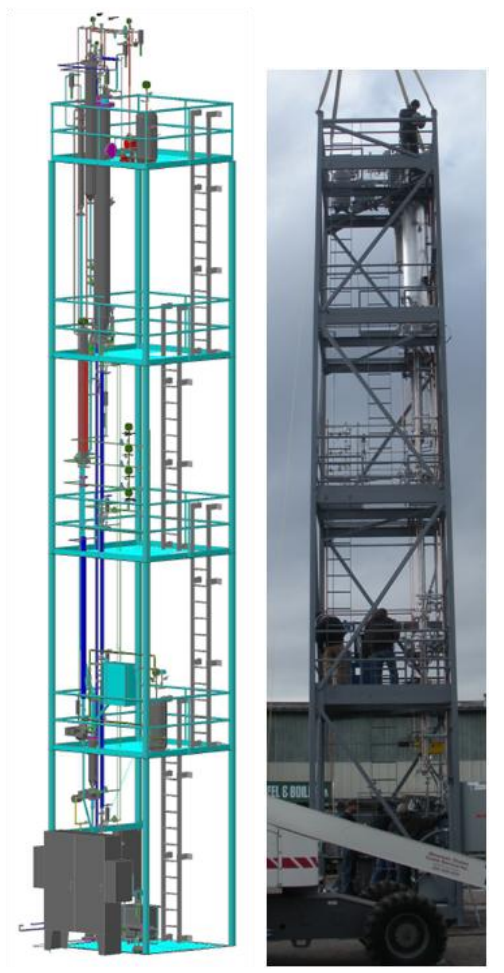

Figure 36: 3D Model Sketch and Photo of 1 kW System

Based on the initial shake-down, several adjustments were made to improve reliability. The equipment was tested again using sand and compressed air at the fabrication location and was prepared for shipping to the first host site, which was Luminant's Martin Lake Steam Electric Station located in Tatum, TX. The $1 \mathrm{~kW}$ pilot was shipped to the site, put into place on a support pad, and connected to the power plant utilities and flue gas. Sand was circulated successfully several times during check out of the system. Then, the first sorbent was placed in the system. A schematic of the operational components (i.e. non-structural) of the $1 \mathrm{~kW}$ pilot is provided in Figure 37. 


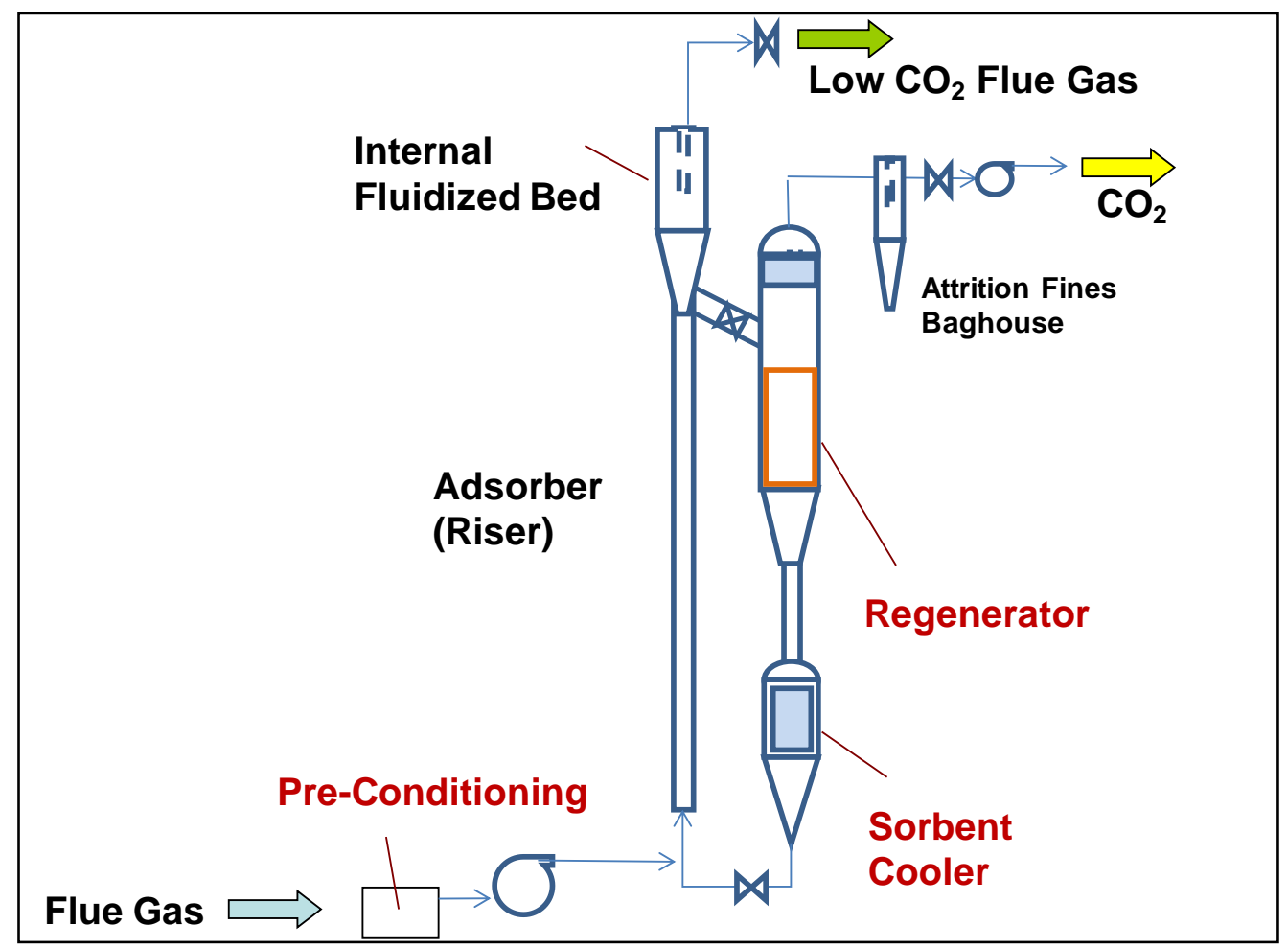

Figure 37: Diagram of 1 kW Pilot $\mathrm{CO}_{2}$ System

The equipment included a flue gas pretreatment section prior to the capture and regeneration system. Pretreatment options included flue gas heating, cooling, $\mathrm{SO}_{2}$ removal, and moisture reduction. A small blower was also included to deliver flue gas to the pilot. The capture system included both $\mathrm{CO}_{2}$ adsorption and sorbent regeneration.

The adsorption occurred in the riser, which was a transport reactor (i.e. the sorbent was entrained by the flue gas). Although the riser was only 1 inch in diameter, it was 40 feet tall, the approximate required height for a commercial system. This height provided a contact time of approximately 3 seconds. There was also an added option for sorbent recirculation if additional contact time was required.

Nominally $5 \mathrm{cfm}$ of treated flue gas was sent through the adsorption riser, where it entrained and reacted with the sorbents. Unless otherwise specified, the sorbent circulation rate was $40 \mathrm{lb} / \mathrm{hr}$. This sorbent circulation rate would provide $90 \% \mathrm{CO}_{2}$ removal if the sorbent working $\mathrm{CO}_{2}$ capacity was approximately $10 \mathrm{wt} \%$, depending on the $\mathrm{CO}_{2}$ concentration in the flue gas. The riser temperature was maintained at approximately $130^{\circ} \mathrm{F}$, although the exothermic reaction often made isothermal operation impossible.

The $\mathrm{CO}_{2}$ capture occurred as the solids were entrained by the flue gas in the 1-inch riser, but at the top of the riser the diameter expanded, which resulted in significant solids dropout and permitted the $\mathrm{CO}_{2}$-lean flue gas to pass through a filter bag, which separated the remainder of the solids. Due to the small size of this pilot, the $\mathrm{CO}_{2}$-lean gas was vented to the atmosphere rather than routing it back to the host duct. 
The regenerator consisted of a fluidized bed. Expected regeneration temperatures were in the range of $210^{\circ} \mathrm{F}$ to $250^{\circ} \mathrm{F}$. For the $1 \mathrm{~kW}$ system, electric heaters were used for the heat input, although in a commercial system indirect steam or some other source of heat would likely be more advantageous. The fluidizing media was $\mathrm{N}_{2}$, although in a commercial-system $\mathrm{CO}_{2}$ or a mixture of $\mathrm{CO}_{2}$ and steam would be a superior selection for fluidization gas. The specified design maximum residence time in the regenerator was approximately 500 seconds. An ID fan was used to extract the enriched $\mathrm{CO}_{2}$ stream. If any sorbent was carried with the $\mathrm{CO}_{2}$ gas stream, it was captured in a cyclone or a fines baghouse. After the sorbent was heated and the $\mathrm{CO}_{2}$ was removed the sorbent was sent through a cooler that utilized jacketed cooling to reduce the temperature of the sorbents to approximately the riser temperature.

The pilot was instrumented to provide monitoring and control of pressures and temperatures throughout the system. Key gas measurement, pressure, and temperature measurement locations are indicated in the sketches in Figure 38, Figure 39, and Figure 40.

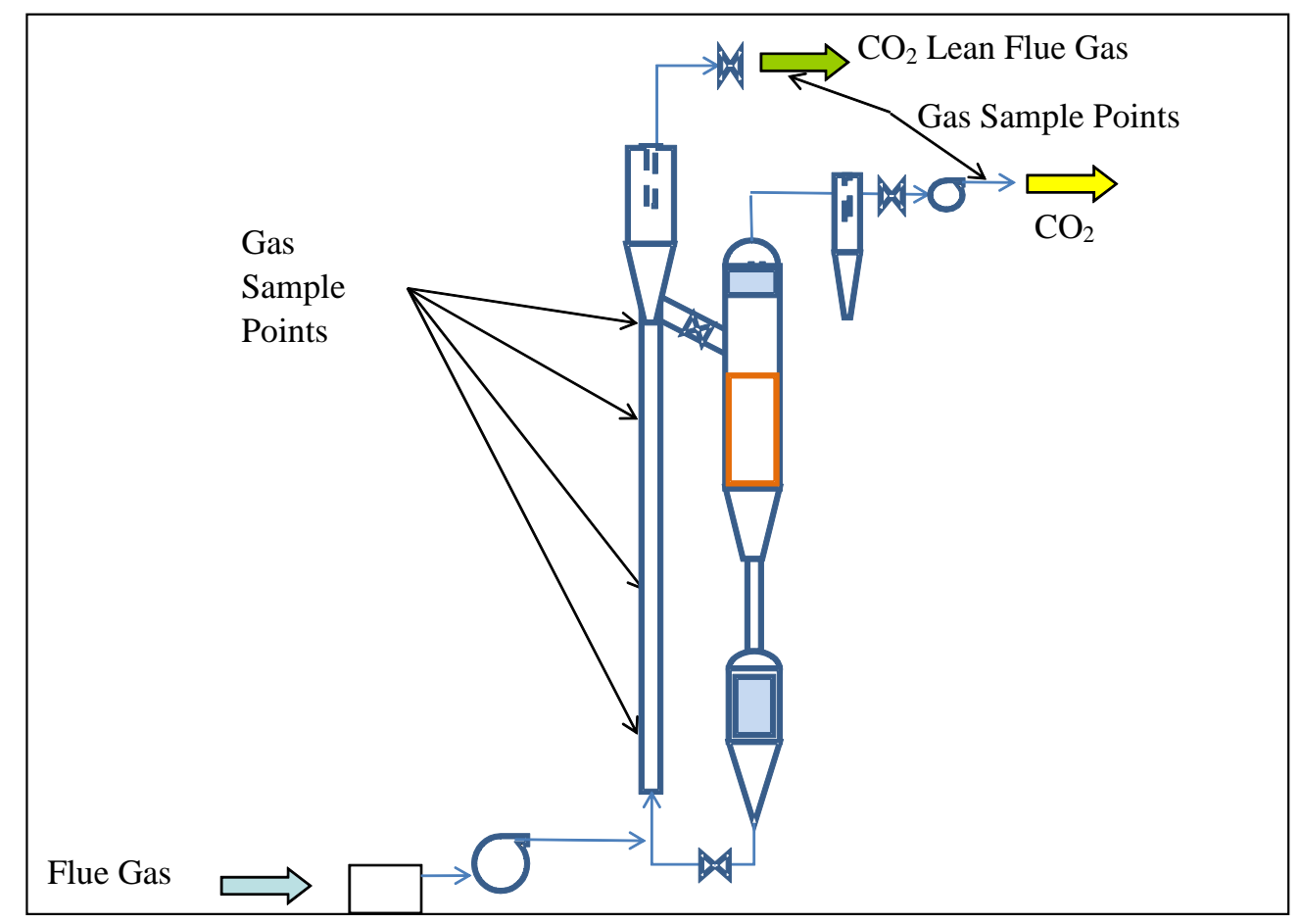

Figure 38: Sketch of Gas Sampling Locations 


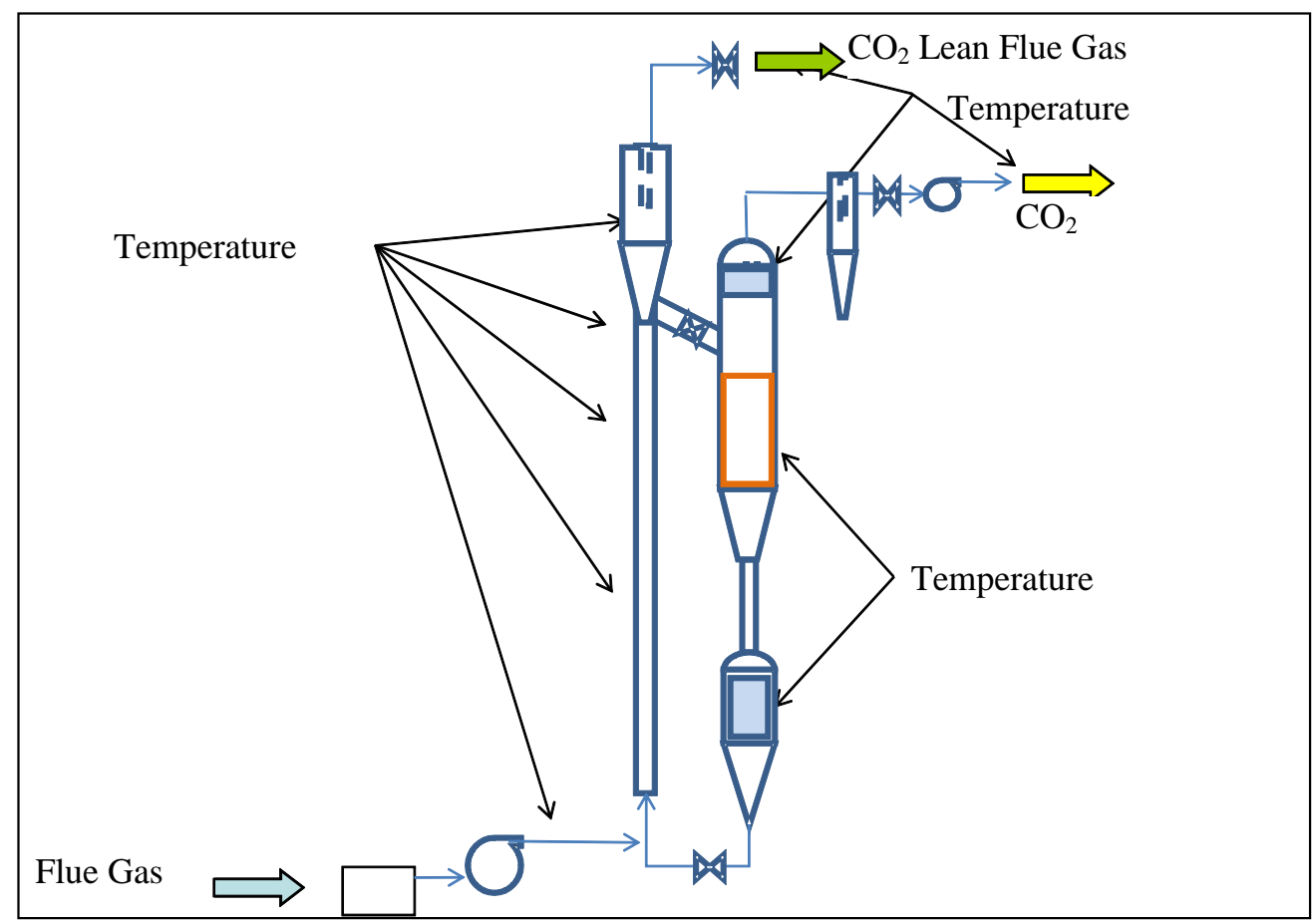

Figure 39: Sketch of Temperature Measurement Locations

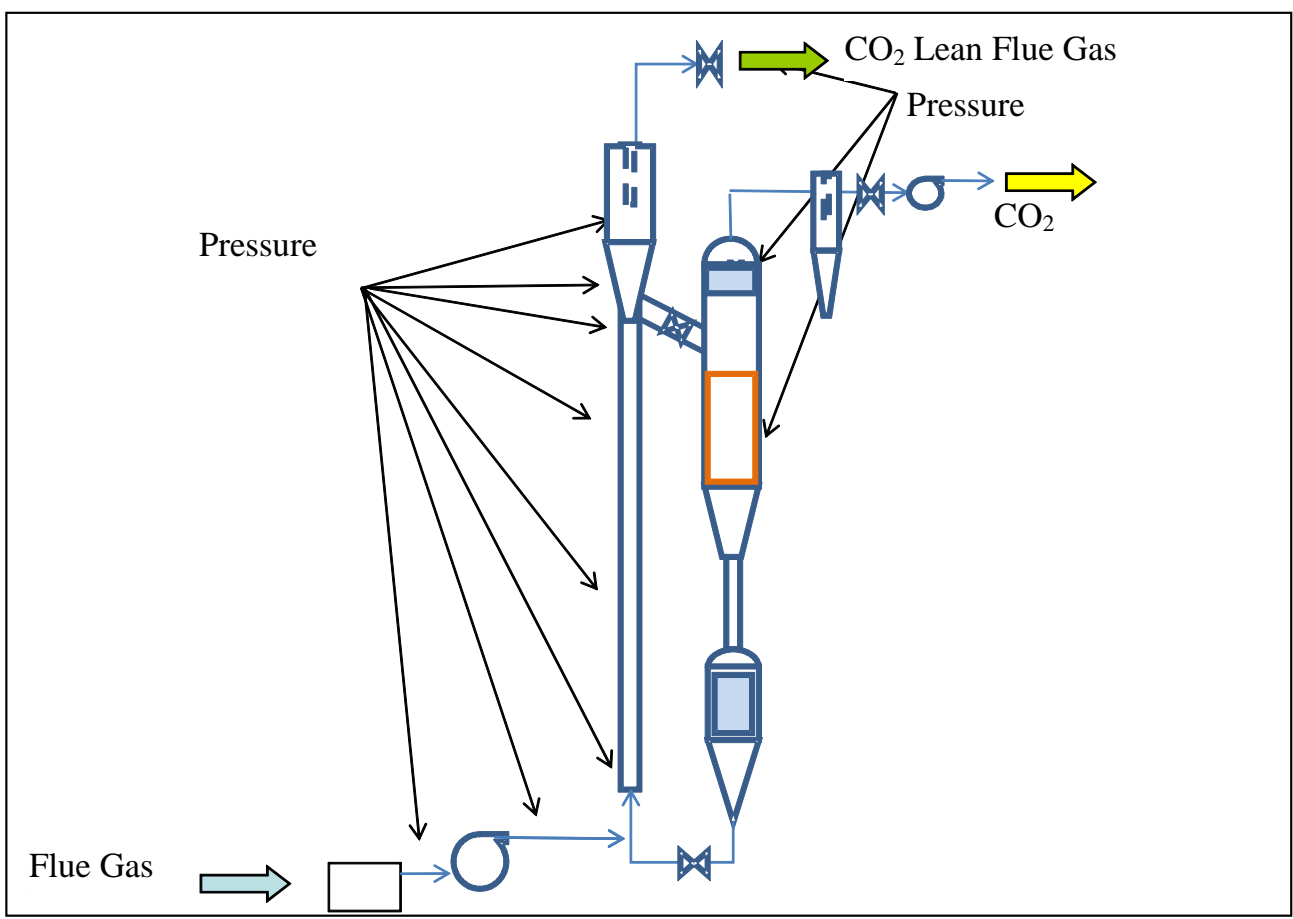

Figure 40: Sketch of Pressure Measurement Locations

The $1 \mathrm{~kW}$ pilot was used to effectively compare different sorbents under the same operating conditions. However, it was not possible to maintain $90 \%$ continuous $\mathrm{CO}_{2}$ capture with any of 
the sorbents tested to date using such a configuration. Two theoretical isotherms and the $1 \mathrm{~kW}$ pilot configuration are provided together in Figure 41 to facilitate explanation of why it was difficult to achieve high removal levels in the $1 \mathrm{~kW}$ pilot with the sorbents evaluated in the screening program.

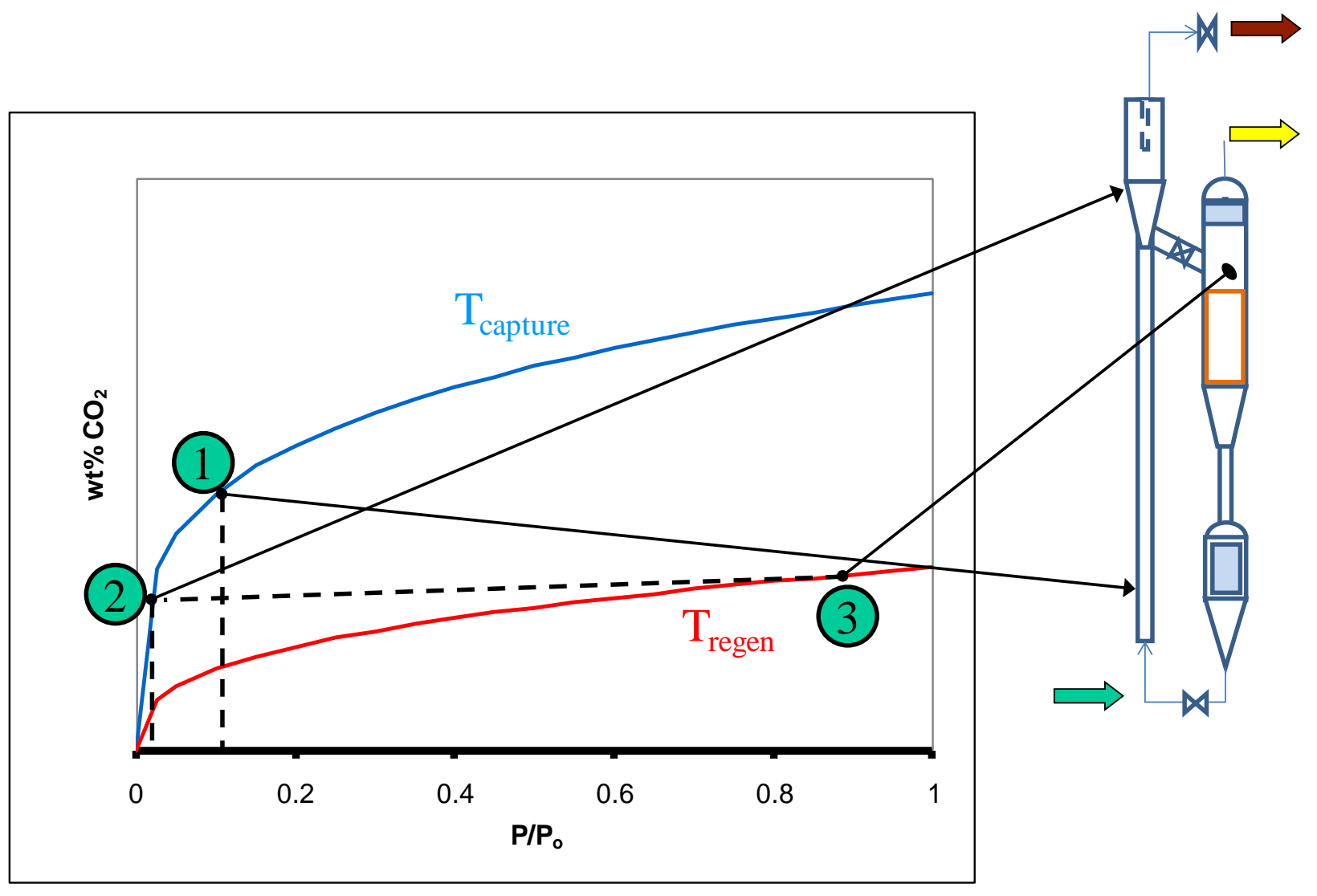

Figure 41: $1 \mathrm{~kW}$ Pilot with Theoretical Isotherms

The two isotherms provided in Figure 41 are theoretical, but are similar in shape to what has been measured previously for supported amine sorbents. The y-axis corresponds to the equilibrium $\mathrm{CO}_{2}$ capacity (in wt\%) of a sorbent and the $\mathrm{x}$-axis corresponds to the partial pressure of $\mathrm{CO}_{2}$ in the gas. The upper, blue isotherm signifies the relationship between sorbent $\mathrm{CO}_{2}$ loading and $\mathrm{CO}_{2}$ partial pressure in the gas at the adsorption/capture temperature, while the red isotherm represents the same relationship at the regeneration temperature. The $1 \mathrm{~kW}$ pilot consisted of a riser (i.e. transport reactor) for adsorption. Therefore, the maximum driving force for $\mathrm{CO}_{2}$ uptake to the sorbent is at the bottom of the riser where the flue gas $\mathrm{CO}_{2}$ concentration was the greatest (point 1). As the sorbent began to remove the $\mathrm{CO}_{2}$ from the gas, the driving force for the sorbent to continue removing $\mathrm{CO}_{2}$ decreased because the partial pressure of $\mathrm{CO}_{2}$ in the gas was decreasing. At the top of the riser the partial pressure of $\mathrm{CO}_{2}$ in the gas was lower than that at the bottom, thus, the equilibrium $\mathrm{CO}_{2}$ loading of the sorbent was lower (point 2). A fluidized bed with a downcomer tube was used for the regenerator. Ideally when the sorbent moved from the riser to the regenerator it would release $\mathrm{CO}_{2}$ due to only a temperature swing with only $\mathrm{CO}_{2}$ as the fluidization gas. Because the regenerator was a slow bubbling fluidized bed the sorbent was not always in contact with $\mathrm{N}_{2}$. To regenerate quickly in this type of fluidized bed the sorbent would have to regenerate in the presence of pure $\mathrm{CO}_{2}$. Although 
different sorbent isotherms (as shown in the Task 2.1.2 discussion) demonstrate that some sorbents regenerate in the presence of $\mathrm{CO}_{2}$, this will only occur if the $\mathrm{CO}_{2}$ loading during adsorption was high enough to create a driving force for high partial pressure regeneration. In this example, when comparing the $\mathrm{CO}_{2}$ loading on the sorbent at the top of the riser (point 2) to the $\mathrm{CO}_{2}$ loading in the regenerator (point 3) there is no driving force for regeneration. Therefore, the regeneration is slow as the sorbent only regenerates when in the presence of the fluidization $\mathrm{N}_{2}$. The sorbents evaluated in the screening program cannot be used to maintain $90 \% \mathrm{CO}_{2}$ removal in this type of adsorption/regeneration system. However, the system was still effective at comparing the removal level for different materials.

\section{Task 2.3. Parametric Field Tests}

Field testing with the $1 \mathrm{~kW}$ pilot occurred at two different power plants: Martin Lake and Sherco. A picture of the $1 \mathrm{~kW}$ pilot installed at Martin Lake and Sherco plant are provided in Figure 42 and Figure 43, respectively.

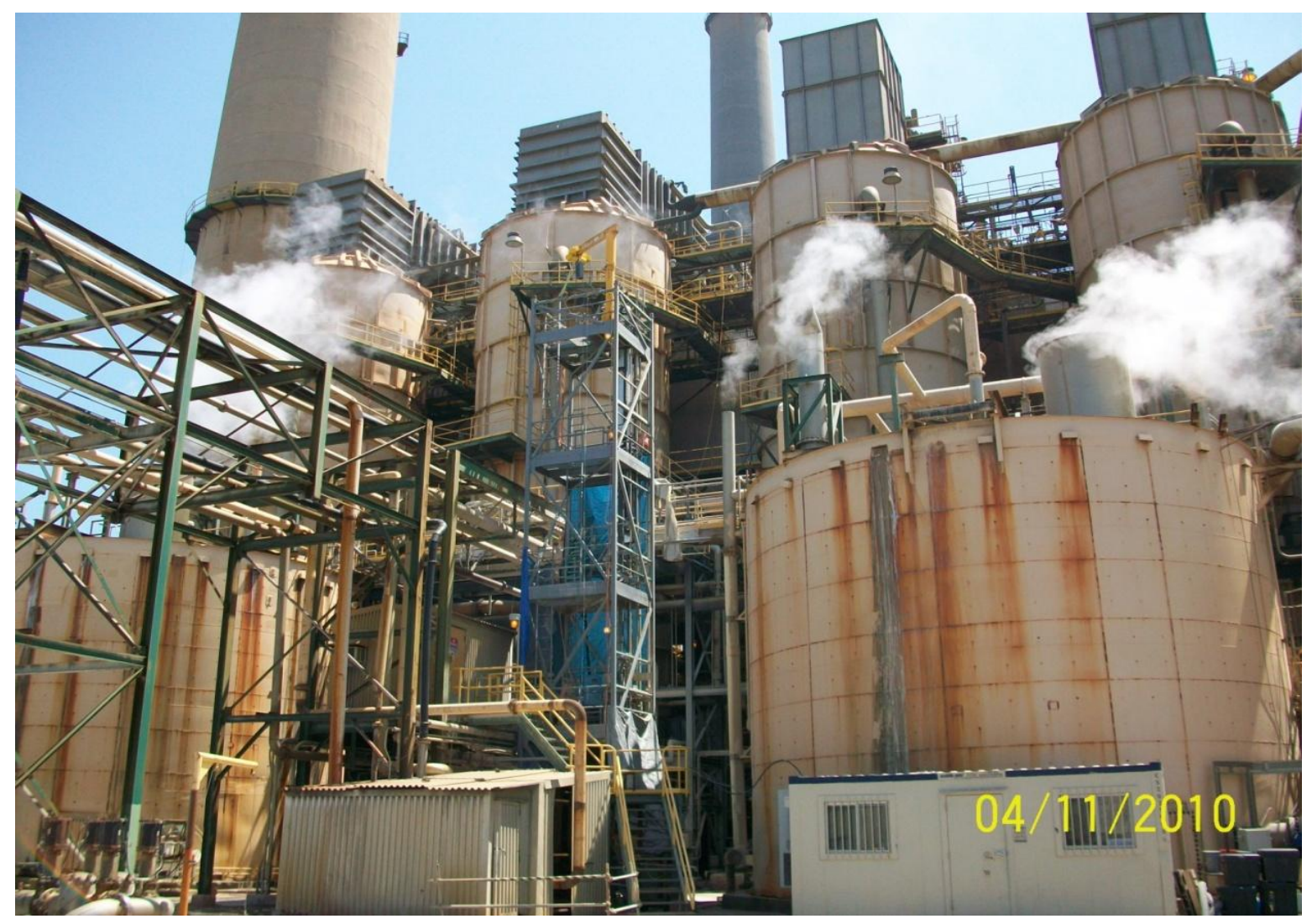

Figure 42: Picture of the $1 \mathrm{~kW}$ Pilot Installed at Martin Lake 


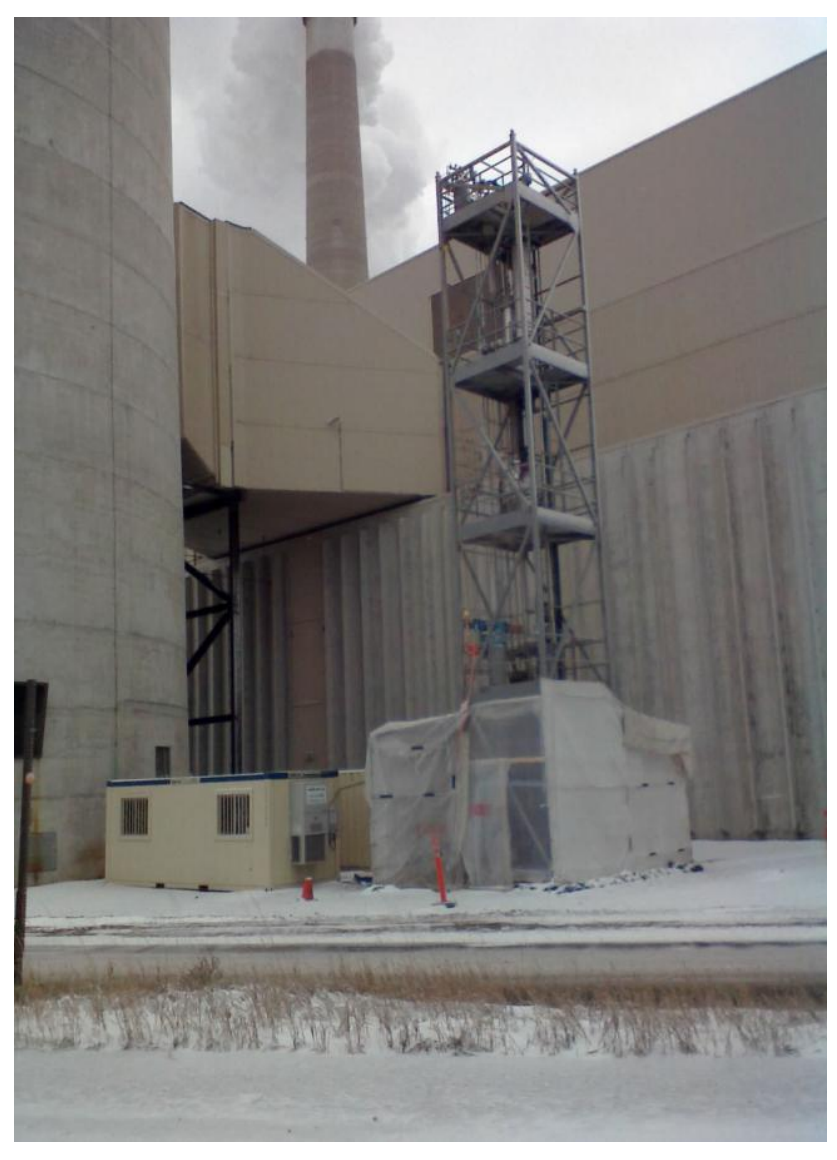

\section{Figure 43: Picture of $1 \mathrm{~kW}$ Pilot Installed at Sherco}

Due to the cold ambient temperatures of the Minnesota winter at Sherco, the lower section of the tower was covered in tarps. This covering and heaters added to the lower levels prevented freezing of the moisture laden flue gas and $\mathrm{SO}_{2}$ scrubbers.

\section{$1 \mathrm{~kW}$ Pilot Testing - Martin Lake}

The first host site for $1 \mathrm{~kW}$ pilot testing was Luminant's Martin Lake Steam Electric Station. The test equipment was first operated with sand as a surrogate for sorbent to ensure proper operation of the system. Then, sorbent $\mathrm{R}$, which was a supported amine sorbent developed by researchers at NETL was evaluated. This was the only sorbent tested in the $1 \mathrm{~kW}$ pilot at Martin Lake. Sorbent $\mathrm{R}$ was selected because it exhibited the greatest total $\mathrm{CO}_{2}$ capacity under simulated flue gas conditions and superior cyclic stability compared to many other supported amine sorbents evaluated to date. During laboratory testing the theoretical regeneration energy for sorbent $\mathrm{R}$ was calculated to be approximately $2200 \mathrm{~kJ} / \mathrm{kg} \mathrm{CO}_{2}$, compared to the MEA benchmark of $3600 \mathrm{~kJ} / \mathrm{kg} \mathrm{CO}$. The first $1 \mathrm{~kW}$ pilot scale parametric test of sorbent $\mathrm{R}$ occurred on $3 / 10 / 2010$. During this first test, the temperature in the regenerator was maintained low enough to prevent regeneration. This approach was used to confirm the cycle time of the sorbent through the system by monitoring when spent sorbent re-entered the bottom of the riser. If the $\mathrm{CO}_{2}$ removal levels decreased significantly in less than two hours, the sorbent was not moving through the system as expected.

Two graphs including data collected during the first test are presented in Figure 44. The inlet 
$\mathrm{CO}_{2}$ concentration, outlet $\mathrm{CO}_{2}$ concentration, and $\mathrm{CO}_{2}$ removal are shown in the top graph while several temperatures in the riser and ICFB are provided in the second graph. During this test run, flue gas was introduced into the system at approximately 17:00 with sorbent already circulating. The $\mathrm{CO}_{2}$ removal in the riser stabilized at approximately $60 \%$. Then, at approximately 17:50 fluidization gas was added to the ICFB, which caused the sorbent in the ICFB to begin circulating. Over $90 \%$ removal was achieved before the $\mathrm{CO}_{2}$ capture decreased.

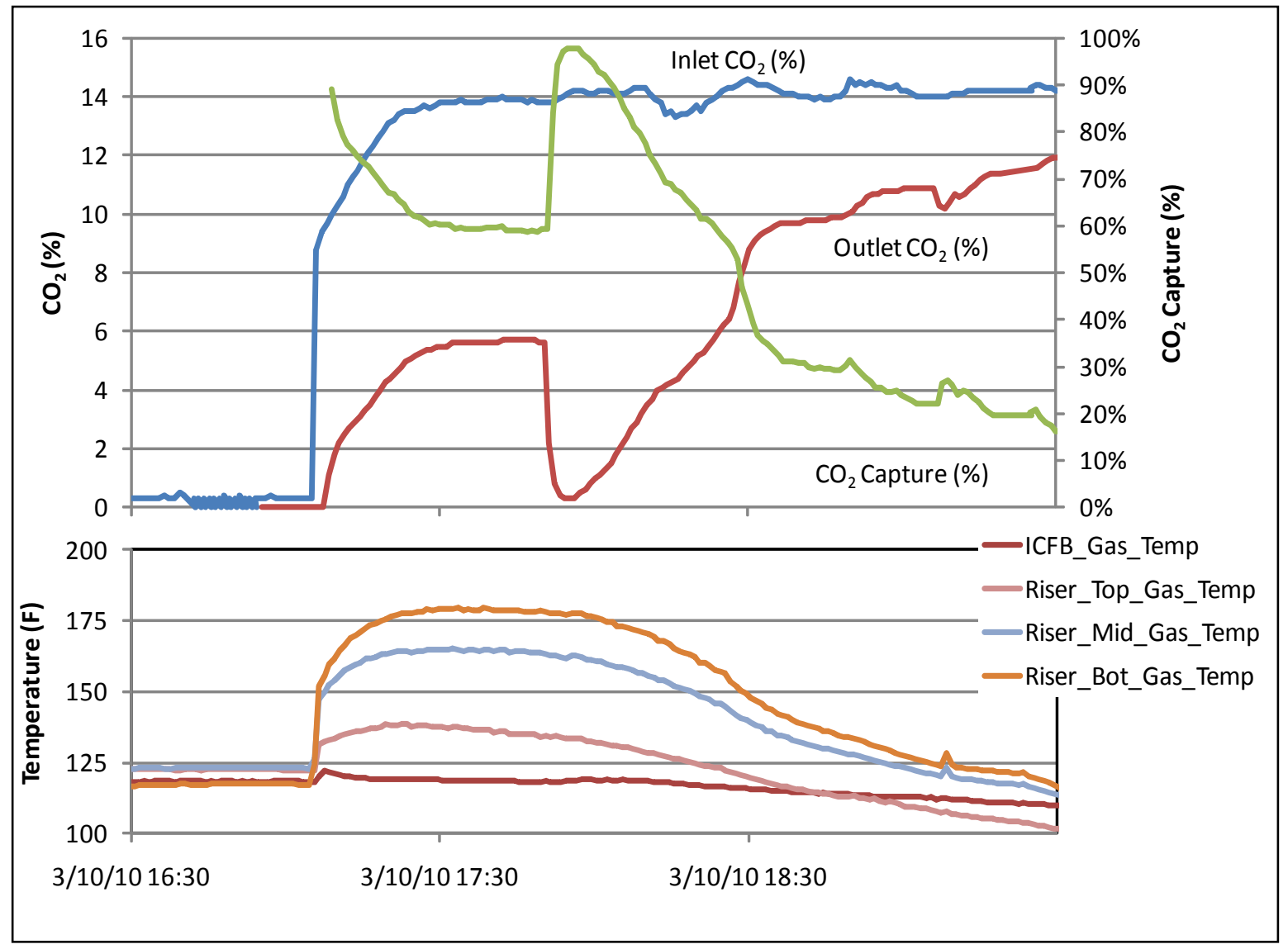

\section{Figure 44: $\mathrm{CO}_{2}$ Concentration, $\mathrm{CO}_{2}$ Removal, and Temperature Information Collected During Parametric Testing of Sorbent R}

The temperature increases observed in the second graph in Figure 44 were caused by the exothermic reaction between the sorbent and $\mathrm{CO}_{2}$. Since the temperature increase at the bottom of the riser was significantly larger than that at the top of the riser, the residence time in the riser is likely sufficient for most of the reaction to occur. In the laboratory testing the reaction between sorbent $\mathrm{R}$ and the $\mathrm{CO}_{2}$ was characterized by a fast reaction rate followed by a much slower reaction rate before equilibrium was achieved. In a system where the gas/solid contact times are characterized be seconds, rather than minutes or hours, only fast reactions can be utilized as part of the working capacity. A fast reaction can reduce the overall size and capital cost of the equipment, but it also can increase the challenge related to controlling the temperature. If most of the reaction occurs at one location, the heat of reaction must be removed at that location. 
Although the $1 \mathrm{~kW}$ pilot was designed to operate continuously, it was flexible enough to be operated in batch mode. There were two different ways to operate in batch mode. The first method was to halt sorbent circulation, which led to only the sorbent in the regenerator being regenerated, approximately one half of the sorbent inventory. Similarly, the system could be operated in batch mode by circulating sorbent using air instead of flue gas in the riser. The second method of batch regeneration results in regeneration of the entire sorbent inventory. During the initial operation of the system the first method of batch regeneration was utilized to determine whether the sorbent had been permanently degraded (i.e. it would not regenerate). In addition, if the heat input into the system was sufficient and fairly uniform, the time required for sorbent regeneration should reflect the lab-scale results (i.e. less than 30 minutes). After heating and fluidizing the sorbent in batch mode for over four hours, $\mathrm{CO}_{2}$ release was still measurable, suggesting that the temperature was not the only important condition to instigate regeneration. Even though the sorbent was not fully regenerated, it was clear that improved regeneration had been achieved during batch regeneration compared to continuous operation. The outlet concentration and $\mathrm{CO}_{2}$ removal levels after the batch regeneration are provided in Figure 45 .

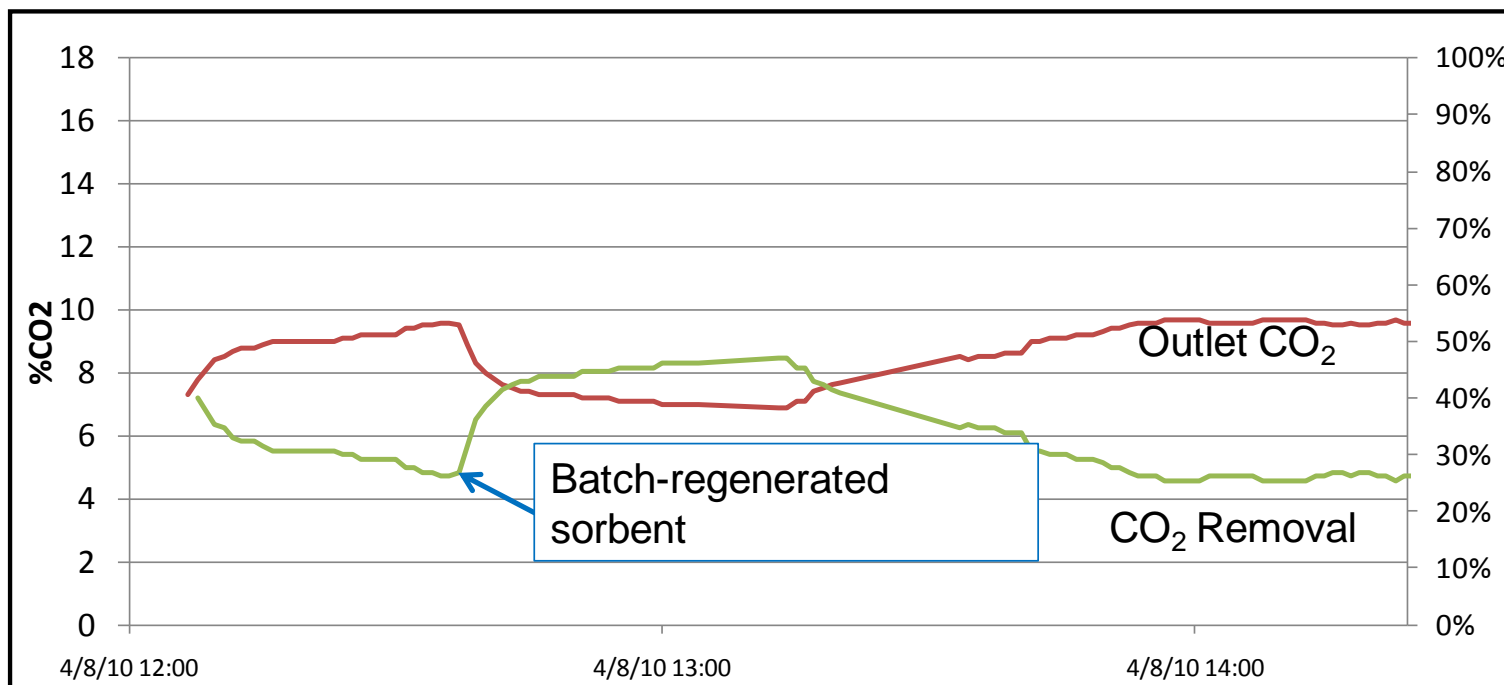

Figure 45: Outlet $\mathrm{CO}_{2}$ and $\mathrm{CO}_{2}$ Removal after Batch Regeneration

In Figure 45, testing began at approximately 12:10 when sorbent was introduced into the riser from the cooler section; material in the cooler had not been included in the batch regenerated material. Initially, the $\mathrm{CO}_{2}$ removal level began decreasing, which could be expected from partially spent material. At approximately 12:40 a significant increase in the $\mathrm{CO}_{2}$ capture level was observed. This was attributed to the introduction of the sorbent that had been regenerated in batch mode. Since the regenerator contained approximately $50 \%$ of the sorbent inventory (40 lbs out of $80 \mathrm{lbs}$ ), at a sorbent circulation rate of $40 \mathrm{lb} / \mathrm{hr}$, the higher $\mathrm{CO}_{2}$ removal levels were expected to continue for one hour, the estimated time required to feed all material included in batch regeneration into the riser. However, after 30 to 40 minutes a significant decrease in the $\mathrm{CO}_{2}$ removal was observed, suggesting that some regenerated material was being retained in the regenerator and some spent material was short circuiting through the regenerator. 
To resolve the presumed sorbent flow issue through the regenerator, the team decided to fabricate and operate a cold-flow model of the regenerator at the ADA offices in Littleton, Colorado. New fluidization nozzles were added to the regenerator to promote better fluidization gas distribution and then the team resumed $1 \mathrm{~kW}$ pilot testing of sorbent $\mathrm{R}$. Based on the amount of time required for the $\mathrm{CO}_{2}$ removal level to decrease, it was concluded that the modifications to the regenerator had been successful and the sorbent was moving through the regenerator in a much more uniform manner. However, as is shown in

Figure 46, the $\mathrm{CO}_{2}$ removal could still not be maintained at the desired level of $\geq 90 \%$. The lower removal levels can be attributed to the design of the $1 \mathrm{~kW}$ pilot (see discussion surrounding Figure 41).

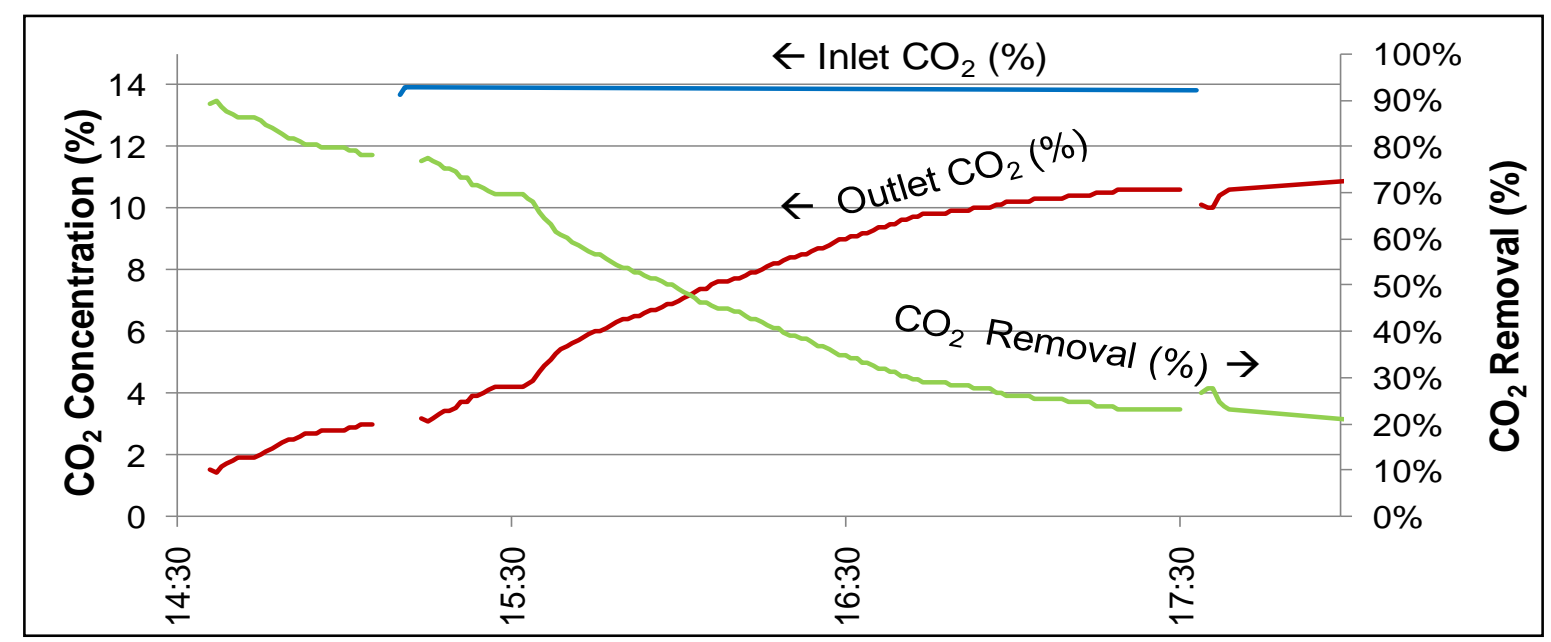

Figure 46: $\mathrm{CO}_{2}$ Concentrations and Removal during Continuous $1 \mathrm{~kW}$ Testing of Sorbent $\mathrm{R}$

In addition to measuring the overall $\mathrm{CO}_{2}$ removal the riser was fabricated with several ports that allowed sample gas to be collected from a number of different locations. The $\mathrm{CO}_{2}$ concentration at the system inlet, ICFB outlet, and three locations along the riser are provided in Figure 47. Note that for sorbent $\mathrm{R} 50 \%$ of the total $\mathrm{CO}_{2}$ removal occurs in the first three feet of the riser. 


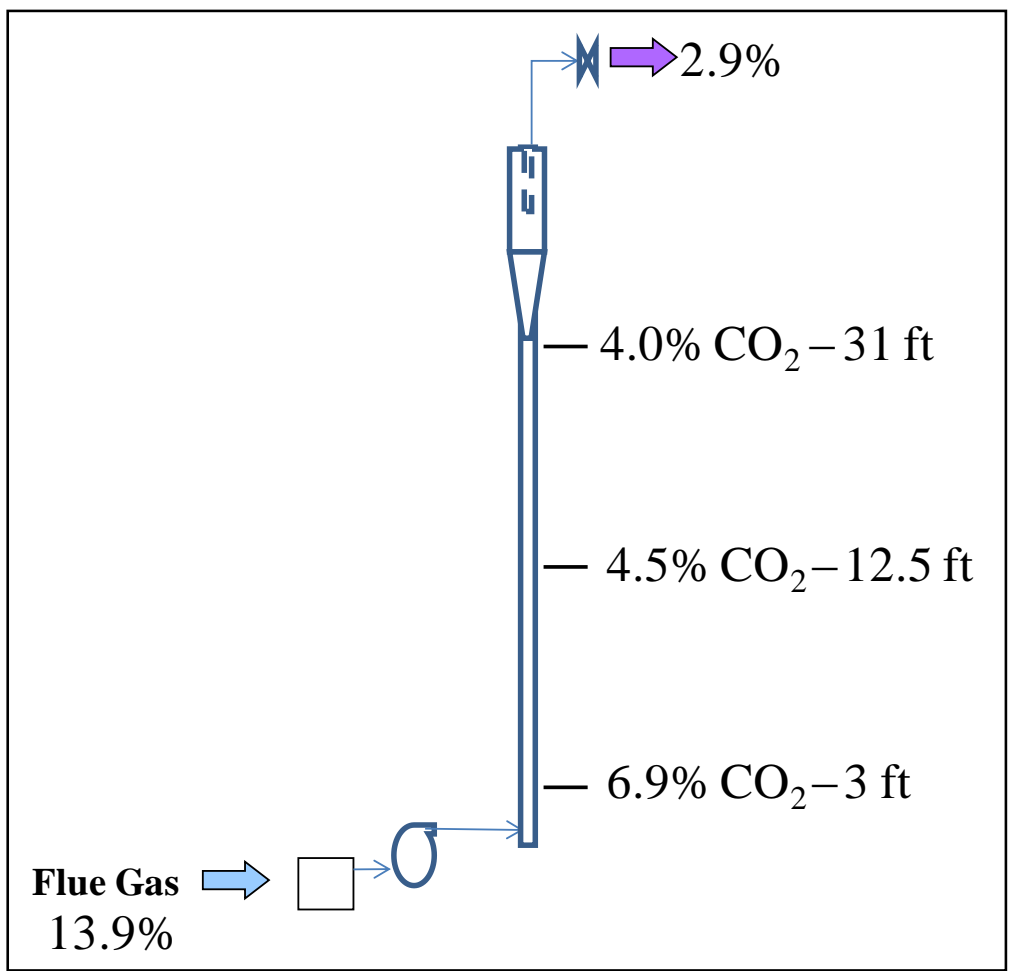

\section{Figure 47: $\mathrm{CO}_{2}$ Concentrations at Different Locations in the Riser}

To ensure that the failure to maintain $90 \% \mathrm{CO}_{2}$ removal in continuous mode testing was not caused by sorbent degradation, the system was operated in batch mode. To operate in batch mode, the flue gas in the riser (adsorption section) was replaced with air, while all other operating parameters, except occasionally the sorbent circulation rate, remained unchanged from the continuous operating conditions. An example of the $\mathrm{CO}_{2}$ concentration and removal during one batch adsorption step is shown in Figure 48. 


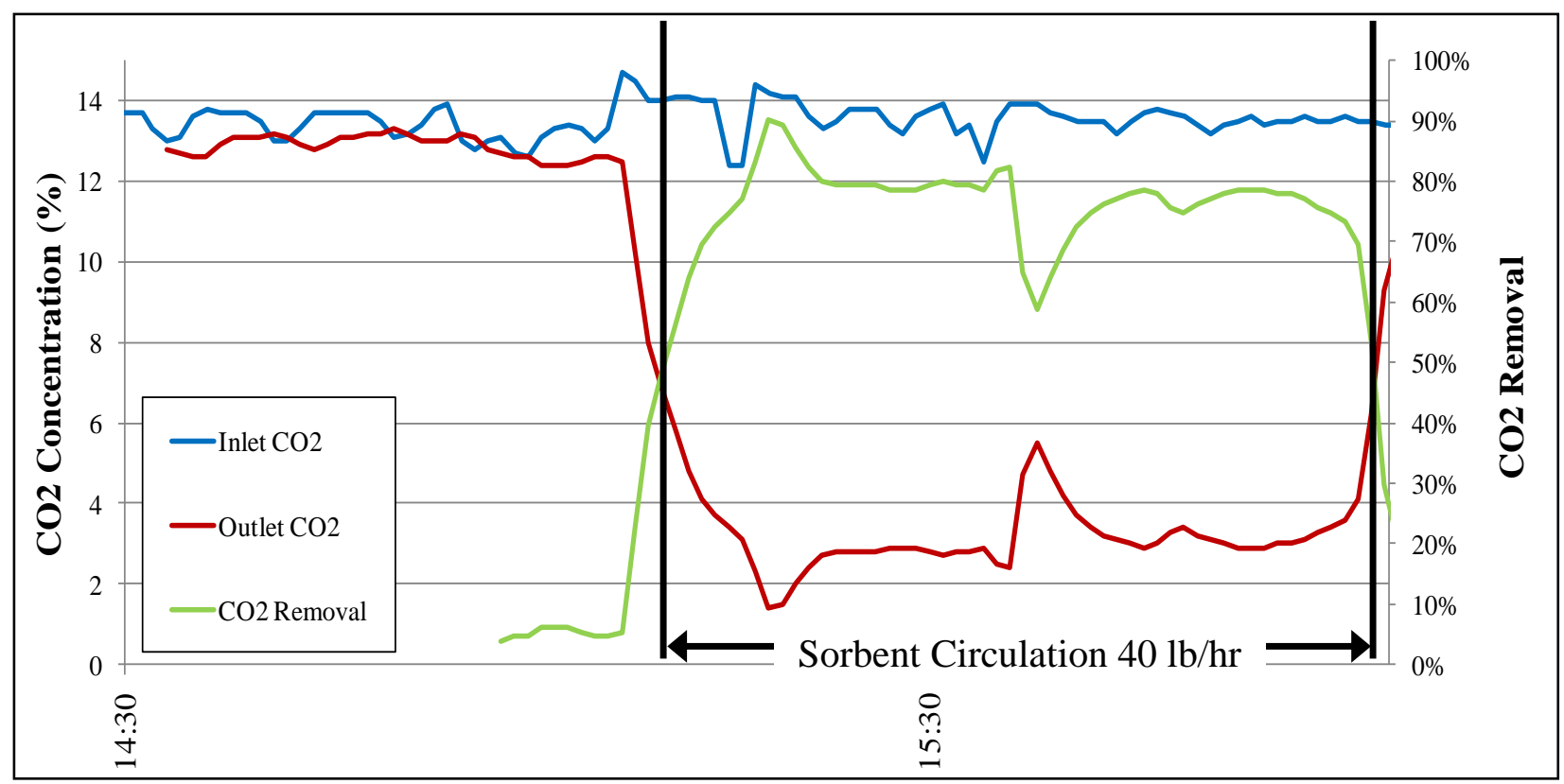

Figure 48: $\mathrm{CO}_{2}$ Concentrations and Removal during Batch $1 \mathrm{~kW}$ Testing of Sorbent $\mathrm{R}$

Ten adsorption/regeneration cycles were completed in batch mode using sorbent $\mathrm{R}$. The $\mathrm{CO}_{2}$ removal levels during these ten cycles are shown in Figure 49. Note that several conditions were varied during the different cycles, such as the time allowed for regeneration and the sorbent circulation rate during regeneration, so the difference in the $\mathrm{CO}_{2}$ removal levels can mostly be attributed to such factors.

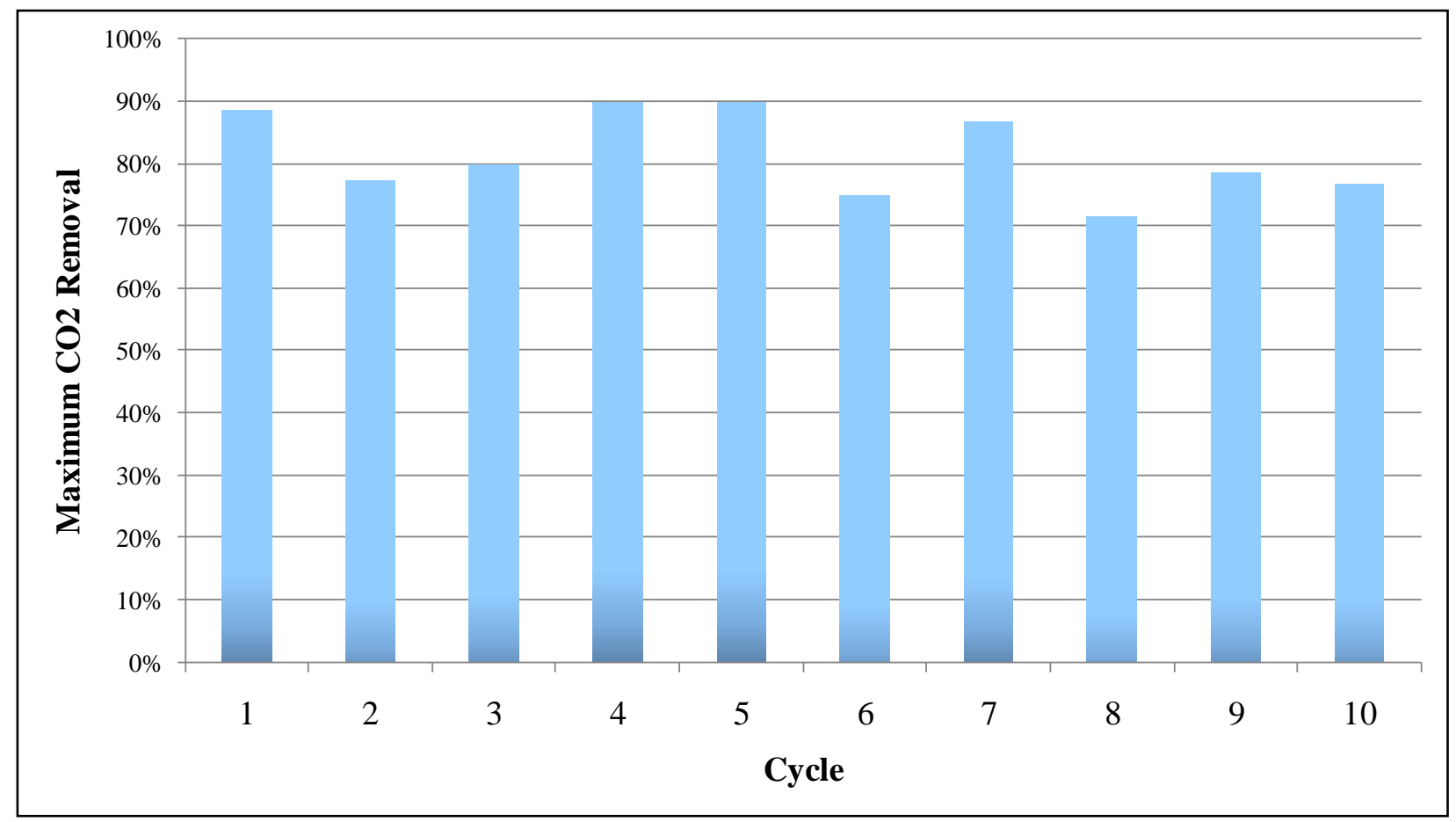

Figure 49: $\mathrm{CO}_{2}$ Removal Levels during Batch Operation of Sorbent $\mathrm{R}$ 
It was determined that the sorbent could be fully regenerated in batch mode; hence the $1 \mathrm{~kW}$ pilot system was operating as designed, but this system due to the means of gas/solids contacting was unable to achieve high $\mathrm{CO}_{2}$ removal levels (see discussion surrounding Figure 41 for additional details).

\section{$1 \mathrm{~kW}$ Pilot Testing - Sherco}

Xcel Energy's Sherburne Generating Station (Sherco) was the second field site at which the $1 \mathrm{~kW}$ pilot was operated. Sorbents for $1 \mathrm{~kW}$ testing at Sherco were down-selected from more than 140 screened by ADA on simulated flue gas in the laboratory (see text related to subtask 2.1.2). A comparison of the theoretical regeneration energy based on laboratory-scale tests for the four sorbents selected for testing at Sherco to that of aqueous MEA (represented by the red dashed line $)^{3}$, is presented in Figure 50 .

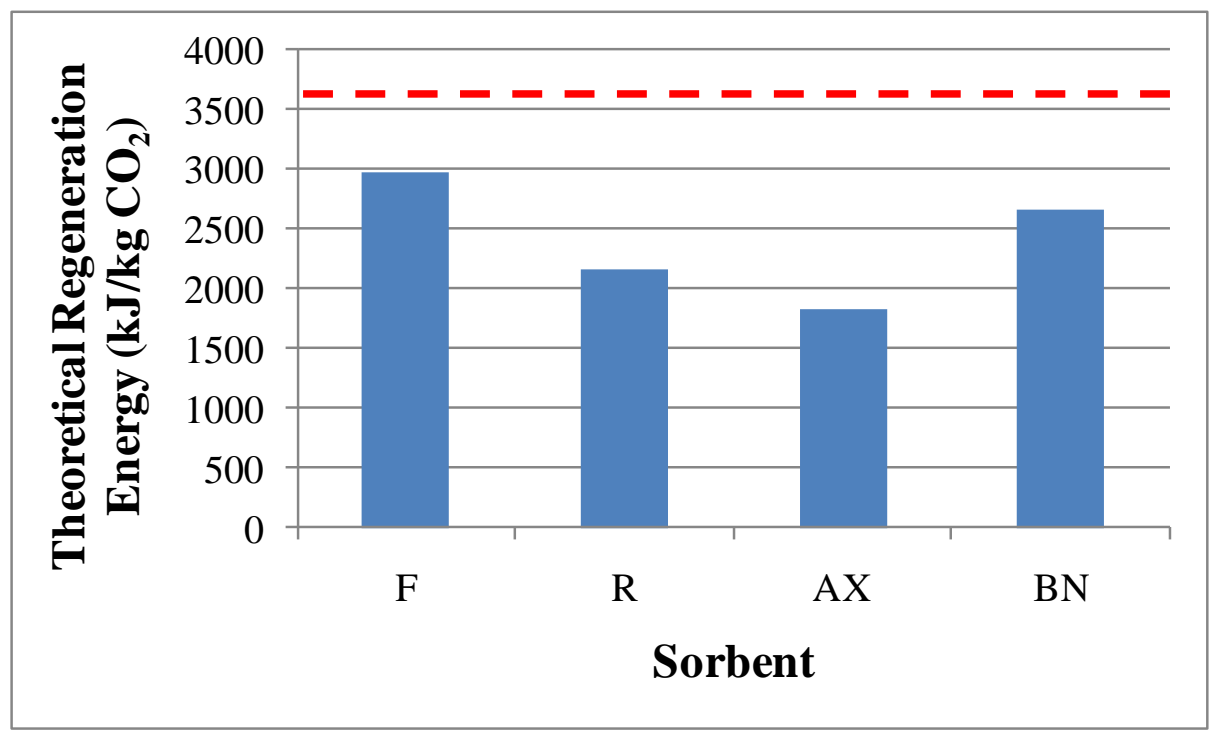

Figure 50: Summary of Sorbent Screening Results

In addition to the theoretical regeneration energy the cyclic stability of the sorbent was also considered as a key sorbent selection criteria. Sorbents F, R, AX, and BN all exhibited superior cyclic stability when evaluated for up to 260 adsorption/regeneration cycles in the laboratory. The final selection criterion was that the materials could be produced in greater than $225 \mathrm{~kg}$ (500 lb) quantities. Several potentially promising sorbents were not tested at the $1 \mathrm{~kW}$ scale because they could not be produced in the appropriate quantities due to toxic or exotic raw materials. The four supported amine sorbents selected for evaluation at Sherco are discussed in the following subsections.

Sorbent $\mathrm{R}$ was a supported amine sorbent, originally invented by researchers at NETL. During the ten batch mode adsorption cycles measured during tests at Martin Lake $90 \% \mathrm{CO}_{2}$ removal could not be maintained when operating the $1 \mathrm{~kW}$ pilot continuously with sorbent R; however, over $90 \% \mathrm{CO}_{2}$ removal was possible when the system was operated in batch mode. Sorbent $\mathrm{AX}$, which was similar to sorbent $\mathrm{R}$ except the substrate was a different porous silica, was operated in batch mode at Sherco. The maximum $\mathrm{CO}_{2}$ removal demonstrated by the two sorbents is provided in 
Figure 51. Although the removal observed in cycle 5 for sorbent AX was significantly lower than the other cycles, it is believed that this was caused by equipment issues due to extremely low temperatures, rather than a decrease in sorbent performance.

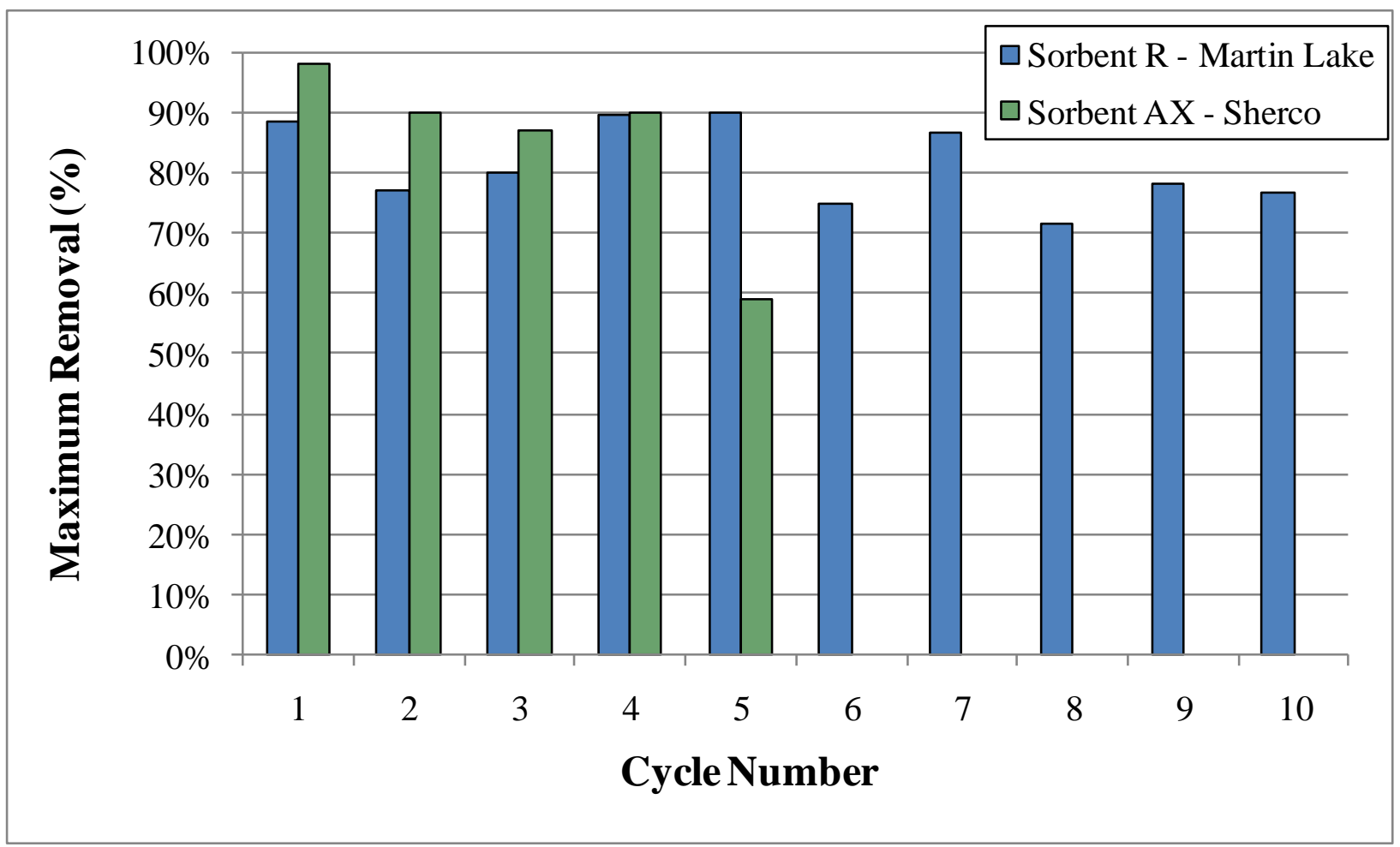

\section{Figure 51: Maximum $\mathrm{CO}_{2}$ Removal for Sorbent $\mathrm{R}$ at Martin Lake and Sorbent $\mathrm{AX}$ at Sherco}

When operated in batch mode using sorbent R or AX at Martin Lake or Sherco, respectively, there was little difference in the performance of the system or the sorbents. Note that the different removal levels shown in Figure 51 can be attributed to changing conditions, such as the time allowed for regeneration. Note that because the test conditions were not consistent for the different batch cycles, changes in $\mathrm{CO}_{2}$ removal are not necessarily related to changes in the sorbent performance.

During testing at Sherco, the test team changed the testing protocol. The $1 \mathrm{~kW}$ pilot was used to carry out steady state separation of $\mathrm{CO}_{2}$ from the flue gas and compare the different $\mathrm{CO}_{2}$ removal levels for different sorbents. In some instances the $1 \mathrm{~kW}$ pilot was also operated in batch mode (for sorbent $\mathrm{AX}$ ) to demonstrate that $90 \% \mathrm{CO}_{2}$ capture could be achieved. Following testing in the $1 \mathrm{kWe}$ pilot, samples of the the four supported amine sorbents were further tested on a slipstream of Sherco flue gas using the laboratory-scale fixed bed system to determine cyclic stability in the flue gas.

At Sherco Sorbent R was evaluated using the $1 \mathrm{kWe}$ system during March 2011 for several cycles during a continuous test (i.e. not operated in batch mode). The $\mathrm{CO}_{2}$ concentration at the $1 \mathrm{kWe}$ pilot inlet, outlet, and regenerator as well as the $\mathrm{CO}_{2}$ removal measured at Sherco are provided in Figure 52. 


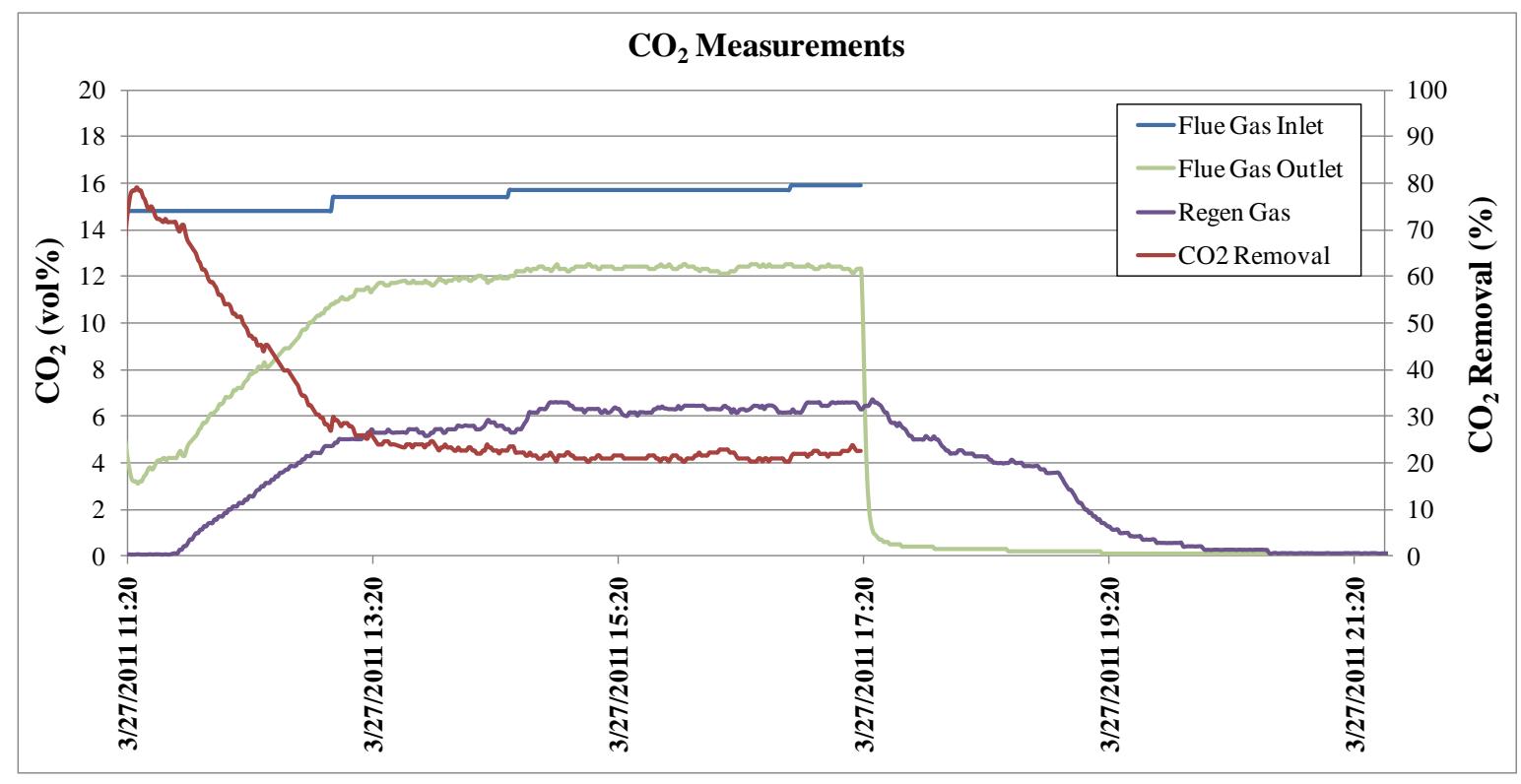

Figure 52: 1 kW Pilot Evaluation of Sorbent $R$ at Sherco

As was observed consistently at Martin Lake, the $\mathrm{CO}_{2}$ removal was initially high ( $~ 80 \%$ as sorbent circulation was begun), but decreased to approximately $20 \%$ removal at steady state. The lack of continuous removal was due primarily to the combination of a co-current adsorption system with a fluidized bed for regeneration, a combination which did not provide an adequate driving force for regeneration (see text surrounding Figure 41 for additional details). Sorbent $\mathrm{R}$ consisted of a polymeric amine coated on a silica substrate. It is believed that the $50 \%$ amine loaded resulted in mass diffusion limitations related to the $\mathrm{CO}_{2}$ uptake rate and further reduce the $\mathrm{CO}_{2}$ loading achieved during the adsorption step.

Sorbent $\mathrm{F}$ was also a supported amine, but differed significantly from sorbents $\mathrm{R}$ and AX. Rather than silica coated by an amine, an aminosilane compound was actually grafted to the surface of a mesoporous silica during a series of pore expansion steps. In theory, this sorbent was particularly promising because the amine groups were covalently bonded to the surface of the substrate, which was expected to lead to 1) increased stability and 2) faster kinetics because the pores were more easily accessible by the gaseous $\mathrm{CO}_{2}$. Although the total $\mathrm{CO}_{2}$ capacity of sorbent AX measured in the laboratory was greater than that for sorbent $\mathrm{F}$, it was believed that the working capacity of sorbent $\mathrm{F}$ could be superior in the $1 \mathrm{~kW}$ pilot because the time required for the reaction to occur was significantly lower. One major concern with sorbent $F$ was that the smaller particle size (mean particle diameter of $\sim 10 \mu \mathrm{m}$ ). Although the transport reactor and fluidized bed used in the $1 \mathrm{~kW}$ pilot were designed to operate with different materials, this particle size was outside the system specifications. Still, the project team decided to attempt to test this sorbent in the hopes that positive results would outweigh any testing difficulties. The maximum regeneration temperature for sorbent $\mathrm{F}$ was $120^{\circ} \mathrm{C}\left(250^{\circ} \mathrm{F}\right)$. ADA worked with Gelest, Inc., a specialty chemical production company, to produce sorbent $\mathrm{F}$ in the bench-scale quantity of $250 \mathrm{~kg}$. Similar to the material that has been produced at the laboratory scale previously, the average particle diameter for sorbent $\mathrm{F}$ was approximately $10 \mu \mathrm{m}$, which can be considered a fine powder. 
Prior to testing sorbent $\mathrm{F}$ at Sherco, some of the potential issues with sorbent $\mathrm{F}$ were recognized. ADA operated a physical model of the regenerator at the ADA corporate office in Littleton, $\mathrm{CO}$ to evaluate whether sorbent $\mathrm{F}$ could be circulated. During this short cold flow model test, it was demonstrated that sorbent $\mathrm{F}$ could move as designed through the mock up regenerator. The only significant obstacle was that particle carry-over (i.e. entrainment in the fluidization gas) was visually higher for the smaller particle size than previously witnessed for sorbent R or AX. Although the particle size was non-ideal for operation in the fluidized bed, ADA attempted to circulate sorbent $\mathrm{F}$ through the $1 \mathrm{~kW}$ pilot by reducing the fluidization gas. However, the sorbent was immediately entrained in the fluidization gas and carried out the top of the regenerator, often plugging the line downstream of the regenerator. After conferring with the research team at Southern Company who helped develop the $1 \mathrm{~kW}$ pilot, it was decided to mix sorbent $\mathrm{F}$ with inert sand with the same particle size as sorbents $\mathrm{R}, \mathrm{AX}$, and $\mathrm{BN}$. The basis of this decision was that the circulation of the sand could be easily accomplished. If the sand mixed well with the sorbent then it was hoped that it would entrain the sorbent and both the sorbent and the inert material would move through the $1 \mathrm{~kW}$ pilot together. Unfortunately, the sand and the sorbent particle size and density differences were too large for a homogenous mixture to be maintained. Even with the addition of sand sorbent F could not be circulated through the system.

The actual $1 \mathrm{kWe}$ pilot system operates with a greater gas velocity through the regenerator exhaust. This greater velocity likely resulted in increased sorbent entrainment in the actual system. Due to the high level of sorbent carryover from the regenerator to the attrition fines baghouse during operation at Sherco, the baghouse became plugged rapidly. The pluggage could be overcome by a bag cleaning cycle, but the due to the small size of the system, the attrition fines bag cleaning pulse resulted in a large impact on flow patterns and system pressures. For example, the backpressure caused by frequent bag cleaning reversed the regenerator fluidizing flows up through the transfer leg, preventing sorbent flow down the transfer leg from the ICFB to the regenerator.

Sorbent BN consisted of a primary amine covalently bonded to a cross linked polystyrene support. Sorbent BN was originally produced in a beaded form. For it to be tested in the $1 \mathrm{~kW}$ pilot, it was ground to a particle size of approximately $80-120 \mu \mathrm{m}$, similar to sorbents $\mathrm{R}$ and AX. The maximum regeneration temperature for sorbent $\mathrm{BN}$ was $120^{\circ} \mathrm{C}\left(250^{\circ} \mathrm{F}\right)$. Sorbent $\mathrm{BN}$ was selected for inclusion in the Sherco field tests based on previous laboratory results when after exhibiting 1) a greater than average ( $>4 \mathrm{wt} \%$ ) working $\mathrm{CO}_{2}$ capacity when regenerated in pure $\mathrm{CO}_{2}$ at $120^{\circ} \mathrm{C}$, 2) superior cyclic stability, and 3) demonstrated faster kinetics compared to many other. Sorbent BN was evaluated at Sherco using the $1 \mathrm{~kW}$ pilot on 03/14/11. The $\mathrm{CO}_{2}$ inlet, outlet, concentration downstream of the regenerator, and the removal level are provided in Figure 53. 


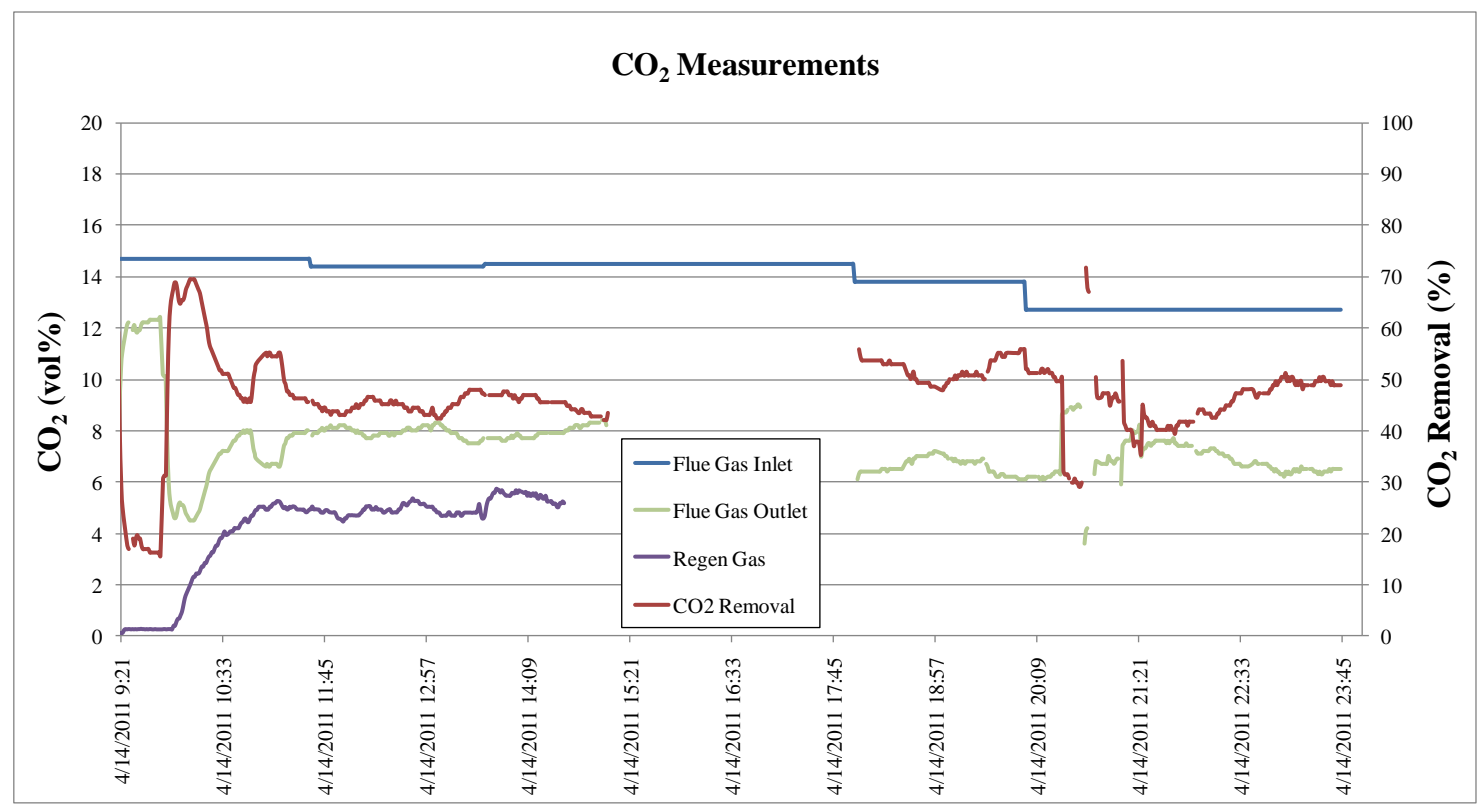

Figure 53: 1 kW Pilot Evaluation of Sorbent BN at Sherco

The $1 \mathrm{~kW}$ pilot testing of sorbent BN can be divided into two separate phases. Prior to 15:00 the system was operating under the same conditions as had been used previously for sorbent $\mathrm{R}$ and sorbent AX (sorbent circulation rate of $40 \mathrm{lb} / \mathrm{hr}$ and gas flow rate of $\sim 4.5-5.3 \mathrm{acfm}$ ). These conditions were maintained and $\mathrm{CO}_{2}$ removal was consistently above $40 \%$ and often as high as $45 \%$. Under these conditions maintaining $90 \%+\mathrm{CO}_{2}$ capture would require the sorbent to maintain a working $\mathrm{CO}_{2}$ capacity of approximately $11 \mathrm{wt} \%$, which is more than double the working capacity of aqueous MEA systems.

At approximately 15:00 the flue gas sample was lost and the pump had to be repaired. After 18:00 the sorbent circulation was resumed. However, the flue gas flow rate was decreased in the hopes of increasing the $\mathrm{CO}_{2}$ removal level. At 19:30 the flue gas circulation rate was reduced to $4.1 \mathrm{acfm}$. Then at 22:25 the sorbent circulation rate was increased to $45 \mathrm{lb} / \mathrm{hr}$. By changing the gas and sorbent flow rates the $\mathrm{CO}_{2}$ removal was increased to over $50 \%$. With a sorbent circulation rate of $45 \mathrm{lb} / \mathrm{hr}$ and a flue gas flow rate of $4.1 \mathrm{acfm}$ the sorbent working capacity would have to be approximately $8 \mathrm{wt} \%$ to achieve $90 \% \mathrm{CO}_{2}$ capture, which was not achieved. Although capacities of $8 \mathrm{wt} \%$ were demonstrated in the laboratory for sorbent BN when regenerating in an atmosphere of pure $\mathrm{N}_{2}$, this working capacity could not be achieved when operating with a co-current flue gas/sorbent contactor. However, the $1 \mathrm{~kW}$ pilot was used to demonstrate that using a different sorbent (i.e. BN compared to $\mathrm{AX}$ and $\mathrm{R}$ ) can significantly increase the $\mathrm{CO}_{2}$ capture levels.

\section{Task 2.4. Sorbent Performance Report}

The Sorbent Performance Report was completed and submitted to the DOE and other project team members on May 31, 2011.

\section{Task 3. Full-Scale Equipment Assessment and Design}

Assessing the viability of solids-based $\mathrm{CO}_{2}$ capture technology must include an evaluation of potential full-scale process equipment integrated into an operating plant. The activities included 
under Task 3 were dedicated to the development and assessment of a commercial-scale $\mathrm{CO}_{2}$ capture process concept. Key sorbent related costs are provided in Table 7.

Table 7: Key Solid-Sorbent Related Costs

\begin{tabular}{|c|c|c|c|}
\hline Costs & $\begin{array}{l}\text { Proposal } \\
\text { Estimates }\end{array}$ & Proposed Goal & $\begin{array}{l}\text { Calculated or } \\
\text { Measured } \\
\text { During } \\
\text { Project }\end{array}$ \\
\hline $\begin{array}{l}\text { Sorbent Cost for Large } \\
\text { Quantities } \\
\text { (\$/kg sorbent) }\end{array}$ & $5^{*}-15^{*}$ & $2-10$ & $5.0^{* * * * * *}$ \\
\hline $\begin{array}{l}\text { Sorbent Replacement Cost } \\
\text { (\$/ton } \mathrm{CO}_{2} \text { removed) }\end{array}$ & $2^{* * *}-13^{*}$ & $\leq 2$ & 4.4 \\
\hline $\begin{array}{l}\text { Removal of Moisture from } \\
\text { Purified } \mathrm{CO}_{2} \text { Stream }\left(\$ / \text { ton } \mathrm{CO}_{2}\right. \\
\text { removed) }\end{array}$ & $\begin{array}{l}\text { Minimize or } \\
\text { eliminate }\end{array}$ & TBD & $\begin{array}{c}\text { Sorbent } \\
\text { dependent }\end{array}$ \\
\hline $\begin{array}{l}\text { Equipment Capital Costs } \\
\text { ( } \varnothing \text { /MWh) }\end{array}$ & $3.9^{* *}$ & $<4$ & 2.45 \\
\hline $\begin{array}{l}\text { Annual Operating Cost } \\
\left(\$ / \text { ton } \mathrm{CO}_{2} \text { removed }\right)\end{array}$ & $10^{* * *}-90^{*}$ & $\begin{array}{c}\leq 35 \% \text { increase } \\
\text { in } \mathrm{COE}^{* * * *} *\end{array}$ & 45 \\
\hline \multicolumn{4}{|l|}{$\begin{array}{l}* 26 \\
* * 15\end{array}$} \\
\hline \multicolumn{4}{|l|}{${ }^{* * *}$ Unpublished estimates from ARI } \\
\hline
\end{tabular}

\section{Task 3.1. Technology Survey to Identify Equipment Options}

The complete results of the technology survey were discussed in Topical Report 1, 2, and 3 (combined into a single document). ${ }^{28}$ Only the highlights and key conclusions are included in the following sections. Stantec Consulting Ltd worked with ADA to complete an extensive technology survey of equipment and process options that could have applicability for sorbent based post-combustion $\mathrm{CO}_{2}$ capture. The first step of this process was identifying the unit operations that would be required. A basic process flow diagram relating the main components of $\mathrm{CO}_{2}$ capture into a power plant is provided in Figure 54. 


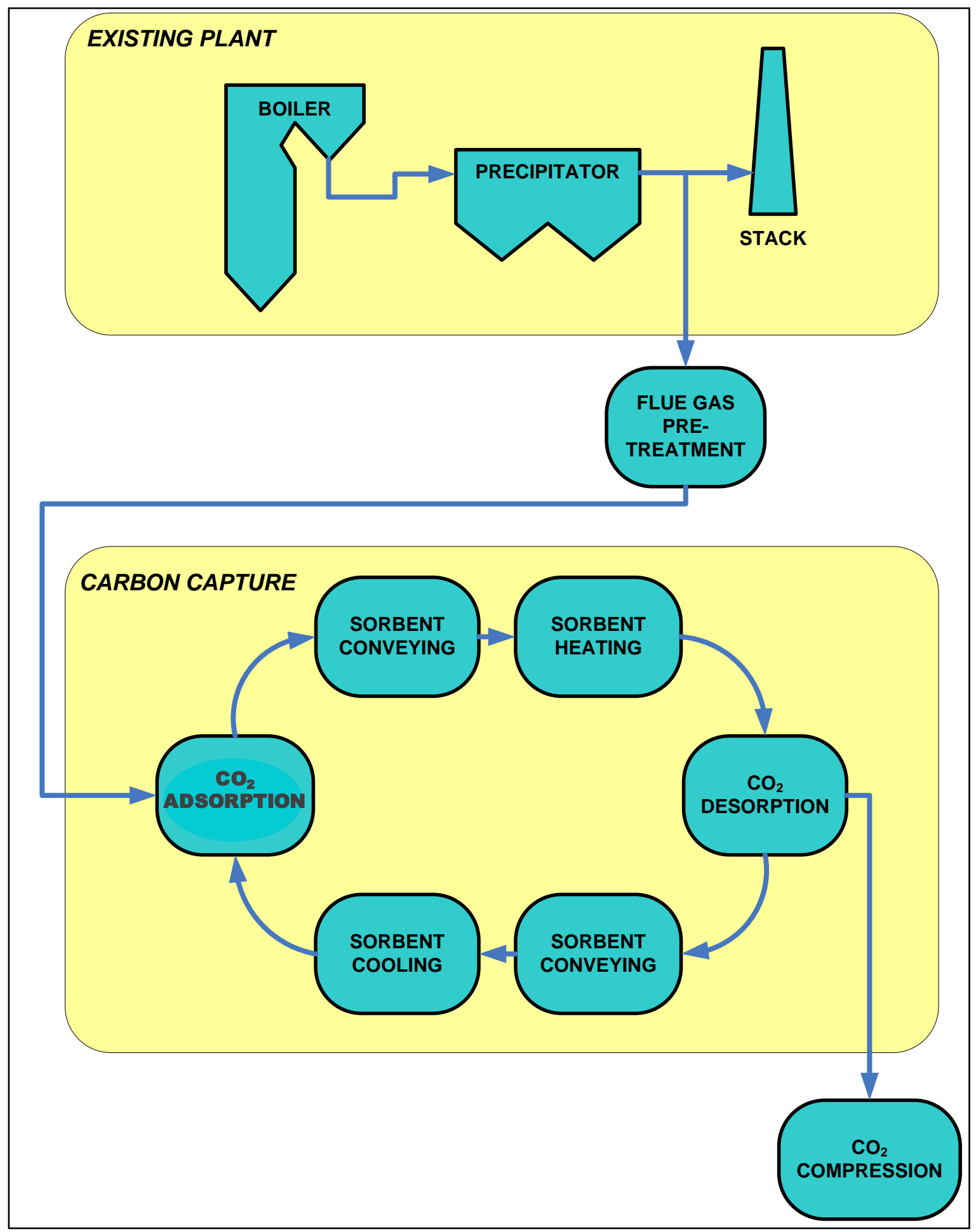

Figure 54: Solid-Based $\mathrm{CO}_{2}$ Capture Process Flow Diagram

As the preliminary process flow diagram shown in Figure 54 was developed it was determined that the necessary technologies would be divided into the following categories (note that the commercial availability of both pretreatment and compression options are fairly advanced, and are not discussed in detail): 
- Adsorption

- Heating and cooling, or heat transfer

- Conveying

- Desorption

With the four main unit operations related to $\mathrm{CO}_{2}$ capture in mind, a technology review was conducted. The review included collecting information from a wide variety of sources, including published papers, advertisements, web searches, and vendor interviews. A technology survey sheet was generated for each technology; they are all provided in the appendix of Topical Report 4. ${ }^{29}$ For each technology, key typical information collected (at least qualitatively) during the technology survey included:

- Brief process description, including configuration of gas solids contact and regeneration method

- Simple flow sheet

- Space requirement

- Experience record (number of units, application type, vendors, reliability, etc.)

- Date commercially available

- Chemicals used (physical properties in comparison with proposed $\mathrm{CO}_{2}$ sorbents)

- Retention time

- Pressure drop

- Materials of construction

- Operating temperature range

- Attrition of sorbent

- Power requirements

- Water requirements

- Capital cost $\$ / \mathrm{kW}$ from published costs or quotes

- Operation cost $\$ / \mathrm{MWh}$

- Compatibility with existing power plant equipment.

During the technology survey, information was gathered on each technology related to the level of development, current vendors, and operation. As different technologies were evaluated they were grouped according to which unit operation they would be most applicable. In several cases technologies were appropriate for multiple operations. For example, a heated screw conveyor could be used for heat transfer, conveying and desorption. The following sections discuss the results of the technology survey. The equipment and processes are described according to the $\mathrm{CO}_{2}$ capture step they are most applicable (i.e. adsorption, heat transfer, conveying, and desorption or regeneration). In several cases, commercial examples of a particular technology are provided.

\section{Adsorption}

Technologies considered viable for adsorption must include an effective means for gas/solids contacting. There are many different commercial options available today that include a contacting scheme that could be applicable to solid-based $\mathrm{CO}_{2}$ capture. A full description of 
each option is provided in Topical Report 1,2 , and $3 .^{28}$ Potential processes for adsorption that could be used for effective gas/solids contacting reviewed in the technology survey included:

- Fixed Bed

- Rotating Bed

- Moving Bed

- Dry Carbonate $\mathrm{CO}_{2}$ Capture Process (RTI bench-scale)

- J-Power ReACT ${ }^{\mathrm{TM}}$ - Regenerative Activated Coke Technology (commercially available and performance guaranteed)

- Fluid Bed

- Gas Suspension Adsorber

○ Semi-dry Flue Gas Purification

- Entrained Flow

- Alstom Best Available Recovery Technology (ABART ${ }^{\mathrm{TM}}$ )

- Dry Flue Gas Scrubbing (several designs)

○ Dry Sorbent Injection

- Alstom Novel Integrated Desulphurization (NID ${ }^{\mathrm{TM}}$ ) System

- Spray Dryer Adsorber (SDA)

\section{Heat Transfer}

Effective heat transfer will be extremely important in a temperature swing system. In addition to the temperature swing required for regeneration, there could be several opportunities to utilize and recover heat from the system, but the appropriate heat exchangers must be selected. If the $\mathrm{CO}_{2}$ capture system is optimally integrated with the power plant, efficient heat exchangers could lead to a reduction in the $\mathrm{CO}_{2}$ capture operating costs.

There are many different types of heat exchangers that could be used to transfer heat between the sorbents and an appropriate working fluid (flue gas, condensing steam, oil, etc.). Heat exchangers are not as easily classified as reactor types. Several heat exchanger options that may have applicability for $\mathrm{CO}_{2}$ capture were described in the technology survey, including:

- Cooling or Heating Solids

$\circ$ Dry Carbonate $\mathrm{CO}_{2}$ Process - Jacketed heat exchangers

- Solex Moving Bed Heat Exchanger

○ Rotary Kiln

- Cooling or Heating Flue Gas

$\circ$ Condensing Heat Exchanger (CHX)

$\circ$ Pipe Heat Exchanger (Bry-Air)

\section{Desorption}

There are cases of dry, regenerable sorbents used in the power industry. For example, as described previously the ReACT process is an example of a commercial process that utilizes a moving bed for regeneration. The Dry Carbonate $\mathrm{CO}_{2}$ Capture Process is not commercially available, but provides another potential conceptual design for the regeneration step (i.e. heated screw conveyor). Several of the technologies and processes described previously in other sections (e.g. heated screw conveyor, rotary kiln, etc) were also considered options for the regeneration step because effective heat transfer is one of the most important aspects of 
regeneration. Because $\mathrm{CO}_{2}$ desorption is coupled with heat transfer, potential configurations for desorption are not discussed separately.

\section{Conveying}

Unless a fixed bed or a rotating bed system is used for both adsorption and regeneration some form of material conveying will be required. Ideally, conveying will be integrated into adsorption, regeneration, or sorbent cooling to maximize efficiency. There are several different options for materials conveying. Those highlighted in the technology survey included:

- Bucket Conveyors

- Screw Conveyors

- Pneumatic Conveying

\section{Task 3.2. Technology Assessment}

A weighted scoring system was used to objectively analyze and screen the technologies. The process detailed in "The New Rational Manager" by Kepner and Tregoe was utilized in this analysis. ${ }^{27}$ A list of criteria was compiled, and each was given a weight according to the perceived importance of each item. When a technology was screened, it was given a score from 1 to 10 against each criterion, and the weighted score was the product of the weight and the score. A summation of the weighted scores provided a total score, which was then compared to all the other technologies. This method allowed each technology to be compared against others, and higher scoring technologies were then selected for further investigation. In many cases technologies were applicable to more than one of the four main categories (adsorption, heat transfer, convey, and desorption). In such cases, the technology was rated separately applicability in each category. An example of the screening criteria for adsorption is provided in Table 8. 
Table 8: Adsorption Screening Criteria

\begin{tabular}{|c|c|c|c|c|}
\hline \multicolumn{2}{|c|}{$\begin{array}{l}\text { Criteria } \\
\text { Number }\end{array}$} & Criteria & Weight & Description of Criteria \\
\hline \multicolumn{2}{|c|}{1.0} & Economic - $30 \%$ & & Analysis of System Economics \\
\hline & 1.1 & Capital Cost & 15 & Appraisal of apparent capital costs \\
\hline & 1.2 & Operating Cost & 15 & Appraisal of apparent operating costs \\
\hline & & SUB-TOTAL & 30 & \\
\hline \multicolumn{2}{|l|}{2.0} & Risk - $25 \%$ & & Analysis of Process Risk Items \\
\hline & 2.1 & Turndown & 1 & Ability to operate at reduced capacity \\
\hline & 2.2 & Availability / Reliability & 1 & Dependability of equipment \\
\hline & 2.3 & Erosion & 1 & Susceptibility to erosive wear \\
\hline & 2.4 & Corrosion & 1 & Susceptibility to corrosion \\
\hline & 2.5 & Plugging & 1 & Susceptibility to solids pluggage \\
\hline & 2.6 & Scaling & 1 & Susceptibility to scaling \\
\hline & 2.7 & Simplicity & 4 & Measure of system complexity \\
\hline & 2.8 & Modularization & 1 & $\begin{array}{l}\text { Ability to modularize equipment into parallel } \\
\text { operations }\end{array}$ \\
\hline & 2.9 & Technology Maturity & 1 & Measure of development of the equipment \\
\hline & 2.10 & Commercial Scale & 4 & Suitability of equipment for a $500 \mathrm{MW}$ sized unit \\
\hline & 2.11 & Construction Schedule & 0.5 & Any impacts to schedule due to long lead times \\
\hline & 2.12 & Retrofit Integration & 1 & Appraisal of difficulty of retrofit \\
\hline & 2.13 & Safety & 1 & Measure of any safety concerns \\
\hline & 2.14 & Attrition & 3 & Estimate of physical or chem. damage to solid sorbent \\
\hline & 2.15 & $\begin{array}{l}\text { Materials of } \\
\text { Construction }\end{array}$ & 0.5 & Analysis of typical system metallurgy \\
\hline & 2.16 & Maintenance & 3 & Estimate of maintenance requirements \\
\hline & & SUB-TOTAL & 25 & \\
\hline \multicolumn{2}{|l|}{3.0} & Performance $-35 \%$ & & Efficiency and Performance of System \\
\hline & 3.1 & Residence Time & 6 & Ability to provide or modify reaction residence time \\
\hline & 3.2 & $\Delta \mathrm{P}$ & 10 & Pressure drop of the system \\
\hline & 3.3 & Footprint & 6 & $\begin{array}{l}\text { Measure of how much plan area is required to arrange } \\
\text { equipment }\end{array}$ \\
\hline & 3.4 & Energy Use & 10 & Parasitic power consumption \\
\hline & 3.5 & Automation & 3 & Ability to automate system \\
\hline & & SUB-TOTAL & 35 & \\
\hline \multicolumn{2}{|l|}{4.0} & Environmental - $10 \%$ & & Analysis of Environmental Impacts of Equipment \\
\hline & 4.1 & CO-benefits & 2.5 & $\begin{array}{l}\text { Additional benefits provide for emissions control, or if } \\
\text { equipment can accomplish several steps of the process. }\end{array}$ \\
\hline & 4.2 & Waste Quantity & 2.5 & $\begin{array}{l}\text { Measure of any additional waste generated through use } \\
\text { of the equipment }\end{array}$ \\
\hline & 4.3 & Waste Containment & 2.5 & Ability of the system to contain any wastes \\
\hline & 4.4 & Fugitive Emissions & 2.5 & $\begin{array}{l}\text { Ability of the system to not produce any additional } \\
\text { emissions }\end{array}$ \\
\hline & & SUB-TOTAL & 10 & \\
\hline
\end{tabular}


For all steps in the $\mathrm{CO}_{2}$ capture process the major categories of the scoring sheets and their respective scoring weights were:

- Economic - 30\%: the economic rating was based primarily on capital and operating costs

- Risk - 25\%: the risk rating was based on different criteria for the different $\mathrm{CO}_{2}$ capture steps, but included considerations such as reliability, scaling, safety, attrition, retrofit integration, etc.

- Performance - 35\%: the performance rating was also based on different criteria for the different $\mathrm{CO}_{2}$ capture steps, but included concerns such as residence time, pressure drop, footprint, and automation

- Environmental - 10\%: the environmental rating included co-benefits (i.e. the ability to remove emissions other than $\mathrm{CO}_{2}$ ), waste quantity, waste containment, and fugitive emissions

After each technology was scored in all the listed areas, a final score was determined, which was used to compare the different technology options. The results of the technology screening are provided in Table 9. For the purposes of this review, the heat transfer technologies have been included in the desorption category. Also note that the highest possible score is 10.

Table 9: Technology Screening Results

\begin{tabular}{|lccc|}
\hline Technology & Adsorption & Desorption & Conveying \\
\hline Down Flow Reactor & 7.3 & & \\
Moving Bed & 5.6 & 5.8 & \\
Static Fixed Bed & 5.7 & & \\
Rotating Bed Reactor & 5.2 & & \\
Circulating Fluidized Bed & 7.2 & 5.5 & $\checkmark$ \\
Rotary Kiln & & 7.3 & $\checkmark$ \\
Heated Screw Conveyor & & 6.4 & $\checkmark$ \\
Bucket/Belt Conveyor & & & 4.3 \\
Pneumatic Conveyor & & & 4.1 \\
\hline
\end{tabular}

\section{Adsorption}

After scoring all select adsorption technologies, the two highest scoring technologies were the down flow reactor (used in the Dry Carbonate $\mathrm{CO}_{2}$ System) and the circulating fluidized bed (specifically a CFB characterized by entrained flow). The two technologies are very similar in that they both rely on a co-current flow pattern. The down flow reactor has not been manufactured at commercial scale and some assumptions were made for this assessment. However, both the down flow reactor and the circulating fluidized bed were considered options because the particle size of the solid sorbent has not been finalized. Should larger particles be 
suitable, then the down flow reactor may be preferable, as it uses simple gravity to separate the solids from the flue gas. If the particles are much smaller in size, then a circulating fluidized bed where the particles are entrained by the flue gas may be required, which would employ cyclones or fabric filters to separate the gas and solid particles. Since the two options are similar, the circulating fluidized bed, which is commercially available and thus has more readily available cost information, were used to conduct the preliminary $500 \mathrm{MW}$ conceptual design and cost analysis.

\section{Desorption/Heat Transfer}

Based on the scoring results provided in Table 9, the rotary kiln was selected as the model for the preliminary $500 \mathrm{MW}$ conceptual design. One of the reasons that this technology was selected was because it can be used for simultaneous heat transfer and conveying, which makes it an ideal option for a regenerator. Another design that was of technical merit was an indirect heat exchanger operating as a moving bed. At the time of the survey, the size of commercially available systems was limited, which would result in multiple units for a $500 \mathrm{MW}$ application which downgraded this option during the viability-phase assessment. However, it is expected that options beyond a rotary kiln will be considered during subsequent phases of the overall technology development plan for solid sorbents.

\section{Conveying}

It is expected that conveying the solid materials will be required to reduce the overall energy input for $\mathrm{CO}_{2}$ capture. If the sorbent is stationary during a temperature swing cycle, it is likely that the equipment as well as the sorbent will need to be heated to achieve the temperature swing. If this is the case, the advantage of using sorbents with a low specific heat has been diminished. If conveying is required, based on the technology scores a bucket conveyor was a superior choice over pneumatics. However, for the preliminary $500 \mathrm{MW}$ conceptual design the adsorption step includes entrained flow and the regenerator is a rotary kiln, both of which also include conveying. Therefore, no additional conveying was required. If additional conveying is required in the future, the technology scoring will be taken into consideration.

\section{Task 3.3. Develop Capital and Operating Costs}

High level initial operating cost estimates were addressed during the technology scoring as discussed previously. The details are discussed under Task 3.7. To calculate the cost of $\mathrm{CO}_{2}$ captured in the same manner as the MEA system as reported by the $\mathrm{DOE}^{3}$, the following equation was used:

$$
\mathrm{CO}_{2} \text { Captured Cost }=\frac{\text { Incremental LCOE }}{\mathrm{CO}_{2} \text { Captured }}
$$

Based on this calculation method, the $\mathrm{CO}_{2}$ Captured Cost for the Final Technology Selection was $\$ 45 /$ ton $\mathrm{CO}_{2}$ captured. As is discussed in the Task 3.7 section, this cost is an order of magnitude estimate. Further research and development are required to determine the costs based on a commercial process. In addition, integration with the power plant, which was outside the scope of this study, could lead to significant energy and cost savings. 


\section{Task 3.4. Identify and Assess Impacts}

Impacts on power plant operation were taken into consideration and are included in the Task 3.2 discussion. The most important considerations related to impacts on the power plant include 1) energy penalty due to auxiliary power and steam usage, 2) water usage, 3) pressure drop, and 4) increase $\mathrm{SO}_{2}$ removal requirements. For the process chosen in Task 3.6. Final Technology Selection, the pressure drop is low enough that blowers can be used to overcome it with relatively low operating cost. Thus, for this process the major impact on the power plant is the usage of steam to drive the sorbent regeneration process. Because of the formation of heat stable salts due to the reaction between $\mathrm{SO}_{2}$ and supported amine sorbents, it is possible that additional $\mathrm{SO}_{2}$ scrubbing will be required. It is expected that $\mathrm{SO}_{2}$ emissions from a power plant that includes amine based $\mathrm{CO}_{2}$ capture, whether solid or liquid based, will have extremely low, if not negligible, emissions of $\mathrm{SO}_{2}$.

\section{Task 3.5. Conduct Cursory Life-Cycle $\mathrm{CO}_{2}$ Emissions Estimate}

For any emissions control process, it is important to conduct a life cycle analysis study at every stage of the development process. A life cycle analysis for an emissions control technology consists of a cradle to grave assessment of the emissions and wastes produced due to implementation of the process. For post-combustion $\mathrm{CO}_{2}$ capture, it is important to identify the $\mathrm{CO}_{2}$ and other gaseous emissions and waste generated. As the technology development progresses, a life cycle analysis should become more detailed and thorough. Because this project was an early-stage viability assessment, the goal of the life-cycle analysis was not to quantify all emissions and waste generated, but to identify and qualitatively compare potential $\mathrm{CO}_{2}$ emission sources due to $\mathrm{CO}_{2}$ capture. ADA worked closely with engineers at Stantec Consulting Ltd. to evaluate the impacts with implementing a sorbent based $\mathrm{CO}_{2}$ capture process at Conesville Unit 5. Before the project was begun, several potential areas where $\mathrm{CO}_{2}$ could be generated were identified, including:

- Lost power due to the $\mathrm{CO}_{2}$ capture process

- Sorbent production and transportation

- Additional $\mathrm{SO}_{2}$ scrubbing

- Additional waste generation and disposal

The one-time $\mathrm{CO}_{2}$ produced in the manufacturing, fabrication, transportation, and installation of the capital equipment was not included in the evaluation.

By far the most important source of additional $\mathrm{CO}_{2}$ was the power lost to the grid due to the implementation of $\mathrm{CO}_{2}$ capture. For the purposes of this work, AEP's Conesville Unit \#5 was used as the reference plant. Without any $\mathrm{CO}_{2}$ capture, this power plant had a net electricity generation of $434 \mathrm{MW}$. According to the DOE, with an aqueous amine-based $\mathrm{CO}_{2}$ capture system this unit would produce $303 \mathrm{MW}$ of electricity. ${ }^{3}$ The sorbent-based $\mathrm{CO}_{2}$ capture process would result in a lower energy penalty with a net power generation of $343 \mathrm{MW}$. For this study, it was assumed that the coal usage would remain the same and, therefore, the $\mathrm{CO}_{2}$ generation for the base case or plant with $\mathrm{CO}_{2}$ capture was $866,102 \mathrm{lb} / \mathrm{hr}$. However, the electricity produced decreased from 434 to $343 \mathrm{MW}$ (21\% energy penalty). Assuming that the electricity used to replace the $91 \mathrm{MW}$ had the same $\mathrm{CO}_{2}$ energy intensity as Conesville Unit \#5, the additional $\mathrm{CO}_{2}$ emissions to replace the lost power would be $181,880 \mathrm{lb} \mathrm{CO}_{2} / \mathrm{hr}$. 
Prior to beginning the viability assessment, it was determined that only regenerable sorbents would be considered. This was concluded, in part, due to the prohibitive quantity required for non-regenerable sorbents. Based on mass balance, it was determined that the quantity of nonregenerable sorbents would greatly exceed the amount of coal used at the power plant. With non-regenerable sorbents the $\mathrm{CO}_{2}$ emissions from production, transportation, and disposal of the sorbent would likely present a life cycle concern. Although some sorbent replacement will be required over time in a capture process based on regenerable sorbents, the quantity of sorbent consumed in the process will be several orders of magnitude less than what would be consumed in a process based on non-regenerable sorbents. During the life cycle analysis implications of the sorbents these materials were treated similar to the installation of the equipment, the first time charge of the system with sorbent was not considered. Rather, the replacement sorbent was the focus of the life cycle assessment. The sorbent replacement rate was assumed to be $0.005 \%$ per cycle based on estimates ${ }^{30}$ of catalyst loss in fluidized catalytic cracking (FCC) units; which equated to 4.12 tons/day (3.74 tonnes/day) for this power plant size and capture process conditions. This material loss is insignificant compared to the coal usage of 4493 tons coal/day. For this reason it was assumed that the $\mathrm{CO}_{2}$ emissions from sorbent transportation will be negligible, especially compared to the emissions from the energy penalty. The $\mathrm{CO}_{2}$ production due to the raw materials was not documented. However, no raw materials were consumed in the process. Solvents such as methanol may be used during sorbent manufacturing. These solvents would be recycled in a commercial process. Based on the low replacement rate it was assumed that the $\mathrm{CO}_{2}$ emissions during sorbent preparation were negligible.

Additional $\mathrm{SO}_{2}$ scrubbing upstream of the $\mathrm{CO}_{2}$ capture process may be necessary for some power plants due to the formation of heat stable salts when the immobilized amine reacts with $\mathrm{SO}_{2}$. If this additional $\mathrm{SO}_{2}$ scrubbing is deemed necessary, $1 \mathrm{~mol}$ of $\mathrm{CO}_{2}$ will be released for every mol $\mathrm{SO}_{2}$ removed. The reported concentration of $\mathrm{SO}_{2}$ in the gas at Conesville Unit \#5 is low due to existing FGD system. Economics will dictate whether additional $\mathrm{SO}_{2}$ scrubbing is required. For the sake of the life cycle analysis it was assumed that the $\mathrm{SO}_{2}$ concentration must be lowered to $10 \mathrm{ppm}$. After the existing $\mathrm{SO}_{2}$ scrubber, the $\mathrm{SO}_{2}$ emissions at Conesville Unit \#5 were $\sim 110 \mathrm{ppm}$. To remove $100 \mathrm{ppm}$ of $\mathrm{SO}_{2}$ at Conesville would result in an additional release of $360 \mathrm{lb} \mathrm{CO} / \mathrm{hr}$, which is not significant compared to the $\mathrm{CO}_{2}$ emissions from the energy penalty. The $\mathrm{CO}_{2}$ emissions from $\mathrm{SO}_{2}$ scrubbing will vary between plants, but it is unlikely that this will become a major concern regarding additional $\mathrm{CO}_{2}$ emissions due to sorbent based $\mathrm{CO}_{2}$ capture.

Additional waste generation and disposal can be attributed primarily to the loss of sorbent through either physical attrition or chemical poisoning. However, at the replacement rate of 4.12 tons/day, the $\mathrm{CO}_{2}$ emissions from this waste stream are not expected to be significant. Future evaluations will be important to determine whether spent sorbent can be processed and reused.

\section{Task 3.6. Final Technology Selection}

Using the circulating fluidized bed for adsorption and the rotary kiln (for both desorption and cooling) that were selected during the technology scoring; a complete conceptual $\mathrm{CO}_{2}$ capture process can be pieced together. The conceptual flow sheet provided in Figure 55 shows how the selected equipment could be arranged in a power plant to capture carbon dioxide from flue gas. 


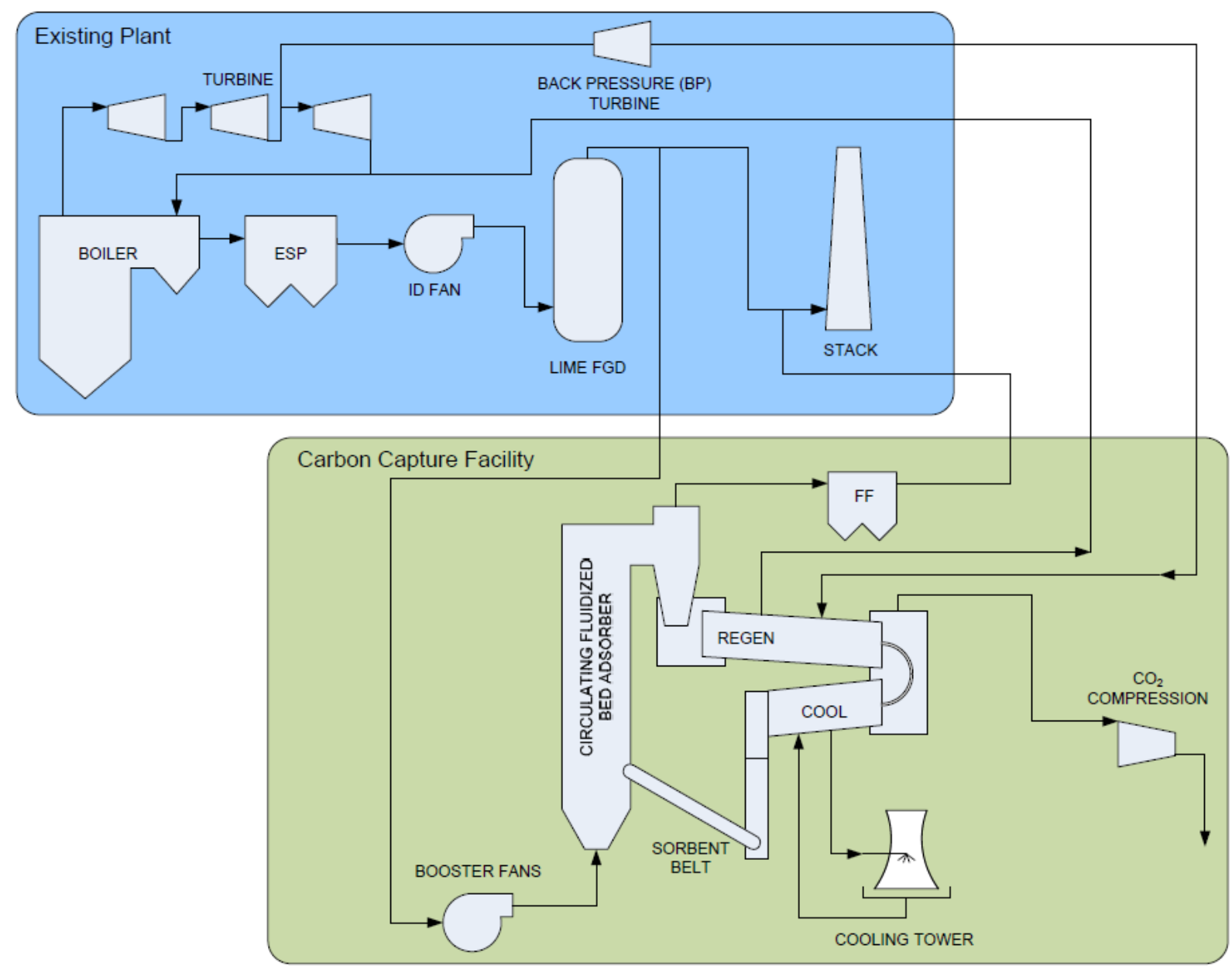

Figure 55: Conceptual Flow Sheet

In this conceptual arrangement, flue gas is sourced from the existing unit after particulate removal. It then proceeds through a heat recovery device, where the flue gas is cooled. The recovered heat is incorporated with the regeneration of the sorbent. The cooled flue gas then enters a wet FGD system for desulphurization and additional cooling. The pretreated gas then proceeds through a booster fan, then through a vertically arranged adsorber. Cooled solid sorbent is introduced to the bottom of the adsorber, and the flue gas carries it upwards in a circulating fluidized bed (i.e. transport reactor). 
Carbon dioxide is adsorbed by the solid particles (either through a physical reaction, a chemical reaction, or a combination of the two), which are separated from the flue gas by a cyclone. The flue gas then proceeds back to stack, while the solids are directed towards regeneration. A rotary kiln, jacketed to provide heat, conveys the solids slowly away from the adsorber, and then back. The $\mathrm{CO}_{2}$ is driven off as the reaction is reversed and is withdrawn for compression. A final kiln is jacketed for cooling, which prepares the sorbent for reintroduction to the adsorber. Figure 56 shows a rough plot plan area for the main equipment plus the fabric filter and compression plant.
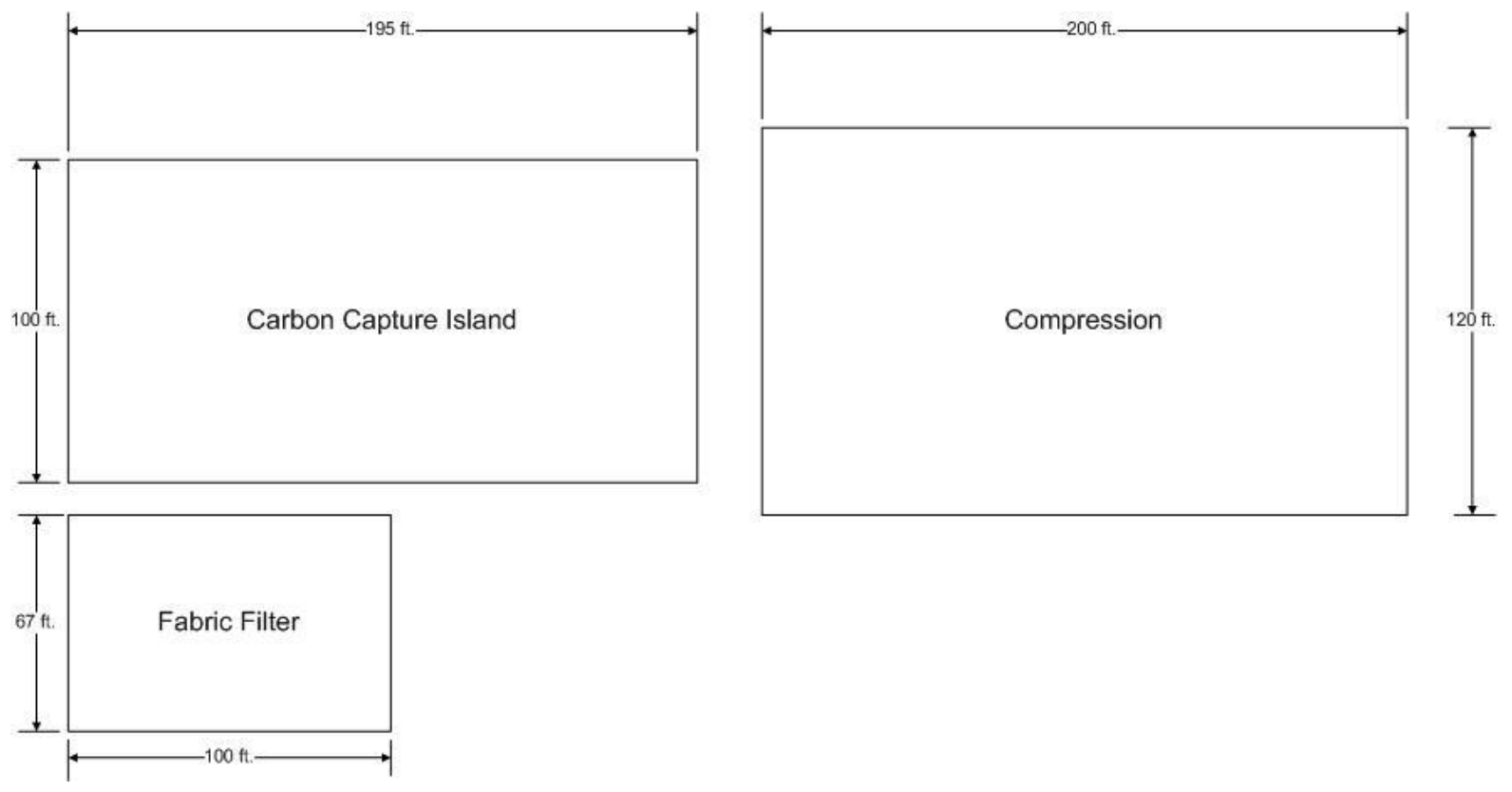

Figure 56: Carbon Capture Estimated Footprint

\section{Task 3.7. Develop Commercial-Scale Initial Concept Design and Cost Estimate}

Engineers at Stantec Consulting Ltd. used the $\mathrm{CO}_{2}$ capture process shown in Figure 55 to evaluate the capital costs, operating costs, footprint, and other important criteria for a commercial-scale power plant that is retrofit for $\mathrm{CO}_{2}$ capture. Stantec approached the cost estimate from the perspective of an owners engineer with a great deal of experience evaluating $\mathrm{CO}_{2}$ capture processes. Although using an independent engineering firm to complete early stage cost estimates may be an unusual approach, it was determined that this would provide the most through and objective results. Stantec compiled a cost analysis report, which is provided in its entirety in Appendix A. The level of cost accuracy for this concept design most closely matched a Class V estimate, as determined by the Association for the Advancement of Cost Engineering International (AACE). A Class V estimate is of suitable accuracy for screening purposes, and applies when a low level of project definition exists. All the costs are estimated in US dollars.

Items specifically excluded from this estimate include:

- Significant modifications to the steam cycle / turbine: It is assumed that steam from the IP crossover is available from a terminal point in the turbine hall.

- Closed loop heating has not been included. During investigation of rotary heaters, it was found that it is common to allow steam to proceed through the shell of the heater via 
tubes. Utilities may not be comfortable with this in the end and an additional intermediate heat transfer fluid could be used, for minimal expense.

- $\mathrm{CO}_{2}$ pipeline and end user costs: The estimate terminal point with regards to $\mathrm{CO}_{2}$ is the outlet flange of the final stage of compression.

- Specific owner costs pertaining to licensing fees; onsite expertise and allowance for interest during construction.

Stantec provided high level costs grouped into the following categories:

- Feedstock O\&M

$\circ \quad$ Natural gas used to dry $\mathrm{CO}_{2}$

- Variable O\&M

- Levelized make-up power

- Sorbent replacement

- Costs for additional chemicals for $\mathrm{SO}_{2}$ scrubbing

- Make-up water

o Water disposal

- Fixed O\&M

○ Employees

- Maintenance

- Capital

$\circ \mathrm{CO}_{2}$ capture equipment

- Back pressure turbine

○ Compressors

Because the technology selection and cost analysis began concurrently with the start of sorbentrelated experimental data collection by ADA, Stantec made several assumptions based on publicly available literature. Key assumptions used for the cost analysis included:

- Particles physically resemble activated carbon with respect to size and density (provided by ADA)

- Five seconds of reaction time required for adsorption (provided by ADA based on initial fixed bed tests)

- Five hundred seconds of reaction time is required for desorption (provided by ADA based on initial fixed bed tests)

- Heat capacity ${ }^{26}$ of the sorbent was $0.3 \mathrm{BTU} / \mathrm{lb} \cdot{ }^{\circ} \mathrm{F}$

- Working capacity ${ }^{26}$ of solid sorbents was $10 \mathrm{wt} \%$

- Heat of reaction was $760 \mathrm{Btu} / \mathrm{lb} \mathrm{CO}_{2}$ adsorbed

- Solid sorbent loss of $0.005 \%$ per cycle due to physical attrition ${ }^{30}$

- $\mathrm{CO}_{2}$ product pipeline and storage was not included ${ }^{28}$

- The power plant capacity factor ${ }^{28}$ was $85 \%$

- Make-up power cost was $7.02 \varnothing / \mathrm{kWh}(2010 \text { dollars })^{28}$

- Costs extracted from the DOE report ${ }^{3}$ were adjusted to 2010 dollars using an annual inflation rate ${ }^{28}$ of $2.35 \%$

- Potential revenue from selling $\mathrm{CO}_{2}$ product was excluded ${ }^{28}$ 
Two different options for a solid-based system were evaluated. For Option A there was no heat exchange mechanism provided between the hot $\mathrm{CO}_{2}$ lean sorbent exiting the regenerator and the cooler $\mathrm{CO}_{2}$ laden sorbent entering the regenerator. For Option $\mathrm{B}$ two heat exchangers were used, with a heat transfer fluid circulated between the two, to transfer sensible heat from the hot $\mathrm{CO}_{2}$ lean sorbent exiting the regenerator to the cooler $\mathrm{CO}_{2}$ lean sorbent entering the regenerator. The configuration of this regenerator is provided in Appendix A. Option B further reduced the energy penalty and cooling requirements versus aqueous MEA, but also resulted in additional capital cost due to the purchase of the heat exchangers.

The fundamental reason that solid sorbents are being evaluated for post-combustion $\mathrm{CO}_{2}$ capture is to reduce the energy penalty associated with the release of the $\mathrm{CO}_{2}$ during sorbent regeneration. Using the assumptions provided, Stantec evaluated the energy penalty from the MEA and sorbent-based $\mathrm{CO}_{2}$ capture processes. The energy output for the power plant with and without $\mathrm{CO}_{2}$ capture is provided in Figure 57. The blue bars in the figure represent the net electricity generation from the power plant. Conesville Unit 5 without $\mathrm{CO}_{2}$ capture generates $430 \mathrm{MW}$ net electricity. The purple bars represent the additional power generated using the back pressure turbine, which was used to generate steam at the appropriate temperature and pressure necessary for regeneration. The green and red bars represent the energy penalty (negative in value) due to the steam derate and auxiliary power, respectively. Because significantly less steam is required for the sorbent-based process, Option A and Option B at Conesville result in $343 \mathrm{MW}$ and $346 \mathrm{MW}$ of electricity generation, respectively, while the MEA process results in 303 MW net electricity generation. Since the case with MEA-based capture required more steam than the sorbent-based process, the BP turbine for MEA generated more electricity. It is possible that at a new power plant where the steam can be extracted directly from the low pressure turbine the sorbent-based capture options would perform even more favorably compared to the MEA process. 


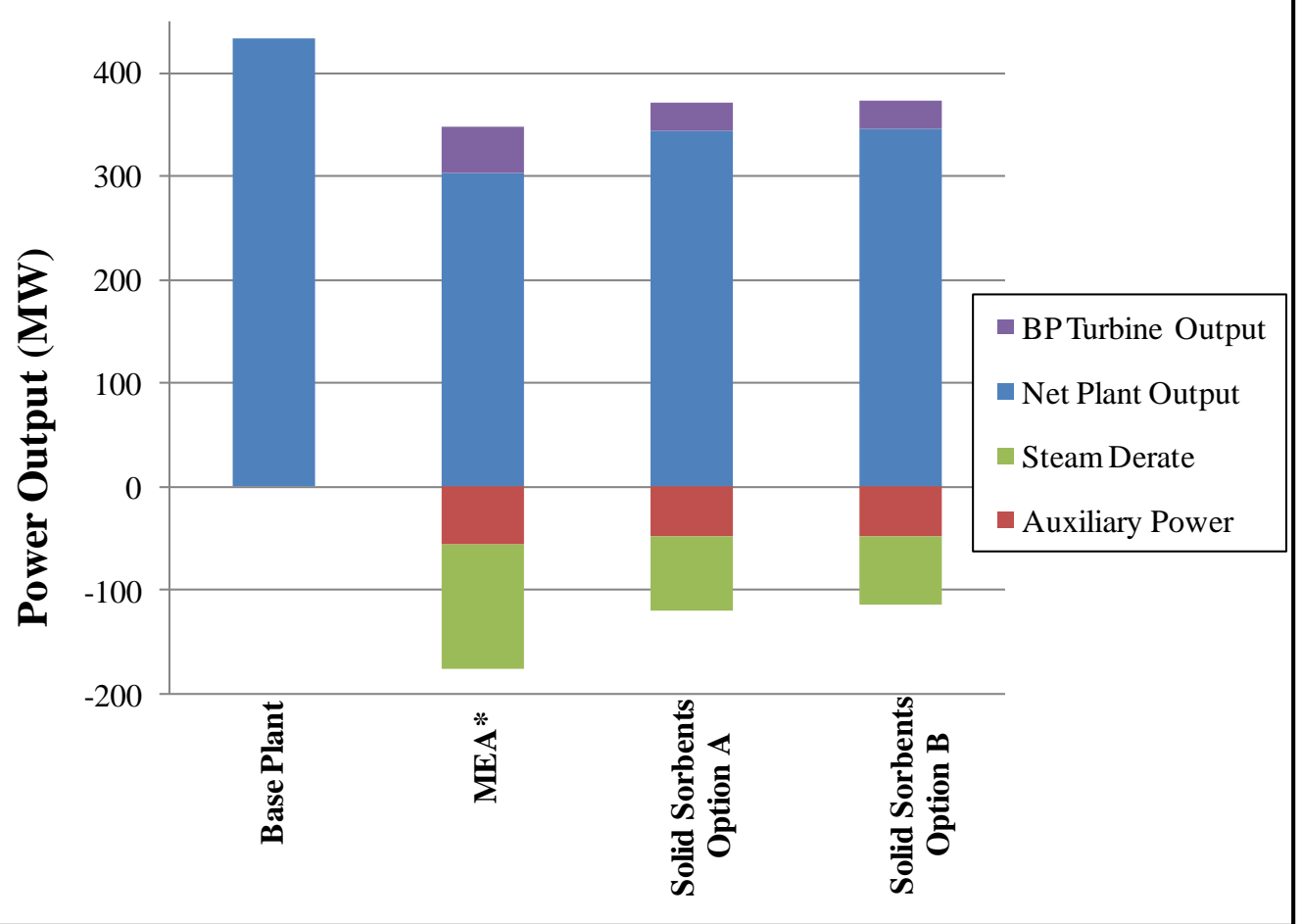

Figure 57: Comparison of Energy Penalty for MEA and Solid Sorbent-Based $\mathrm{CO}_{2}$ Capture at AEP's Conesville Power Plant.

The contribution to the levelized cost of electricity (LCOE) for MEA ${ }^{3}$ and the two sorbent based options are provided in Figure 58. All costs have been non-dimensionalized using the overall estimated LCOE increase for MEA $(7.59 \notin / \mathrm{kWh})$. Between the two sorbent-based processes, Option A is less costly compared to Option B because the capital costs associated with two heat exchangers is greater than the cost savings by recovering some of the sensible heat from the sorbent exiting the regenerator. 


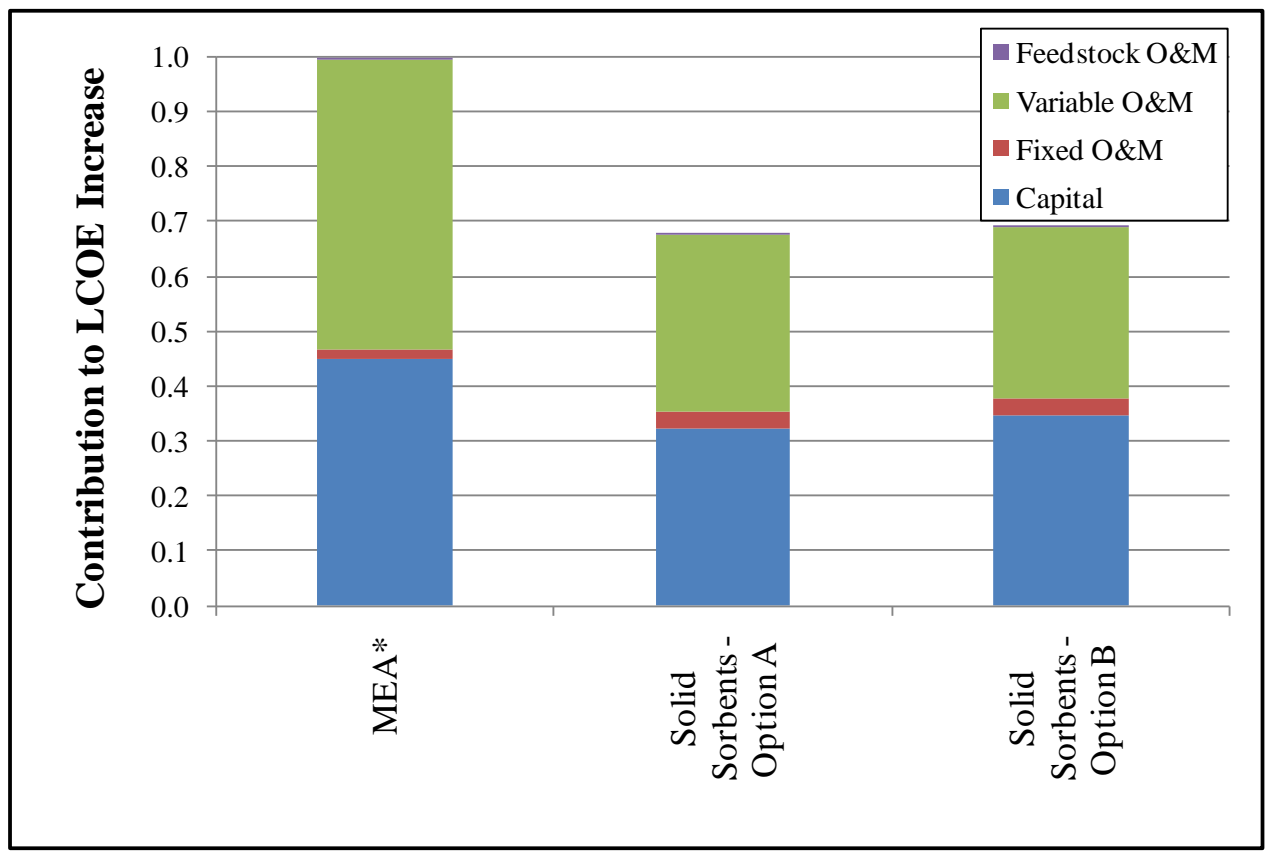

Figure 58: Contribution of LCOE Increases for $\mathrm{CO}_{2}$ Capture Options at AEP's Conesville Power Plant ("MEA Costs from NETL, 2007 with costs scaled to 2010 dollars)

As expected the operating costs are significantly less for the sorbent-based processes compared to the MEA system. As expected this can be attributed to the lower energy penalty. The capital costs as projected by Stantec are also lower than that of the MEA system, therefore leading to an overall LCOE savings of $32 \%$ and $31 \%$ for Option A and Option B, respectively. 
Table 10: Emissions and Cost Comparison

\begin{tabular}{|c|c|c|c|c|}
\hline \multirow[b]{2}{*}{ Description } & \multirow[b]{2}{*}{ Unit } & \multirow[b]{2}{*}{$\begin{array}{c}\text { MEA } \\
\text { DOE/NETL }\end{array}$} & \multicolumn{2}{|c|}{$\begin{array}{c}\text { Solid Sorbent } \\
\text { Base Case } \\
\text { (Without FGD, With Turbine) }\end{array}$} \\
\hline & & & $\begin{array}{l}\text { OPTION A: } \\
\text { Without Heat } \\
\text { Recovery }\end{array}$ & $\begin{array}{c}\text { OPTION B: } \\
\text { With Heat Recovery } \\
\text { Integration }\end{array}$ \\
\hline \multicolumn{5}{|c|}{ Power Plant Performance } \\
\hline $\begin{array}{l}\text { Net Plant Output (w/o } \mathrm{CO}_{2} \\
\text { Capture) }\end{array}$ & $(\mathrm{kW})$ & 433,778 & 433,778 & 433,778 \\
\hline $\begin{array}{l}\text { Total Parasitic Load Due To } \\
\mathrm{CO}_{2} \text { Capture }\end{array}$ & $(\mathrm{kW})$ & 175,789 & 118,981 & 114,681 \\
\hline $\begin{array}{l}\text { Auxiliary Power (Additional } \\
\text { Trim FGD/Cooler) }\end{array}$ & $(\mathrm{kW})$ & 0 & 0 & 0 \\
\hline $\begin{array}{l}\text { Auxiliary Power }\left(\mathrm{CO}_{2}\right. \\
\text { Capture) }\end{array}$ & $(\mathrm{kW})$ & 55,004 & 48,008 & 48,008 \\
\hline Steam Derate $\left(\mathrm{CO}_{2}\right.$ Capture $)$ & $(\mathrm{kW})$ & 120,785 & 70,973 & 66,673 \\
\hline BP Turbine Output & $(\mathrm{kW})$ & 45,321 & 28,526 & 26,999 \\
\hline $\begin{array}{l}\text { Net Plant Output (with } \mathrm{CO}_{2} \\
\text { Capture) }\end{array}$ & $(\mathbf{k W})$ & 303,310 & 343,323 & 346,096 \\
\hline \multicolumn{5}{|c|}{$\mathrm{CO}_{2}$ Capture Parameters } \\
\hline $\mathrm{CO}_{2}$ Removal Efficiency & $(\%)$ & 90 & 90 & 90 \\
\hline Regeneration Energy & $\left(\mathrm{Btu} / \mathrm{lb} \mathrm{CO} \mathrm{CO}_{2}\right)$ & 1,550 & 760 & 760 \\
\hline Steam Requirement & (MMBtu/hr) & $1,218.10$ & 725 & 681 \\
\hline \multicolumn{5}{|c|}{ Costs } \\
\hline \multirow{2}{*}{ Total Investment Cost } & $(\$ 1,000)$ & 439,049 & 357,706 & 386,411 \\
\hline & $(\$ / \mathrm{kW})$ & 1,448 & 1,042 & 1,116 \\
\hline Fixed O\&M Cost & $(\$ 1000 / y r)$ & 2,737 & 5,066 & 5,320 \\
\hline Variable O\&M Cost & $(\$ 1000 / \mathrm{yr})$ & 19,363 & 13,014 & 12,940 \\
\hline Feedstock O\&M Cost & $(\$ 1000 / \mathrm{yr})$ & 717 & 465 & 465 \\
\hline $\begin{array}{l}\text { Levelized, Make-Up Power } \\
\text { Cost }\end{array}$ & $(\$ 1000 / y r)$ & 68,250 & 47,281 & 45,833 \\
\hline $\begin{array}{l}\text { Parasitic Load due to } \mathrm{CO}_{2} \\
\text { Capture }\end{array}$ & $(\mathrm{kW})$ & 130,468 & 90,454 & 87,683 \\
\hline \multicolumn{5}{|c|}{ Incremental LCOE Contributions } \\
\hline Capital Component & $(\phi / \mathrm{kWh})$ & 3.4 & 2.45 & 2.62 \\
\hline Fixed O\&M Component & $(\phi / \mathrm{kWh})$ & 0.14 & 0.23 & 0.24 \\
\hline Variable O\&M Component & $(\not / \mathrm{kWh})$ & 4.01 & 2.44 & 2.36 \\
\hline Feedstock O\&M Component & $(ф / \mathrm{kWh})$ & 0.03 & 0.02 & 0.02 \\
\hline Total Incremental LCOE & $(\boldsymbol{c} / \mathbf{k W h})$ & 7.59 & 5.14 & 5.24 \\
\hline $\begin{array}{l}\mathrm{CO}_{2} \text { captured cost }= \\
\text { Incremental } \mathrm{LCOE} / \mathrm{CO}_{2} \\
\text { captured }\end{array}$ & $(\$ /$ ton $)$ & 59 & 45 & 46 \\
\hline $\begin{array}{l}\text { \% Change in LCOE } \\
\text { Compared to Amine }\end{array}$ & $(\%)$ & $0 \%$ & $-32 \%$ & $-31 \%$ \\
\hline
\end{tabular}


The high level cost analysis conducted by Stantec used equipment currently utilized in other industries for different applications (i.e. not $\mathrm{CO}_{2}$ capture). For this reasons the capital costs can only be considered order of magnitude estimates, but such estimates are still helpful in the areas of importance for future technology development. The results for the incremental LCOE evaluation are illustrated in Figure 59.

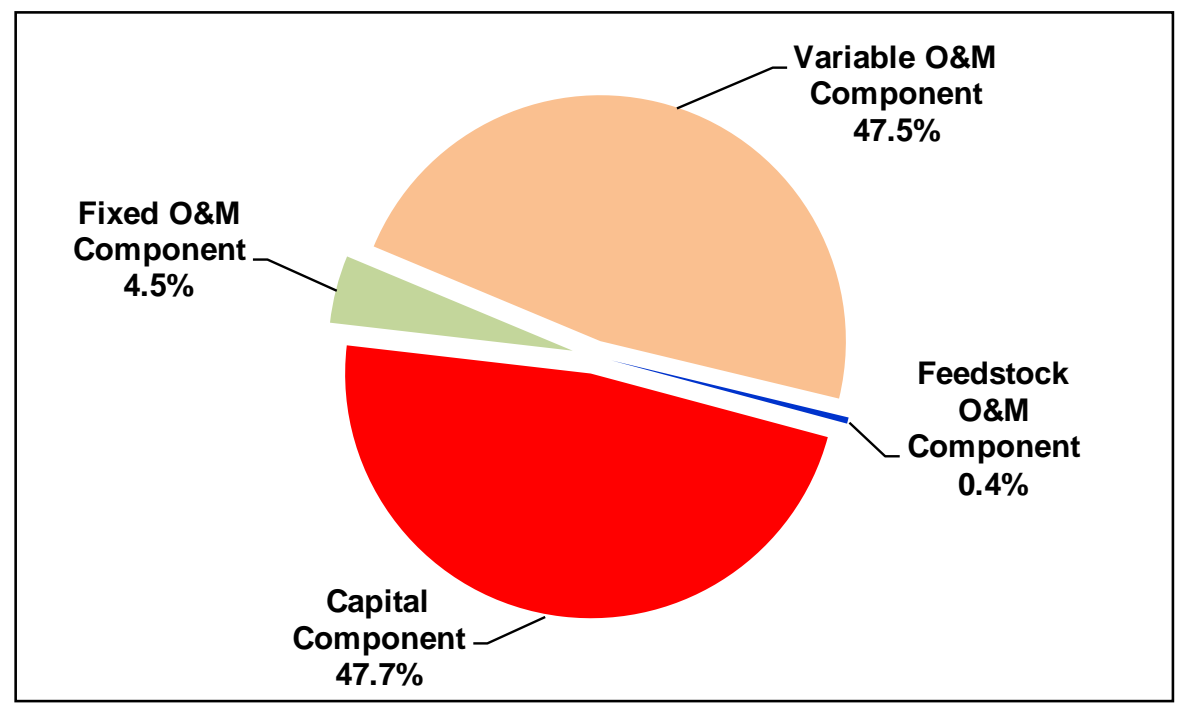

Figure 59: Incremental LCOE Contributions

With a new coal power plant with a cost of electricity of 6 to $7 \notin / \mathrm{kWh}$, the increase in the LCOE is calculated to be in the range of 73 to $86 \%$, which does not meet the DOE target of $35 \%$. A sensitivity analysis was performed to determine what drivers make the biggest contribution to the incremental LCOE. It was conducted by varying parameters that impact the economic analysis. There were two types of parameters analyzed, process-related and cost-related parameters. The process-related parameters reflected the energy optimization and the process integration of a $\mathrm{CO}_{2}$ capture system into the coal-fired power plant. They include a heat recovery system, an installation of a trim FGD / cooler to clean the flue gas ( $\leq 1 \mathrm{ppmv} \mathrm{SO}_{2}$ if existing FGD is insufficient) before entering the $\mathrm{CO}_{2}$ capture and a use of a back pressure turbine to gain electricity from steam. Together, they generate two options and each option has four cases as follows:

- Option A: Without Heat Recovery System

- Case 1A: WITHOUT a trim FGD / cooler, WITH a BP turbine (Option A in Table 10)

- Case 2A: WITHOUT a trim FGD / cooler, WITHOUT a BP turbine

- Case 3A: WITH a trim FGD / cooler, WITH a BP turbine

- Case 4A: WITH a trim FGD / cooler, WITHOUT a BP turbine

- Option B: With Heat Recovery System

- Case 1B: WITHOUT a trim FGD / cooler, WITH a BP turbine

- Case 2B: WITHOUT a trim FGD / cooler, WITHOUT a BP turbine

- Case 3B: WITH a trim FGD / cooler, WITH a BP turbine

- Case 4B: WITH a trim FGD / cooler, WITHOUT a BP turbine 
Note that Case 1A is the same as Option A in Table 10, which was developed under Task 3.6. For a complete discussion regarding the sensitivity analysis completed for all options, please refer to Appendix A. Only the main conclusions are provided in the following discussion.

Across the span of the four cases investigated, the Case 1A gave the minimum LCOE. Without a trim FGD / cooler, both capital and O\&M costs were decreased whereas an installation of a BP turbine improved the net power output, which could offset capital cost and reduce make-up power cost. It should be noted that when the sorbent degradation due to the $\mathrm{SO}_{2}$ concentration in the flue gas becomes a serious concern, an installation of a trim FGD / cooler to reduce $\mathrm{SO}_{2}$ concentration will be considered to be essential for this adsorption process to remove $\mathrm{CO}_{2}$ efficiently despite an increase in costs.

The acceptable costs to meet the DOE target of 35\% increase in LCOE are provided in Table 11. In order to reach this aggressive target, the incremental LCOE due to the $\mathrm{CO}_{2}$ capture can be no higher than $2.10 \phi / \mathrm{kWh}$ above the LCOE of the non-capture equivalent power plant $(6.0 \phi / \mathrm{kWh})$, or in other words, $3.04 \phi / \mathrm{kWh}$ must be removed from the Case 1A's incremental LCOE. Assuming the cut is evenly shared between the two major costs - capital and variable O\&M, both capital and variable O\&M costs $(\$ 1000 / y r)$ were reduced simultaneously to 0.93 and 0.92 $\varnothing / \mathrm{kWh}$, respectively. Results in Table 11 show that a significant $62 \%$ reduction on the capital cost and variable O\&M cost are necessary to achieve the DOE target of $2.10 \notin / \mathrm{kWh}$.

Table 11: Comparable Incremental LCOE Between Base Case and Base Case with $35 \%$ Increase in LCOE - Reduction in Costs

\begin{tabular}{|c|c|c|c|}
\hline Description & Unit & Case 1A & $\begin{array}{c}\text { Base Case with } \\
35 \% \text { Increase } \\
\text { in LCOE } \\
\end{array}$ \\
\hline \multicolumn{4}{|c|}{ Costs } \\
\hline Total Investment Cost & $\$ 1000$ & 357,706 & 135,841 \\
\hline Fixed O\&M Cost & $\$ 1000 / y r$ & 5,066 & 5,066 \\
\hline Variable O\&M Cost & $\$ 1000 / y r$ & 53,886 & 20,323 \\
\hline Feedstock O\&M Cost & $\$ 1000 / y r$ & 465 & 465 \\
\hline \multicolumn{4}{|c|}{ Incremental LCOE Contributions } \\
\hline Capital Component & $\phi / \mathrm{kWh}$ & 2.45 & 0.93 \\
\hline Fixed O\&M Component & $\phi / \mathrm{kWh}$ & 0.23 & 0.24 \\
\hline Variable O\&M Component & $\phi / \mathrm{kWh}$ & 2.44 & 0.92 \\
\hline Feedstock O\&M Component & $\phi / \mathrm{kWh}$ & 0.02 & 0.02 \\
\hline Total incremental LCOE & c/kWh & 5.14 & 2.10 \\
\hline $\begin{array}{l}\% \text { Change in Total Investment } \\
\text { Cost }\end{array}$ & $\%$ & $0 \%$ & $-62 \%$ \\
\hline $\begin{array}{l}\% \text { Change in Variable O\&M } \\
\text { Cost }\end{array}$ & $\%$ & $0 \%$ & $-62 \%$ \\
\hline \% Change in LCOE & $\%$ & $0 \%$ & $-59 \%$ \\
\hline
\end{tabular}


The sensitivity chart in Figure 60 shows that the incremental LCOE can be varied from 2.10 to $8.18 \phi / \mathrm{kWh}$ at a $\pm 62 \%$ variation of both costs.

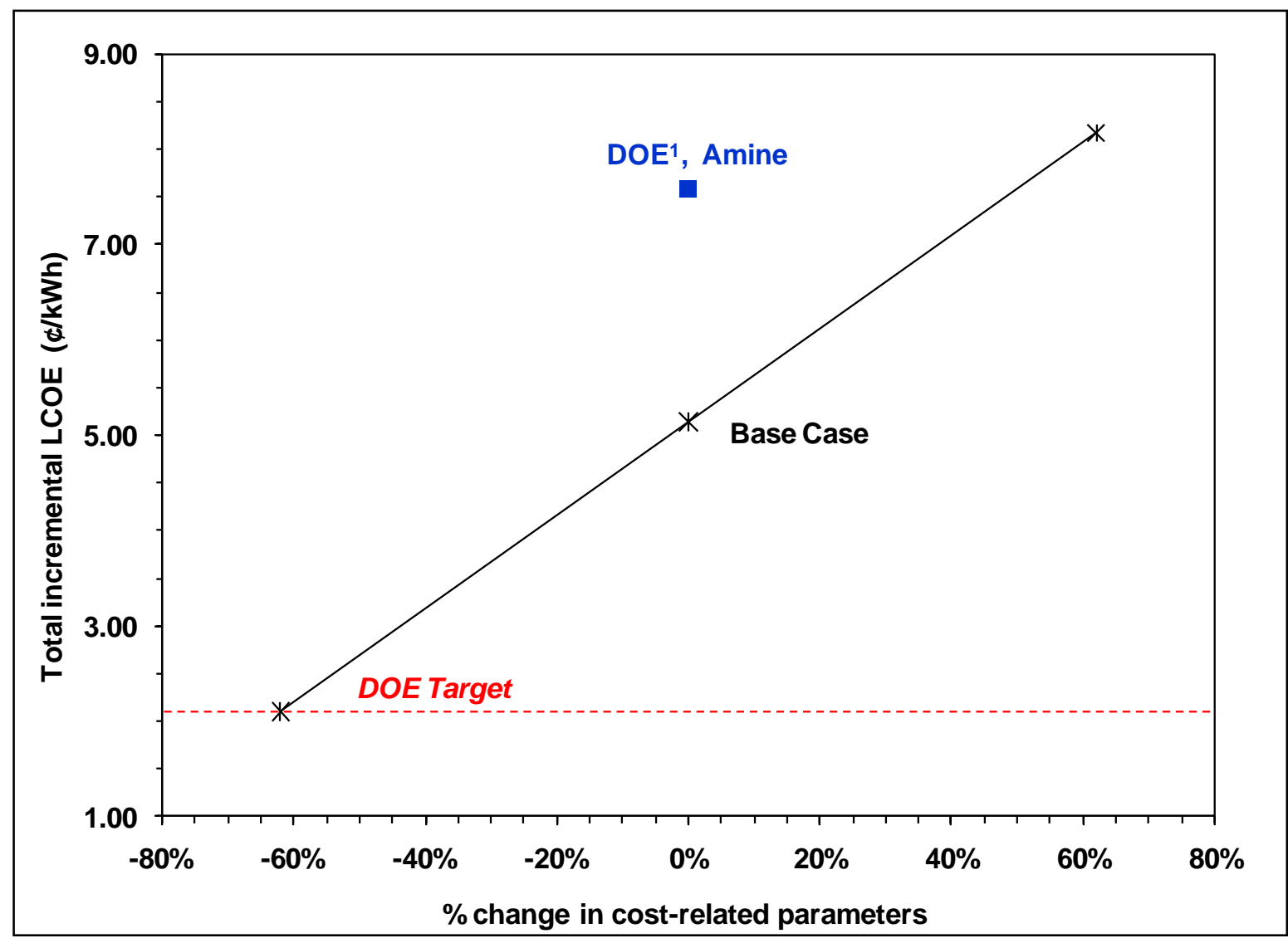

Figure 60: Sensitivity Analysis of Capital Cost and Variable O\&M Cost of Base Case

\section{Task 4. Project Management and Reporting}

Although considerable effort was required to manage the project, only the activities related to technology transfer are discussed in this final technical report. Regular and rigorous technology transfer was conducted during this award period. The national and international conferences and meetings where a project update was provided via presentation or poster included:

- Power Plant Air Pollutant Control "MEGA" Symposium, Baltimore, MA, August 25 28, 2008 (Poster)

- Air \& Waste Management Association Annual Conference and Exhibition, Portland, OR., June 24 - 26, 2008 (Presentation)

- Energy Utility and Environment Conference (EUEC), Phoenix, AZ., February 1 -4, 2009 (Presentation)

- $8^{\text {th }}$ Annual Carbon Capture and Sequestration Conference, Pittsburgh, PA, May 4-7, 2009 (Poster)

- Air \& Waste Management Association Annual Conference and Exhibition, Detroit, MI., June 16 - 19, 2009 (Presentation) 
- IEA Carbon Capture Meeting, Regina, Canada, September 29 - October 1, 2009 (Poster)

- Air Quality (AQVII) Conference in Arlington, VA., October 26 - 29, 2009 (Presentation)

- American Institute of Chemical Engineers (AIChE) Annual Conference, Nashville, TN., November 6-9, 2009 (Presentation)

- $9^{\text {th }}$ Annual Conference on Carbon Capture and Sequestration, Pittsburgh, PA., May 10 13, 2010 (Presentation)

- Air \& Waste Management Association Annual Conference and Exhibition, Calgary, Alberta, Canada, June 22 - 25, 2010 (Presentation)

- NETL CCS R\&D Meeting, Pittsburgh, PA, September 13 - 17, 2010 (Presentation)

- AIChE Annual Conference, Salt Lake City, UT., November 7 - 10, 2010 (Presentation)

- Energy Utility and Environment Conference (EUEC), Phoenix, AZ., January 31 February 1, 2011 (Presentation)

- International Colloquium on Environmentally Preferred Advanced Power Generation (ICEPAG) Conference, Costa Mesa, CA., February 8 - 10, 2011 (Presentation)

- $10^{\text {th }}$ Annual Conference on Carbon Capture and Sequestration, Pittsburgh, PA, May $2-$ May 5, 2011 (Presentation)

The following articles were accepted into conference proceedings after being peer reviewed:

- Krutka, H., Sjostrom, S., Bustard, C.J., Durham, M., Baldrey, K., Stewart, R., "Summary of Post-Combustion $\mathrm{CO}_{2}$ Capture Technologies for Existing Coal-Fired Power Plants" Air \& Waste Management Association Annual Conference, paper \#808, Portland, OR, June 24-26, 2008.

- Krutka, H.M., Sjostrom, S.J., Bustard, C.J., "Results from Lab and Field Testing of Novel $\mathrm{CO}_{2}$ Sorbents for Existing Coal-Fired Power Plants, paper \#173, Power Plant Air Pollutant Control "MEGA" Symposium, Baltimore, MA, August 25-28, 2008.

- Sjostrom, S., Krutka, H., Sonobe, N. "Comparison of Low-Temperature $\mathrm{CO}_{2}$ Sorbents Based on Laboratory and Field Screening, paper \#381, Detroit, MI, June 16 - 19, 2009.

- Krutka, H., Sjostrom, S., Martin, C., Campbell, T., Starns, T., O'Palko, A., 'Results from Experimental Evaluations of Post-Combustion $\mathrm{CO}_{2}$ Sorbents, papers \#59, Air \& Waste Management Association Annual Conference, Calgary, Alberta, Canada, June 24, 2010.

The following articles were accepted into peer reviewed scientific journals:

- Sjostrom, S.; Krutka, H.; Evaluation of Solid Sorbents as a Retrofit Technology for $\mathrm{CO}_{2}$ Capture, Fuel, 2010, 89, 1298-1306.

- Sjostrom, S.; Krutka, H.; Starns, T.; Campbell, T. Pilot Test Results of Post-Combustion $\mathrm{CO}_{2}$ Capture Using Solid Sorbents, Energy Procedia, 2011, 4, 1584-1592. 


\section{SUMMARY AND CONCLUSIONS}

The overall objective of this project was to assess the viability and accelerate development of post-combustion $\mathrm{CO}_{2}$ capture based on solid sorbents. To meet this objective, a review of candidate sorbents and full-scale process design concepts was completed. Sorbents were screened in a small-scale laboratory fixture. Four of the most promising materials were further evaluated using a $1 \mathrm{kWe}$ slipstream pilot designed and fabricated during the project. In a concurrent effort, commercial-scale processes and equipment options were evaluated for their applicability to sorbent-based $\mathrm{CO}_{2}$ capture. A cost analysis was completed that can be used to direct future technology development efforts. A summary of each viability focus area, sorbents and equipment, is presented below.

\section{Sorbent Assessment}

The sorbent assessment program conducted by ADA under the current and other related projects included both fixed-bed laboratory-scale and small-scale (1 kWe equivalent) kinetic slipstream tests. Sorbent screening tests were conducted at the laboratory-scale to characterize materials and down-select promising candidates for further testing at the slipstream scale. Criteria established for sorbent evaluations included the $\mathrm{CO}_{2}$ working capacity, the cyclic stability, the tendency of the sorbents to be affected by typical flue gas constituents such as moisture and $\mathrm{SO}_{2}$, performance over a range of adsorption and regeneration temperatures, theoretical regeneration energy, and the cost and projected availability of the materials. The benchmark regeneration energy used for comparison was for a liquid $\mathrm{MEA} \mathrm{CO}_{2}$ capture system, $3600 \mathrm{~kJ} / \mathrm{kg} \mathrm{CO} \mathrm{CO}_{2}(1550$ BTU/lb $\mathrm{CO}_{2}$ ), as reported by DOE in $2007 .^{3}$ This is not a theoretical regeneration energy, but is an actual regeneration energy based on achievable working capacities and heat integration. It is important to note that it is valuable only for a high level comparison with a sorbent's theoretical regeneration energy, which does not include integration.

The general observations from the sorbent evaluations are summarized below:

- $\quad$ Supported Amines. More than half of the materials evaluated were supported amines. This promising family of sorbents consists of various types of amines supported on inert substrates.

○ 87 supported amines were evaluated at the laboratory scale

$\circ$ In general, supported amines exhibited high $\mathrm{CO}_{2}$ capacities under simulated flue gas conditions (up to $14 \mathrm{wt} \%$ total capacity by weight)

- Several supported amine materials demonstrated cyclic stability over many adsorption/regeneration cycles.

○ Theoretical regeneration energies for supported amines were as low as $1240 \mathrm{~kJ} / \mathrm{kg}$ $\mathrm{CO}_{2}\left(530 \mathrm{BTU} / \mathrm{lb} \mathrm{CO} \mathrm{CO}_{2}\right)$

$\circ$ The laboratory-scale fixed bed field tests, in conjunction with specialized laboratory testing, confirmed that $\mathrm{SO}_{2}$ can permanently degrade the supported amine sorbents. In addition, $\mathrm{NO}_{2}$ can also partially degrade the sorbents. $\mathrm{NO}$ did not result in any noticeable degradation in performance.

- Due to design limitations of the $1 \mathrm{kWe}$ system, primarily related to the fundamental characteristics of the co-current reactor design with a fluidized bed 
for regeneration, $90 \% \mathrm{CO}_{2}$ removal was achieved but not maintainable during continuous operation.

- Large batches of 4 supported amines and evaluations were conducted at the 1 kWe slipstream scale (Sorbents R, AX, BN, and F). Sorbent R was tested at Luminant's Martin Lake Steam Electric Station and the second host site was Xcel Energy's Sherburne County Generating Station (Sherco). All other materials were tested only at Sherco.

- Sorbent $\boldsymbol{R}$, a polymeric amine coated on a silica substrate

- Laboratory-scale $\mathrm{CO}_{2}$ capacity: $9.7 \%$ at Martin Lake and $6.5 \%$ at Sherco, on average.

- During $1 \mathrm{kWe}$ testing in batch mode, sorbent $\mathrm{R}$ was able to remove up to $90 \% \mathrm{CO}_{2}$ for several cycles. Approximately $50 \%$ of the total removal occurred in the first three feet of the adsorption reactor, indicating very fast adsorption kinetics. $\mathrm{CO}_{2}$ removal decreased to approximately $20 \%$ removal at steady state.

- Performance in the $1 \mathrm{kWe}$ pilot and the shape of the laboratoryscale breakthrough curves suggested that the $50 \%$ amine loaded sorbent resulted in mass diffusion limitations related to the $\mathrm{CO}_{2}$ uptake rate.

- Sorbent $\boldsymbol{A X}$ was similar to Sorbent R, but on a different substrate.

Performance of R and AX in the field was nearly identical

- Laboratory-scale $\mathrm{CO}_{2}$ capacity at Sherco: $5.5 \%$ average

- Sorbent $\boldsymbol{F}$ was too fine for successful testing in the $1 \mathrm{kWe}$ system

- Laboratory-scale $\mathrm{CO}_{2}$ capacity at Sherco: $5.8 \%$ average

- Sorbent $\boldsymbol{B N}$, an amine supported on a resin,

- Laboratory-scale $\mathrm{CO}_{2}$ capacity at Sherco: 6.5\%, average

- $1 \mathrm{kWe}$ testing: $90 \% \mathrm{CO}_{2}$ was achievable. During continuous operation, steady state $\mathrm{CO}_{2}$ removal was consistently above $40 \%$ and often as high as $45 \%$, which was approximately double that of sorbent R. Since the fixed-bed average capacity for $R$ and $B N$ was identical, the superior $1 \mathrm{kWe}$ results with BN highlighted the importance of sorbents without kinetic limitations.

- Amine-based materials will degrade at high temperatures, thus the regeneration temperature must be carefully controlled, which is a consideration for a full-scale system.

- Amines can be supported on durable, relatively low attrition materials.

\section{- Carbon-based materials}

○ 31 carbon based materials were evaluated at the laboratory-scale.

$\circ$ The $\mathrm{CO}_{2}$ capacities of carbon-based $\mathrm{CO}_{2}$ sorbents were typically $<1.2 \mathrm{wt} \%$.

- Carbon-based demonstrated cyclic stability on simulated and actual flue gas.

- Carbon-based were much more resistant to poisoning and degradation from flue gas constituents than supported amines.

- One activated carbon was identified for testing at the $1 \mathrm{kWe}$ scale. No testing was completed because of the low capacity of the material required significant modifications to the system to allow the increased sorbent circulation rate. 
- The $\mathrm{CO}_{2}$ capacity for carbon-based sorbents must be improved and selectivity quantified before determining whether a cost-effective process can be developed using carbon-based sorbents.

- Activated carbon materials are relatively soft and may result in higher attrition rates and related higher sorbent replacement rates in a full-scale system.

\section{- $\quad \underline{\text { Zeolites }}$}

○ 6 zeolites were evaluated at the laboratory scale.

- Zeolites preferentially adsorb $\mathrm{H}_{2} \mathrm{O}$ over $\mathrm{CO}_{2}$, making them ineffective for the purpose of post-combustion $\mathrm{CO}_{2}$ capture

\section{- Supported Carbonates}

○ 7 supported carbonates were evaluated at the laboratory-scale under separate funding.

- Carbonates produced and evaluated by ADA were not optimized, but allowed for some screening and evaluation. The heat of reaction for carbonates is significantly higher than that of other materials (i.e. approximately $-130 \mathrm{~kJ} / \mathrm{mol}$ for regeneration of sodium carbonate versus $-60 \mathrm{~kJ} / \mathrm{mol}$ for supported amines) and the theoretical regeneration energy was approximately $5000 \mathrm{~kJ} / \mathrm{kg} \mathrm{CO}_{2}$, which is not competitive with aqueous MEA.

\section{- Hydrotalcites}

$\circ 10$ Hydrotalcites were evaluated at the laboratory-scale during this project

- There may be some applicability for post-combustion $\mathrm{CO}_{2}$ capture, although these materials may be useful at temperatures greater than what was used for the simulated flue gas in this project.

Based on the program results, supported amine sorbents were the most promising materials and offer the potential to significantly reduce the energy penalty associated with post-combustion $\mathrm{CO}_{2}$ capture if they can be used in a system/process that can take advantage of their beneficial properties. With further development it is possible that carbon-based sorbents may also be useful for this application.

\section{Full Scale Equipment Assessment and Design}

The project team reviewed currently-available commercial scale equipment that had features applicable for post-combustion capture using solid sorbents in a temperature-swing process to determine a first order viability cost estimate and to determine the key cost drivers. A technology survey was completed across the power, chemical, and minerals industries (i.e. coal handling, cement, mining, etc.) to identify equipment costs and capabilities. A variety of processes and equipment were identified that may be applicable, with some design modifications, for post-combustion $\mathrm{CO}_{2}$ capture using solids in a temperature-swing system. The survey results were grouped based on the four main unit operations involved with sorbent based capture: adsorption, heating and cooling (or heat transfer), conveying, and desorption. The identified commercial equipment and technologies were then evaluated using scoring criteria established by the project team to select the technologies for the final conceptual design. Cost savings were identified when one technology could accomplish more than one operation. The final concept design incorporated a circulating fluidized bed for adsorption, which could simultaneously accomplished both adsorption and conveying, and a rotary kiln for regeneration and cooling, which simultaneously accomplished conveying and effective heat transfer. The 
final technology selection was used to complete a preliminary cost assessment for a conceptual $500 \mathrm{MW} \mathrm{CO}_{2}$ capture process.

The economic evaluation of the final concept design highlighted that a sorbent-based capture system had the potential to yield significant energy penalty and cost savings versus an aqueous amine system. In the absence of a $\mathrm{CO}_{2}$ laden/lean sorbent heat exchanger, the LCOE increase was over 30\% lower than that of the MEA capture process. It is important to note that the fullscale cost estimates were developed using a co-current adsorber design, which is also the basis of the $1 \mathrm{kWe}$ design. As discussed in this report, this co-current design did not achieve the technical project goals under continuous operation with the currently available sorbents. However, it is believed that the high-level cost estimate completed during this project is appropriate for this stage in the development process because it identifies key high-level costs and significant cost drivers. Future process development efforts will focus on the cost drivers identified during this project.

\section{General Conclusions}

The project objective was to address the viability and accelerate development of a solid-based post-combustion $\mathrm{CO}_{2}$ capture technology that can be retrofit to the existing fleet of coal-fired power plants. Based on sorbent equipment evaluations, it was determined that solid sorbents are capable of removing $90 \% \mathrm{CO}_{2}$ from coal-fired flue gas and are a promising option for postcombustion $\mathrm{CO}_{2}$ capture. Specifically, the lower sensible heat could result in a significant reduction in the energy penalty versus solvent based capture systems, if the sorbents can be paired with a process and equipment that takes advantage of the beneficial sorbent properties. A high-level cost assessment was completed based on existing commercial-scale equipment. The results of the cost analysis highlighted the advantage of sorbents versus solvents. Additional technology development in sorbents and process design with associated cost reductions will be required to continue making progress towards limiting the increase in the cost of electricity to 35\%. Development efforts on solids-based post combustion technologies should continue. 


\section{REFERENCES}

1. NETL: Carbon Sequestration. http://www.netl.doe.gov/technologies/carbon_seq/index.html (Accessed October 2007).

2. MIT, The Future of Coal, 2007, web.mit.edu/coal/The_Future_of_Coal_Summary_Report.pdf (Accessed September 2007).

3. Ramezan M., Skone T.J., Nsakala N., Liljedahl G.N., "Carbon Dioxide Capture from Existing Coal-Fired Power Plants", Final Report DOE/NETL-401/110907, December, 2007.

4. Birbara P.J., Filburn T.P., Nalette T.A., United Technologies Corporation. Regenerable Solid Amine Sorbent., US 5,876,488: 1999.

5. Gray M.L., Champagne K.J., Fauth D., Baltrus J.P., Pennline, H., Performance of Immobilized Tertiary Amine Solid Sorbents for the Capture of Carbon Dioxide, International Journal of Greenhouse Gas Control, 2008, 2, 3-8.

6. Drage T.C., Arenillas A., Smith K.M., Snape C.E., Thermal Stability of Polyethylenimine Based Carbon Dioxide Adsorbents and its Influence on Selection of Regeneration Strategies, Microporous and Mesoporous Materials, 2008, 116, 506-512.

7. Siriwardane R.V., The United States Department of Energy, Solid Sorbents for Removal of Carbon Dioxide from Gas Streams at Low Temperatures., US 6,908,497: 2005.

8. Harlick P.J.E., Sayari A., Applications of Pore-Expanded Mesoporous Silica. 5. Triamine Grafted Material with Exceptional $\mathrm{CO}_{2}$ Dynamic and Equilibrium Adsorption Performance, Ind. Eng. Chem. Res., 2007, 45, 446-458.

9. Kim S., Ida J., Guliants V.V., Lin J.Y.S., Tailoring Pore Properties of MCM-48 Silica for Selective Adsorption of $\mathrm{CO}_{2}$, J. Phys. Chem. B, 2005, 109, 6287-6293.

10. Hicks J.C., Drese J.H., Fauth D.J., Gray M.L., Qi G., Jones C.W., Designing Adsorbents for $\mathrm{CO}_{2}$ Capture form Flue Gas - Hyperbranched Aminosilicas Capable of Capturing $\mathrm{CO}_{2}$ Reversibility, J. Am. Chem. Soc., 2008, 130, 2902-2903.

11. Drage T.C., Arenillas A., Smith K.M., Pevida C., Piippo S., Snape C.E., Preparation of Carbon Dioxide Adsorbents from the Chemical Activation of Urea-Formaldehyde and Melamine-Formaldehyde Resins, Fuel, 2007, 86, 22-31.

12. Plaza M.G., Pevida C., Arenillas A., Rubiera F., Pis J.J., $\mathrm{CO}_{2}$ Capture by Adsorption with Nitrogen Enriched Carbons, Fuel, 2007, 86, 2204-2212.

13. Radosz M., Hu X., Krutkramelis K., Shen Y., Flue-Gas Carbon Capture on Carbonaceous Sorbents: Toward a Low-Cost Multifunctional Carbon Filter for "Green" Energy Producers, Ind. Eng. Chem. Res., 2008, 47, 3783-3794.

14. Lu C., Bai H., Wu B., Su F., Hwang J.F., Comparative Study of $\mathrm{CO}_{2}$ Capture by Carbon Nanotubes, Activated Carbons, and Zeolites, Energy \& Fuels, 2008, 22, 3050-3056.

15. Nelson T., Coleman L., Anderson M., Herr J., Pavani M., The Dry Carbonate Process: Carbon Dioxide Recovery from Power Plant Flue Gas, Annual NETL $\mathrm{CO}_{2}$ Capture Technology for Existing R\&D Meeting, Pittsburgh, PA, March 2009.

16. Shigemoto N., Yanagihara T., Sugiyama S., Hayashi H., Material and Energy Consumption for $\mathrm{CO}_{2}$ Recovery from Moist Flue Gas Employing $\mathrm{K}_{2} \mathrm{CO}_{3}$-on-Activated Carbon and Its Evaluation for Practical Adaptation, Energy \& Fuels, 2006, 20, 721-726.

17. Siriwardane R.V., Shen M.S., Fisher E.P., Poston J.A., Adsorption of $\mathrm{CO}_{2}$ on Molecular Sieves and Activated Carbon, Energy \& Fuels, 2001, 15, 279-284.

18. H. Li, M. Eddaoudi, M. O'Keeffe, O. M. Yaghi, Nature, 1999, 402,276. 
19. M. Eddaoudi, J. Kim, N. Rosi, D. Vodak, J. Wachter, M. O'Keeffe, O.M. Yaghi, Science 2002, 295, 469.

20. D. Li, K. Kaneko, Chemical Physics Letters 2001, 335, 50.

21. Y. S. Bae, K. L. Mulfort, H. Frost, P. Ryan, S. Punnathanam, L. J.Broadbelt, J. T. Hupp, R. Q. Snurr, Langmuir 2008, 24, 8592.

22. Krutka, H., Sjostrom, S., “Topical Report 5: Sorbent Performance Report”, Topical Report 05649T05, May 2011 (resubmitted June 2011).

23. Hoffman, J.S., Richards, G.A., Pennline, H.W., Fischer, D., Keller, G, (2008) Factors in Reactor Design for Carbon Dioxide Capture with Solid, Regenerable Sorbents, Clearwater Coal Conference, Clearwater, FL.

24. Birbara, P. J., Filburn, T. P., Nalette, T. A., 2006, US Patent 6,364,938

25. Serna-Guerrero, R., Belmabkhout, Y., Sayari, A. Triamine-Grafted Pore-Expanded Mesoporous Silica for $\mathrm{CO}_{2}$ Capture: Effect of Moisture and Adsorbent Regeneration Strategies, Adsorption, 2010, 16, 567-575.

26. Tarka, T.J.; Ciferno, J.P.; Gray, M.L.; Fauth, D. $\mathrm{CO}_{2}$ Capture Systems Using Amine Enhanced Solid Sorbents, $5^{\text {th }}$ Annual Conference on Carbon Capture \& Sequestration, Alexandria, VA, 2006.

27. Kepner, Charles, and Benjamin Tregoe. The Rational Manager. Princeton Research Press, 1997.

28. Martin, C., Sjostrom, S., Krutka, H., Richard, M., Cameron, D., “Topical Report 1, 2, and 3: Technology Survey, Screening, and Final Selection, Topical Report 05649T01, July 2010.

29. Krutka, H., Sjostrom, S., Richard, M., “Topical Report 4: Conceptual 500 MW Design”, Topical Report 05649T04, May 2011.

30. Unpublished conversation with Fluidized Catalytic Cracking Specialists at Shaw Group. 


\section{LIST OF ACRONYMS AND ABBREVIATIONS}

\begin{tabular}{|c|c|}
\hline AACE & Association for the Advancement of Cost Engineering Internationa \\
\hline A\&WMA & Air \& Waste Management Association \\
\hline $\mathrm{AC}$ & Alternating Current \\
\hline acfm & Actual cubic feet per minute \\
\hline ADA & ADA Environmental Solutions \\
\hline Ads & Adsorption \\
\hline AEP & American Electric Power \\
\hline AIChE & American Institute of Chemical Engineers \\
\hline ARI & Adsorption Research Inc. \\
\hline $\mathrm{BP}$ & Back Pressure \\
\hline BTU & British Thermal Unit \\
\hline${ }^{\circ} \mathrm{C}$ & Degree Celsius \\
\hline $\mathrm{CCS}$ & Carbon Capture and Sequestration \\
\hline CFB & Circulating Fluidized Bed \\
\hline $\mathrm{cfm}$ & Cubic Feet Per Minute \\
\hline $\mathrm{CHX}$ & Condensing Heat Exchanger \\
\hline $\mathrm{cm}$ & Centimeter \\
\hline$\phi / \mathrm{MWhr}$ & Cents Per Megawatt Hour \\
\hline $\mathrm{CO}_{2}$ & Carbon Dioxide \\
\hline $\mathrm{COE}$ & Cost of Energy \\
\hline DOE & Department of Energy \\
\hline EPRI & Electric Power Research Institute \\
\hline ESP & Electrostatic Precipitator \\
\hline EUEC & Energy \& Environment Conference \\
\hline${ }^{\circ} \mathrm{F}$ & Degree Fahrenheit \\
\hline FD & Forced Draft \\
\hline $\mathrm{FF}$ & Filtration Fraction \\
\hline FGD & Flue gas Desulfurization \\
\hline
\end{tabular}




\begin{tabular}{|c|c|}
\hline $\mathrm{ft}$ & Foot \\
\hline FRP & Fiberglass Reinforced Plastic \\
\hline $\mathrm{g}$ & Gram \\
\hline $\mathrm{Hg}$ & Mercury \\
\hline HHV & Higher Heating Value \\
\hline $\mathrm{H}_{2} \mathrm{O}$ & Water \\
\hline hr & Hour \\
\hline ICFB & Internal Circulating Fluidized Bed \\
\hline ID & Induced Draft \\
\hline K & Degree Kevin \\
\hline $\mathrm{kg}$ & Kilogram \\
\hline $\mathrm{kJ}$ & Kilojoule \\
\hline $\mathrm{kW}$ & Kilowatt \\
\hline$L$ & Loading term \\
\hline $1 b$ & Pound \\
\hline LCOE & Levelized cost of energy \\
\hline $\mathrm{m}$ & Meter \\
\hline MEA & Monoethanolamine \\
\hline $\mathrm{mg}$ & Milligram \\
\hline $\min$ & Minute \\
\hline $\mathrm{mL}$ & Milliliter \\
\hline $\mathrm{mm}$ & Millimeter \\
\hline MMBtu/hr & One Million BTU per Hour \\
\hline MOF & Metal Organic Frameworks \\
\hline mol & Mole \\
\hline MW & Megawatt \\
\hline$\mu \mathrm{m}$ & Micrometer \\
\hline NCCC & National Carbon Capture Center \\
\hline NDIR & Nondispersive Infrared Sensor \\
\hline NEPA & National Environmental Policy Act \\
\hline NETL & National Energy Technology Laboratory \\
\hline
\end{tabular}




\begin{tabular}{|c|c|}
\hline $\mathrm{N}_{2}$ & Nitrogen \\
\hline $\mathrm{NH}_{3}$ & Ammonia \\
\hline NO & Nitrogen Monoxide \\
\hline $\mathrm{NO}_{2}$ & Nitrogen Dioxide \\
\hline $\mathrm{NO}_{\mathrm{x}}$ & Nitrous Oxides \\
\hline $\mathrm{O}_{2}$ & Oxygen \\
\hline O\&M & Operations \& Maintenance \\
\hline $\mathrm{P}$ & Pressure \\
\hline PC & Pulverized coal \\
\hline PLC & Programmable Logic Controller \\
\hline ppb & Parts per Billion \\
\hline ppm & Parts per Million \\
\hline $\mathrm{PVC}$ & Polyvinyl chloride \\
\hline Regen & Regeneration \\
\hline RTI & Research Triangle Institute \\
\hline s & Second \\
\hline $\mathrm{sccm}$ & Standard Cubic Centimeters per Minute \\
\hline SDA & Spray Dryer Adsorber \\
\hline $\mathrm{SO}_{2}$ & Sulfur Dioxide \\
\hline $\mathrm{SO}_{\mathrm{x}}$ & Sulfur Oxides \\
\hline $\mathrm{T}$ & Temperature \\
\hline TBD & To be Determined \\
\hline TGA & Thermogravimetric Analyzer \\
\hline TSA & Temperature Swing Adsorption \\
\hline TVA & Tennessee Valley Authority \\
\hline wt & Weight \\
\hline $\mathrm{yr}$ & Year \\
\hline
\end{tabular}




\section{APPENDIX A: STANTEC REPORT: SOLID SORBENT COST OF ELECTRICITY}


Stantec

ADA ENVIRONMENTAL SOLUTIONS

SOLID SORBENT CONCEPT - COST OF ELECTRICITY REPORT

Executive Summary

February 17, 2011

\section{Executive Summary}

The following report provides details on a concept design for the use of solid sorbents for the adsorption of carbon dioxide $\left(\mathrm{CO}_{2}\right)$ from a flue gas. The equipment is designed to capture $90 \%$ of the carbon dioxide arising from the combustion of coal. The equipment is sized to be able to treat $100 \%$ of the flue gas from a specific power plant, in this case AEP Conesville's Unit \#5, which is approximately $430 \mathrm{MW}$ in size.

After providing details on the concept design, the report proceeds to develop high-level capital and operating cost estimates, which are used to produce incremental Levelized Cost of Electricity (LCOE) estimates to add the system to a new coal fired power plant. These calculations were completed using the methodology outlined by the NETL Existing Plant, Emissions and Capture (EPEC) report from April of 2009. Table E-1 shows the results for the base equipment configuration.

The base case plant is assumed to include a Flue Gas Desulphurization (FGD) system; the economics are excluded from the results below.

All the costs are estimated in US dollars.

Table E-1 Calculated Incremental LCOE of the Concept Design

\begin{tabular}{|c|c|}
\hline Parameter & Value \\
\hline Capital Component & $2.45 \mathrm{\phi} / \mathrm{kWh}$ \\
\hline Fixed O\&M Component & $0.23 \$ / \mathrm{kWh}$ \\
\hline Variable O\&M Component & $2.44 \mathrm{c} / \mathrm{kWh}$ \\
\hline Feedstock O\&M Component & $0.02 \$ / k W h$ \\
\hline Total Incremental LCOE & $5.14 \$ / \mathrm{kWh}$ \\
\hline
\end{tabular}

With a new coal power plant LCOE between 6 and $7 \mathrm{\phi} / \mathrm{kWh}$, the increase in LCOE is calculated to be in the range of 73 to $86 \%$, which does not meet the DOE target of $35 \%$. Achieving this target would require a significant (62\%) reduction in capital and variable O\&M costs - major contributors to the LCOE, or a $\mathrm{CO}_{2}$ product revenue of $\mathrm{US} \$ 25.50 /$ tonne $\mathrm{CO}_{2}$.

A sensitivity analysis was performed on the results to determine what drivers make the biggest contribution to the incremental LCOE. It was found that the order of sensitivity of these parameters from the most to the least effect on incremental LCOE was:

capital cost $>$ make-up power cost $>>$ sorbent cost $\approx$ attrition rate $>$ full-time employee amount 
Stantec

ADA ENVIRONMENTAL SOLUTIONS

SOLID SORBENT CONCEPT - COST OF ELECTRICITY REPORT

Executive Summary

February 17, 2011

Comparing with advanced amine-based capture technology integrated with the AEP Conesville's Unit \#5 conducted by DOE/NETL, the solid-based $\mathrm{CO}_{2}$ capture technology demonstrated its potential as a candidate for carbon capture. Table E-2 compares the results from this study to advanced amine results from the DOE work, escalated to today's dollars.

Table E-2 Comparable Technologies

\begin{tabular}{|c|c|c|c|c|}
\hline \multirow[b]{3}{*}{ Description } & \multirow[b]{3}{*}{ Unit } & \multirow[b]{3}{*}{ DOE/NETL } & \multirow{2}{*}{\multicolumn{2}{|c|}{$\begin{array}{c}\text { Solid Sorbent } \\
\text { Base Case } \\
\text { (Without FGD, With Turbine) }\end{array}$}} \\
\hline & & & & \\
\hline & & & $\begin{array}{l}\text { OPTION A: } \\
\text { Without Heat } \\
\text { Recovery }\end{array}$ & $\begin{array}{l}\text { OPTION B: } \\
\text { With Heat } \\
\text { Recovery } \\
\text { Integration } \\
\end{array}$ \\
\hline \multicolumn{5}{|l|}{ Power Plant Performance } \\
\hline 1. Net Plant Output (w/o $\mathrm{CO}_{2}$ Capture) & $(k W)$ & 433,778 & 433,778 & 433,778 \\
\hline $\begin{array}{l}\text { 2. } \begin{array}{l}\text { Total Parasitic Load } \\
\text { due to } \mathrm{CO}_{2} \text { Capture }\end{array} \\
\end{array}$ & $(\mathrm{kW})$ & 175,789 & 118,981 & 114,681 \\
\hline $\begin{array}{ll}2.1 & \text { Auxiliary Power } \\
& \text { (Additional Trim FGD/Cooler) }\end{array}$ & $(\mathrm{kW})$ & 0 & 0 & 0 \\
\hline 2.2 Auxiliary Power $\left(\mathrm{CO}_{2}\right.$ Capture $)$ & $(\mathrm{kW})$ & 55,004 & 48,008 & 48,008 \\
\hline 2.3 Steam Derate $\left(\mathrm{CO}_{2}\right.$ Capture $)$ & $(\mathrm{kW})$ & 120,785 & 70,973 & 66,673 \\
\hline 3. $\quad$ BP Turbine Output & $(\mathrm{kW})$ & 45,321 & 28,526 & 26,999 \\
\hline Net Plant Output (with $\mathrm{CO}_{2}$ Capture) & $(\mathrm{kW})$ & 303,310 & 343,323 & 346,096 \\
\hline \multicolumn{5}{|l|}{$\mathrm{CO}_{2}$ Capture Parameters } \\
\hline $\mathrm{CO}_{2}$ Removal Efficiency & $(\%)$ & 90 & 90 & 90 \\
\hline Solvent Regeneration Energy & $\left(\mathrm{Btu} / \mathrm{lb} \mathrm{CO} \mathrm{CO}_{2}\right)$ & 1,550 & 760 & 760 \\
\hline Steam Requirement & (MMBtu/hr) & $1,218.1$ & 725 & 681 \\
\hline \multicolumn{5}{|l|}{ Costs } \\
\hline \multirow[t]{2}{*}{ Total Investment Cost } & $(\$ 1000)$ & 439,049 & 357,706 & 386,411 \\
\hline & $(\$ / \mathrm{kW})$ & 1,448 & 1,042 & 1,116 \\
\hline Fixed O\&M Cost & $(\$ 1000 / y r)$ & 2,737 & 5,066 & 5,320 \\
\hline Variable O\&M Cost & $(\$ 1000 / y r)$ & 19,363 & 13,014 & 12,940 \\
\hline Feedstock O\&M Cost & $(\$ 1000 / y r)$ & 717 & 465 & 465 \\
\hline Levelized, Make-Up Power Cost & $(\$ 1000 / y r)$ & 68,250 & 47,281 & 45,833 \\
\hline Parasitic Load due to $\mathrm{CO}_{2}$ Capture & $(\mathrm{kW})$ & 130,468 & 90,454 & 87,683 \\
\hline \multicolumn{5}{|l|}{ Incremental LCOE Contributions } \\
\hline Capital Component & $(\Phi / \mathrm{kWh})$ & 3.40 & 2.45 & 2.62 \\
\hline Fixed O\&M Component & $(\Phi / \mathrm{kWh})$ & 0.14 & 0.23 & 0.24 \\
\hline Variable O\&M Component & $(\Phi / \mathrm{kWh})$ & 4.01 & 2.44 & 2.36 \\
\hline Feedstock O\&M Component & $(\$ / \mathrm{kWh})$ & 0.03 & 0.02 & 0.02 \\
\hline Total Incremental LCOE & (\$/kWh) & 7.59 & 5.14 & 5.24 \\
\hline $\begin{array}{l}\text { \% Change in LCOE } \\
\text { Compared to Amine }\end{array}$ & (\%) & $0 \%$ & $-32 \%$ & $-31 \%$ \\
\hline
\end{tabular}


Stantec

ADA ENVIRONMENTAL SOLUTIONS

SOLID SORBENT CONCEPT - COST OF ELECTRICITY REPORT

February 17, 2011

\section{Table of Contents}

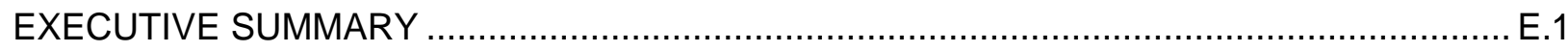

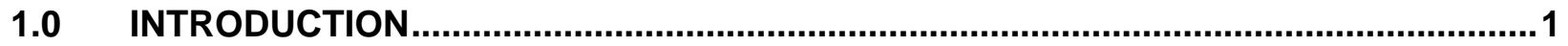

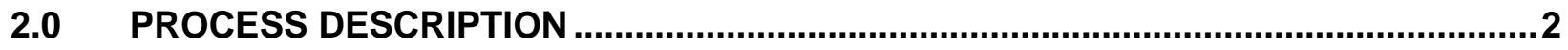

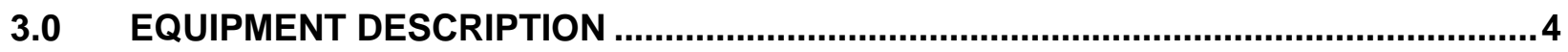

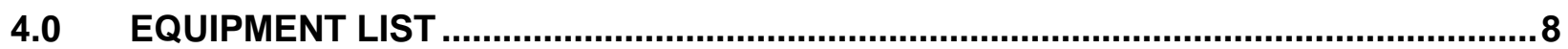

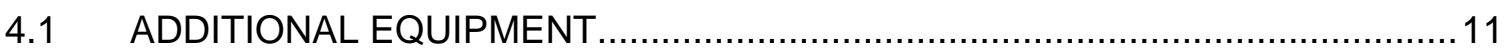

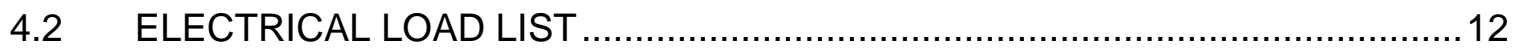

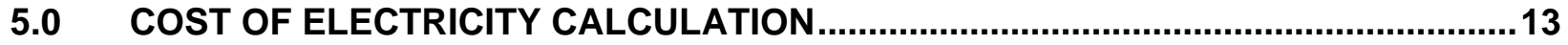

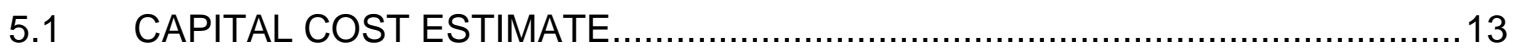

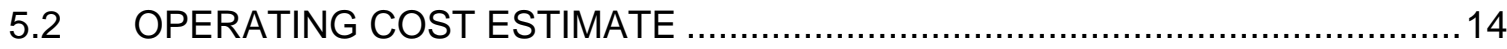

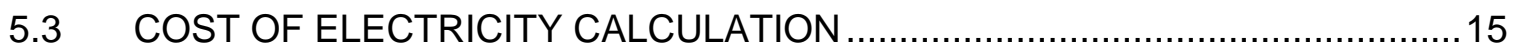

5.3.1 Methodology ................................................................... 15

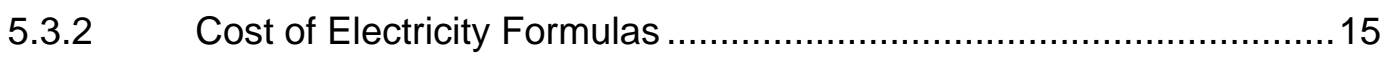

5.3.3 Results ................................................................................. 17

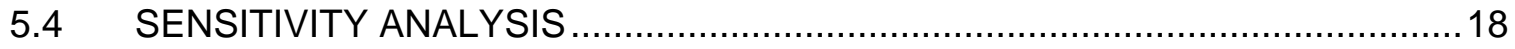

5.4.1 Methodology ........................................................................ 18

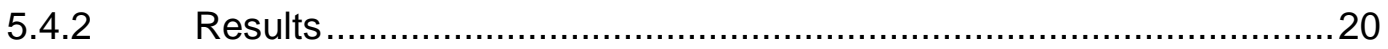

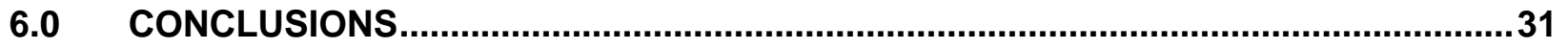

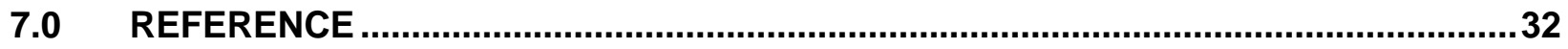

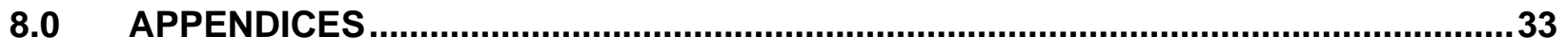

APPENDIX A: COST ESTIMATE DATA ...................................................... 33 
Stantec

ADA ENVIRONMENTAL SOLUTIONS

SOLID SORBENT CONCEPT - COST OF ELECTRICITY REPORT

Introduction

February 17, 2011

\subsection{Introduction}

The following report provides details on a concept design for the use of solid sorbents for the adsorption of carbon dioxide $\left(\mathrm{CO}_{2}\right)$ from a flue gas. The equipment is designed to capture $90 \%$ of the carbon dioxide arising from the combustion of coal. The equipment is sized to be able to treat $100 \%$ of the flue gas from a specific power plant, in this case AEP Conesville's Unit \#5, which is approximately $430 \mathrm{MW}$ in size.

This following design is based on preliminary information provided by ADA-ES pertaining to the expected performance of solid sorbents that they are currently investigating. ADA-ES is pursuing two separate families of sorbents:

- Supported amines

- Activated carbon

Based on experimental results, the proposed capture plant is designed based on the following parameters:

- Particles physically resemble activated carbon with respect to size and density.

- Five seconds of reaction time is required for adsorption.

- 500 seconds of reaction time is required for desorption.

- Heat capacity of the sorbent is $0.3 \mathrm{Btu} / \mathrm{lb}^{\circ} \mathrm{F}$.

- Heat of reaction is $760 \mathrm{Btu} / \mathrm{lb} \mathrm{CO} \mathrm{CO}_{2}$ adsorbed. 


\section{Stantec}

ADA ENVIRONMENTAL SOLUTIONS

SOLID SORBENT CONCEPT - COST OF ELECTRICITY REPORT

Process Description

February 17, 2011

\subsection{Process Description}

An extensive review of equipment capable of employing solid sorbents for carbon capture was carried out in the early phases of this work. During this review, certain technologies were selected that offered the most advantages for contacting flue gas with solids, separating them from the flue gas, heating the solids for regeneration, then cooling them for return to the adsorber. The results of this study were summarized in a Topical Report compiled by ADA-ES entitled "Topical Report 1, 2 and 3: Technology Survey, Screening and Final Selection."

The following technologies were chosen as candidates for the large-scale design:

- Adsorbers:

o Upflow reactor

o Circulating fluidized bed

- Desorbers:

o Rotary kiln / rotary dryer

- Conveying:

o Bucket / belt conveyor 


\section{Stantec}

ADA ENVIRONMENTAL SOLUTIONS

SOLID SORBENT CONCEPT - COST OF ELECTRICITY REPORT

Process Description

February 17, 2011

The different components selected above were then combined in order to meet the process requirements for $\mathrm{CO}_{2}$ adsorption. The final concept arrived at is seen in Figure 2-1.

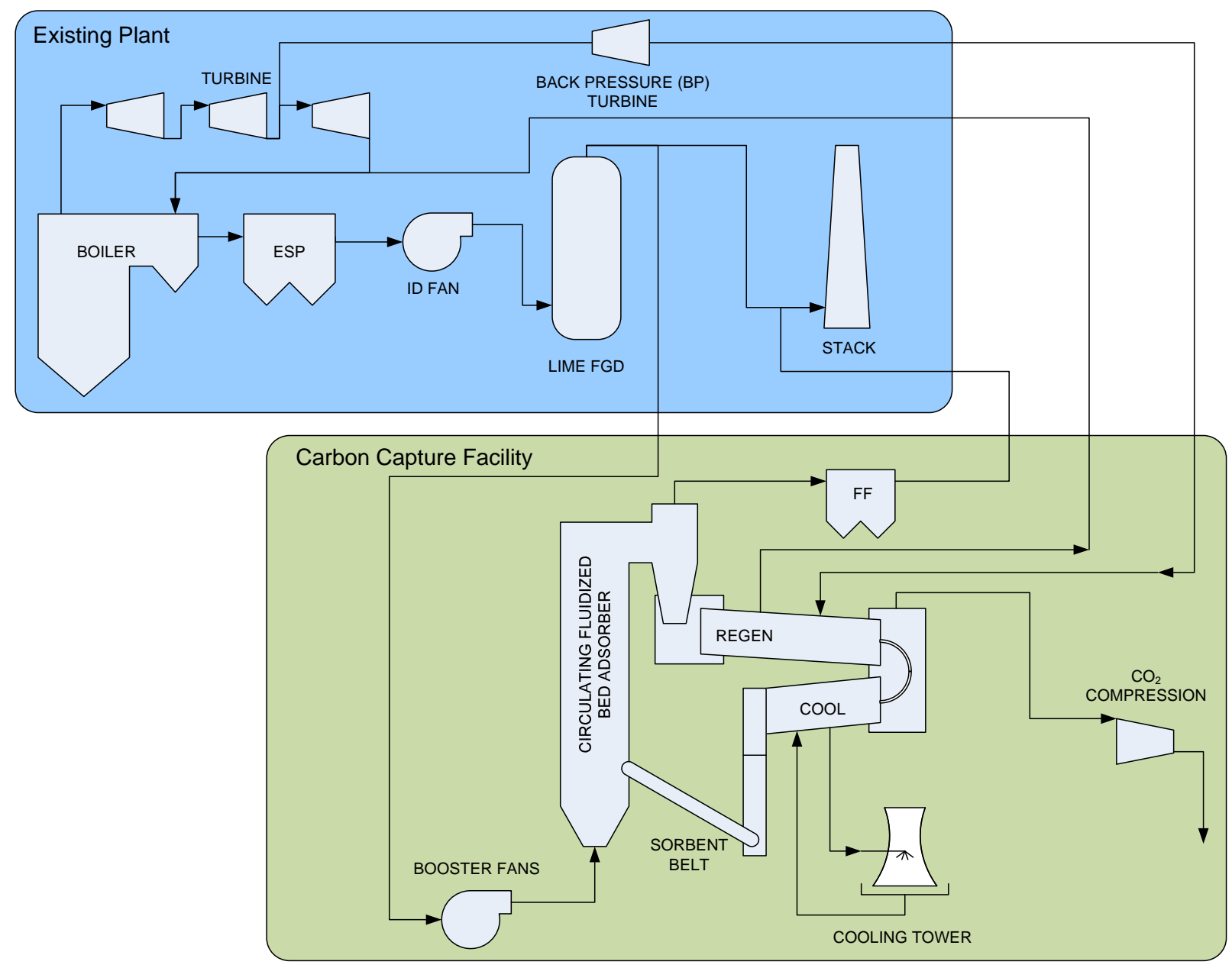

Figure 2-1 Solid-Based $\mathrm{CO}_{2}$ Capture Process Flow Diagram 
Stantec

ADA ENVIRONMENTAL SOLUTIONS

SOLID SORBENT CONCEPT - COST OF ELECTRICITY REPORT

Equipment Description

February 17, 2011

\subsection{Equipment Description}

Flue gas is routed from the existing plant through ductwork to the new carbon capture island. The existing temperature of the Conesville's flue gas after the existing FGD is already at $136^{\circ} \mathrm{F}$, which is a fairly low temperature. A new booster fan is installed to provide sufficient pressure to pass the flue gas through the carbon capture equipment, and return it via ductwork back to the original stack.

Flue gas then enters an adsorber vessel. This vessel is a vertical, cylindrical vessel constructed of carbon steel. Flue gas enters the bottom and proceeds upwards at sufficient velocity to fluidize and transport the solid sorbent, which is also added to the bottom of the vessel. The flue gas and sorbent proceed upwards together, with sufficient height provided in the vessel to provide five seconds of reaction time.

At the top of the vessel, the flue gas exits through four identical banks of multiclones. Multiclones are an older technology previously used in the power industry to remove particulate from flue gas and are essentially comprised of many cyclones arranged in a bank. As the flue gas enters the cyclones and spins, the heavier, denser sorbents are flung to the periphery of the device and collected in hoppers at the bottom of the cyclones, while the flue gas leaves from the side of the device.

The flue gas that leaves the four banks of multiclones is recombined in a duct and is routed to a pulse jet fabric filter, which removes any remaining sorbent, ensuring none is lost or emitted as a pollutant when the flue gas is returned to the stack. The fabric filter will remove very fine sorbent that may have been damaged through attrition, thus collected solids could be removed for disposal if required. Solids could also be routed back to the regenerator from this location. A capital allowance for either option is included in the estimate.

The solids that have been collected in the multiclones fall to the bottom of the devices into four separate hoppers. Here, the regeneration of the solids is broken into two separate equipment trains, which allows for a more reasonable equipment size based on the solids flow rate and desorption time, thus two multiclones banks feed each regeneration train. Sorbent is discharged from the multiclones hoppers through a rotary valve, a gas tight valve that introduces the sorbent into the regenerator, which in this case resembles an indirectly heated kiln, or rotary dryer. This device is essentially a 140-foot long carbon steel tube, with interior flutes that slowly conveys the sorbent from one end to the other along a gentle decline as the whole device turns. Steam from the turbine extracted from the IP/LP crossover pipe is expanded through a back pressure (BP) turbine producing electricity before indirectly heating the devices exterior through a jacket arrangement.

$\mathrm{CO}_{2}$ is released from the sorbent and is transferred to the compression plant through a small fabric filter within the compression plant island in order to protect the compression equipment, 
Stantec

ADA ENVIRONMENTAL SOLUTIONS

SOLID SORBENT CONCEPT - COST OF ELECTRICITY REPORT

Equipment Description

February 17, 2011

then through two, $50 \%$ compression plants that both cools and compresses the $\mathrm{CO}_{2}$ to supercritical conditions suitable for pipeline transport.

The sorbent reaches the end of the regenerator and drops through a chute into the mouth of another rotary vessel, except this vessel is used to cool the sorbent back down to adsorption temperatures. This chute seals both ends of the rotating vessels, which allows the $\mathrm{CO}_{2}$ to be withdrawn and be routed to the compression plant.

The sorbent is cooled by cooling water provided from a four cell-cooling tower of standard design. Water treatment equipment is provided to treat makeup water for this cooling tower.

The now cooled sorbent is discharged to a 60 inch wide belt conveyor which returns to the sorbent to the adsorber. Gas tight equipment is employed here to separate the rich $\mathrm{CO}_{2}$ environment of the regeneration train from the flue gas present in the adsorber. At this point, the two separated regenerator trains are recombined, and the sorbent cycle begins again.

Figure 3-1 shows a conceptual representation of adsorption and desorption equipment along with preliminary sizing. It serves only to demonstrate the preliminary sizes of the important pieces of equipment. Figure 3-2 shows a rough plot plan area for the main equipment plus the fabric filter and compression plant. 
Stantec

ADA ENVIRONMENTAL SOLUTIONS

SOLID SORBENT CONCEPT - COST OF ELECTRICITY REPORT

Equipment Description

February 17, 2011

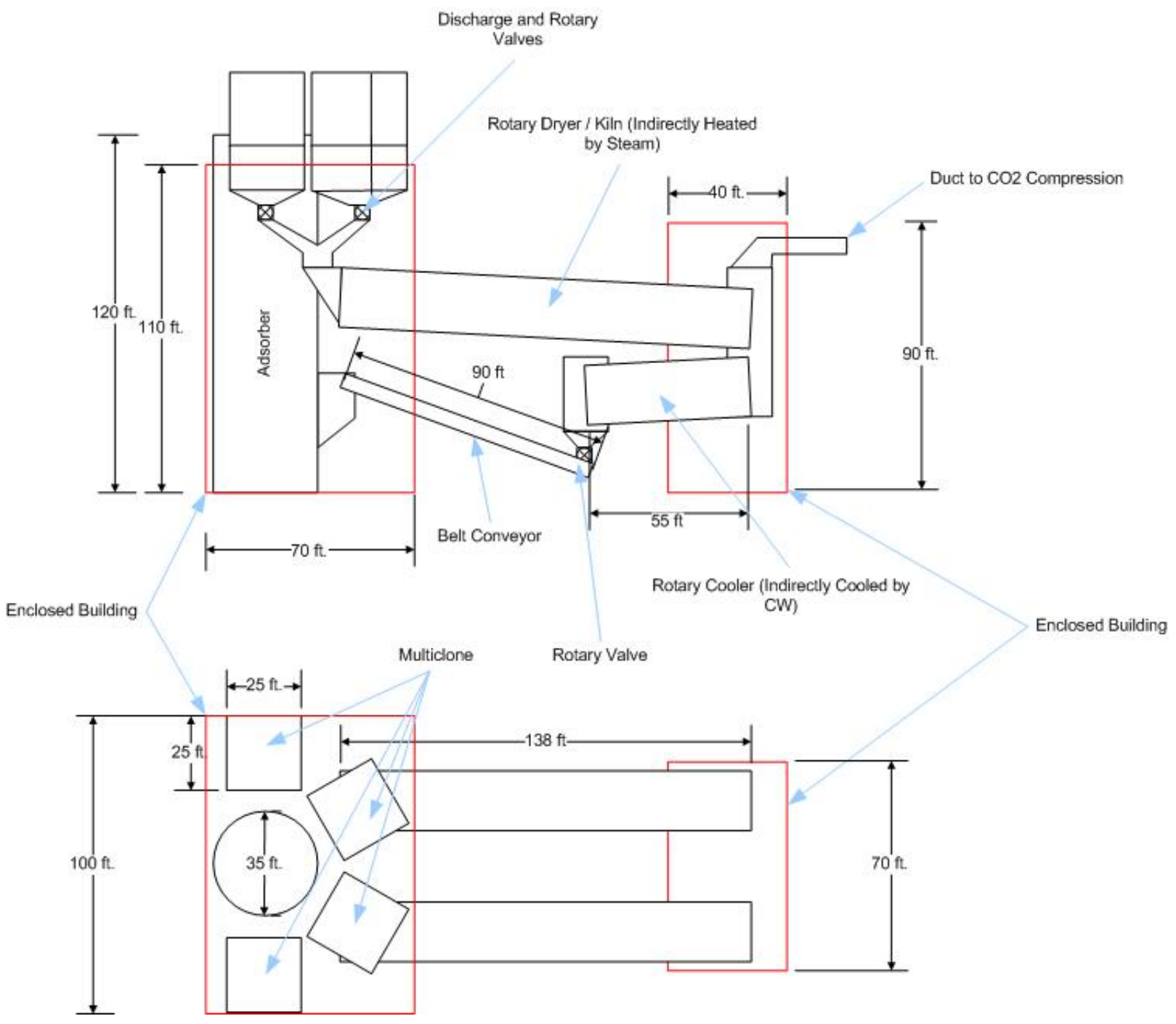

Figure 3-1 Carbon Capture System Key Components 
Stantec

ADA ENVIRONMENTAL SOLUTIONS

SOLID SORBENT CONCEPT - COST OF ELECTRICITY REPORT

Equipment Description

February 17, 2011
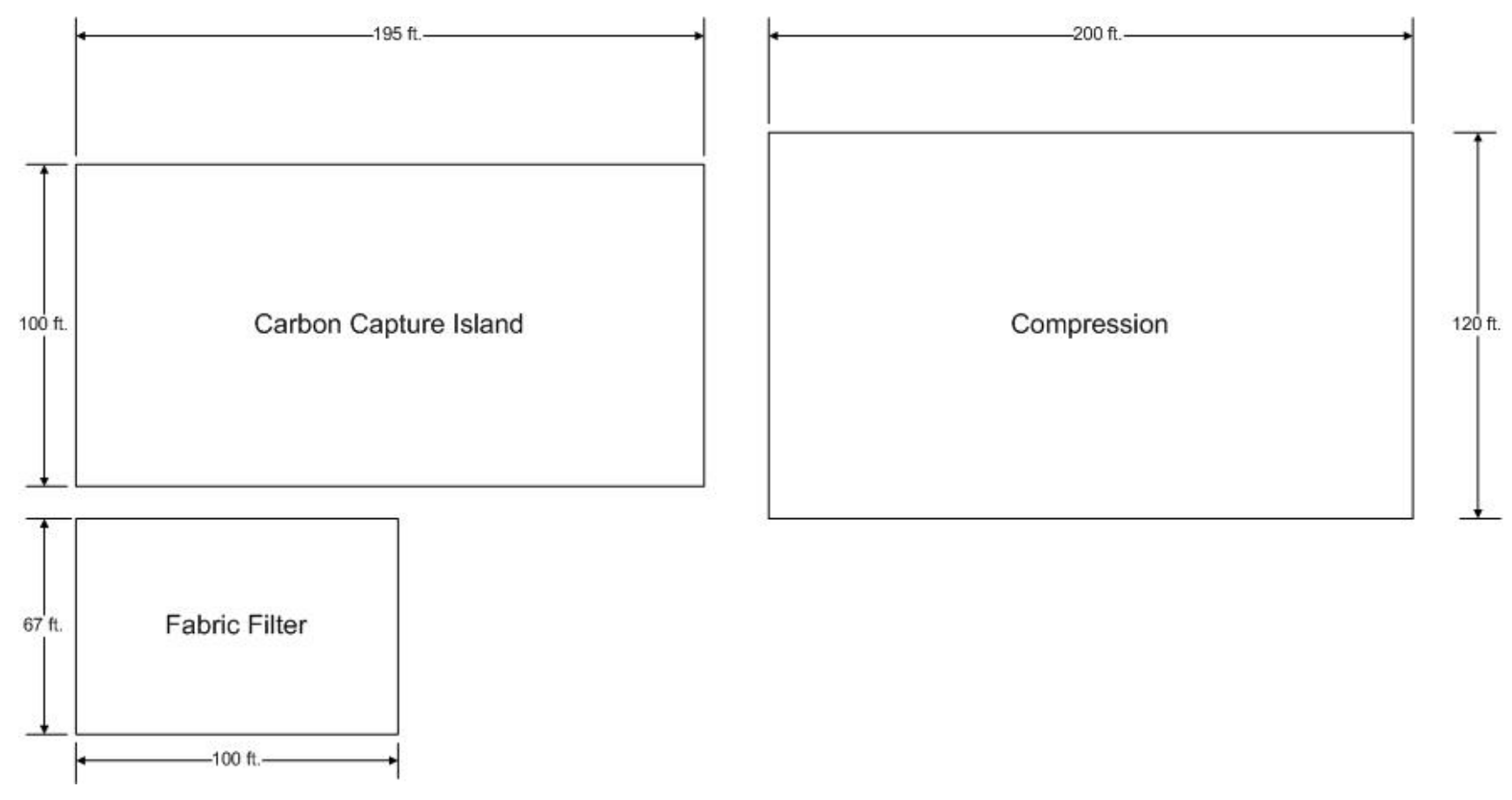

Figure 3-2 Carbon Capture Estimated Footprints 
Stantec

ADA ENVIRONMENTAL SOLUTIONS

SOLID SORBENT CONCEPT - COST OF ELECTRICITY REPORT

Equipment List

February 17, 2011

\subsection{Equipment List}

The following list describes the individual components of the system in more detail:

1. Ductwork from Power Plant to Booster Fan

- Insulated stainless steel

- Length 200 feet

- 21 feet by 21 feet, square duct

2. Trim FGD / Cooler

- 55 feet diameter

- 120 feet tall, stainless steel vessel

- Dual stage, with internals for heat transfer in the cooler section

- Caustic used as scrubber chemical, produces sodium sulphite liquid stream byproduct

3. Back Pressure Turbine ${ }^{1}$

- Air-cooled generator, 3,600 rpm

- $50 \mathrm{MW}$ at a power factor of 0.9

4. Booster Fan

- One, 6,000 HP

5. Ductwork to Adsorber from Booster Fan

- Insulated stainless steel

- Length 200 feet

- 21 feet by 21 feet, square duct

6. Ductwork from Adsorber to Fabric Filter

- Insulated carbon steel

- Length 200 feet

- 21 feet by 21 feet, square duct

\footnotetext{
* Not required for base case, see section 5.4 for details.
} 
Stantec

ADA ENVIRONMENTAL SOLUTIONS

SOLID SORBENT CONCEPT - COST OF ELECTRICITY REPORT

Equipment List

February 17, 2011

7. Ductwork From Fabric Filter Back to Stack

- Insulated carbon steel

- Length 200 feet

- 21 feet by 21 feet, square duct

8. Adsorber

- Insulated carbon steel

- Cylindrical vessel, vertical

- 35 feet diameter

- 120 feet high

9. Multiclones

- Four individual multiclone banks

- 280,000 ACFM per bank

- Dimensions ( $L$ by $W$ by $H$ ): 25 feet by 25 feet by 25 feet

- 325 cyclone tubes per bank

- Discharge hopper on bottom

10. Multiclone Rotary Valves

- Four rotary valves

- 1.8 million pound / hour solids flow per valve

11. Primary Fabric Filter

- Eight compartments

- Overall dimensions 100 feet by 67 feet

- Pulse jet style

12. Regenerator Rotary Heaters

- Two rotary heaters

- 20 feet diameter and 138 feet in length each

- Two, 2,500 HP motors to turn vessel

- Carbon steel

- Jacketed for steam use for heat 
Stantec

ADA ENVIRONMENTAL SOLUTIONS

SOLID SORBENT CONCEPT - COST OF ELECTRICITY REPORT

Equipment List

February 17, 2011

13. Rotary Coolers

- Two rotary coolers

- 20 feet diameter and 55 feet in length each

- Two, 2,300 HP motors to turn vessel

- Carbon steel

- Jacketed for cooling water use

14. Belt Conveyor

- Two separate conveyors side by side

- Two, 100 HP drive motors

- 30 degree incline

- 90 feet in length

- 60 inch belt width

15. Steam Line and Condensate Return

- Steam Supply:

o 250 feet of 52 inch steam pipe from turbine hall to carbon capture island

o 200 feet of branching steam pipe, 36 inches in diameter, one line to each rotary heater

- Condensate return:

o 10 inch diameter and 300 feet long condensate pipe

- Two, 50\% condensate return pumps, $150 \mathrm{HP}$ each

o Condensate storage vessel: 12 feet diameter and 18 feet long horizontal cylindrical vessel

16. $\mathrm{CO}_{2}$ Compressors and Piping

- 200 feet of 8 feet by 8 feet square $\mathrm{CO}_{2}$ duct

- Two, $50 \%$ compressor trains

- $23,500 \mathrm{HP}$ of electrical power for each train

- Includes all gas pretreatment equipment i.e. dust removal (fabric filter)

17. Heat Rejection

- Four, cross flow cells; 36 feet, square cells

- Tower fan power $400 \mathrm{KW}$ 
Stantec

ADA ENVIRONMENTAL SOLUTIONS

SOLID SORBENT CONCEPT - COST OF ELECTRICITY REPORT

Equipment List

February 17, 2011

- Basin is 51 feet by 144 feet

- Piping is 36 inch and 500 feet HDPE piping; buried

- Two, $50 \%$ pumps; $350 \mathrm{HP}$

- Lime softener and reverse osmosis plant

- Flow rate 500 USgpm through water treatment plant

18. Electrical

- Transformers suitable to feed loads described above

- Factors to provide cabling, switchgear, motor control centre (MCC), etc.

19. Instrumentation and Controls

- Factored estimated based on equipment above

20. Site Preparation

- Assume level and clearing of footprint

21. Buildings

- Adsorber enclosure:

o 70 feet by 100 feet by 110 feet tall

- Rotary heater discharge building:

o 70 feet by 40 feet by 90 feet tall

- Compression building:

o 200 feet by 120 feet by 50 feet tall

\subsection{ADDITIONAL EQUIPMENT}

Due to the high level, conceptual nature of this estimate and the level of accuracy, there are undoubtedly some overlooked items. Specific areas that require additional research include instances where mechanical rotary valves or other devices are used to maintain gas seals from the adsorption and regeneration areas. In practice, large industrial screw conveyors may be required to provide a reliable seal, where rotary valves may not be available at the size required. Locations where this might be necessary would be from the discharge of the multiclones into rotary heaters, or from the discharge of the conveyor belts back to the adsorber. As is typical for estimates of this nature, a contingency solely for scope overlooked is included to cover these items. As work progressed, a case was investigated where heat recovery from the regenerated sorbent back to the spent is included in the design. Further details are found in Section 5.4. 
Stantec

ADA ENVIRONMENTAL SOLUTIONS

SOLID SORBENT CONCEPT - COST OF ELECTRICITY REPORT

Equipment List

February 17, 2011

\subsection{ELECTRICAL LOAD LIST}

In order to calculate the derate cost for parasitic power, Table 4-1: Electrical Load List was developed. Electrical motors were sized based on the preliminary equipment sizing described earlier in this section.

Table 4-1 Electrical Load List

\begin{tabular}{||l|c||}
\hline Parameter & HP \\
\hline Booster Fan & 6,000 \\
\hline Rotary Heater A & 2,500 \\
\hline Rotary Heater B & 2,500 \\
\hline Rotary Cooler A & 2,300 \\
\hline Rotary Cooler B & 2,300 \\
\hline Sorbent Belt A & 100 \\
\hline Sorbent Belt B & 100 \\
\hline Condensate Return Pump A & 150 \\
\hline Condensate Return Pump B & 150 \\
\hline Compressor Train A & 23,500 \\
\hline Compressor Train B & 23,500 \\
\hline Tower Fan Power & 540 \\
\hline CW Supply Pump A & 350 \\
\hline CW Supply Pump B & 350 \\
\hline FGD Recirc Pump A & 400 \\
\hline FGD Recirc Pump B & 400 \\
\hline DCC Recirc Pump A & 400 \\
\hline DCC Recirc Pump A & 400 \\
\hline FGD Bleed Pump A & 100 \\
\hline FGD Bleed Pump B & 100 \\
\hline DCC Bleed Pump A & $\mathbf{4 9 , 3 4 0}$ \\
\hline DCC Bleed Pump B & \\
\hline TOTAL & 100 \\
\hline TOTAL & MW \\
\hline
\end{tabular}


Stantec

ADA ENVIRONMENTAL SOLUTIONS

SOLID SORBENT CONCEPT - COST OF ELECTRICITY REPORT

Cost of Electricity Calculation

February 17, 2011

\subsection{Cost of Electricity Calculation}

\subsection{CAPITAL COST ESTIMATE}

The level of cost accuracy for this concept design most closely matches a Class V estimate, as determined by the Association for the Advancement of Cost Engineering International (AACE). A Class $V$ estimate is of suitable accuracy for screening purposes, and applies when a low level of project definition exists. All the costs are estimated in US dollars.

Items specifically excluded from this estimate include:

- Significant modifications to the steam cycle / turbine: It is assumed that steam from the IP crossover is available from a terminal point in the turbine hall.

- Closed loop heating has not been included. During investigation of rotary heaters, it was found that it is common to allow steam to proceed through the shell of the heater via tubes. Utilities may not be comfortable with this in the end and an additional intermediate heat transfer fluid could be used, for minimal expense.

- $\mathrm{CO}_{2}$ pipeline and end user costs: The estimate terminal point with regards to $\mathrm{CO}_{2}$ is the outlet flange of the final stage of compression.

- Specific owner costs pertaining to licensing fees; onsite expertise and allowance for interest during construction.

The capital cost is estimated as an Engineering, Procurement and Construction (EPC) type contract. While this tends to be higher in cost than other contractual arrangements, it tends to have lower risk for the utility.

In this study, the $\mathrm{CO}_{2}$ compression cost is estimated from the compression costs for aminebased $\mathrm{CO}_{2}$ capture processes published in the DOE report ${ }^{2}$. Included in the costs are not only the $\mathrm{CO}_{2}$ compression costs, but also the BP turbine cost and the steam cycle modification costs. The BP turbine cost obtained from the DOE report ${ }^{2}$ is subtracted and is considered as a separate cost. The contribution of the steam cycle modification costs to the compression costs is, however, unknown. As a result, the $\mathrm{CO}_{2}$ compression cost used in this report will provide some unknown, but minor allowance for the steam cycle modification.

Table 5-1 summarizes the capital cost estimate results. Appendix A contains the complete capital cost table. 
Stantec

ADA ENVIRONMENTAL SOLUTIONS

SOLID SORBENT CONCEPT - COST OF ELECTRICITY REPORT

Cost of Electricity Calculation

February 17, 2011

Table 5-1 Capital Cost Summary

\begin{tabular}{||l|c||}
\hline \multicolumn{1}{|c|}{ Parameter } & $\begin{array}{c}\text { Cost } \\
\text { (US\$) }\end{array}$ \\
\hline Direct Subtotal Costs & $\$ 325,100,000$ \\
\hline Expected Extra Scope & $\$ 32,600,000$ \\
\hline Total Direct Cost & $\$ 357,700,000$ \\
\hline
\end{tabular}

Note: A significant portion of the mechanical equipment capital cost $(\sim 20 \%)$ is comprised of compression.

\subsection{OPERATING COST ESTIMATE}

Operating costs were developed based on the following:

- 22 full-time employees (FTE required), assuming 3 shifts, 5 workers per shift plus 7 auxiliary staff (lab technicians, instrument technicians). The annual full cost per full-time employee was estimated to be US\$135,000.

- Maintenance labour cost estimated at $1.5 \%$ of the mechanical equipment.

- Steam derate was estimated using data from the DOE report ${ }^{1}$. A steam derate of 70.9 MW results.

- Parasitic power derate was estimated from Table 4-1 at 49.5 MW.

- Solid sorbent loss of $0.005 \%$ per cycle (attrition).

- Consumables pricing (caustic, lime, sulphuric acid, solid sorbent, etc.) can be found in Appendix A.

Table 5-2 Operating Cost Summary

\begin{tabular}{|l|c|}
\hline \multicolumn{1}{|c|}{ Parameters } & $\begin{array}{c}\text { Cost } \\
\text { (US } \$ \text { ) }\end{array}$ \\
\hline Total Fixed Costs & $\$ 5,066,000 / \mathrm{yr}$ \\
\hline Total Variable Costs & $\$ 13,014,000 / \mathrm{yr}$ \\
\hline Feedstock Costs & $\$ 465,000 / \mathrm{yr}$ \\
\hline Make Up Power Costs & $\$ 47,281,000 / \mathrm{yr}$ \\
\hline
\end{tabular}


Stantec

ADA ENVIRONMENTAL SOLUTIONS

SOLID SORBENT CONCEPT - COST OF ELECTRICITY REPORT

Cost of Electricity Calculation

February 17, 2011

\subsection{COST OF ELECTRICITY CALCULATION}

\subsubsection{Methodology}

In this report, the cost estimating methodology developed by DOE/NETL was used to calculate the incremental Levelized Cost of Electricity (LCOE) due to $\mathrm{CO}_{2}$ capture ${ }^{2}$. The project capital cost estimates (total investment cost or TIC) and the calculated operation and maintenance cost (O\&M) costs were estimated on the basis of October 2010 US dollars.

The cost estimates were developed based on the following assumptions:

- $\mathrm{CO}_{2}$ product pipeline and storage was not included.

- The plant capacity factor was $85 \%$.

- Make-up power cost of $7.02 \mathrm{\$} / \mathrm{kWh}$ (2010 dollar) was used to represent a 20-year levelized cost of electricity of a new subcritical pulverized coal-fired power plant (Greenfield) without carbon capture.

- Costs extracted from the DOE report ${ }^{2}$ for consumables were adjusted to 2010 dollars with an annual inflation rate of $2.35 \%$.

- Potential revenue from selling $\mathrm{CO}_{2}$ product was excluded.

- Makeup sorbent was required to replenish a loss due to degradation of impregnated solvent and attrition. A leakage loss was not accounted for.

\subsubsection{Cost of Electricity Formulas}

Incremental LCOE over a 20-year period was calculated by a following equation. It was a simplified model derived from the NETL Power Systems Financial Model ${ }^{3}$.

$$
\mathrm{LCOE}_{\mathrm{P}}=\frac{\left(\mathrm{CCF}_{\mathrm{P}}\right)(\mathrm{TPC})+\left[\left(\mathrm{LF}_{\mathrm{F} 1}\right)\left(\mathrm{OC}_{\mathrm{F} 1}\right)+\left(\mathrm{LF}_{\mathrm{F} 2}\right)\left(\mathrm{OC}_{\mathrm{F} 2}\right)+\ldots\right]+(\mathrm{CF})\left[\left(\mathrm{LF}_{\mathrm{V} 1}\right)\left(\mathrm{OC}_{\mathrm{V} 1}\right)+\left(\mathrm{LF}_{\mathrm{V} 2}\right)\left(\mathrm{OC}_{\mathrm{V} 2}\right)+\ldots\right]}{(\mathrm{CF})(\mathrm{kWh})}
$$

where

$$
\begin{array}{lll}
\mathrm{LCOE} & = & \text { levelized cost of electricity over } \mathrm{P} \text { years }(\mathrm{\phi} / \mathrm{kWh}) \\
\mathrm{P} & = & \text { levelization period }(e . g ., 10,20 \text { or } 30 \text { years }) \\
\mathrm{CCF} & = & \text { capital charge factor for a levelization period of } \mathrm{P} \text { years } \\
\mathrm{TPC} & = & \text { total plant cost } \\
\mathrm{LF}_{\mathrm{Fn}} & = & \text { levelization factor for category } n \text { fixed operating cost } \\
\mathrm{OC}_{\mathrm{Fn}} & = & \text { category } n \text { fixed operating cost for the initial year of operation (but } \\
\mathrm{CF} & = & \text { expressed in "first-year-of-construction" year dollars }
\end{array}
$$




\section{Stantec}

ADA ENVIRONMENTAL SOLUTIONS

\section{SOLID SORBENT CONCEPT - COST OF ELECTRICITY REPORT}

Cost of Electricity Calculation

February 17, 2011

$$
\begin{array}{lll}
\mathrm{LF}_{\mathrm{Vn}} & = & \begin{array}{l}
\text { levelization factor for category } n \text { variable operating cost } \\
\mathrm{OC}_{\mathrm{Vn}}
\end{array} \quad \begin{array}{l}
\text { category } n \text { variable operating cost at } 100 \% \text { capacity factor for the } \\
\text { initial year of operation (but expressed in "first-year-of- } \\
\text { construction" year dollars }
\end{array} \\
\mathrm{kWh} & =\begin{array}{l}
\text { annual net kilowatt-hours of power generated at } 100 \% \text { capacity } \\
\text { factor }
\end{array}
\end{array}
$$

To reflect the retrofit, total plant cost (TPC) was replaced with TIC in this study. TIC is the sum of bare erected costs - costs of process equipment, support facilities, direct and indirect labor, detailed design costs, construction / project management costs, project and process contingencies.

The capital charge factor and levelization factors were listed in Table 5-3.

Table 5-3 Economic Parameters for Incremental LCOE Calculation

\begin{tabular}{|l|c|c|}
\hline Parameter & Unit & Value \\
\hline Capital Charge Factor & - & 0.175 \\
\hline Fixed O\&M Levelization Factor & - & 1.1568 \\
\hline Variable O\&M Levelization Factor & - & 1.1568 \\
\hline Feedstock O\&M Levelization Factor & - & 1.1651 \\
\hline
\end{tabular}


Stantec

ADA ENVIRONMENTAL SOLUTIONS

SOLID SORBENT CONCEPT - COST OF ELECTRICITY REPORT

Cost of Electricity Calculation

February 17, 2011

These factors were derived from the economic assumptions listed in Table 5-4.

Table 5-4 Economic Assumptions

\begin{tabular}{|l|c|c|}
\hline Parameter & Unit & Value \\
\hline Income Tax Rate & $\%$ & 38 \\
\hline Repayment Term of Debt & years & 15 \\
\hline Grace Period on Debt Repayment & years & 0 \\
\hline Debt Reserve Fund & - & None \\
\hline Depreciation (150\% declining balance) & years & 20 \\
\hline Working Capital (all parameters) & $\$$ & 0 \\
\hline Plant Economic Life & years & 30 \\
\hline Investment Tax Credit & $\%$ & 0 \\
\hline Tax Holiday & years & 0 \\
\hline Start-Up Costs (\% of EPC) & $\%$ & 2 \\
\hline All other additional capital costs & $\$$ & 0 \\
\hline EPC Escalation & $\%$ & 0 \\
\hline Duration of Construction & years & 3 \\
\hline
\end{tabular}

\subsubsection{Results}

The results for the incremental LCOE evaluation are illustrated in Table 5-5 and Figure 5-1.

Table 5-5 Incremental LCOE Contributions

\begin{tabular}{|c|c|}
\hline Parameter & Value \\
\hline Capital Component & $2.45 \mathrm{c} / \mathrm{kWh}$ \\
\hline Fixed O\&M Component & $0.23 \mathrm{\phi} / \mathrm{kWh}$ \\
\hline Variable O\&M Component & $2.44 \mathrm{c} / \mathrm{kWh}$ \\
\hline Feedstock O\&M Component & $0.02 \mathrm{c} / \mathrm{kWh}$ \\
\hline Total Incremental LCOE & 5.14 \$/kWh \\
\hline
\end{tabular}




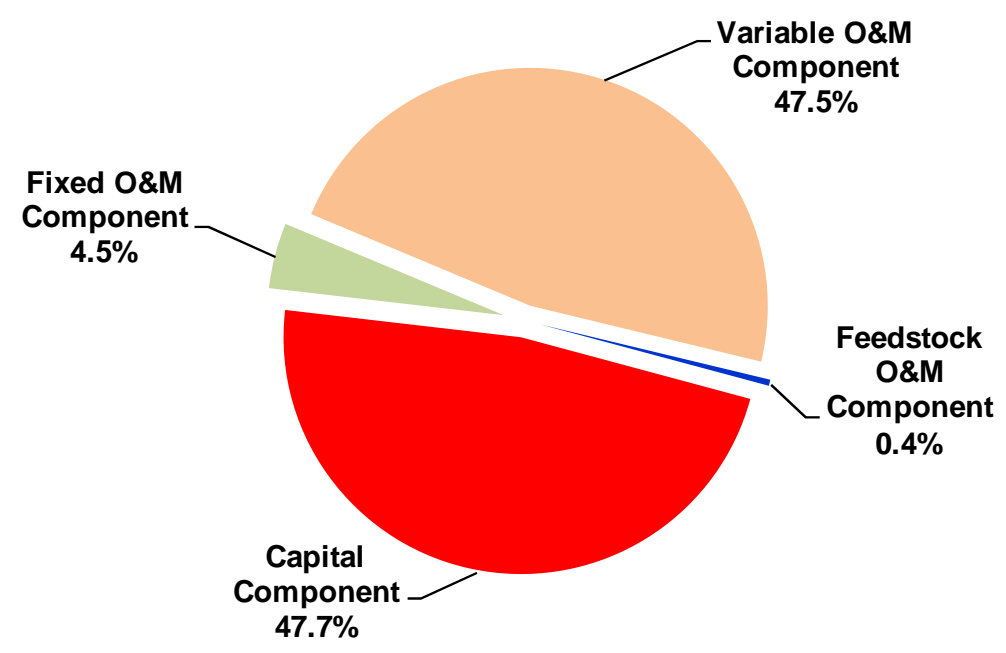

Figure 5-1 LCOE Percentage

For a new coal-fired power plant with a LCOE of 6 to $7 \mathrm{\$} / \mathrm{kWh}$ (DOE report value) ${ }^{4}$, this represents an increase in the cost of electricity of 73 to $86 \%$, greater than the DOE target of $35 \%$. Capital and variable O\&M costs are the two largest contributions ( $95 \%$ combined) to the incremental LCOE.

\subsection{SENSITIVITY ANALYSIS}

\subsubsection{Methodology}

A sensitivity analysis was carried out to understand the parametric effects on the incremental LCOE. It was conducted by varying parameters that impact the economic analysis. There were two types of parameters analyzed, process-related and cost-related parameters. The processrelated parameters reflected the energy optimization and the process integration of a $\mathrm{CO}_{2}$ capture system into the coal-fired power plant. They include a heat recovery system, an installation of a trim FGD / cooler to clean the flue gas ( $\leq 1 \mathrm{ppmv} \mathrm{SO}_{2}$ if existing FGD is insufficient) before entering the $\mathrm{CO}_{2}$ capture and a use of a back pressure turbine to gain electricity from steam attemperation. Together, they generate two options and each option has four cases as follows:

\section{Option A: Without Heat Recovery System}

- Case 1A: WITHOUT a trim FGD / cooler, WITH a BP turbine (Base Case)

- Case 2A: WITHOUT a trim FGD / cooler, WITHOUT a BP turbine

- Case 3A: WITH a trim FGD / cooler, WITH a BP turbine

- Case 4A: WITH a trim FGD / cooler, WITHOUT a BP turbine 
Stantec

ADA ENVIRONMENTAL SOLUTIONS

SOLID SORBENT CONCEPT - COST OF ELECTRICITY REPORT

Cost of Electricity Calculation

February 17, 2011

\section{Option B: With Heat Recovery System}

- Case 1B: WITHOUT a trim FGD / cooler, WITH a BP turbine

- Case 2B: WITHOUT a trim FGD / cooler, WITHOUT a BP turbine

- Case 3B: WITH a trim FGD / cooler, WITH a BP turbine

- Case 4B: WITH a trim FGD / cooler, WITHOUT a BP turbine

Note that Case 1A is the base process configuration from Section 5.3.

The heat recovery system was designed to use water as a heat transfer fluid to transfer sensible heat from the pre-cooler to preheat the solid sorbents in the pre-heater as shown in Figure 5-2. The approach temperature was assumed to be $18^{\circ} \mathrm{F}$. This energy optimization was expected to reduce the steam requirement for sorbent regeneration and the size of the cooling tower, which would result in reduced cooling water consumption.

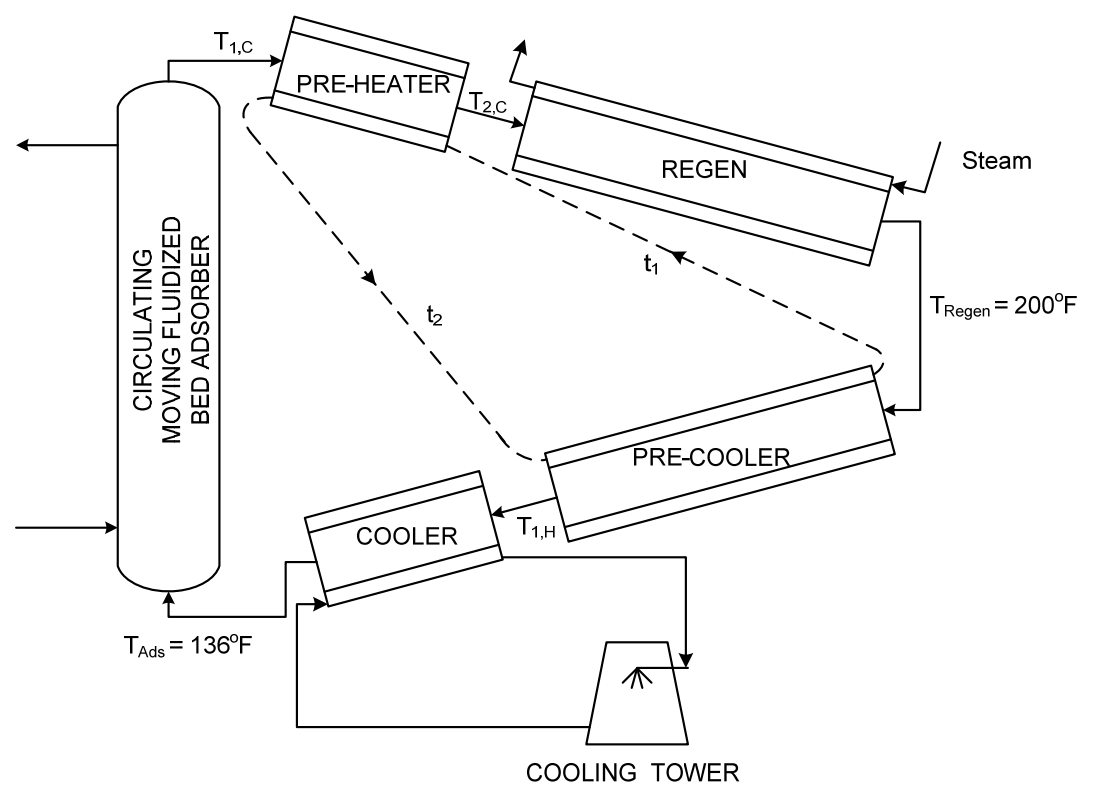

Figure 5-2 Simplified Solid-Based $\mathrm{CO}_{2}$ Capture Process Flow Diagram with Heat Recovery System

Confining the analysis to the Base Case, each of the cost-related parameters, attrition rate, sorbent cost, capital cost, the number of full-time employees and makeup-power cost, was varied $\pm 10 \%$ of the original value and all remaining parameters were left unchanged. The trends of these sensitivities were assumed to be identical for the other seven cases.

A further analysis to meet the DOE target of $35 \%$ increase in $\mathrm{LCOE}$, a reduction in the capital and variable O\&M costs - major contributors to $\mathrm{LCOE} \mathrm{-} \mathrm{and} \mathrm{a} \mathrm{CO}_{2}$ product revenue to offset LCOE was also investigated. 
Stantec

ADA ENVIRONMENTAL SOLUTIONS

SOLID SORBENT CONCEPT - COST OF ELECTRICITY REPORT

Cost of Electricity Calculation

February 17, 2011

\subsubsection{Results}

1. Option A: Without Heat Recovery System

Economic Analysis

Results in Figure 5-3 were presented in terms of a percent change in the incremental LCOE compared to the Base Case LCOE as the parameter of interest was varied. The base value was represented by the point where all the sensitivity curves intercept.

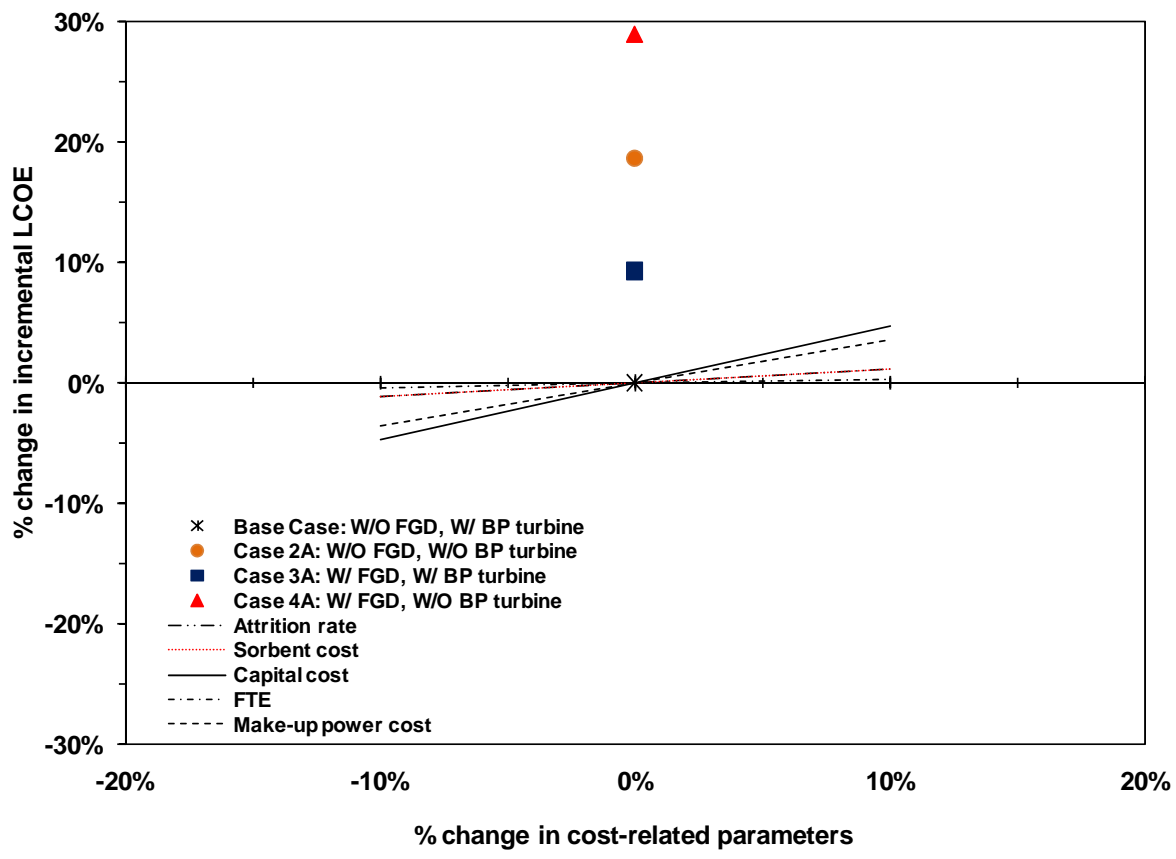

Figure 5-3 Sensitivity Analysis of Parameters of Option A (without Heat Recovery System) on the Percent Change in Incremental LCOE

Economic results for all cases were summarized in Table 5-6. Across the span of the four cases investigated, the Base Case gave the minimum LCOE. Without a trim FGD / cooler, both capital and O\&M costs were decreased whereas an installation of a BP turbine improved the net power output, which could offset capital cost and reduce makeup power cost. It should be noted that when the sorbent degradation due to the $\mathrm{SO}_{2}$ concentration in the flue gas becomes a serious concern, an installation of a trim FGD / cooler to reduce $\mathrm{SO}_{2}$ concentration will be considered to be essential for this adsorption process to remove $\mathrm{CO}_{2}$ efficiently despite an increase in costs. From the annual costs and the incremental LCOE breakdown of Case 3A shown in Figure 5-4, an installation of a trim FGD / cooler can contribute up to $13.3 \%$ of the total cost (or $8.1 \%$ of LCOE) whereas the cost of the BP turbine is $4.1 \%$ of the total cost (or $2.3 \%$ of LCOE). The details of cost breakdown were given in Table 5-7. 
Stantec

ADA ENVIRONMENTAL SOLUTIONS

SOLID SORBENT CONCEPT - COST OF ELECTRICITY REPORT

Cost of Electricity Calculation

February 17, 2011

In particular, the incremental $\mathrm{LCOE}$ of the Base Case varied within the maximum range of $\pm 5 \%(4.89-5.38 \mathrm{\phi} / \mathrm{kWh})$ as the cost-related parameters were changed within $\pm 10 \%$. In general, an increase in these parameters would cause an increase in the incremental LCOE. The order of sensitivity of these parameters from the most to the least effect on incremental LCOE was: capital cost > make-up power cost $>>$ sorbent cost $\approx$ attrition rate $>$ full-time employee number.

Table 5-6 Economic Results for Option A

\begin{tabular}{|c|c|c|c|c|c|}
\hline Description & Unit & $\begin{array}{l}\text { Base Case } \\
\text { (without } \\
\text { FGD, with } \\
\text { BP turbine) }\end{array}$ & $\begin{array}{c}\text { Case 2A } \\
\text { (without } \\
\text { FGD, without } \\
\text { BP turbine) }\end{array}$ & $\begin{array}{c}\text { Case 3A } \\
\text { (with FGD, } \\
\text { with BP } \\
\text { turbine) } \\
\end{array}$ & $\begin{array}{c}\text { Case 4A } \\
\text { (with FGD, } \\
\text { without BP } \\
\text { turbine) }\end{array}$ \\
\hline \multicolumn{6}{|l|}{ Power Plant Performance } \\
\hline $\begin{array}{l}\text { Net Plant Output } \\
\text { (without } \mathrm{CO}_{2} \text { Capture) }\end{array}$ & $\mathrm{kW}$ & 433,778 & 433,778 & 433,778 & 433,778 \\
\hline $\begin{array}{l}\text { Auxiliary Power } \\
\text { (Trim FGD / Cooler) }\end{array}$ & $\mathrm{kW}$ & 0 & 0 & 1,492 & 1,492 \\
\hline Auxiliary Power $\left(\mathrm{CO}_{2}\right.$ Capture $)$ & $\mathrm{kW}$ & 48,008 & 48,008 & 48,008 & 48,008 \\
\hline Steam Derate $\left(\mathrm{CO}_{2} \text { Capture }\right)^{\dagger}$ & $\mathrm{kW}$ & 70,973 & 70,973 & 70,973 & 70,973 \\
\hline BP Turbine Output & $\mathrm{kW}$ & 28,526 & 0 & 28,526 & 0 \\
\hline $\begin{array}{l}\text { Net Plant Output } \\
\text { (with } \mathrm{CO}_{2} \text { Capture) }\end{array}$ & kW & 343,323 & 314,797 & 341,831 & 313,305 \\
\hline \multicolumn{6}{|l|}{ Costs } \\
\hline Total Investment Cost & $\begin{array}{l}\$ 1000 \\
\$ / \mathrm{kW}\end{array}$ & $\begin{array}{r}357,706 \\
1,042 \\
\end{array}$ & $\begin{array}{r}339,860 \\
1,080 \\
\end{array}$ & $\begin{array}{r}414,651 \\
1,213 \\
\end{array}$ & $\begin{array}{r}396,905 \\
1,267 \\
\end{array}$ \\
\hline Fixed O\&M Cost & $\$ 1000 / \mathrm{yr}$ & 5,066 & 4,917 & 5,546 & 5,397 \\
\hline Variable O\&M Cost & $\$ 1000 / y r$ & 13,014 & 13,014 & 13,271 & 13,271 \\
\hline Feedstock O\&M Cost & $\$ 1000 / y r$ & 465 & 465 & 465 & 465 \\
\hline $\begin{array}{l}\text { Levelized Makeup Power Cost } \\
\text { Parasitic Load due to } \mathrm{CO}_{2} \text { Capture }\end{array}$ & $\begin{array}{c}\$ 1000 / \mathrm{yr} \\
\mathrm{kW}\end{array}$ & $\begin{array}{l}47,281 \\
90,454 \\
\end{array}$ & $\begin{array}{r}62,192 \\
118,981 \\
\end{array}$ & $\begin{array}{l}48,061 \\
91,946 \\
\end{array}$ & $\begin{array}{r}62,972 \\
120,473 \\
\end{array}$ \\
\hline \multicolumn{6}{|l|}{ Incremental LCOE Contributions } \\
\hline Capital Component & $\Phi / \mathrm{kWh}$ & 2.45 & 2.54 & 2.85 & 2.98 \\
\hline Fixed O\&M Component & $\Phi / \mathrm{kWh}$ & 0.23 & 0.24 & 0.25 & 0.27 \\
\hline Variable O\&M Component & $\Phi / \mathrm{kWh}$ & 2.44 & 3.30 & 2.49 & 3.36 \\
\hline Feedstock O\&M Component & $\$ / \mathrm{kWh}$ & 0.02 & 0.02 & 0.02 & 0.02 \\
\hline Total incremental LCOE & $\$ / k W h$ & 5.14 & 6.10 & 5.62 & 6.63 \\
\hline \% Change in LCOE & $\%$ & $0 \%$ & $18.7 \%$ & $9.3 \%$ & $29.0 \%$ \\
\hline
\end{tabular}

\footnotetext{
${ }^{\dagger}$ The steam derate was estimated for the energy requirement of $725 \mathrm{MMBtu} / \mathrm{hr}$ for sorbent regeneration.
} 
Stantec

ADA ENVIRONMENTAL SOLUTIONS

SOLID SORBENT CONCEPT - COST OF ELECTRICITY REPORT

Cost of Electricity Calculation

February 17, 2011

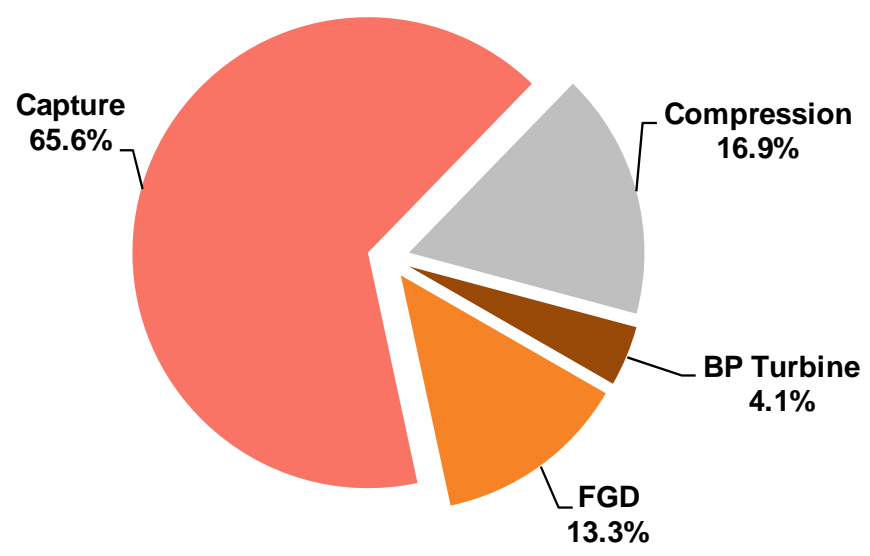

(a) Annual Cost

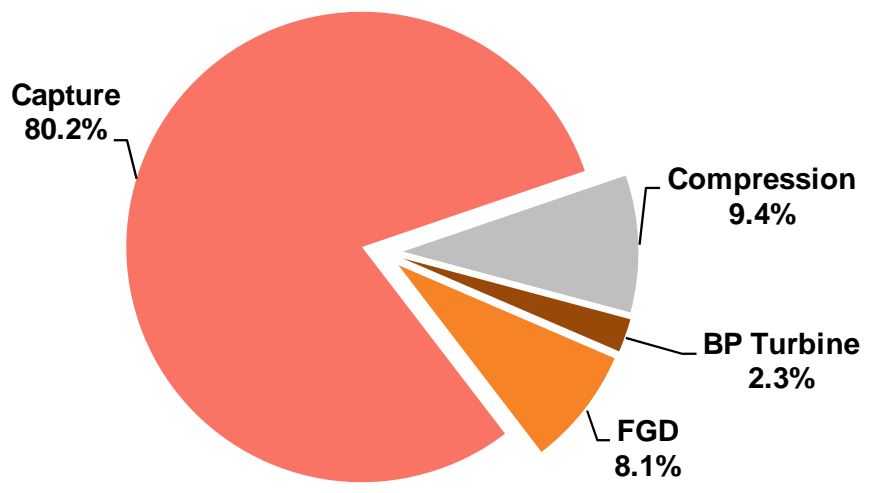

(b) Incremental LCOE

Figure 5-4 Cost Breakdown of Case 3A 
Stantec

ADA ENVIRONMENTAL SOLUTIONS

SOLID SORBENT CONCEPT - COST OF ELECTRICITY REPORT

Cost of Electricity Calculation

February 17, 2011

Table 5-7 Details of Cost Breakdown for Case 3A

\begin{tabular}{|c|c|c|c|c|c|c|}
\hline Description & Unit & BP Turbine & FGD & Capture & Compression & Total \\
\hline \multicolumn{7}{|l|}{ Costs (Annual) } \\
\hline Capital Cost & $1000 \$ / y r$ & $17,846,000$ & $57,046,000$ & $267,166,000$ & $72,794,000$ & $414,852,000$ \\
\hline Fixed O\&M Cost & $1000 \$ / y r$ & 149,000 & 480,000 & $4,305,000$ & 612,000 & $5,546,000$ \\
\hline $\begin{array}{l}\text { Variable O\&M Cost } \\
\text { Variable Cost } \\
\text { Make-up Power Cost } \\
\text { Power Reduction }\end{array}$ & $\begin{array}{c}1000 \$ / \mathrm{yr} \\
1000 \$ / \mathrm{yr} \\
\mathrm{kW}\end{array}$ & $\begin{array}{l}0 \\
0 \\
0\end{array}$ & $\begin{array}{r}256,000 \\
780 \\
1,492 \\
\end{array}$ & $\begin{array}{r}13,014,000 \\
47,300 \\
90,454 \\
\end{array}$ & $\begin{array}{l}0 \\
0 \\
0\end{array}$ & $\begin{array}{r}13,270,000 \\
48,080 \\
91,946 \\
\end{array}$ \\
\hline Feedstock O\&M Cost & $1000 \$ / y r$ & 0 & 0 & 464,900 & 0 & 464,900 \\
\hline Total & $1000 \$ / y r$ & $17,995,000$ & $57,782,780$ & $284,997,200$ & $73,406,000$ & $434,180,980$ \\
\hline Percentage & $\%$ & 4.1 & 13.3 & 65.6 & 16.9 & 100 \\
\hline \multicolumn{7}{|l|}{ Incremental LCOE } \\
\hline Capital Component & $\Phi / \mathrm{kWh}$ & 0.12 & 0.39 & 1.84 & 0.50 & 2.85 \\
\hline Fixed O\&M & $\$ / k W h$ & 0.01 & 0.02 & 0.20 & 0.03 & 0.25 \\
\hline \begin{tabular}{|l|} 
Variable O\&M \\
Variable \\
Make-up Power Cost \\
\end{tabular} & $\begin{array}{l}\Phi / k W h \\
\Phi / k W h\end{array}$ & $\begin{array}{l}0 \\
0 \\
\end{array}$ & $\begin{array}{l}0.01 \\
0.03 \\
\end{array}$ & $\begin{array}{l}0.59 \\
1.86 \\
\end{array}$ & $\begin{array}{l}0 \\
0 \\
\end{array}$ & $\begin{array}{l}0.60 \\
1.89 \\
\end{array}$ \\
\hline Feedstock O\&M & $\$ / k W h$ & 0 & 0 & 0.02 & 0 & 0.02 \\
\hline Total & $1000 \$ / y r$ & 0.13 & 0.46 & 4.50 & 0.53 & 5.62 \\
\hline Percentage & $\%$ & 2.3 & 8.1 & 80.2 & 9.4 & 100 \\
\hline
\end{tabular}

Achieving the DOE Target - Capital and Variable O\&M Costs

In order to reach the DOE target of $35 \%$ increase in LCOE, the incremental LCOE due to the $\mathrm{CO}_{2}$ capture can be no higher than $2.10 \mathrm{~g} / \mathrm{kWh}$ above the LCOE of the non-capture equivalent power plant $(6.0 \mathrm{\$} / \mathrm{kWh})$, or in other words, $3.04 \mathrm{\$} / \mathrm{kWh}$ must be removed from the Base Case's incremental LCOE. Assuming the cut is evenly shared between the two major costs - capital and variable O\&M, both capital and variable O\&M costs ( $\$ 1000 / \mathrm{yr})$ were reduced simultaneously to 0.93 and $0.92 \mathrm{\$} / \mathrm{kWh}$, respectively. Results in Table 5-8 show that a significant $62 \%$ reduction on the capital cost and variable O\&M cost are necessary to achieve the DOE target of $2.10 \mathrm{\$} / \mathrm{kWh}$. In addition, the sensitivity chart in Figure 5-5 shows that the incremental LCOE can be varied from 2.10 to 8.18 $\$ / \mathrm{kWh}$ at a $\pm 62 \%$ variation of both costs. Comparing to the LCOE of amine-based capture technology at $7.59 \mathrm{\$} / \mathrm{kWh} 1$ implies that in order for the solid-based capture technology to remain competitive, the costs should not be increased by more than $50 \%$ of the Base Case costs. A detailed comparison between these two technologies can be found in Section 5.4.2. 
ADA ENVIRONMENTAL SOLUTIONS

SOLID SORBENT CONCEPT - COST OF ELECTRICITY REPORT

Cost of Electricity Calculation

February 17, 2011

Table 5-8 Comparable Incremental LCOE between Base Case and Base Case with $35 \%$ Increase in LCOE - Reduction in Costs

\begin{tabular}{|c|c|c|c|}
\hline Description & Unit & Base Case $^{\ddagger}$ & $\begin{array}{c}\text { Base Case with } \\
35 \% \text { Increase in } \\
\text { LCOE }\end{array}$ \\
\hline \multicolumn{4}{|l|}{ Costs } \\
\hline Total Investment Cost & $\$ 1000$ & 357,706 & 135,841 \\
\hline Fixed O\&M Cost & $\$ 1000 / y r$ & 5,066 & 5,066 \\
\hline Variable O\&M Cost ${ }^{\S, *}$ & $\$ 1000 / y r$ & 53,886 & 20,323 \\
\hline Feedstock O\&M Cost & $\$ 1000 / y r$ & 465 & 465 \\
\hline \multicolumn{4}{|l|}{ Incremental LCOE Contributions } \\
\hline Capital Component & $\Phi / k W h$ & 2.45 & 0.93 \\
\hline Fixed O\&M Component & $\Phi / \mathrm{kWh}$ & 0.23 & 0.24 \\
\hline Variable O\&M Component & $\Phi / k W h$ & 2.44 & 0.92 \\
\hline Feedstock O\&M Component & $\Phi / \mathrm{kWh}$ & 0.02 & 0.02 \\
\hline Total incremental LCOE & $\Phi / k W h$ & 5.14 & 2.10 \\
\hline$\%$ Change in Total Investment Cost & $\%$ & $0 \%$ & $-62 \%$ \\
\hline$\%$ Change in Variable O\&M Cost & $\%$ & $0 \%$ & $-62 \%$ \\
\hline$\%$ Change in LCOE & $\%$ & $0 \%$ & $-59 \%$ \\
\hline
\end{tabular}

${ }^{\ddagger}$ An increase in LCOE of Base Case was 86\%.

$\S$ The makeup power cost was included in the variable O\&M cost.

** Unlike the variable O\&M cost, the annual makeup power cost was calculated from the levelized makeup power cost $(\mathrm{\Phi} / \mathrm{kWh})$ and, therefore, was not multiplied by the variable O\&M levelization factor when calculating the incremental LCOE. A sum of these two costs without adjusting the annual makeup power cost will not yield the same incremental LCOE. To correct this problem, the new annual makeup power cost was recalculated where the variable O\&M levelization factor was taken into consideration. As a result, the total annual variable O\&M cost given in this table was not equal to the sum of the annual variable O\&M cost and levelized makeup power cost given in Table 5-6 (Base Case). 
Stantec

ADA ENVIRONMENTAL SOLUTIONS

SOLID SORBENT CONCEPT - COST OF ELECTRICITY REPORT

Cost of Electricity Calculation

February 17, 2011

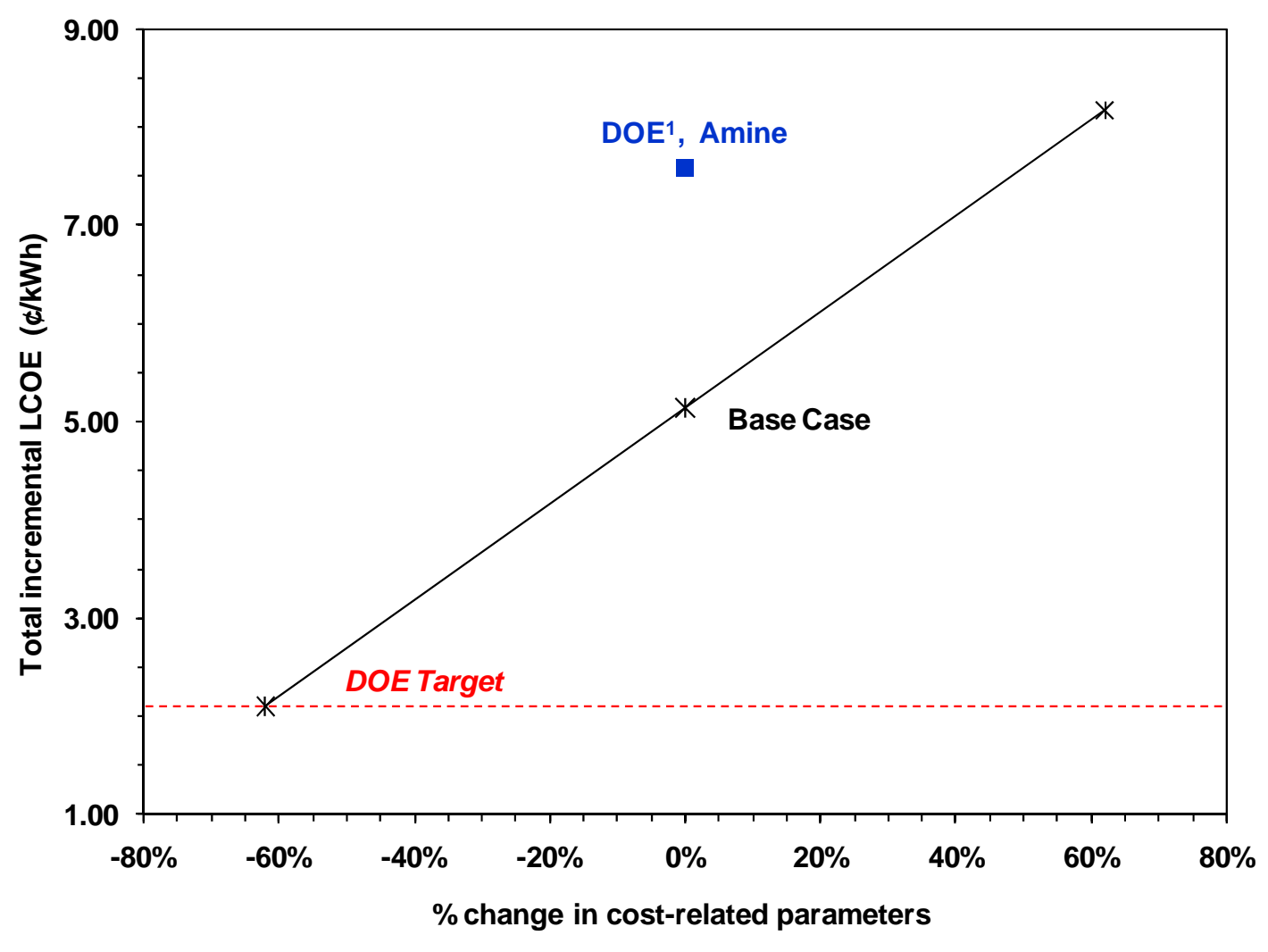

Figure 5-5 Sensitivity Analysis of Capital Cost and Variable O\&M Cost of Base Case

Achieving the DOE Target $-\mathrm{CO}_{2}$ Product Revenue

The objective of this section was to find the $\mathrm{CO}_{2}$ product selling price that can offset the incremental LCOE by $3.04 \mathrm{~d} / \mathrm{kWh}$. Results in Table 5-9 suggest that the $\mathrm{CO}_{2}$ product selling price should be approximately US $\$ 25.50$ /tonne $\mathrm{CO}_{2}$. Although $\mathrm{CO}_{2}$ sales are not a component of this study, sale of $\mathrm{CO}_{2}$ for EOR purposes has a major effect or system economics. 
Stantec

ADA ENVIRONMENTAL SOLUTIONS

SOLID SORBENT CONCEPT - COST OF ELECTRICITY REPORT

Cost of Electricity Calculation

February 17, 2011

Table 5-9 Comparable Incremental LCOE Between Base Case and Base Case With $35 \%$ Increase in LCOE - $\mathrm{CO}_{2}$ Product Revenue

\begin{tabular}{|c|c|c|c|}
\hline Description & Unit & Base Case $^{\dagger \dagger}$ & $\begin{array}{c}\text { Base Case } \\
\text { with } 35 \% \text { increase } \\
\text { in LCOE }\end{array}$ \\
\hline \multicolumn{4}{|l|}{ Costs } \\
\hline Total Investment Cost & $\$ 1000$ & 357,706 & 357,706 \\
\hline Fixed O\&M Cost & $\$ 1000 / y r$ & 5,066 & 5,066 \\
\hline Variable O\&M Cost & $\$ 1000 / y r$ & 13,014 & 13,014 \\
\hline Feedstock O\&M Cost & $\$ 1000 / y r$ & 465 & 465 \\
\hline Levelized, Make-up Power Cost & $\$ 1000 / y r$ & 47,281 & 47,281 \\
\hline $\begin{array}{l}\mathrm{CO}_{2} \text { Product Revenue } \\
\mathrm{CO}_{2} \text { product selling price } \\
\mathrm{CO}_{2} \text { product }\end{array}$ & $\begin{array}{c}\$ 1000 / \mathrm{yr} \\
\$ / \text { tonne } \\
\mathrm{kg} / \mathrm{hr} \\
\text { tonne/yr }\end{array}$ & $\begin{array}{r}0 \\
0 \\
353,890 \\
2,635,065\end{array}$ & $\begin{array}{r}67,127 \\
25.5 \\
353,890 \\
2,635,065\end{array}$ \\
\hline \multicolumn{4}{|l|}{ Incremental LCOE Contributions } \\
\hline Capital Component & $\$ / k W h$ & 2.45 & 2.45 \\
\hline Fixed O\&M Component & $\Phi / k W h$ & 0.23 & 0.23 \\
\hline Variable O\&M Component & $\Phi / \mathrm{kWh}$ & 2.44 & 2.44 \\
\hline Feedstock O\&M Component & $\$ / k W h$ & 0.02 & 0.02 \\
\hline $\mathrm{CO}_{2}$ Product Revenue & $\Phi / \mathrm{kWh}$ & 0 & (3.04) \\
\hline Total incremental LCOE & $\Phi / k W h$ & 5.14 & 2.10 \\
\hline
\end{tabular}

2. Option B: Heat Recovery

\section{Effect on $\mathrm{CO}_{2}$ Capture Process}

Results in Figures 5-6 and 5-7 demonstrated that 33\% of the sensible heat can be recovered by the heat recovery system to preheat the sorbent from $144^{\circ} \mathrm{F}$ to $162^{\circ} \mathrm{F}$ and precool it from $200^{\circ} \mathrm{F}$ to $179^{\circ} \mathrm{F}$. This resulted in a $6 \%$ and $32 \%$ reduction in steam and cooling water consumptions, respectively, when comparing with Option A in Table 5-10.

Economic Analysis

As summarized in Table 5-11, Option $B$ gave the same trend of a percent change in the incremental LCOE compared to the Case 1B LCOE as that of Option A, where Case 1B would offer a minimum LCOE. From these results, it was uneconomical to apply heat recovery system to the solid-based $\mathrm{CO}_{2}$ capture process since the LCOEs of Option $\mathrm{B}$ were slightly higher than those of Option A. This was due to an increase in the capital

\footnotetext{
${ }^{{ }^{\dagger+}}$ An increase in LCOE of Base Case was $86 \%$.
} 
Stantec

ADA ENVIRONMENTAL SOLUTIONS

\section{SOLID SORBENT CONCEPT - COST OF ELECTRICITY REPORT}

\section{Cost of Electricity Calculation}

February 17, 2011

cost that would trade-off the benefits gained from the heat recovery system - a reduction of the variable O\&M cost and the makeup power cost as well as an increase in net plant output due to a small steam requirement. Also, the capital cost saved from a reduced cooling tower was too small to negate the additional capital cost required for the heat recovery system.

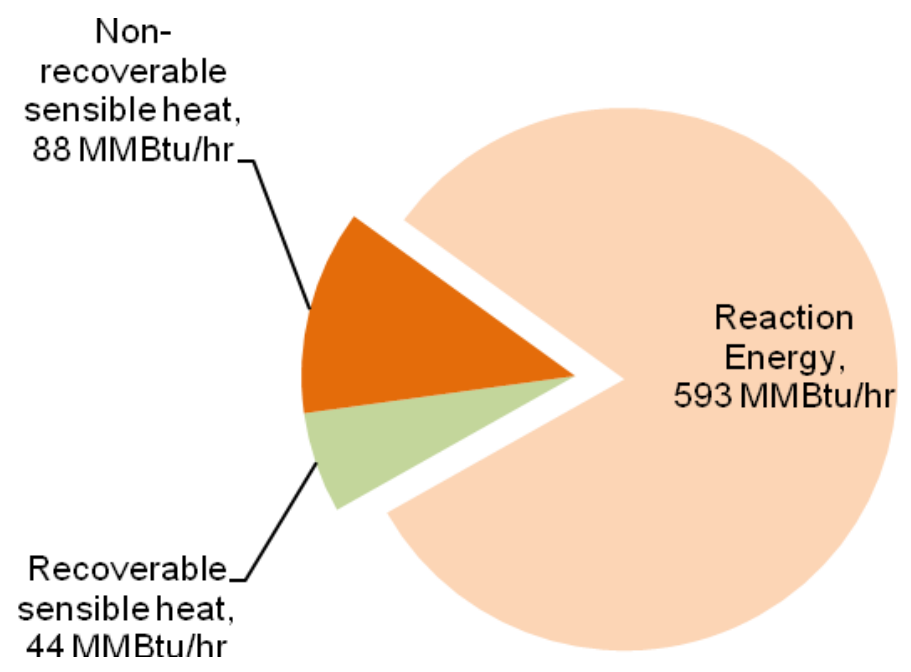

Figure 5-6 Regeneration Energy Requirement

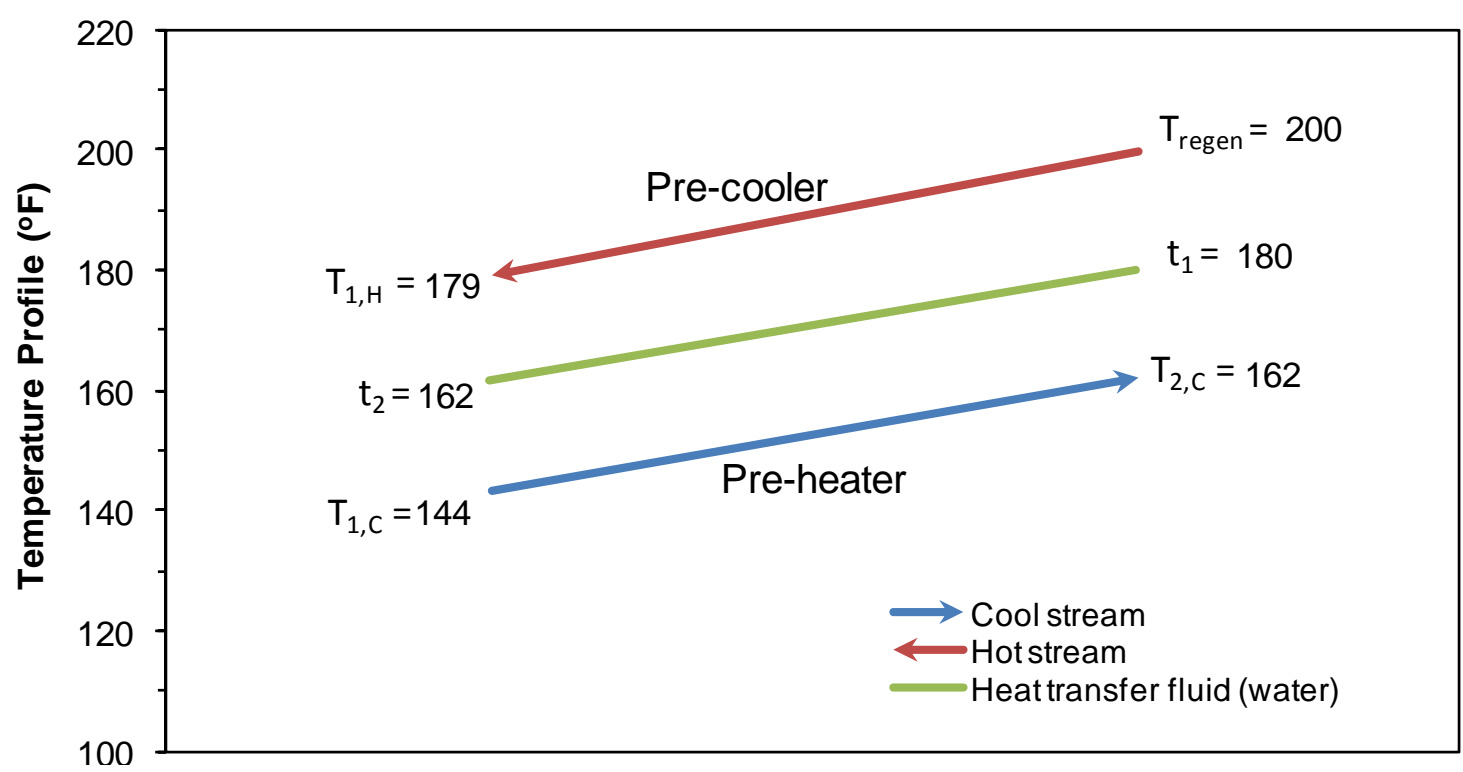

Figure 5-7 Temperature Profile 
Stantec

ADA ENVIRONMENTAL SOLUTIONS

SOLID SORBENT CONCEPT - COST OF ELECTRICITY REPORT

Cost of Electricity Calculation

February 17, 2011

Table 5-10 Comparable Steam and Cooling Water Consumption

\begin{tabular}{|c|c|c|c||}
\hline \multicolumn{1}{|c|}{ Description } & Unit & $\begin{array}{c}\text { Option A: } \\
\text { Without Heat } \\
\text { Recovery System }\end{array}$ & $\begin{array}{c}\text { Option B: } \\
\text { With Heat } \\
\text { Recovery System }\end{array}$ \\
\hline 1. Total Steam Requirement & $(\mathrm{MMBtu} / \mathrm{hr})$ & 725 & 681 \\
\hline 1.1. Reaction Energy & $(\mathrm{MMBtu} / \mathrm{hr})$ & 593 & 593 \\
\hline 1.2. Net Sensible Heat Requirement & $(\mathrm{MMBtu} / \mathrm{hr})$ & 132 & 88 \\
\hline$\bullet$ Non-Recoverable & $(\mathrm{MMBtu} / \mathrm{hr})$ & 132 & 88 \\
\hline$\bullet$ Recoverable & $(\mathrm{MMBtu} / \mathrm{hr})$ & 0 & 44 \\
\hline $1.3 \%$ Total Sensible Heat & $(\mathrm{MMBtu} / \mathrm{hr})$ & 132 & 132 \\
\hline 2. Cooling Water Consumption & $(\%)$ & 0 & 6 \\
\hline
\end{tabular}


Stantec

ADA ENVIRONMENTAL SOLUTIONS

SOLID SORBENT CONCEPT - COST OF ELECTRICITY REPORT

Cost of Electricity Calculation

February 17, 2011

Table 5-11 Economic Results for Option B

\begin{tabular}{|c|c|c|c|c|c|}
\hline Description & Unit & $\begin{array}{c}\text { Case 1B } \\
\text { (without FGD, } \\
\text { with BP } \\
\text { turbine) } \\
\end{array}$ & $\begin{array}{c}\text { Case 2B } \\
\text { (without FGD, } \\
\text { without BP } \\
\text { turbine) } \\
\end{array}$ & $\begin{array}{c}\text { Case 3B } \\
\text { (with FGD, } \\
\text { with BP } \\
\text { turbine) } \\
\end{array}$ & $\begin{array}{c}\text { Case 4B } \\
\text { (with FGD, } \\
\text { without BP } \\
\text { turbine) } \\
\end{array}$ \\
\hline \multicolumn{6}{|l|}{ Power Plant Performance } \\
\hline $\begin{array}{l}\text { Net Plant Output } \\
\text { (without } \mathrm{CO}_{2} \text { Capture) }\end{array}$ & $\mathrm{kW}$ & 433,778 & 433,778 & 433,778 & 433,778 \\
\hline $\begin{array}{l}\text { Auxiliary Power } \\
\text { (Trim FGD / Cooler) }\end{array}$ & kW & 0 & 0 & 1,492 & 1,492 \\
\hline Auxiliary Power $\left(\mathrm{CO}_{2}\right.$ Capture $)$ & $\mathrm{kW}$ & 48,008 & 48,008 & 48,008 & 48,008 \\
\hline Steam Derate $\left(\mathrm{CO}_{2} \text { Capture }\right)^{\ddagger \ddagger}$ & $\mathrm{kW}$ & 66,673 & 66,673 & 66,673 & 66,673 \\
\hline BP Turbine Output & $\mathrm{kW}$ & 26,999 & 0 & 26,999 & 0 \\
\hline $\begin{array}{l}\text { Net Plant Output } \\
\text { (with } \mathrm{CO}_{2} \text { Capture) }\end{array}$ & kW & 346,096 & 319,097 & 344,604 & 317,605 \\
\hline \multicolumn{6}{|l|}{ Costs } \\
\hline Total Investment Cost & $\begin{array}{l}\$ 1000 \\
\$ / k W\end{array}$ & $\begin{array}{r}386,411 \\
1,116 \\
\end{array}$ & $\begin{array}{r}369,068 \\
1,157 \\
\end{array}$ & $\begin{array}{r}443,457 \\
1,287 \\
\end{array}$ & $\begin{array}{r}426,114 \\
1,342 \\
\end{array}$ \\
\hline Fixed O\&M Cost & $\$ 1000 / y r$ & 5,320 & 5,175 & 5,800 & 5,655 \\
\hline Variable O\&M Cost & $\$ 1000 / y r$ & 12,940 & 12,940 & 13,197 & 13,197 \\
\hline Feedstock O\&M Cost & $\$ 1000 / y r$ & 465 & 465 & 465 & 465 \\
\hline $\begin{array}{l}\text { Levelized Makeup Power Cost } \\
\text { Parasitic Load due to } \mathrm{CO}_{2} \\
\text { Capture }\end{array}$ & $\begin{array}{l}\$ 1000 / \mathrm{yr} \\
\mathrm{kW}\end{array}$ & $\begin{array}{l}45,833 \\
87,683\end{array}$ & $\begin{array}{r}59,945 \\
114,682\end{array}$ & $\begin{array}{l}46,613 \\
89,175\end{array}$ & $\begin{array}{r}60,725 \\
116,174\end{array}$ \\
\hline \multicolumn{6}{|l|}{ Incremental LCOE Contributions } \\
\hline Capital Component & $\Phi / k W h$ & 2.62 & 2.72 & 3.02 & 3.15 \\
\hline Fixed O\&M Component & $\Phi / \mathrm{kWh}$ & 0.24 & 0.25 & 0.26 & 0.28 \\
\hline Variable O\&M Component & $\$ / \mathrm{kWh}$ & 2.36 & 3.15 & 2.41 & 3.21 \\
\hline Feedstock O\&M Component & $\$ / \mathrm{kWh}$ & 0.02 & 0.02 & 0.02 & 0.02 \\
\hline Total incremental LCOE & $\$ / k W h$ & 5.24 & 6.15 & 5.72 & 6.67 \\
\hline$\%$ Change in LCOE & $\%$ & $0.0 \%$ & $17.2 \%$ & $9.1 \%$ & $27.1 \%$ \\
\hline
\end{tabular}

\# The steam derate was estimated for the energy requirement of $681 \mathrm{MMBtu} / \mathrm{hr}$ for sorbent regeneration. 
Stantec

ADA ENVIRONMENTAL SOLUTIONS

SOLID SORBENT CONCEPT - COST OF ELECTRICITY REPORT

Cost of Electricity Calculation

February 17, 2011

\section{Comparison}

In this section, both performance and economic results of solid sorbents (Cases $1 \mathrm{~A}$ and 1B) were compared with those of advanced amine-based capture technology integrated to the AEP Conesville's Unit \#5 in Table 5-12. Since the information of the amine technology was extracted from a study conducted by DOE/NETL in $2006^{1}$, all the estimated costs were escalated to 2010 dollars.

The solid-based capture technology showed a superior performance to the advanced amine technology as a net plant output in both cases was significantly improved. From the economic viewpoint, it showed positive results where the incremental LCOEs were much lower by $32 \%$ than that of the advanced amine system.

Table 5-12 Comparable Technologies

\begin{tabular}{|c|c|c|c|c|}
\hline \multirow{2}{*}{ Description } & \multirow{2}{*}{ Unit } & \multirow{2}{*}{$\begin{array}{c}\text { MEA } \\
\text { DOE/NETL }\end{array}$} & \multicolumn{2}{|c|}{ Solid Sorbent } \\
\hline & & & CASE 1A & CASE 1B \\
\hline \multicolumn{5}{|l|}{ Power Plant Performance } \\
\hline 1. Net Plant Output (w/o $\mathrm{CO}_{2}$ capture) & $(\mathrm{kW})$ & 433,778 & 433,778 & 433,778 \\
\hline $\begin{array}{l}\text { 2. Total Parasitic Load } \\
\text { due to } \mathrm{CO}_{2} \text { Capture }\end{array}$ & $(\mathrm{kW})$ & 175,789 & 118,981 & 114,681 \\
\hline $\begin{array}{l}\text { 2.1 Auxiliary Power } \\
\text { (Additional Trim FGD/Cooler) }\end{array}$ & $(\mathrm{kW})$ & 0 & 0 & 0 \\
\hline 2.2 Auxiliary Power $\left(\mathrm{CO}_{2}\right.$ Capture) & $(\mathrm{kW})$ & 55,004 & 48,008 & 48,008 \\
\hline 2.3 Steam Derate $\left(\mathrm{CO}_{2}\right.$ Capture $)$ & $(\mathrm{kW})$ & 120,785 & 70,973 & 66,673 \\
\hline 3. $\quad$ BP Turbine Output & $(\mathrm{kW})$ & 45,321 & 28,526 & 26,999 \\
\hline Net Plant Output (with $\mathrm{CO}_{2}$ Capture) & $(\mathrm{kW})$ & 303,310 & 343,323 & 346,096 \\
\hline \multicolumn{5}{|l|}{$\mathrm{CO}_{2}$ Capture Parameters } \\
\hline $\mathrm{CO}_{2}$ Removal Efficiency & $(\%)$ & 90 & 90 & 90 \\
\hline Solvent Regeneration Energy & $\left(\mathrm{Btu} / \mathrm{lbCO}_{2}\right)$ & 1,550 & 760 & 760 \\
\hline Steam Requirement & (MMBtu/hr) & $1,218.1$ & 725 & 681 \\
\hline \multicolumn{5}{|l|}{ Costs } \\
\hline \multirow[t]{2}{*}{ Total Investment Cost } & $(\$ 1000)$ & 439,049 & 357,706 & 386,411 \\
\hline & $(\$ / \mathrm{kW})$ & 1,448 & 1,042 & 1,116 \\
\hline Fixed O\&M Cost & $(\$ 1000 / y r)$ & 2,737 & 5,066 & 5,320 \\
\hline Variable O\&M Cost & $(\$ 1000 / y r)$ & 19,363 & 13,014 & 12,940 \\
\hline Feedstock O\&M Cost & $(\$ 1000 / y r)$ & 717 & 465 & 465 \\
\hline Levelized, Make-Up Power Cost & $(\$ 1000 / y r)$ & 68,250 & 47,281 & 45,833 \\
\hline Parasitic Load due to $\mathrm{CO}_{2}$ Capture & $(\mathrm{kW})$ & 130,468 & 90,454 & 87,683 \\
\hline \multicolumn{5}{|l|}{ Incremental LCOE Contributions } \\
\hline Capital Component & $(\$ / \mathrm{kWh})$ & 3.40 & 2.45 & 2.62 \\
\hline Fixed O\&M Component & $(\mathrm{c} / \mathrm{kWh})$ & 0.14 & 0.23 & 0.24 \\
\hline Variable O\&M Component & $(\$ / \mathrm{kWh})$ & 4.01 & 2.44 & 2.36 \\
\hline Feedstock O\&M Component & $(\$ / \mathrm{kWh})$ & 0.03 & 0.02 & 0.02 \\
\hline Total Incremental LCOE & (\$/kWh) & 7.59 & 5.14 & 5.24 \\
\hline \% Change in LCOE Compared to Amine & $(\%)$ & $0 \%$ & $-32 \%$ & $-31 \%$ \\
\hline
\end{tabular}


Stantec

ADA ENVIRONMENTAL SOLUTIONS

SOLID SORBENT CONCEPT - COST OF ELECTRICITY REPORT

Conclusions

February 17, 2011

\subsection{Conclusions}

Working backwards from the DOE / NETL target of 35\% increase in the cost of electricity, and beginning at $6.0 \mathrm{\$} / \mathrm{kWh}$, implies that the targeted LCOE increase is no higher than $2.10 \mathrm{c} / \mathrm{kWh}$. Solid sorbents as investigated in this report do not meet this target. At the conclusion of a sensitivity analysis, the items below were found to be opportunities to reduce the LCOE.

- Sorbent development could proceed where no FGD or cooling is required to preheat the flue gas. This would eliminate a sizeable portion of capital cost.

- The working capacity of the sorbent (assumed to be $10 \%$ ) could be increased to lower the solids flow rate, and reduce the size of all regenerating equipment.

- A more rigorous look at using back pressure turbines to recover latent heat from the steam used for regeneration.

- Integrating the solid-sorbent technology into the new, capture-ready coal-fired power plant is more economical than retrofitting the existing power plant.

The biggest part of the O\&M costs is the makeup power rate, which is a direct result of the derate. The steam derate is reasonable for what is assumed thus far, and the parasitic load is comprised mostly of the compression load. Opportunities to refine these loads are limited.

Even though the estimate does not meet the DOE target, it is important to note that the results are competitive with state of the art amine systems integrated into AEP Conesville's Unit \# $5^{1}$. 


\section{Stantec}

ADA ENVIRONMENTAL SOLUTIONS

SOLID SORBENT CONCEPT - COST OF ELECTRICITY REPORT

Reference

February 17, 2011

\subsection{Reference}

1 Final report - Carbon Dioxide Capture from Existing Coal-Fired Power Plants, DOE/NETL- 401/110907, November 2007.

2 Final report - Cost and Performance Baseline for Fossil Plants, Volume 1: Bituminous Coal and Natural Gas to Electricity, DOE/NETL-2007/1281, August 2007.

$3 \quad$ Power Systems Financial Model Version 5.0, September 2006.

4 Existing Plants, Emissions and Capture - Setting $\mathrm{CO}_{2}$ Program Goals, DOE/NETL2009/1366, April 2009. 
Stantec

ADA ENVIRONMENTAL SOLUTIONS

SOLID SORBENT CONCEPT - COST OF ELECTRICITY REPORT

Appendices

February 17, 2011

\subsection{Appendices}

APPENDIX A: Cost Estimate Data 


\section{Stantec}

ADA ENVIRONMENTAL SOLUTIONS

SOLID SORBENT CONCEPT - COST OF ELECTRICITY REPORT

February 17, 2011

Cost Estimate Data 


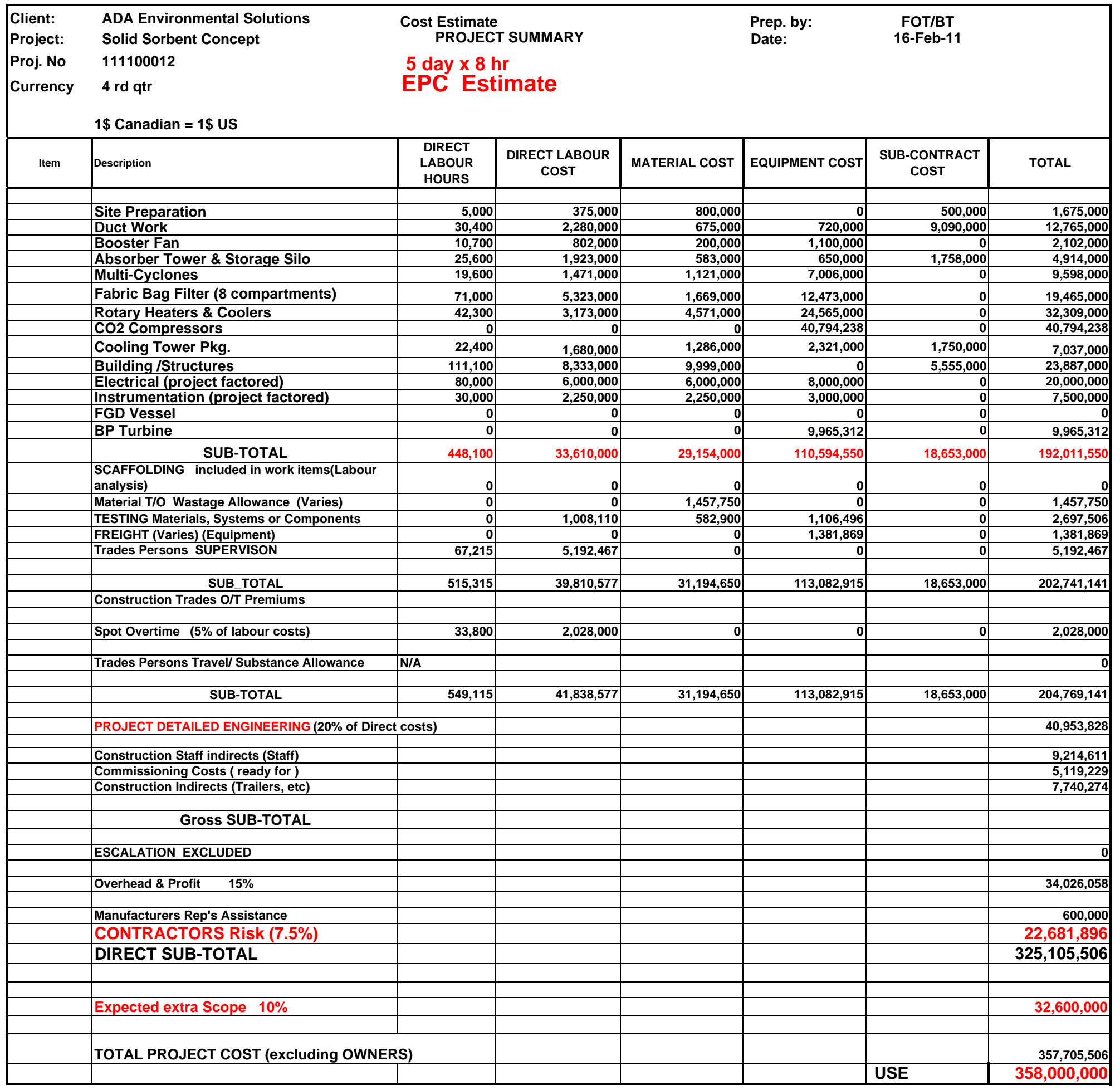


STANTEC CONSULTING LTD.

Project:

ADA

Initial and Annual Operating and Maintenance (O\&M) Cost Estimate

Prepared By: BT

Date:

16-Feb-11

Job No.:

111100012

File Location:

Revision:

Plant Performance:

Note: Input variables in shaded areas.

Net electricity output (w/o capture):

Heat output to capture system:

Total auxiliary power - Power plant:

Total auxiliary power - $\mathrm{CO}_{2}$ capture:

Total auxiliary power - FGD:

BP turbine generator output:

Plant capacity factor:

\begin{tabular}{|c|c|}
\hline 433,778 & kWe \\
\hline 725 & MMBtu/hr \\
\hline 29,700 & kWe \\
\hline 48,008 & kWe \\
\hline 0 & kWe \\
\hline 28,526 & kWe \\
\hline $85.0 \%$ & \\
\hline
\end{tabular}

Net electricity output (w/ capture):

343,324 kWe

Total turbine generator output:

392,505 kWe

\section{FIXED O\&M COSTS:}

1. Annual Operating Labor Cost:

Fulltime employee gross cost:

Fulltime employees:

\begin{tabular}{|r|l}
\hline 135,000 & $\$ /$ year \\
\hline 22 & Person
\end{tabular}

Annual Cost

$2,970,000$

2. Maintenance Labor Cost:

Material cost:

Equipment cost:

Percentage:

\begin{tabular}{|c|c|}
\hline $29,154,000$ & $\$$ \\
\hline $110,594,550$ & $\$$ \\
\hline $1.5 \%$ & \\
\hline
\end{tabular}

$2,096,228$

$5,066,228$

Total Fixed O\&M Costs

\section{VARIABLE O\&M COSTS:}

$\begin{array}{llll}\text { Consumption } & \text { Unit Cost } & \frac{\text { Initial Cost }}{(\$)} & \frac{\text { Annual Cost }}{(\$)}\end{array}$

\section{Chemicals}

Sorbent (tonne)

$\mathrm{NaOH}$ - Chem. Treatment, FGD (tonne)

Lime (tonne)

$\mathrm{H}_{2} \mathrm{SO}_{4}$ (tonne)

\begin{tabular}{|l|r|r|}
\hline 247 & 3.74 & $11,023.11$ \\
\hline 0.00 & 0.14 & 499.75 \\
\hline 0.00 & 0.89 & 242.56 \\
\hline 0.00 & 0.46 & 160.00 \\
\hline
\end{tabular}

$2,722,709$

$12,780,666$

21,707

67,126

22,834

\section{Water}

Makeup water - evaporation (US gallon)

Makeup water - blowdown (US gallon)

Makeup water - FGD (US gallon)

\begin{tabular}{|l|r|r|}
\hline 0.00 & 691,200 & 0.000378 \\
\hline 0.00 & 345,600 & 0.000378 \\
\hline 0.00 & 0 & 0.000378 \\
\hline
\end{tabular}

$\begin{array}{lr}0 & 81,060 \\ 0 & 40,530 \\ 0 & 0\end{array}$

3. Waste disposal

$\mathrm{Na}_{2} \mathrm{SO}_{3}$ waste (tonne)

Waste water (tonne)

\begin{tabular}{|l|r|r|}
\hline 0.00 & 0 & 18.76 \\
\hline 0.00 & 0 & 18.76 \\
\hline
\end{tabular}

18.76

$2,722,709$

$13,013,923$

Fuel 


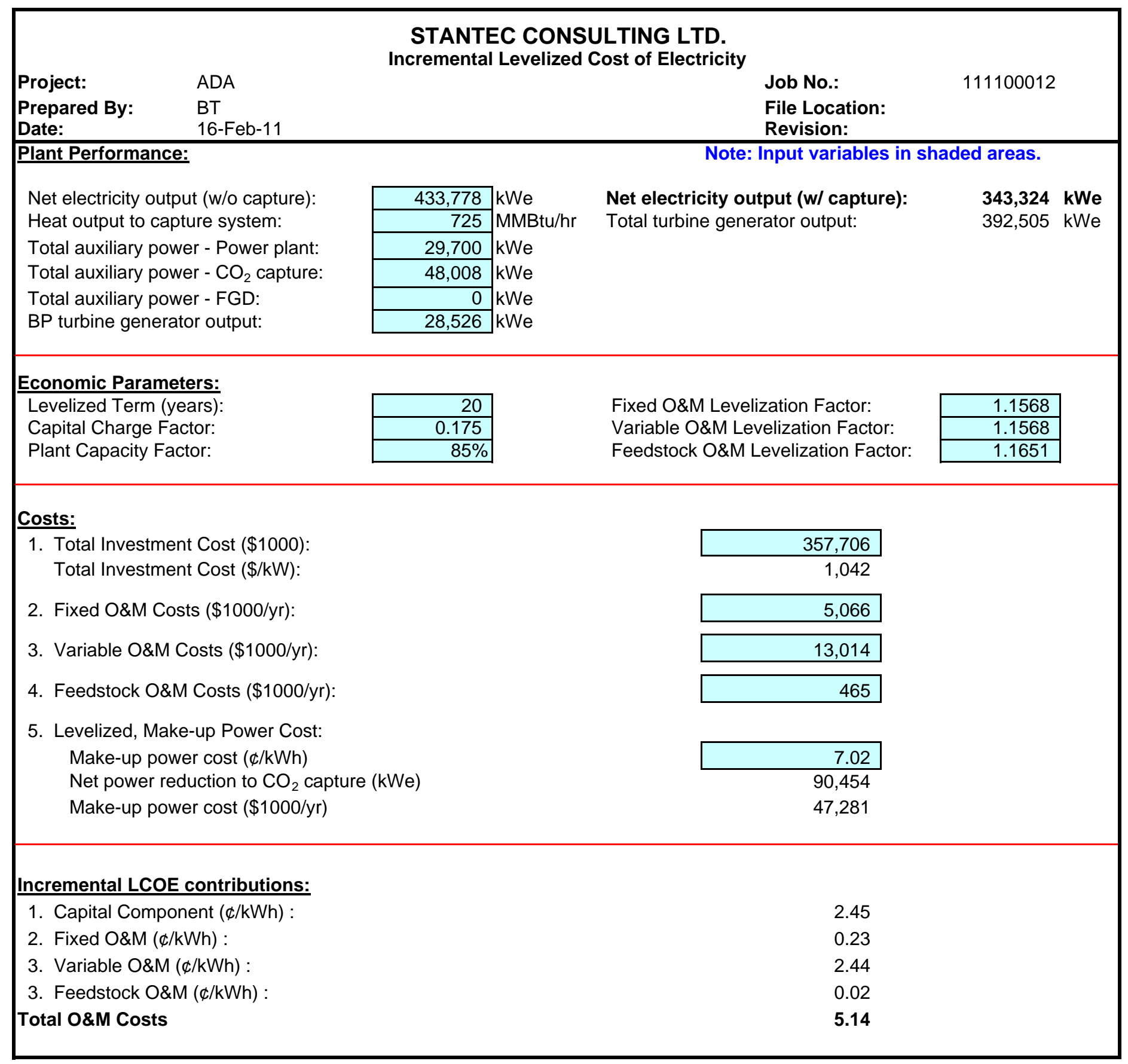

